\title{
Adolescent sexual and reproductive health needs in Uganda
}

Citation for published version (APA):

Nalukwago, H. (2019). Adolescent sexual and reproductive health needs in Uganda: understanding determinants of adolescent sexual behaviors. [Doctoral Thesis, Maastricht University]. ProefschriftMaken Maastricht. https://doi.org/10.26481/dis.20190314jn

Document status and date:

Published: 01/01/2019

DOI:

10.26481/dis.20190314jn

Document Version:

Publisher's PDF, also known as Version of record

\section{Please check the document version of this publication:}

- A submitted manuscript is the version of the article upon submission and before peer-review. There can be important differences between the submitted version and the official published version of record.

People interested in the research are advised to contact the author for the final version of the publication, or visit the DOI to the publisher's website.

- The final author version and the galley proof are versions of the publication after peer review.

- The final published version features the final layout of the paper including the volume, issue and page numbers.

Link to publication

\footnotetext{
General rights rights.

- You may freely distribute the URL identifying the publication in the public portal. please follow below link for the End User Agreement:

www.umlib.nl/taverne-license

Take down policy

If you believe that this document breaches copyright please contact us at:

repository@maastrichtuniversity.nl

providing details and we will investigate your claim.
}

Copyright and moral rights for the publications made accessible in the public portal are retained by the authors and/or other copyright owners and it is a condition of accessing publications that users recognise and abide by the legal requirements associated with these

- Users may download and print one copy of any publication from the public portal for the purpose of private study or research.

- You may not further distribute the material or use it for any profit-making activity or commercial gain

If the publication is distributed under the terms of Article $25 \mathrm{fa}$ of the Dutch Copyright Act, indicated by the "Taverne" license above, 
Adolescent sexual and reproductive health needs

\section{in uganda}

Understanding determinants

of adolescent sexual behaviors 


\section{Credits}

Production: ProefschriftMaken || www.proefschriftmaken.nl

ISBN 9789463802628

Cover Photos: USAID/Communication for Healthy Communities (CHC) project, FHI 360, Uganda

(C) Copyright Judith Nalukwago, USAID/CHC project, \& Maastricht University, 2019 


\title{
Adolescent sexual and reproductive health needs in Uganda
}

\section{Understanding determinants of adolescent sexual behaviors}

\author{
Thesis \\ To obtain the degree of Doctor at the Maastricht University under authority of the \\ Rector Magnificus Prof. dr. Rianne Letschert. \\ In accordance with the decision of the Board of Deans \\ To be defended in public on Thursday, $14^{\text {th }}$ March, 2019 at 12:00 hours
}

By

Judith Nalukwago 


\section{Promotors:}

Prof. dr. Bart van den Borne

Prof. dr. Rik Crutzen

\section{Co-Promotors:}

Dr. Jane Alaii (Context Factor Solutions, Kenya)

Dr. Paul M. Bukuluki (Makerere University, Uganda)

\section{Assessment Committee:}

Prof. dr. Nanne K. de Vries (chair)

Prof. dr. Stef Krem ers

Prof. dr. Rob Ruiter

Prof. dr. Olalekan Abdulwahab Ayo-Yusuf (Sefako Makgatho Health Sciences University, South Africa)

Prof. dr. Michèle van Vugt (University of Am sterdam ) 


\section{Funding and support}

Data collection for the studies in this thesis was supported by United States Agency for International Developm ent (USAID) through a six-year program (June 2013 - June 2019), Com m unication for Healthy Com m unities (CHC) RFA-617-13-000001 under FHI 360 (Fam ily Health International). FHI 360 Uganda office provided the infrastructure for conducting fieldwork for the thesis. Maastricht University provided the required logistical and technical support for the studies. The studies presented in this thesis were included in the program of the Care and Public Health Research Institution (CAPHRI), under the Departm ent of Health Prom otion, of Maastricht University in the Netherlands. CAPHRI participates in the Netherlands School of Public Health and Care Research (CaRe) which is accredited by the Royal Dutch Academ y of Sciences.

\section{Disclaimer}

The $\mathrm{m}$ aterial presented in this thesis does not in any way reflect the views of USAID and FHI 360. The author ensured to accurately present the inform ation as at the tim e of going to press, but this should not be $\mathrm{m}$ isconstrued to be a com plete analysis of the topics or subjects discussed herein. 


\section{Dedication}

I dedicate this work to all deserving individuals who strive towards and are passionate about $\mathrm{m}$ akinga difference in adolescent health, well-being, and

developm ent.

To m ydear parents, Lawrence M. Ssengero and Rose Nyakatura Ssengero for believing in $\mathrm{m}$ eand giving their all for $\mathrm{m}$ y success.

And to my siblings, Cherry, Lillian, Daniel, Nicholas, and Paul for your encouragem ent, $m$ oral and spiritual supporin this endeavor. 


\section{Contents}

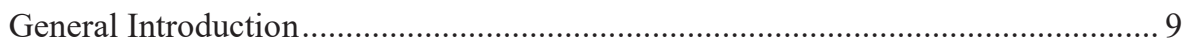

Socio-cognitive factors associated with condom use, m ultiple sexual partnerkips, and contraception use am ong sexually-active adolescent girls in Uganda ............. 23

Gender norm s associated with adolescent sexual behaviors in Uganda ................. 47

Adolescents discussing sexual behaviors with key influencing audiences ............. 73

Application of core processes for understanding multiple concurrent sexual partnerships am ong adolescents in Uganda................................................... 103

Process Evaluation of the Com m unication for Healthy Com m unities Adolescent

Health Program in Uganda......................................................................... 137

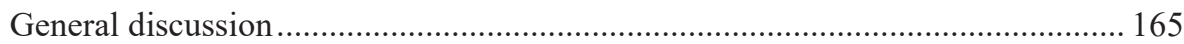

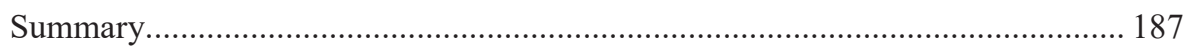

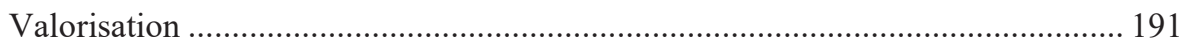

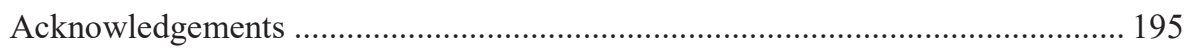

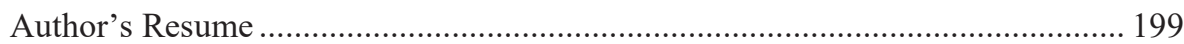

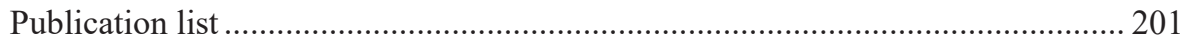





\section{Chapter 1}

General Introduction 


\section{Adolescent sexual and reproductive health in the global context}

Today's generation of adolescents is the largest in history in term s of size, as nearly half of the global population is less than 25 years old (Bearinger, Sieving, Ferguson, $\&$ Sharm a, 2007)Studies show that there are $\mathrm{m}$ ore than one billion adolescents aged 10-19 years, of whom 70\% live in developing countries (Hindin \& Fatusi, 2009; WHO, 2011; Blum \& Nkson-Mm ari, 2004). Globally, the growing number of adolescents has led to the increased debate and recognition that for years the unique health needs associated with adolescence have been lim itedly understood for program developm ent (WHO, 2017). Adolescent are a critical target population with regard to influencing global public health outcom es(WHO, 2011). As such, investm ent in adolescent health brings a triple dividend of benefits for adolescents now, for their future adult lives, and for the next generation, through creating healthier and $\mathrm{m}$ ore sustainable societies (WHO, 2017; Bearinger et al., 2007). Although there is growing concern am ong developm ent practitioners and researchers to im prove adolescent health and to respond more effectively to adolescents' needs, $\mathrm{m}$ any adolescents continue to face health challenges.

In sub-Saharan Africa, m any adolescent girls and boys aged 15-19 years continue to face health challenges related to HIV/AIDS, teenage pregnancies, and lim ited access to sexual and reproductive health (SRH) services. Adolescent girls and young wom en aged 15-24 years are at high risk of HIV infection, accounting for $20 \%$ of new HIV infections globally in 2015 (UNAIDS, 2016). Similarly, in sub-Saharan Africa, adolescent girls and young wom en accounted for $25 \%$ of new HIV infections. Regarding teenage pregnancy, every year, an estim ated $21 \mathrm{~m}$ illion girls aged 1519 years and 2 million girls aged under 15 years become pregnant in developing countries (Darroch, Singh \& Weissm an,2016-a; Darroch, Woog, Bankole \& Ashford, 2016-b). This is not without consequences as adolescent pregnancy rem ains a $\mathrm{m}$ ajor contributor to $\mathrm{m}$ aternal and childm ortalityand to intergenerational cycles of ill-health and poverty (WHO, 2011).

Pregnancy and childbirth com plicationsare the leading cause of death am ong 15-19year-old girls globally, with low and m iddleincom e countries accounting for $99 \%$ of global m aternal deaths of wom en ages 1549 years (WHO, 2017). And yet, in subSaharan Africa, very sm all proportions of unm arrid, sexually experienced girls aged 15-19 years used modern contraceptive m ethods at most recent sex-for exam ple, $4 \%$ in Benin, $10 \cdot 7 \%$ in Kenya, $12 \cdot 4 \%$ in Mali, $5 \cdot 2 \%$ in Zim babwe, and $43 \%$ in Uganda (Bearinger et al., 2007; UBOS, 2018). In countries with higher HIV prevalence, the gender im balance is m ore pronounced. Harm fugender norm s and 
inequalities, insufficient access to education and sexual and reproductive health services, poverty, food insecurity, and violence, are at the root of the increased HIV and teenage pregnancy risk of young wom en and adolescent girls (UNAIDS, 2016; WHO, 2017; Klugm an et al., 2014).

\section{Adolescent sexual and reproductive health Uganda's context}

Uganda is no exception regarding the intricacy of understanding adolescent sexual and reproductive health needs. The country has recorded alarm ing adolescent health statistics related to HIV and teenage pregnancy which contribute to poor health outcom es. Am ong adolescent girls aged 1519 years, 19\% have had a live birth, 10\% of girls and $17 \%$ of boys reported to have had sexual intercourse by age 15 , and an HIV prevalence of $1.8 \%$ was recorded am ong adolescent girls and $0.4 \%$ am ong boys (UBOS, 2018). The use of condom s am ong adolescents is still relatively low in Uganda, where $43 \%$ of girls and $55 \%$ of boys reported using a condom athigh risk sex (UBOS, 2018). While m any studies indicate high knowledgeon condom s, little is known about the consistent and correct use of condom s am ong teenage girls (UBOS, 2018; Am oran, 2012). Studies found widespread resistance to the use of condom $\mathrm{s}$ in stable and longterm relationships because of their association with lack of trust and illicit sex (Maharaj \& Cleland, 2005; Pulerwitz, Gortm aker, \& DeJong, 2000). A young man's selfesteem, his ability to speak openly to a girl, and his cultural $\mathrm{m}$ akeup, were found to influence his readiness to use a condom (Centerwall \& Laack, 2008).

Multiple concurrent partnerships are on the rise am ong adolescents in Uganda. In $2016,2.2 \%$ of girls and $6.6 \%$ of boys reported having two or m ore partners in the past $12 \mathrm{~m}$ onths preceding the survey, as com pared to 2011 where $1.5 \%$ of girls and $5.4 \%$ of boys reported the sam e (UBOS, 2018; UBOS, 2012). Adolescents often have multiple sequential partners because $m$ any of their relationships are short term (Georges, Thom as, \& Bignam i Sim ona, 2014). dolescents who have several sexual partners are at increased risk of contracting STIs, including HIV and teenage pregnancy, especially when they engage in unprotected sex. Therefore, given the scanty literature on the problem of multiple concurrent partneships am ong adolescents in Uganda as com pared to other sexual behaviors, there is still a lot to gain with regard to understanding this behavior. Furtherm ore, the unm et need for contraception am ong adolescents is high. Despite high sexual activity am ong adolescent girls in Uganda, contraceptive uptake is still low with only $43 \%$ sexually active unm arried adolescent girls, and 22\% married adolescent girls using a contraceptive method (UBOS, 2018). The bw contraceptive uptake is linked to negative perceptions on contraceptive use am ong adolescents, partners and parents 
(Hardee et al., 2014; MacPhail, Pettifor, Pascoe, \& Rees, 2007; Murigi et al., 2016; Nalukwago et al., 2018). However, knowledge on the determ inants of sexual behaviors am ong adolescents is stil lim ited in Uganda. Therefore, as developm ent practitioners grapple with designing targeted interventions that address the com plex adolescent health needs, it is im portant to understand the sociocognitive factors and gender norms associated with adolescent sexual behaviors. It is also critical to understand the effect of adolescents discussing sexual behaviors with key influencing audiences and to learn from experiences of already existing program s for scaleup of best practices in future adolescent health targeted program $\mathrm{s}$.

To contextualize the health situation of adolescents in Uganda, it is im perative to define the background inform ation of the country highlighting the geographical boundaries, social, education, and econom ic perspectives.

\section{Uganda's background information}

\section{Uganda's geographical location}

Uganda is a landlocked country situated in East Africa, neighboring Kenya, Tanzania, Rwanda, and Burundi. The country's capital city is Kam pala. Uganda has an area of $240,038 \mathrm{~km}^{2}$ of which $197,323 \mathrm{~km}^{2}$ is covered by land. The country has nine geographically demarcated regions with several administrative units known as districts which are illustratively shown on the $\mathrm{m}$ ap of Uganda (see Figure 1).

Besides underlining the geographical landscape of Uganda, it is imperative to underscore the country's current population status, education background and econom ic status of the population. These factors have been highlighted by several em pirical studies as $\mathrm{m}$ ajocontributors to the health outcom es and indicators (UBOS, 2018; MOH, 2010). 


\section{Map of Uganda showing the different regions}

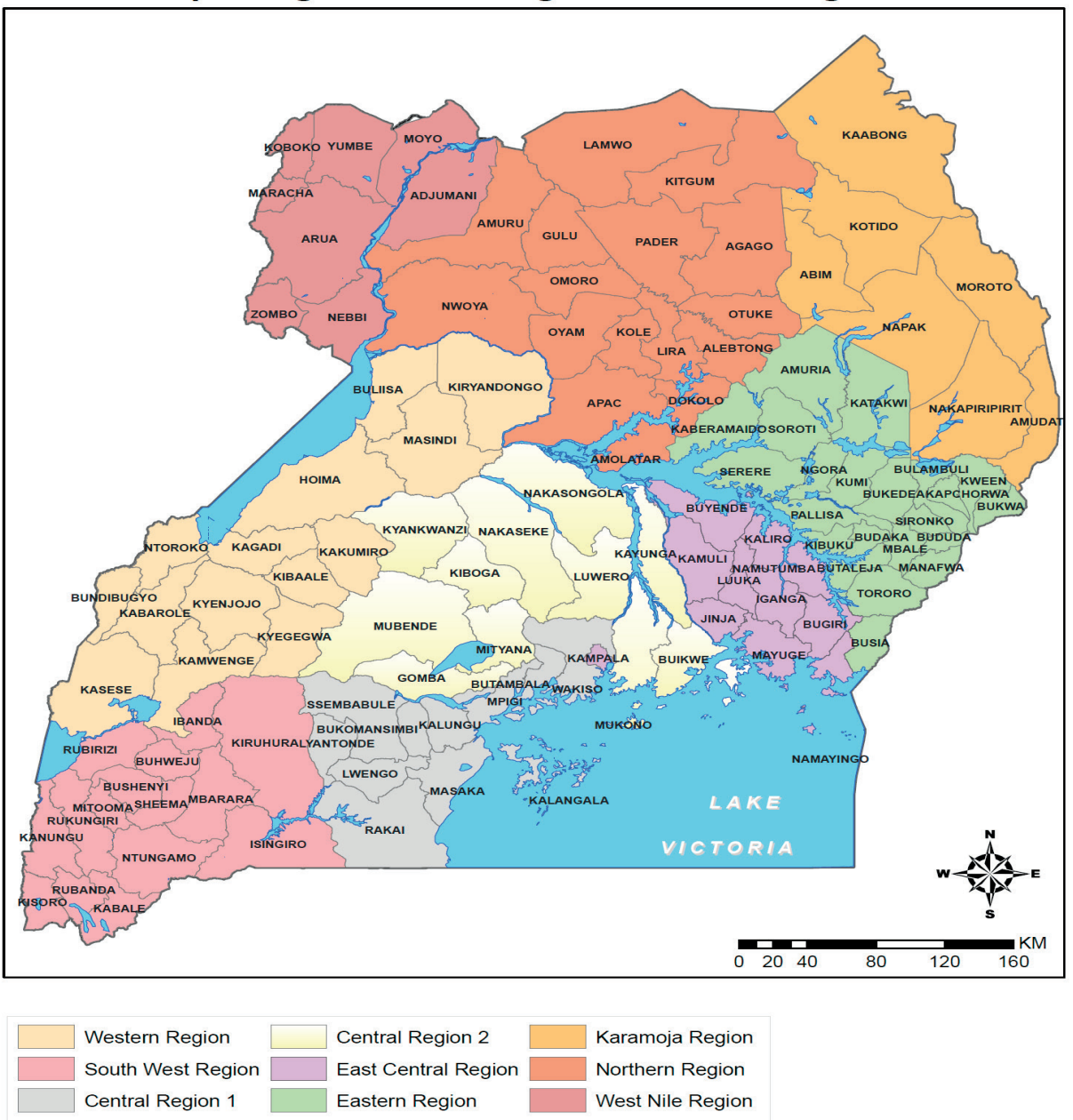

Figure 1: Map of Uganda 


\section{Population}

Uganda is a multicultural country with over 50 ethnic groups and varying cultural traditions. Sim ilarly, it is a m ultilingual country with English as its officiallanguage and Luganda as the most widely spoken indigenous language. According to the Uganda National Housing Survey of 2016/2017, the country's population was estim ated at $37.7 \mathrm{~m}$ illion of which $52 \%$ were fem ales and $48 \% \mathrm{~m}$ ales. The proportion of the population aged below 15 years constituted slightly m ore than half of the total population. Three in every ten households (31\%) were headed by fem ales (UBOS, 2017). According to UBOS, (2018), the broad base of Uganda's population pyram id shows that the majority of the population is young, which is characteristic of developing countries with high fertility and low life expectancy.

\section{Education}

Educational involvem ent and attainm ent in early lifehave been linked with later health outcom es, where im proved education ofwom en has substantial benefits for the health of children worldwide (Viner et al., 2012). In Uganda, the literacy rate for persons aged 10 years was found to be higher for $m$ ales than fem ales (UBOS, 2017). The $m$ ajority of Ugandans reported having either noform al education or only som $\mathrm{e}$ prim ary education. Nineteen percent of wom en and $13 \%$ of $\mathrm{m}$ en ag6 and older have never had any form al education. UBOS (2018) shows that the prim ary school Gender Parity Index (0.98) im plies that there is alm ost no gender gap.Fifty-four percent of wom en and $54 \%$ of $\mathrm{m}$ en had not com pleted prim ary education. Eight percentf wom en and $9 \%$ of $m$ en had com pleted prim ary school (UBOS, 2018). Studies show that education increases girls' knowledge of, and exposure to, the outside world; it strengthens their decision-m aking power within the fam ily, prom otes their social and physical mobility, and increases their econom ic independence and control over resources, all of which enhance their autonom y towards $m$ aking health decisions and choices (Blum \& NelsonMm ari, 2004; Jejeebhoy, 1995).

\section{Economy}

Uganda - a predom inantly agricultural caintry - has m ore people living below the poverty line, and has been ranked as one of the poorest countries on the global Hum an Developm ent Index. As such, the ladk of a com prehensive social security system $\mathrm{m}$ akes the poor more vulnerable in term s of affordaility and choice of health provider (MOH, 2010). Adolescents are often disproportionately affected by social and econom ic inequities that characterize the developm ent landscape. This $\mathrm{m}$ akes them m ore vulnerable to poor health outcom es, especially outcom es related to sexual and reproductive health (WHO, 2011). 
With such a com plex nexus of an individual's behavioral and environm ental setting characterized as having multiple physical, social and econom ic dim ensions that influence a variety of health outcom es(Stokols, 1996), it is im perative to underscore the study's theoretical fram ework to put the different levels of influence into perspective.

\section{Theoretical Framework of the study}

This study mainly used the Social Ecological Model (SEM) to conceptualize the understanding of adolescent sexual behaviors. The current study is em bedded in and draws experience from the United States Agency for International Developm ent (USAID) funded Comm unication for Healthy Com munities (CHC) program in Uganda. The CHC's program ming perspective is largely inform ed by the socio ecological m odel, recognizing individuals as em bedded within larger social system $\mathrm{s}$ and describes the interactive and reinforcing characteristics of individuals and their environm ents - as well as gender and other social norm s - that underlie people's behaviors (McKee et al., 2002; Golden \& Earp, 2012; Langille \& Rodgers, 2010; Stokols, 1996). It describes different levels of influence such as individual (self), inter-personal (peers, fam ily), com m unity, institutional (services, education, religion, politics), and structural level (policy/ legislation, physical and organizational environm ent), with cultural dim ensions ad values as a cross-cutting factor (see Figure 2). 


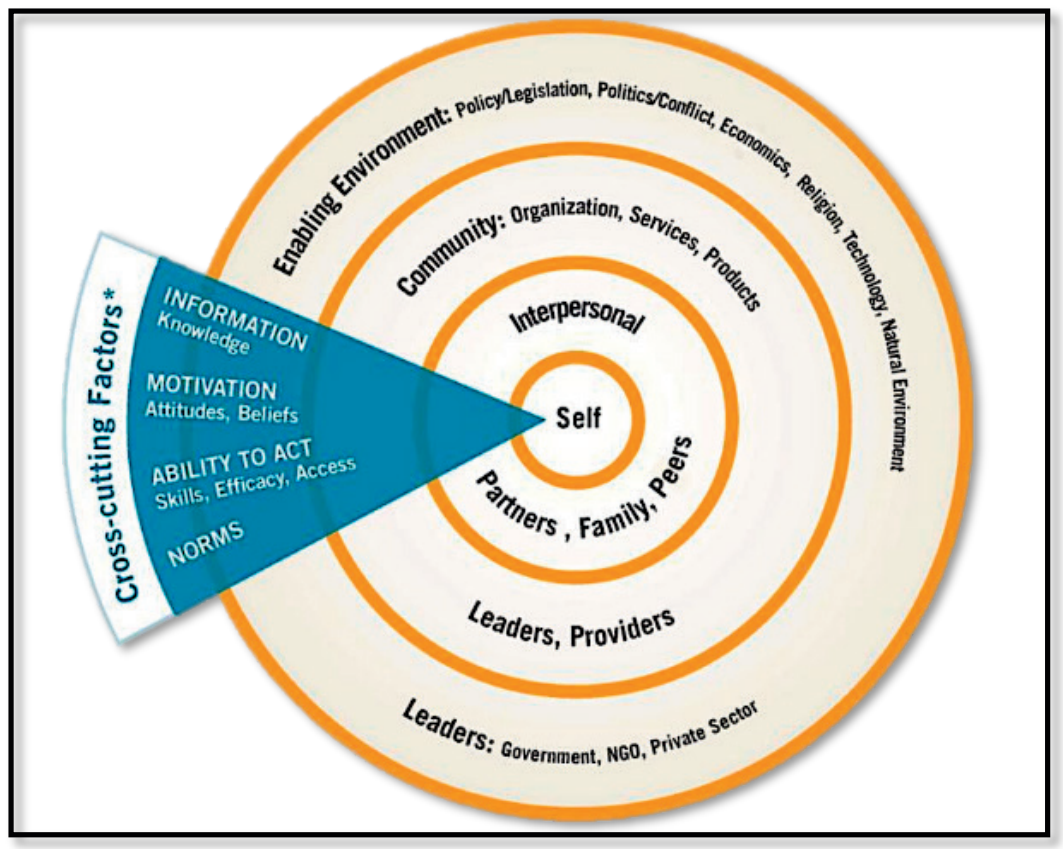

Figure 2: The Social Ecological Model adapted from McK ee et al., (2000)

The SEM postulates that in $\mathrm{m}$ aking decisions, an individual will consider $\mathrm{m}$ ore deeply the interests and views of one's fam ily, peers and com $m$ unity alongside her/his own preferences. Therefore, the model dem onstrates that changing behavior requires a critical look at the different levels of an individual's influence. This study was guided by the SEM constructs to develop specific research objectives aim ed at understanding adolescent sexual behaviors in the context of condom use, contraception use, and multiple sexual partnerships. Specifically, the study used the SEM constructs to construe the socio-cognitive factors and gender norm s assœiated with adolescent sexual behaviors and to assess the effect of discussing sexual and reproductive health issues with key influencing audiences. It also used the SEM constructs to understand why adolescents engage in m ultiple concurrentsexual partnerships. Further still, the SEM was used to assess the effect of already existing adolescent health program s to draw lessons for future program $\mathrm{m}$ ing and scaleup. The study research objectives are explained below. 


\section{Research objectives}

\section{General research objective}

The overall goal of this study was to exam ine the determ inans of adolescent sexual and reproductive health behaviors and needs to guide the design of targeted adolescent health program s. The study aim ed at understanding the determ inants of condom use, m ultiple sexual partnerships, and contraception use am ong adokeents, because knowledge of these determ inants in the Ugandan context is still lim ited. These sexual behaviors are associated with health risks such as HIV/AIDS and teenage pregnancies that contribute to the alarm ing health statistics in Uganda. The study also aim ed at conducting a process evaluation for existing adolescent SRH programs to draw their experiences for future programming. The case of Com m unication for Healthy Com m unities progranm Uganda is used in this study to draw its implem entationand practical experience embedded in its performance m easurem ent.

\section{Specific research objectives}

1. To assess socio-cognitive factors associated with condom use, $m$ ultiple sexual partnerships, and contraception use am ong sexuallyactive adolescent girls in Uganda.

2. To assess the gender norm s associated with adolescent sexual behaviors in Uganda.

3. To establish the effect of discussing sexual and reproductive health issues with key influencing audiences on adolescent perceptions of sexual behaviors.

4. To understand the problem of m ultiple concurrentsexual partnerships am ong adolescents.

5. To assess the effect of already existing interventions targeted at addressing sexual and reproductive health behaviors of adolescents by $m$ eans of a process evaluation to draw lessons for future adolescent health program $\mathrm{m}$ ing. 


\section{Thesis outline}

This thesis provides a multidisciplinary overview of the studies conducted to understand adolescent health needs and the determ inants of adolescent sexual behaviors for targeted adolescent health programm ing.

Chapter 2 describes the socio-cognitive factors associated with condom use, $\mathrm{m}$ ultiple sexual partnerships, and contraception use am ong sexuallyactive adolescent girls, using data drawn from a crosssectional survey conducted in 16 districts of Uganda.

Chapter 3 highlights the perceptions and associations of gender norm s and sexual behaviors am ong adolescents m easured using the Gender Equitable Men scale.

Chapter 4 qualitatively explored the effect of adolescents discussing sexual behaviors with key influencing audiences by m eans of indepth interviews and focus group discussions with adolescents.

Chapter 5 describes the use of core processes, which involve the use of theory and evidence, to understand the problem of why adolescents engage in multiple concurrent sexual partnerships. The scanty em pirical literature on why adolescents engage in $m$ ultiple sexual partnerships in Uganda necessitated this study.

Chapter 6 presents findings from a process evaluation of adolescent sexual and reproductive health interventions in Uganda, using the case of Com m unication for Healthy Com m unities program. Specifically, the study evaluated the context, reach, dose delivered, dose received by the target population, and whether the program was im plem ented with fidetiy.

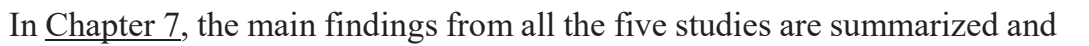
discussed. Im plications and suggestions for future adolescent health program $\mathrm{m}$ ing are $\mathrm{m}$ ade, and areas for further research highlighted. 


\section{References}

Am oran, O. E. (2012). A com parative analysis of predictors of teenage pregnancy and its prevention in a rural town in Western Nigeria. International Journal for Equity in Health, 11(1), 1. doi.org/10.1186/1475-9276-11-37

Bearinger, L. H., Sieving, R. E., Ferguson, J., \& Sharm ą V. (2007). Global perspectives on the sexual and reproductive health of adolescents: patterns, prevention, and potential. The lancet, 369(9568), 1220-1231.

Blum, R. W., \& NelsonMm ari, K. (2004). The health of young people in aglobal context. Journal of Adolescent Health, 35(5), 402-418.

Centerwall, E., \& Laack, S., (2008). Young Men as Equal Partners. RFSU, Riksförbundet för sexuell upplysning, The Swedish Association for Sexuality Education, Stockholm .

Darroch, J. E., Singh, S., \& Weissm an, E. (D16)-a. Adding it up: the costs and benefits of investing in sexual and reproductive health 2014. Estim ation Methodology. Appendix B: Estimating sexual and reproductive health program and systems costs. Guttmacher Institute.

Darroch, J. E., Woog, V., Bankole, A., \& Ashford, L. S. (2016)b. Adding it up: Costs and benefits of $m$ eeting the contraceptive needs of adolescents. New York: Guttm acher Institute, 2016, https://www.guttm acher.org/reportadding-it$\mathrm{m}$ eetingcontraceptiveneeds-of-adolescents

Georges, G., Thom as, L. K., \& Bignam i Sim ona, B. (2014)Sexual risk behavior: Factors associated with the number of sexual partners and consistent condom use among adolescents in four sub-Saharan African countries. Retrieved March 27, 2017, from http://paa2014.princeton.edu/papers/141169

Golden, S. D., \& Earp, J. A. L. (2012). Social ecological approaches to individuals and their contexts: twenty years of health education \& behavior health prom oion interventions. Health Education \& Behavior, 39(3), 364-372.

Hardee, K., Gay, J., Croce-Galis, M., \& AfariDwam ena, N. A. (2014). What HIV program swork for adolescent girls? Journal of Acquired Immune Deficiency Syndromes, 66, S176-S185.

Hindin, M. J., \& Fatusi, A. O. (2009). Adolescent sexual and reproductive health in developing countries: an overview of trends and interventions. International Perspectives on Sexual and Reproductive Health, 35(2), 58-62. doi: $10.1363 / 3505809$

Jejeebhoy, S. J. (1995). Wom en's education, autonom y, and reproductive behaviour: Experience from developing countries. OUP Catalogue.

Klugm an, J., Hanm er, L., Twigg, S., Hasan, T., McClearySills, J., \& Santam aria, J. (2014). Voice and agency: Empowering women and girls for shared 
prosperity. The World Bank.

Langille, J. L. D., \& Rodgers, W. M. (2010). Exploring the influence of a social ecological model on school-based physical activity. Health Education \& Behavior, 37(6), 879-894.

MacPhail, C., Pettifor, A. E., Pascoe, S., \& Rees, H. V. (2007). Contracepion use and pregnancy am ong 15-24-year-old South African wom en: a nationally representative cross-sectional survey. BMC medicine, 5(1), 31.

Maharaj, P., \& Cleland, J. (2005). Risk perception and condom use am ongn arried or cohabiting couples in KwaZulu-Natal, South Africa. International Family Planning Perspectives, 24-29.

Mckee, N., Manoncourt, E., Chin, S.Y. \& Carnegie, R. (2002). Chapter12. Involving People, Evolving Behaviour: The UNICEF experience. In: SERVAES, J. (ed.), Approaches to Development Communication. Paris: UNESCO.

Ministry of Health- MOH. (2010). Health Sector Strategic Plan III 2010/11-2014/15. Governm entof Uganda Kampala, Uganda.

Murigi, M., Butto, D., Barasa, S., Maina, E., \& Munyalo, B. (2016). Overcom ing Barriers to Contraceptive Uptake am ong Adolescents: The Case of Kiam bu County, Kenya. Journal of Biosciences and Medicines, 4(09), 1.

Nalukwago, J., Crutzen, R., Van den Borne, B., Bukuluki, P., Bufum bo, L., Batam wita, R., Zikusodka, A., Lenzi, R., Thom pson, G., Alaii, J. (2018)b. Adolescents discussing sexual behaviors with key influencing audiences. Global Journal of Health Science, 10, 91-106.

Pulerwitz, J., Gortm aker, S. L., \& DeJong, W. (2000)Measuring sexual relationship power in HIV/STD research. Sex Roles, 42(7), 637-660. doi.org/10.1023/A:1007051506972

Stokols, D. (1996). Translating social ecological theory into guidelines for com m unity health promotion.American Journal of Health Promotion, 10(4), 282-298. doi: 10.4278/0890-1171-10.4.282

Uganda Bureau of Statistics (UBOS) and ICF International Inc. (2012). Uganda Demographic and Health Survey 2011. Kam pala, Uganda: UBOS and Calverton, Maryland: ICF International Inc.

Uganda Bureau of Statistics (UBOS) and ICF. (2018). Uganda Demographic and Health Survey 2016. Kam pala, Uganda and Rockville, Maryland, USA: UBOS and ICF.

Uganda Bureau of Statistics (UBOS). (2017). Uganda National Household Survey 2016/2017. Kam pala.Uganda.

UNAIDS. (2016). Get on The Fast-Track: The life-cycle approach to HIV. Finding solutions for everyone at every stage of life.

Viner, R. M., Ozer, E. M., Denny, S., Marm ot, M., Resnick, M., Fatusi, A., \& Currie, 
C. (2012). Adolescence and the social determinants of health.The lancet, 379(9826), 1641-1652.

World Health Organization - WHO. (2011). WHO guidelines on preventing early pregnancy and poor reproductive outcomes among adolescents in developing countries

World Health Organization - WHO. (2017). Global Accelerated Action for the Health of Adolescents (AA-HA!): guidance to support country im plem entation. Sum $m$ ary. Geneva: Wold Health Organization; (WHO/FWC/MCA/17.05). Licence: CC BY-NC-SA 3.0 IGO. 


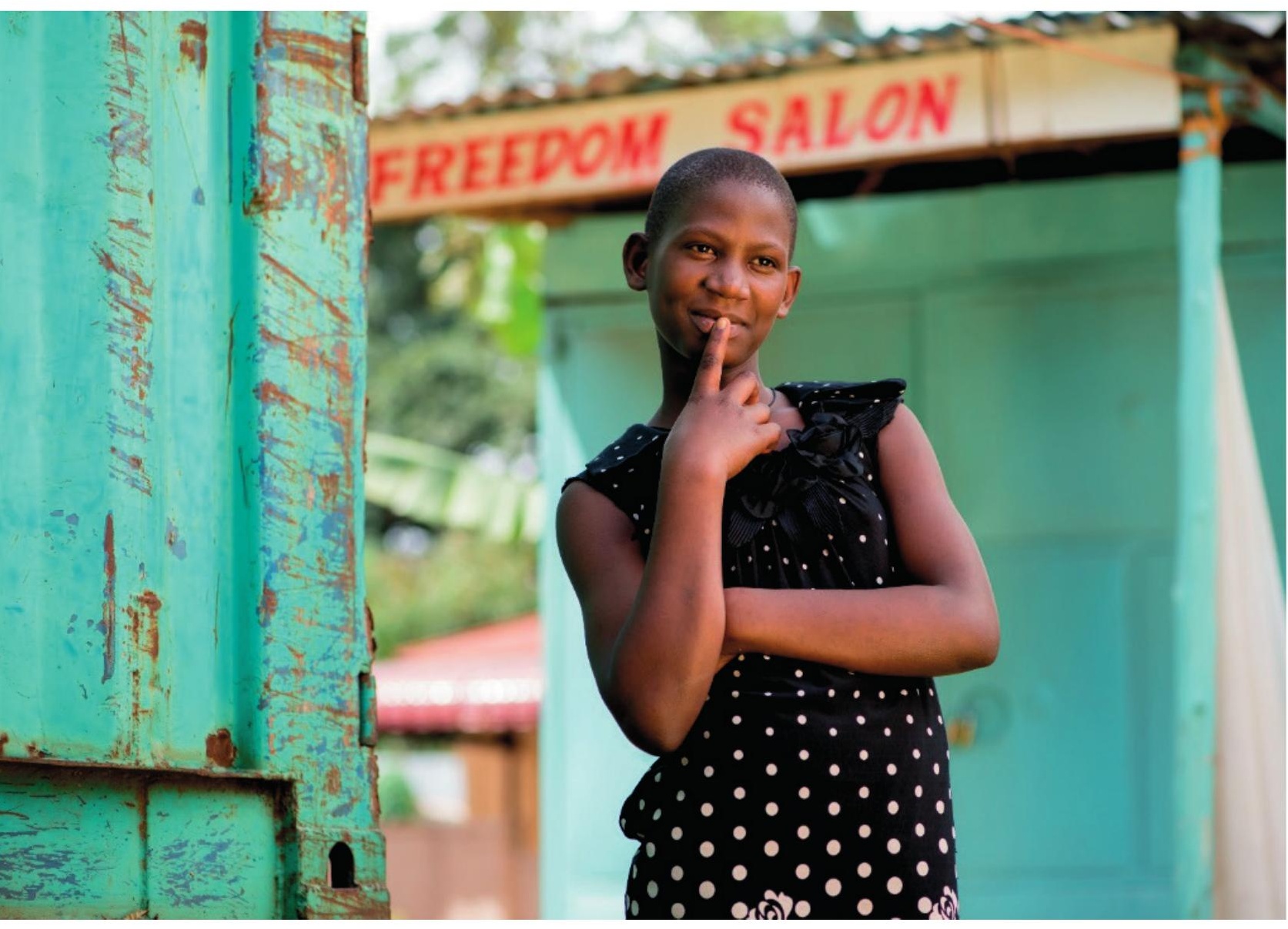




\section{Chapter 2}

\section{Socio-cognitive factors associated with condom use,m ultiple sexual partnerships, and contraception use am ong sexually- active adolescent girls in Uganda}

\section{Published as:}

Nalukwago, J., Crutzen, R., Van den Borne, B., Bukuluki, M. P., Bufum bo, L., Burke, M. H., Field, S., Zikusooka, A., Fiedler, A. A., \& Alaii, J(2018). Sociocognitive factors associated with condom use, $m$ ultiple sexual partnerships, and contraception use am ong sexuallyactive adolescent girls in Uganda. Global Journal of Health Science, 10, 41-54. 


\begin{abstract}
Many adolescent girls start sexual activity early which exposes them to health risks of HIV and unplanned pregnancies. However, adolescent girls are less likely than boys to initiate discussion or dem and use of condom s. Multiple sexual partnerships am ong girls are reported to be on the rise with em inat transactional sex and pre$\mathrm{m}$ arital relationships. The unm et need for contraception am ong adolescent girls is also high. A cross-sectional survey covering 16 districts in Uganda assessed the socio-cognitive factors associated with condom use, m ultiple sexal partnerships and contraception use am ong sexually active adolescent girls $(\mathrm{N}=255)$. There were strong associations between feeling confident to discuss contraceptive methods with a partner $(\mathrm{OR}=9.41,95 \% \mathrm{CI}=3.54,25.06)$, being com fortable to use cortraception $(\mathrm{OR}=30.61,95 \% \mathrm{CI}=4.10,228.64)$, discussing contraception use with som eone $(\mathrm{OR}=10.53,95 \% \mathrm{CI}=5.61,19.78)$, and contraception use. However, there were no significant associations between social cognitive factors (including behavioral intention, attitude, subjective norm, and knowledge) and condom use, as wellas having multiple partners Whereas knowledge was found to have no significant relationship with service uptake, inform ation services rem ain im portant in clearing any $\mathrm{m}$ isconceptions and addressing any hedth concerns. It is im perative to explore com $\mathrm{m}$ unication factors including skillsdevelopm ent and providing adequate health inform ation to guide dialogue am ong adolescents and their key influencers.
\end{abstract}

K eywords: Adolescent girls, condom use, contraception us, multiple sexual partnerships 


\section{Introduction}

Adolescent girls in Uganda face high risks of HIV/AIDS and unplanned pregnancies. The country recorded a 3.0\% HIV prevalence am ong adolescent girls aged 15-19 and a teenage pregnancy rate that slightly increased from $24 \%$ in 2011 to $25 \%$ in 2016 (MOH, 2012; UBOS, 2018). The sexual and reproductive health (SRH) needs of these adolescents are inadequately addressed within the existing services system (Birungi et al., 2008; MOH, 2010). The scantiness of gender and age disaggregated program data for this target group increases the difficulty to develop targeted SRH program s (UNICEF, 2016). Understanding the socio-cognitive factors associated with adolescent sexual behaviors allows for better design of behavioral change program $\mathrm{s}$ targeted at adolescents. Many adolescent girls start sexual activity early, and this exposes them to health risks (Hardee, Gay, CroceGalis, \& AfariDwam ena, 2014; Neem a, Musisi, \& Kibom bo, 2004; UBOS, 2012; MOH, 2004). Health risks such as sexually transm itted infections (STIs) and m aternal deaths associated with unsafe deliveries are aggravated by early marriages and limited access to basic needs (Bantebya, Muhanguzi, \& Watson, 2014; Cortez, Saadat, Marinda, \& Odutolu, 2016; Loaiza \& Liang, 2013). As such, girls are challenged with lim ited opportunities and choices to negotiate, $\mathrm{m}$ ake health decisions, and dem and access to quality SRH services (Klugm anet al., 2014; Singh \& Darroch, 2012; UNICEF, 2015; William son, 2014).

Designing adolescent sexual and reproductive health program s to address the risks requires an understanding of adolescent sexual behaviors such as condom use, m ultiple sexual partnerships, and contraception use. Although a key m otivator to use condom s am og adolescents is the heightened concern for pregnancy prevention over HIV/STIs, girls are less likely than boys to initiate discussion or dem and use of condom s (Cortez et al., 2016; Widdice, Cornell, Liang, \& HalpernFelsher, 2006). The decision to use condom s is often controlkd by a wom an's partner (Baxter \& Abdool Karim, 2016). Multiple sexual partnerships am ong adolescent girls are also reported to be on the rise where transactional sex, girls engaging in pre-m arital relationships with older $\mathrm{m}$ en, arranged $\mathrm{m}$ arriages for finarial gain, sexual coercion, and forced sex are em inent (Bantebya et al., 2014; Am in et al., 2013; Doyle, Mavedzenge, Plum m er, \& Ross, 2012; Kazaura \& Masatu, 2009). In Uganda, adolescent girls aged 15-19 who reported having $m$ ultiple sexual partners in the past $12 \mathrm{~m}$ onths increased from $2.1 \%$ in 2011 to $2.7 \%$ in 2016 [UBOS, 2018; UBOS, 2012]. Further, there is an unm et need for contraception am ong adolescent girls Qbare et al., 2011). Contraceptive use among married and sexually active umarried adolescents aged 15-19 shows a 30\% unm et need for fam ily planning [UBOS, 2018]. Studies show persistent challenges in obtaining and using contraceptives. The challenges include; inadequate knowledge, social stigm a, cost, perceived side effects, 
provider bias, and lim ited health facilities that provide adolescent SRH services (MOH, 2010; Ankom ah, Anyanti, Adebayo,\& Giwa, 2013; Jonas, Crutzen, van den Borne, \& Reddy, 2017; Singh \& Darroch, 2014; Villarruel, Jem m ott III, Jem m ott, \& Ronis, 2004).

Although previous studies have exam ined the prevalence and trends in HIV knowledge and sexual behavior, little is known about the socio-cognitive factors of sexual behaviors am ong sexually active adolescent girls in Uganda. There is less focus on understanding sexual behavioral patterns of adolescent girls aged 15-19 as a distinct group from the oftengeneralized youth or young adults. Therefore, distinctively assessing the factors associated with condom use, multiple sexual partnerships and contraceptive use am ong sexually active adolescent girls is critical, and the focus of this study. This is vital for contextualizing im plem entation of adolescent SRH interventions using relevant theoretical fram eworks that are linked to behavioral models. This study concerns secondary data analysis of a crosssectional survey. Although the aim of the survey was not to test a specific theory, the item s used in the analysis for this paper are linked to constructs based on the Theory of Planned Behavior.

\section{Methods}

A cross-sectional survey was conducted in 2015. The survey covered 16 districts (Lira, Am uru, Ntungam o, Ibanda, Mbale, Kum i, Iganga, Buyende, Arua, Nebbi, Moroto, Kaabong, Mukono, Sem babule, Kasese, Kyenjojo) spread across the eight regions of Uganda. The districts were purposively selected considering; the availability of United States Governm ent (USG) supported health services, the high prevalence of specified health issues like HIV/AIDS and teenage pregnancy; and contextual com parisons of rural and urbancharacteristics. The survey collected data from $m$ en and wom en aged 1-\$49, but for the present study, only data from sexually active adolescent girls aged 15-19 were included.

\section{Study Participants and Sampling}

The study used a stratified $m$ ultistage probability sam pling design where sam pling occurred in four stages. Eighty parishes were random ly selected from the 16 districts using stratified, probability proportional to size (PPS) system atic sam pling. For each sam pled parish, a list of villages in the parishwas obtained and 3 villages random $y$ sam pled using PPS system atic sam pling. Ten households were sam pled from each random ly selected village. Household sam ples were drawn with uniform probability using a sam pling fram e/list generated with the local leaders. A m em ber list for each 
sampled household was generated. Basic dem ographic inform ation about each household member was collected and used for selection of eligible individual participants using a Kish selection grid. The latter is a m ethod for selecting mem bers within a household to be interviewed (Kish, 1949; CHC, 2016). For this study, selected data for 255 sexually active adolescent girls aged 15-19 was used. The sexually active adolescent girls were selected based on adolescent girls that reported the age when they had sexual intercourse for the very first tim e.

\section{Measures}

Socio-dem ographic and sexual behaviors m easures. The study assessed the following socio-dem ographics: age, education level, occupation, begun childbearing, $\mathrm{m}$ arital status, and sexual debut. The scale categories of these variables are listed in Table 1. All three sexual behaviors (condom use, multiple sexual partnerships, and contraception use) were assessed with one item (actual behavior) and dichotom ized (yes/ no and $0-1 / 2$ or $\mathrm{m}$ ore).

Socio-cognitive factors. The socio-cognitive factors that were assessed differed per outcom e. Based on the Theory of Planned Behavior, the sociocognitive factors were categorized as perceived behavioral control/ self-efficacy, attitude, subjective norm, and behavioral intention. Other factors such as psychological barrier and knowledge were included. Tables 2-4 show the operationalization at item level (including scale categories) for all factors regarding condom use, multiple sexualpartnerships, and contraception use respectively.

\section{Ethical Approval}

Ethical approval for the study was obtained from the United States of Am erica federally registered institutional review board of FHI 360 (Fam ily Health International), the Protection of Hum an Subjects Com mittee, under reference 616862-1, and in Uganda by the Governm ent accredited Makerere School of Public Health Research Ethics Com mittee, under reference 259. Consent to conduct the study was obtained from Uganda National Council for Science and Technology and Office of the President. The study team requested and obtained a waiver of written consent to increase confidentiality because signed inform ed consent form s would be the only link to the participants' identity in this study. Adolescent consenting procedures were undertaken in two ways: verbal inform ed consent was obtained from em ancipated adolescent 15-17 years (either m arried or not living under the care of a parent/guardian); and verbal inform ed parental/guardian consent and adolescent assent were obtained from nonem ancipated adolescents 15-17 years ( $m$ inors living under the care of a parent/guardian). For adolescents aged 18-19, verbal inform ed consent was sought from each participant before anystudy-specific activities were 
undertaken. The consenting process was conducted in a local language that the potential participant understood. Participants were given tim e to ask questions for clarity. Per ethical approval, verbal informed consent was obtained for each participant and docum ented viathe signature of the study staff $\mathrm{m}$ em ber who obtained consent.

\section{Data Analysis}

The Theory of Planned Behavior

The study used the theory of planned behavior (TPB) to guide analysis and interpretation of the data. TPB has been globally used to exam ine adolescent sexual behavior, mainly condom use (Buhi \& Goodson, 2007; Heren, Jem m ott III, Mandeya, \& Tyler, 2007; McEachan, Conner, Taylor, \& Lawton, 2011; Fishbein \& Ajzen, 2010). The TPB postulates that intention is the $\mathrm{m}$ ain determ inant of behavior, and it is influenced by attitude, subjective norm, and perceived bhavioral control (self-efficacy) (Fishbein \& Ajzen, 2010; Glanz, Rim er, \& Viswanath. 2008; Cooke \& French, 2008). This study uses the socio-cognitive factors of behavioral intention, attitude, subjective norm, and perceived behavioral control/ selfefficacy to assess associations with actual sexual behavior. The study also includes other factors such as knowledge and psychological barriers that have been widely used and studied in sub-Saharan Africa (SSA) as predictors of behavior (Obare et al., 2011; Bakibinga et al., 2016; Eggers et al., 2016; Krugu, Mevissen, Debpuur, \& Ruiter, 2016). The outcome measureare the actual sexual behaviors (condom use, multiple sexual partnerships, and contraception use) am ong sexually active adolescent girls.

\section{Sample Weights}

Before analysis, sam ple weights were calculated based on parish, village, household and household $\mathrm{m}$ em ber. The weights were determ ined based on probabilities thathe parish is selected; the village is selected conditional to parish being selected; the household is selected conditional to the village being selected, and the household $\mathrm{m}$ em ber is selected conditional to household being selected. Those probabilities were $\mathrm{m}$ ultiplied, and then the inverse was taken as the individual sam pling weights (CHC, 2016). The weight dom ain variable was created, set as 1 if the person was included in the analysis, and 0 if not. In these analyses, the highest-level sam pling unit, the parish, was specified as the prim ary sam pling unit. Adding sam pling weights helped to ensure that individuals were sam pled with equal probabilities (Winship \& Radbill, 1994). It also helped to reduce the bias created by an im perfect sam pling fram e, non response and coverage errors resulting from under orover-representation of certain groups (Antal \& Rđhenbühler, 2015; Verm a \& Lê, 1996; Kalton \& Kasprzyk, 1986). Using weighted data for the estim ation of regression models gives covariance and 
variance estim ates that are unbiased and consistent estim ates of quantities in the population (Kish, 1949).

Descriptive statistics were run, and data were analyzed using logistic regression procedure.

\section{Descriptive Frequencies}

Descriptive frequencies were run to understand the characteristics of the data. For analysis, descriptive frequencies were run for socio-dem ographic characteristics including; age, education level, occupation, whether girls had a child, m arital status, and sexual debut.

\section{Logistic Regression Analysis}

A binary logistic regression m odel was used to analyze the socio-cognitive factors associated with condom use, multiple sexual partnerships, and contraception use. Logistic regression analyses were used because all outcome variables were dichotom ous (Tabachnick \& Fidell, 2013; Field, 2009) The factors in the regression model were categorized as independent (socio-cognitive and $\mathrm{m}$ arital status) and outcom e (sexual behavior) variables. The independent variables were all categorical variables, where the first scale option was used as the reference category. 


\section{Results}

\section{Socio-Demographics}

A total of 255 sexually active adolescent girls were included in the analysis. The $\mathrm{m}$ ajority were 18 years $(31 \%, \mathrm{n}=80)$ or 19 years $(32 \%, \mathrm{n}=82)$ old. Sixty-nine percent $(n=169)$ of the respondents had attained prim ary level education. Thirty-five percent $(n=88)$ reported having a child and $32 \%(n=79)$ reported that they were m arried (Table 1).

Table 1: Socio-demographic characteristics of respondents $(N=255)$

\begin{tabular}{|c|c|c|c|}
\hline Measures & Scale categories & $\begin{array}{l}\text { Number } \\
\text { (frequency) }\end{array}$ & $\begin{array}{l}\text { Percentage } \\
(\%)\end{array}$ \\
\hline \multirow{5}{*}{$\begin{array}{l}\text { Age of respondents in } \\
\text { years }\end{array}$} & 15 & 13 & 5 \\
\hline & 16 & 29 & 11 \\
\hline & 17 & 51 & 20 \\
\hline & 18 & 80 & 31 \\
\hline & 19 & 82 & 32 \\
\hline \multirow{3}{*}{ Education level } & Prim ary & 169 & 69 \\
\hline & Secondary ("O" level) & 70 & 29 \\
\hline & Tertiary & 3 & 1 \\
\hline \multirow{8}{*}{$\begin{array}{l}\text { Occupation } \\
\text { respondents }\end{array}$} & Subsistence farm ers & 43 & 17 \\
\hline & Com m ercial farm ers & 79 & 31 \\
\hline & Fishery-related jobs & 5 & 2 \\
\hline & Laborer/ dom estic worker & 30 & 12 \\
\hline & Petty trader/ Hawker & 14 & 6 \\
\hline & $\begin{array}{l}\text { Owns business with } 3 \text { or } \mathrm{m} \text { ore } \\
\text { em ployees }\end{array}$ & 8 & 3 \\
\hline & Uniform ed services & 4 & 2 \\
\hline & Students & 61 & 24 \\
\hline \multirow[t]{2}{*}{ Begun childbearing } & Yes & 88 & 35 \\
\hline & No & 166 & 65 \\
\hline \multirow{2}{*}{ Marital status } & Married & 79 & 32 \\
\hline & Unm arried & 172 & 68 \\
\hline
\end{tabular}

\section{Sexual Debut Among Adolescent Girls}

Alm ost everybody $(98 \%, n=250)$ m entioned age when they had sexual intercourse for the very first tim e, indicating that they were sexually active (the rem aining $2 \%$ were excluded from further analyses). Of these, $19 \%(n=47)$ reported their age at first 
sex was 14 years, $25 \%(n=62)$ at 15 years, $21 \%(n=53)$ at 16 years, $17 \%(n=43)$ at 17 years, and $10 \%(\mathrm{n}=25)$ at 18 years. The m edian age at first sex for the adolescent girls was 15 years.

\section{Factors Associated With Condom Use Among Adolescent Girls}

Regarding actual condom use, 41\% ( $\mathrm{n}=104)$ of the adolescent girls reported having used a condom at last sexual intercourse. Table 2 sum $m$ arizes the association between socio-cognitive factors and $\mathrm{m}$ arital status with condom use. The results indicate that there were no significant associations with condom use.

Table 2: Factors associated with condom use

\begin{tabular}{|c|c|c|c|c|}
\hline \multirow{2}{*}{ Measures } & \multirow{2}{*}{ Scale categories } & \multirow{2}{*}{ Frequency } & \multicolumn{2}{|l|}{ Bivariate } \\
\hline & & & OR $(95 \% \mathrm{CI})$ & $P$ \\
\hline \multicolumn{5}{|l|}{$\begin{array}{l}\text { Perceived behavioral control/ } \\
\text { self-efficacy on condom use }\end{array}$} \\
\hline \multirow{4}{*}{$\begin{array}{l}\text { Easy to suggest to partner that } \\
\text { we use a condom }\end{array}$} & Strongly disagree & 35 & Ref & \\
\hline & Disagree & 43 & $1.041(0.422,2.565)$ & 0.931 \\
\hline & Agree & 90 & $0.731(0.330,1.619)$ & 0.441 \\
\hline & Strongly Agree & 64 & $0.852(0.369,1.968)$ & 0.708 \\
\hline \multirow{3}{*}{$\begin{array}{l}\text { Comfortable talking with a } \\
\text { sexual partner about condoms }\end{array}$} & $\begin{array}{l}\text { Not very } \\
\text { com fortable }\end{array}$ & 71 & Ref & \\
\hline & $\begin{array}{l}\text { Som ewhat } \\
\text { com fotable }\end{array}$ & 58 & $1.008(0.500,2.033)$ & 0.982 \\
\hline & Very com fortable & 113 & $0.628(0.341,1.157)$ & 0.136 \\
\hline \multicolumn{5}{|l|}{ Attitude } \\
\hline \multirow{4}{*}{$\begin{array}{l}\text { The use of condoms can make } \\
\text { sex more stimulating }\end{array}$} & Strongly disagree & 46 & Ref & \\
\hline & Disagree & 82 & $0.575(0.276,1.197)$ & 0.139 \\
\hline & Agree & 61 & $0.582(0.266,1.276)$ & 0.177 \\
\hline & Strongly Agree & 13 & $1.150(0.335,3.946)$ & 0.824 \\
\hline \multirow{4}{*}{ Condoms are unreliable } & Strongly disagree & 35 & Ref & \\
\hline & Disagree & 78 & $0.662(0.297,1.477)$ & 0.314 \\
\hline & Agree & 83 & $0.433(0.193,0.974)$ & 0.041 \\
\hline & Strongly Agree & 33 & $0.700(0.271,1.807)$ & 0.461 \\
\hline \multicolumn{5}{|l|}{ Subjective norm } \\
\hline \multirow{2}{*}{$\begin{array}{l}\text { Discussed condom use with } \\
\text { anyone in the last six months }\end{array}$} & No & 181 & Ref & \\
\hline & Yes & 72 & $0.538(0.301,0.963)$ & 0.037 \\
\hline \multicolumn{5}{|l|}{ Psychological barrier } \\
\hline & Strongly disagree & 41 & Ref & \\
\hline It would be embarrassing to be & Disagree & 66 & $0.858(0.388,0.963)$ & 0.707 \\
\hline \multirow[t]{2}{*}{ seen buying condoms in a store } & Agree & 75 & $0.912(0.421,1.978)$ & 0.816 \\
\hline & Strongly Agree & 65 & $0.842(0.381,1.862)$ & 0.671 \\
\hline
\end{tabular}




\begin{tabular}{|c|c|c|c|c|}
\hline \multirow{2}{*}{ Measures } & \multirow{2}{*}{ Scale categories } & \multirow{2}{*}{ Frequency } & \multicolumn{2}{|l|}{ Bivariate } \\
\hline & & & OR $(95 \% \mathrm{CI})$ & $P$ \\
\hline \multicolumn{5}{|l|}{ Knowledge on condoms } \\
\hline \multirow{2}{*}{$\begin{array}{l}\text { Condoms can protect someone } \\
\text { from HIV }\end{array}$} & $\begin{array}{l}\text { Strongly } \\
\text { Disagree }\end{array}$ & 9 & Ref & \\
\hline & Strongly Agree & 239 & $0.920(0.232,3.641)$ & 0.905 \\
\hline $\begin{array}{l}\text { Condoms are an effective } \\
\text { method of preventing the }\end{array}$ & $\begin{array}{l}\text { Strongly } \\
\text { Disagree }\end{array}$ & 17 & Ref & \\
\hline $\begin{array}{l}\text { spread of HIV/AIDS and other } \\
\text { STDs }\end{array}$ & Strongly Agree & 225 & $0.985(0.363,2.672)$ & 0.977 \\
\hline \multicolumn{5}{|l|}{ Behavioral intention } \\
\hline & Very Unlikely & 70 & Ref & \\
\hline Likely to use a condom during & Unlikely & 51 & $0.992(0.477,2.060)$ & 0.982 \\
\hline \multirow[t]{2}{*}{ sex in the next six months } & Likely & 67 & $0.605(0.299,1.223)$ & 0.161 \\
\hline & Very Likely & 47 & $1.027(0.485,2.171)$ & 0.945 \\
\hline Likely to use a condom the next & Very Unlikely & 63 & Ref & \\
\hline \multirow[t]{3}{*}{ time one has sexual intercourse } & Unlikely & 38 & $1.303(0.580,2.927)$ & 0.522 \\
\hline & Likely & 86 & $0.719(0.367,1.410)$ & 0.337 \\
\hline & Very Likely & 55 & $0.815(0.386,1.718)$ & 0.591 \\
\hline \multicolumn{5}{|l|}{ Marital status } \\
\hline \multirow[t]{2}{*}{ Current marital status } & Not Married & 174 & Ref & \\
\hline & Married & 80 & $1.572(0.918,2.692)$ & 0.099 \\
\hline
\end{tabular}

Note. $\mathrm{CI}=$ confidence; $\mathrm{OR}=\mathrm{Odds}$ Ratios; $P=\mathrm{P}$-value.

\section{Factors associated with multiple sexual partnerships among adolescent girls}

In this study, $14 \%(n=35)$ of the adolescent girls reported having two or $m$ ore partners. Table 3 sum $\mathrm{m}$ arizes the association between sociecognitive factors and $\mathrm{m}$ arital status with having multiple partners. The results indicate that there were no significant associations between socio-cognitive factors and having $\mathrm{m}$ ultiple partners. There was a strong negative association between being $\mathrm{m}$ arried and having $\mathrm{m}$ ultiple partners. 
Table 3: Factors associated with multiple sexual partners

\begin{tabular}{|c|c|c|c|c|}
\hline \multirow{2}{*}{ Measures } & \multirow{2}{*}{ Scale categories } & \multirow{2}{*}{ Frequency } & \multicolumn{2}{|l|}{ Bivariate } \\
\hline & & & OR $(95 \% \mathrm{CI})$ & $P$ \\
\hline \multicolumn{5}{|l|}{$\begin{array}{l}\text { Perceived behavioral } \\
\text { control/ self-efficacy to } \\
\text { have one sexual partner }\end{array}$} \\
\hline \multirow{3}{*}{$\begin{array}{l}\text { Confident to have only one } \\
\text { sexual partner in the next } \\
\text { six months }\end{array}$} & Not at all confident & 23 & Ref & \\
\hline & $\begin{array}{l}\text { Moderately } \\
\text { confident }\end{array}$ & 44 & $1.090(0.291,4.092)$ & 0.898 \\
\hline & Very confident & 179 & $0.568(0.175,1.850)$ & 0.348 \\
\hline \multicolumn{5}{|l|}{ Subjective norm } \\
\hline $\begin{array}{l}\text { Discussed the risk of } \\
\text { having multiple sexual }\end{array}$ & No & 163 & Ref & \\
\hline $\begin{array}{l}\text { partners with someone in } \\
\text { the last six months }\end{array}$ & Yes & 86 & $0.994(0.469,2.106)$ & 0.987 \\
\hline \multicolumn{5}{|l|}{$\begin{array}{l}\text { Knowledge on the risk of } \\
\text { having multiple sexual } \\
\text { partners }\end{array}$} \\
\hline \multirow{3}{*}{$\begin{array}{l}\text { Reducing one's number of } \\
\text { sexual partners can limit } \\
\text { the spread of HIV }\end{array}$} & Disagree & 5 & Ref & \\
\hline & Agree & 140 & $0.558(0.059,5.256)$ & 0.610 \\
\hline & Strongly Agree & 109 & $0.672(0.071,6.364)$ & 0.729 \\
\hline \multicolumn{5}{|l|}{ Behavioral intention } \\
\hline \multirow{4}{*}{$\begin{array}{l}\text { Likely to have only one } \\
\text { sexual partner in the next } \\
\text { six months }\end{array}$} & Very Unlikely & 10 & Ref & \\
\hline & Unlikely & 18 & $0.524(0.029,9.469)$ & 0.662 \\
\hline & Likely & 77 & $1.553(0.178,13.583)$ & 0.691 \\
\hline & Very Likely & 138 & $1.199(0.142,10.158)$ & 0.868 \\
\hline \multicolumn{5}{|l|}{ Marital status } \\
\hline \multirow{2}{*}{ Current marital status } & Not Married & 217 & Ref & \\
\hline & Married & 35 & $0.052(0.007,0.390)$ & 0.004 \\
\hline
\end{tabular}

Note. $\mathrm{CI}=$ confidence; $\mathrm{OR}=\mathrm{Odds}$ Ratios; $P=\mathrm{P}$-value. 


\section{Factors Associated With Contraception Use Among Adolescent Girls}

Regarding actual use of contraception, 31\% $(n=76)$ of the adolescent girls reported that they were using contraception with the m ainpartner to prevent pregnancy. Table 4 sum $\mathrm{m}$ arizes the association between sociecognitive factors and $\mathrm{m}$ arital status and using contraception. Specifically, feeling confident to discuss contraceptive m ethods with a partner and com fortable to use contraception were strongly associated with using it. Also, having discussed contraception use with som eone was strongly associated with contraception use. Finally, the likelihood to use a contraceptive method was associated with actual contraception use. None of the other socio cognitive factors, nor $\mathrm{m}$ arital status were associated with contraception use.

Table 4: Factors associated with contraception use among adolescent girls

\begin{tabular}{|c|c|c|c|c|}
\hline \multirow{2}{*}{ Measures } & \multirow{2}{*}{ Scale categories } & \multirow{2}{*}{ Frequency } & \multicolumn{2}{|l|}{ Bivariate } \\
\hline & & & OR $(95 \% \mathrm{CI})$ & $P$ \\
\hline \multicolumn{5}{|l|}{$\begin{array}{l}\text { Perceived behavioral } \\
\text { control/ self-efficacy } \\
\text { on contraception use }\end{array}$} \\
\hline Comfortable & Not very com fortable & 65 & Ref & \\
\hline $\begin{array}{l}\text { discussing } \\
\text { contraceptive methods }\end{array}$ & $\begin{array}{l}\text { Som ewhat } \\
\text { com fortable }\end{array}$ & 42 & $5.485(1.777,16.930)$ & 0.003 \\
\hline $\begin{array}{l}\text { with } \\
\text { spouse/partner }\end{array}$ & Very comfortable & 133 & $9.414(3.536,25.059)$ & 0.000 \\
\hline Confident to use a & Not at all confident & 46 & Ref & \\
\hline contraceptive method & Moderately confident & 51 & $20.158(2.537,160.165)$ & 0.005 \\
\hline if one wanted to & Extrem ely confident & 147 & $30.606(4.097,228.640)$ & 0.001 \\
\hline \multicolumn{5}{|l|}{ Attitude } \\
\hline Side effects from using & Strongly disagree & 12 & Ref & \\
\hline contraception usually & Disagree & 29 & $2.295(0.414,12.722)$ & 0.342 \\
\hline $\begin{array}{l}\text { disappear after a few } \\
\text { months }\end{array}$ & Agree & 118 & $2.812(0.584,13.555)$ & 0.198 \\
\hline contraception use & Strongly Agree & 38 & $4.535(0.869,23.651)$ & 0.073 \\
\hline \multicolumn{5}{|l|}{ Subjective norm } \\
\hline Discussed & No & 155 & Ref & \\
\hline contraception with & & & & \\
\hline $\begin{array}{l}\text { someone in the last six } \\
\text { months }\end{array}$ & Yes & 93 & $10.531(5.607,19.781)$ & 0.000 \\
\hline $\begin{array}{l}\text { Knowledge } \\
\text { contraception }\end{array}$ & & & & \\
\hline A woman and her child & Disagree & 6 & Ref & \\
\hline will be healthier if $a$ & Agree & 140 & $2.352(0.265,20.887)$ & 0.443 \\
\hline
\end{tabular}




\begin{tabular}{|c|c|c|c|c|}
\hline \multirow{3}{*}{$\begin{array}{l}\text { Measures } \\
\text { woman waits at least } \\
\text { two years between } \\
\text { pregnancies }\end{array}$} & \multirow{2}{*}{ Scale categories } & \multirow{2}{*}{ Frequency } & \multicolumn{2}{|l|}{ Bivariate } \\
\hline & & & OR $(95 \% \mathrm{CI})$ & $P$ \\
\hline & Strongly Agree & 102 & $2.093(0.233,18.821)$ & 0.510 \\
\hline \multirow{4}{*}{$\begin{array}{l}\text { Having too many } \\
\text { children can be } \\
\text { harmful to the health } \\
\text { and well-being of } \\
\text { women and their } \\
\text { families }\end{array}$} & Strongly disagree & 3 & Ref & \\
\hline & Disagree & 11 & $0.194(0.008,4.670)$ & 0.312 \\
\hline & Agree & 119 & $0.704(0.060,8.230)$ & 0.779 \\
\hline & Strongly Agree & 114 & $1.112(0.095,12.953)$ & 0.933 \\
\hline \multirow{4}{*}{$\begin{array}{l}\text { It is easy for most } \\
\text { women to get pregnant } \\
\text { soon after they stop } \\
\text { using contraception }\end{array}$} & Strongly disagree & 5 & Ref & \\
\hline & Disagree & 17 & $0.899(0.072,11.171)$ & 0.934 \\
\hline & Agree & 124 & $2.269(0.247,20.836)$ & 0.469 \\
\hline & Strongly Agree & 64 & $2.760(0.293,26.019)$ & 0.375 \\
\hline \multirow{4}{*}{$\begin{array}{l}\text { Knowledge on the } \\
\text { different types of } \\
\text { contraceptives to try }\end{array}$} & Strongly disagree & 4 & Ref & \\
\hline & Disagree & 1 & $0.000(0.000)$ & 1.000 \\
\hline & Agree & 141 & $1.560(0.157,15.467)$ & 0.704 \\
\hline & Strongly Agree & 82 & $1.282(0.126,12.999)$ & 0.833 \\
\hline \multicolumn{5}{|l|}{ Behavioral intention } \\
\hline \multirow{4}{*}{$\begin{array}{l}\text { Likely to use a } \\
\text { contraceptive method } \\
\text { in the next six months }\end{array}$} & Very Unlikely & 71 & Ref & \\
\hline & Unlikely & 34 & $0.636(0.065,6.189)$ & 0.697 \\
\hline & Likely & 59 & $14.903(4.370,50.820)$ & 0.000 \\
\hline & Very Likely & 74 & $\begin{array}{l}36.088 \\
120.540)\end{array}$ & 0.000 \\
\hline \multicolumn{5}{|l|}{ Marital status } \\
\hline \multirow{2}{*}{ Current marital status } & Not Married & 168 & Ref & \\
\hline & Married & 80 & $0.578(0.314,1.064)$ & 0.078 \\
\hline
\end{tabular}

Note. $\mathrm{CI}=$ confidence; $\mathrm{OR}=\mathrm{Odds}$ Ratios; $P=\mathrm{P}$-value 


\section{Discussion}

This study assessed social cognitive factors associated with sexual behaviors am ong sexually active adolescent girls in Uganda. Bivariate analyses showed that the sociocognitive factors of perceived behavioral control/ self-efficacy, subjective norm, behavioral intention, and $\mathrm{m}$ arital status were strongly associated with using contraception. We found no significant association between socio-cognitive factors and $m$ arital status with condom use. Sim ilarly, the results indicate no significant association between socio-cognitive factors and having m ultiple sexual partners. These findings are surprising, but this could (partly) result from the study not being designed from the outset to test TPB constructs and the relatively sm all sam ple size could have affected the accuracy of estim ating associations.

Nonetheless, som e of the findings are com parable to other studies conducted in SSA. While m any studies indicate high knowledge on condom s, little is known about the consistent and correct use of condom s am ong teenage girls (UBOS, 2018; Am oran, 2012). This is evident in the study finding which showed no significant relationship between knowledge and use of condom s. Whereas knowledge was found to have no significant relationship with the use of condom s, inform ation services rem ain im portant in clearing any $\mathrm{m}$ isconceptions and addressingny health concerns. Although several studies found that socio-cognitive factors such as perceived social norm, selfefficacy, attitudes, behavioral beliefs were significant predictors of intention to use condom s (Villarruel et al., 2004; Buhi \& Goodson2007; Rijsdijk et al., 2012), our study found that such socio-cognitive factors were not associated with the actual use of condom s am ong sexually active adolescent girls. In concurrence with our findings, Catania et al., (1989) found that self-efficacy and subjective norm s were non-significant predictors of condom use am ong adolescent girls. Sim ilarly, Eggers et al., (2015) found that attitude, subjective norm, and selfefficacy were weakly correlated with condom use. The findings of this study seem to suggst the need to explore other socio-cognitive factors such as gender norm $\mathrm{s}$, having stable and long-term relationships, selfesteem, and cultural $\mathrm{m}$ akeup that are associated with condom use am ong adolescents, as well as health com m unication factors to asses their effect on sexual behaviors. Gender norm $s$ that put $m$ en in a position of sexual dom inance were found to lim it wom eis ability to control their own reproductive and sexual health, as often seen in the belief that girls who carry or suggest using condom $\mathrm{s}$ are prom iscuous (Pulerwitz, Michaelis, Verm ą\& Weiss, 2010; Varga, 2003). Studies found widespread resistance to the use of condoms in stable and longterm relationships because of their association with lack of trust and illicit sex (Maharaj \& Cleland, 2005; Pulerwitz, Gortm aker, \& DeJong, 2000). A young m ais self-esteem , his ability to speak openly to a girl, and his cultural $\mathrm{m}$ akeup, were found to influence his readiness to use the condom (Centerwall \& Laack, 2008). 
Regarding m ultiple sexual partneships, it has been shown that adolescents often have $m$ ultipb sequential partners because $m$ any of their relationships are short term (Georges, Thom as, \& Bignam i Sim ona, 2014). Our study found a strong negative correlation between being $\mathrm{m}$ arried and having multiple sexual partners. This is consistent with Santelli, Brener, Lowry, Bhatt, \& Zabin, (1998) finding that $\mathrm{m}$ arried fem ales were significantly less likely than their neverm arried counterparts to have had $\mathrm{m}$ ultiple partners in the past three m onths. A stdy by Catania et al., (1989) found that the increased num berof sexual partners was associated with susceptibility beliefs to HIV, poorer sexual com m unication with partner, and greater peer acceptance for being sexually active. Our findings indicate that confidence to have only one sexual partner and discussing the risk of having $m$ ultiple sexual partners withsom eonewere not significantly associated with m ultiple sexual parnerships am ong adolescent girls. Therefore, there is need to assess other factors found to be associated with m ultiple sexual partnerships such as susceptibility beliefs to HIV, gender power relations and beliefs found to indicate that young $m$ en often think that it is heroic to have $m$ any sexual partners and girls engaging in transactional sex with older $\mathrm{m}$ en who are seen as better able to provide for them econom ically (Catania et al., 1989; Centerwall \& Laack, 2008; Bantebya, Muhanguzi, \& Watson, 2014).

Contraceptive continuation over sustained periods of tim e is not assured for adolescents particularly because they tend to have $m$ ore lim ited access than older individuals to fam ily planning, m ore unpredictable and irregular sexual activity, and are less knowledgeable about how to use contraceptive m ethods effectively (Burger \& Inderbitzen, 1985). In concurrence with other studies (Blanc, Tsui, Croft, \& Trevitt, 2009), our survey found that knowledge on contraception is not significantly associated with its use. However, the unm et need for contraception, despite the desire to lim it births or delay them for at least two years is high am ong unm arried adolescents in SSA - $\mathrm{m}$ ore than $40 \%$ in m ost countries (Bakibinga et al., 2016; Hindin \& Fatusi, 2009). Despite high sexual activity am ong adolescent girls in Uganda, contraceptive uptake is still low with only $43 \%$ sexually active unm arried adolescent girls, and 22\% m arried adolescent girls using a contraceptive m ethod (UBOS, 2018). Our findings indicate that there is no significant association between $\mathrm{m}$ arital status and contraception use. The low contraceptive uptake is linked to negative perceptions on contraceptive use am ong adolescents, partners and parents (Hardee et al., 2014; Kinaro, 2011; MacPhail, Pettifor, Pascoe, \& Rees, 2007; Murigi, Butto, Barasa, Maina, \& Munyalo, 2016). Studies in Ghana and Bangladesh on correlates of contraceptive use am ong fem ale adolescents found that knowledge and contraception use had significant relationships (Khan, Hossain, \& Hoq,2012; Nyarko, 2015), which contradicts our findings showing almost everyone agreeing to the knowledge statem ents, but not translated into use. However, Chandra-Mouli et al., (2017) found that knowledge gaps and $\mathrm{m}$ isconceptions on contraception both reduce uptake and 
increase discontinuation of contraceptive use. Our study found that three sociocognitive factors including perceived behavioral control/ self-efficacy, subjective norm, and behavioral intention were strongly associated with contraception use. This finding supports other studies that found contraceptive use to be associated with the ability to discuss sexual topics with sex partners and other influencers such as parents (Davies et al., 2006; Whitaker, Miller, May, \& Levin, 1999; Shrier, Goodm an, \& Em ans, 1999; Mbalinda, Kiwanuka, Eriksson, Wanyenze, \& Kaye, 2015). Although interventions that aim to increase contraceptive knowledge and availability to prevent unintended pregnancy would have little effect on their own (Chandra-Mouli et al., 2017), health prom otion program s should strive to address broader aspects in adolescent health program $m$ ing that include creating an enabling environm ent which is dully supported by theoretical models. To increase contraception use am ong adolescents, aspects such as gender inequalities, social norm s, and understanding adolescent dynam ics of $\mathrm{m}$ arrid and unm arried adolescents ought to be explored and addressed (Chandra-Mouli et al., 2017).

\section{Limitations of the Study}

The study findings rely on self-report data which $m$ ay have lim itations of sexual activity recall bias and the potential for under-reporting of sexual behavior due to the sensitive nature of the subject (Mbalinda et al., 2015; Reid \& Aiken, 2011). Our focus on sexually active adolescent girls $\mathrm{m}$ ay lim it generaikation to the entire population. The relatively sm all sam ple size in the study proided results in very wide confidence intervals, which $\mathrm{m}$ ade it hard to dem onstrate the association for som e variables. The predictive m easures of the study were approached heoretically using TPB, but the self-reported questionnaire was not structured as such. Therefore, given that the study was not designed to test TPB m eans that operationalization of the study constructs m aynot be in line with TPB guidelines (Ajzen, nd; Ajzen, 1991). For exam ple, som e $m$ easures- such as discussing contraception and condom use with others- $m$ ight be indicative of subjective norm, but $\mathrm{m}$ ay not clearly be in line with the conceptualization, nor the operationalization, as specified in the TPB (Ajzen, nd). However, these findings give us a contextual understanding of how socio-cognitive factors are variedly associated with contraception use, condom use, and having m ultiple sexual partners am ong adolescents The study was cross-sectional in nature where behavioral predictors were not studied over a long period of tim e to confirm the tem poral assumptions. Therefore, longitudinal and experim ental studies are required to confirm the assum ptions (Sniehotta, 200). 


\section{Conclusion}

Health prom otion program $\mathrm{s}$ in SSA are faced with the intricate challenge of designing practicable intervention approaches to address the reality that $\mathrm{m}$ any adolescents are increasingly becom ing sexually active by age 15 . Based on our findingsthat indicate strong associations between perceived behavioral control/ self-efficacy, subjective norm, and behavioral intertion, it is important to improve contraception com m unication am ong adolescents and their key influencers. Specifically, health promotion program s should provide adequate inform ation on SRH to guide dialogue am ong adolescents and their key influencers suchas health workers, parents, partners, and peers (Jonas et al., 2016; Pilgrim et al., 2014; Aarø et al., 2014). Creating an enabling environm ent that addresses aspects such as gender inequalities, social norm $\mathrm{s}$, and understanding adolescent dynam ics of $\mathrm{m}$ arried and unm arried adolescents is pertinent (Chandra-Mouli et al., 2017). In this regard, further research is needed to find out other factors such as gender differences associated with adolescent sexual behavior, and practicable approaches on strengthening com m unication skills for key influencers of adolescents such as-parents, health workers, and religious leaders-to prom ote open dialogue on sexuality and SRH services. It is also im portant to learn from the experience of piloted adolescent health program s hat have im plem ented aspects of interpersonal com $\mathrm{m}$ unication with and service delivery to adolescents. This will help in generating lessons for addressing the persistent challenges outlined in this paper, and guide im provem ents in the new and followon adolescent health targeted interventions. 


\section{References}

Aarø, L. E., Mathews, C., Kaaya, S., Katahoire, A. R., Onya H., Abraham , C., \& De Vries, H. (2014). Prom oting sexual and reproductive health am ong adolescents in southern and eastern Africa (PREPARE): project design and conceptual fram ework.BMC Public Health, 14(1), 54. doi.org/10.1186/1471-2458-14-54

Ajzen, I. (nd). Constructing Theory of Planned Behavior Questionnaire. Retrieved May 8, 2018, from https://people.um ass.edu/aizen/pdf/tpb.m easurem ent.pdf

Ajzen, I. (1991). The theory of planned behavior. Organizational Behavior and Human Decision Processes, 50(2), 179-211. doi.org/10.1016/07495978(91)90020-T

Am in, S., Austrian K., Chau M., Glazer K., Green E., Stewart D., Stoner M. (2013). The Adolescent Girls Vulnerability Index: Guiding strategic investment in Uganda.

Am oran, O. E. (2012). A com parative analysis of predictors of teenage pregnancy and its prevention in a rural town in Western Nigeria. International Journal for Equity in Health, 11(1), 1. doi.org/10.1186/1475-9276-11-37

Ankom ah, A., Anyanti,J., Adebayo, S., \& Giwa, A. (2013). Barriers to Contraceptive Use am ong Married Young Adults in Nigeria: A Qualitative Study.

Antal, E., \& Rothenbühler, M. (2015). Weighting in the Swiss Household Panel Technical report. Retrieved Novem ber 15, 2017, from http://forscenter.ch/wp content/uploads/2014/12/Weighting_technical_report.pdf

Bakibinga, P., Matanda, D. J., Ayiko, R., Rujum ba, J., Muiruri, C., Am endah, D., \& Atela, M. (2016). Pregnancy history and current use of contraception am ong wom en of reproductive age in Burundi, Kenya, Rwanda, Tanzaniaand Uganda: analysis of demographic and health survey data. BMJ open, 6(3), doi.org/10.1136/bm jopen2015-009991

Bantebya G. K., Muhanguzi F. K., \& Watson C. (2014). Adolescent girls in the balance: Changes and continuity in social norms and practices around marriage and education in Uganda. Retrieved February 25, 2017, from, https://www.odi.org/sites/odi.org.uk/files/odi-assets/publications-opinionfiles/9180.pdf

Baxter C., \& Abdbol Karim S. (2016). Com bination HIV prevention options for young wom en in Africa. African Journal of AIDS Research, 15(2), 109-121. doi.org/10.2989/16085906.2016.1196224

Birungi, H., Mugisha, J. F., Nyom bi, J., Obare, F., Evelia, H., \&Nyinkavu, H. (2008). Sexual and reproductive health needs of adolescents perinatally infected with HIV in Uganda. FRONTIERS Final Report.

Blanc, A. K., Tsui, A. O, Croft, T. N, \& Trevitt, J.L. (2009). Patterns and trends in adolescents' contraceptive use and discontinuation in developing countries and com parisons with adult wom en.International Perspectives on Sexual and Reproductive health, 63-71. doi.org/10.1363/3506309 
Buhi, E. R., \& Goodson, P. (2007). Predictors of adolescent sexual behavior and intention: A theory-guided system atic review. Journal of Adolescent Health, 40(1), 4-21. doi.org/10.1016/j.jadohealth.2006.09.027

Burger, J. M., \& Inderbitzen, H. M. (1985). Predicting contracepive behavior am ong college students: The role of com m unication, kowledge, sexual anxiety, and self-esteem. Archives of Sexual Behavior, 14(4), 343-350. doi.org/10.1007/BF01550849

Catania, J. A., Coates, T. J., Greenblatt, R. M., Dolcini, M. M., Kegeles, S. M., Puckett, S., ... \& Miller, J. (1989). Predictors of condom use and m ultiple partnered sex am ong sexually-active adolescent wom en: Im plications for aids related health interventions.

Centerwall, E., \& Laack, S., (2008). Young Men as Equal Partners. RFSU, Riksförbundet för sexuell upplysning, The Swedish Association for Sexuality Education, Stockholm .

Chandra-Mouli, V., Param eshwar, P. S., Parry, M., Lane, C., Hainsworth, G., Wong, S., ... \& Say, L. (2017). A neverbefore opportunity to strengthen investm ent and action on adolescent contraception, and what we m ust do to $m$ ake full use of it. Reproductive health, 14(1), 85. doi.org/10.1186/s12978-017-0347-9

CHC-Com m unication for Healthy Com m unities. (2016)Evaluative survey of an Integrated Health Communication Campaign in Uganda - Observation 1 Report. USAID and FHI360. Kam pala, Uganda.

Cooke, R., \& French, D.P. (2008). How well do the theory of reasoned action and theory of planned behaviour predict intentions and attendance at screening program mes? A m etannalysis. Psychology and Health, 23(7), 745-765. doi.org/10.1080/08870440701544437

Cortez, R., Saadat, S., Marinda, E., \& Odutolu, O. (2016).Adolescent Fertility and Sexual Health in Nigeria.

Davies, S. L., DiClem ente, R. J., Wingood, G. M., Person, S. D., Dix, E. S., Harrington, K., ... \& Oh, K. (2006). Predictors of inconsistent contraceptive use am ong adolescent girls: findings from a prospective study.Journal of Adolescent Health, 39(1), 43-49. doi.org/10.1016/j.jadohealth.2005.10.011

Doyle, A. M., Mavedzenge, S. N., Plum m er, M. L., \& Ross, D. A. (2012). The sexual behaviour of adolescents in sub-Saharan Africa: patterns and trends from national surveys. Tropical Medicine \& International Health, 17(7), 796-807. doi.org/10.1111/j.1365-3156.2012.03005.x

Eggers, S. M., Aarø, L. E., Bos, A. E., Mathews, C., Kaaya, S. F., Onya, H., \& de Vries, H. (2016). Socio-cognitive predictors of condom use and intentions am ong adolescents in three sub-Saharan sites. Archives of Sexual Behavior, 45(2), 353-365. doi.org/10.1007/s10508-015-0525-1

Eggers, S. M., Taylor, M., Sathiparsad, R., Bos, A. E., \& de Vries, H. (2015). Predicting safe sex: Assessm ent of autoregressive and crosslagged effects within the Theory of Planned Behavior. Journal of Health Psychology, 20(11), 
1397-1404. doi.org/10.1177/1359105313512354

Field, A. (2009). Discovering Statistics Using SPSS (3rd ed.). SAGE Publications Ltd. London.

Fishbein, M., \& Ajzen, I. (2010). Predicting and Changing Behavior. The Reasoned Action Approach. Psychology press. Taylor \& Francis Group. New York, USA.

Georges, G., Thom as, L. K., \& Bignam i Sim ona, B. (2014)exual risk behavior: Factors associated with the number of sexual partners and consistent condom use among adolescents in four sub-Saharan African countries. Retrieved March 27, 2017, from http://paa2014.princeton.edu/papers/141169

Glanz, K., Rim er, B. K., \& Viwanath, K. (2008). Health Behavior and Health Education: Theory, Research, and Practice (4th ed.). John Wiley \& Sons, Inc. San Francisco, CA- USA,

Hardee, K., Gay, J., Croce-Galis, M., \& AfariDwam ena, N. A. (2014). What HIV program s work for adolescent girls? Journal of Acquired Immune Deficiency Syndromes, 66, S176-S185. doi.org/10.1097/QAI.0000000000000182

Heeren, G. A., Jem m ott III, J. B., Mandeya, A., \& Tyler, J. C. (2007)Theory-Based Predictors of Condom Use am onguniversity Students in the United States and South Africa. AIDS Education \& Prevention, 19(1), 1-12. doi.org/10.1521/aeap.2007.19.1.1

Hindin, M. J., \& Fatusi, A. O. (2009). Adolescent sexual and reproductive health in developing countries: an overview of trends and interventions. International Perspectives on Sexual and Reproductive Health, 35(2), 58-62. doi.org/10.1363/3505809

Jonas, K., Crutzen, R., van den Borne, B., \& Reddy, P. (2017). Healthcare workers behaviors and personal determ inants associated with providing adequate sexual and reproductive healthcare services in sub-Saharan Africa: a system atic review. BMC Pregnancy and Childbirth, 17(1), 86. doi.org/10.1186/s12884-017-1268$\mathrm{X}$

Jonas, K., Reddy, P., van den Borne, B., Sewpaul, R., Nyem bezi, A., Naidoo, P., \& Crutzen, R. (2016). Predictors of nurses' and midwives' intentions to provide $\mathrm{m}$ aternal and child healthcare services to adolescents in South Africa. BMC Health Services Research, 16(1), 658. doi.org/10.1186/s12913-016-1901-9

Kalton, G., \& Kasprzyk, D. (1986). The treatm ent $\$ \mathrm{~m}$ issing survey data. Survey methodology, 12(1), 1-16.

Kazaura, M. R., \& Masatu, M. C. (2009). Sexual practices am ong unm arried adolescents in Tanzania. BMC Public Health, 9(1), 373. doi.org/10.1186/14712458-9-373

Khan, M. M., Hossain, M. E., \& Hoq, M. N (2012). Determ inants of contraception use am ong fem ale adolescents in BangladeshAsian Social Science, 8(12), 181.

Kinaro, J. W. (2011). Perceptions as a barrier to Contraceptive Use Among Adolescents: A case Study of Nairobi, Kenya (Unpublished m asters thesis). Population Studies and Research Institute (PSRI), University of Nairobi, Kenya. 
Kish, L. (1949). A procedure for objective respondent selection within the household. Journal of the American Statistical Association, 44(247), 380-387. doi.org/10.1080/01621459.1949.10483314

Klugm an, J., Hanm er, L., Twigg, S., Hasan, T., McClearySills, J., \& Santam aria, J. (2014). Voice and agency: Empowering women and girls for shared prosperity: World Bank Publications. doi.org/10.1596/978-1-4648-0359-8

Krugu, J. K., Mevissen, F. E. F., Debpuur, C., \& Ruiter, R. A. C. (2016).Psychosocial correlates of condom use intentions am ong junior high school students in Bolgatanga Municipality of Ghana. International Journal of Sexual Health, 28, 96-110. doi.org/10.1080/19317611.2015.1124162

Loaiza, E., \& Liang, M. (2013).Adolescent pregnancy: a review of the evidence. UNFPA, New York, USA.

MacPhail, C., Pettifor, A. E., Pascoe, S., \& Rees, H. V. (2007). Contraception use and pregnancy am ong 15-24 year-old South African wom en: a nationally representative cross-sectional survey. BMC medicine, 5(1), 31. doi.org/10.1186/1741-7015-5-31

Maharaj, P., \& Cleland, J. (2005). Risk perception and condom use am ong m arried or cohabiting couples in KwaZulu-Natal, South Africa. International Family Planning Perspectives, 24-29. doi.org/10.1363/3102405

Mbalinda, S. N., Kiwanuka, N., Eriksson, L. E., Wanyenze, R. K., \& Kaye, D. K. (2015). Correlates of ever had sex am ong perinatally HIVinfected adolescents in Uganda. Reproductive Health, 12(1), 96. doi.org/10.1186/s12978-015-0082$\mathrm{Z}$

McEachan, R. R. C., Conner, M., Taylor, N. J., \& Lawton, R. J. (2011). Prospective prediction of health-related behaviours with the theory of planned behaviour: A metaanalysis. Health Psychology Review, 5(2), 97-144. doi.org/10.1080/17437199.2010.521684

Ministry of Health- MOH. (2004). National Adolescent Health Policy for Uganda. Ministry of Health Reproductive Health Division. Kam pala Uganda. Retrieved Decem ber 30, 2016, from ww.youth policy.com/Policies/UGAyouthpol2004.pdf

Ministry of Health- MOH. (2010). Health Sector Strategic Plan III 2010/11-2014/15. Governm entof Uganda Kam pala, Uganda.

Ministry of Health- MOH. (2012). Uganda AIDS Indicator Survey 2011. Ministry of Health. Kam pala, Uganda.

Murigi, M., Butto, D., Barasa, S., Maina, E., \& Munyalo, B. (2016). Overcom ing Barriers to Contraceptive Uptake am ong Adolescents: The Case of Kiam bu County, Kenya. Journal of Biosciences and Medicines,4(09),1. doi.org/10.4236/jbm .2016.49001

Neem a, S., Musisi, N., \& Kibom bo, R. (2004).Adolescent sexual and reproductive health in Uganda: a synthesis of research evidence (Vol. 14). Alan Guttm acher Institute. 
Nyarko, S. H. (2015). Prevalence and correlates of contraceptive use am ong fem ale adolescents in Ghana. BMC Women's Health, 15(1), 60. doi.org/10.1186/s12905-015-0221-2

Obare, F., Birungi, H., Undie, C. C., Wanjiru, M., Liam bila, W., \& Askew, I. (2011). Levels trends and determinants of contraceptive use among adolescent girls in Kenya. APHIA II Operations Research Project/ Population Council.

Pilgrim, N. A., Ahm ed, S., Gray, R. H., Sekasanvu, J., Lutalo, T., Nalugoda, F., \& Wawer, M. J. (2014). Fam ily structure effects on early sexual debut am ong adolescent girls in Rakai, Uganda. Vulnerable Children and Youth Studies, 9(3), 193-205. doi.org/10.1080/17450128.2013.842027

Pulerwitz, J., Gortm aker, S. L., \& DeJong, W. (2000). Measuring sexual relationship power in HIV/STD research. Sex Roles, 42(7), 637-660. doi.org/10.1023/A:1007051506972

Pulerwitz, J., Michaelis, A., Verm a, R., \& Weiss, E. (2010). Addressing gender dynam ics and engaging $m$ en in HIV program s: lessons learned from Horizons research. Public Health Reports, 125(2), 282-292. doi.org/10.1177/003335491012500219

Reid, A. E., \& Aiken, L. S. (2011). Integration of five health behaviour m odels: com $\mathrm{m}$ on strengths and unique contributions to understanding condom use. $\begin{array}{llll}\text { Psychology } \quad \text { Health, 26(11), 1499-1520. } & \text {. }\end{array}$ doi.org/10.1080/08870446.2011.572259

Rijsdijk, L. E., Bos, A. E., Lie, R., Ruiter, R. A., Leerlooijer, J. N., \& Kok, G. (2012). Correlates of delayed sexual intercourse and condom use am ong adolescents in Uganda: a cross-sectional study. BMC Public Health, 12(1), 817. doi.org/10.1186/1471-2458-12-817

Santelli, J. S., Brener, N. D., Lowry, R., Bhatt, A., \& Zabin,L. S. (1998). Multiple sexual partners am ong US adolescents and young adults. Family Planning Perspectives, 271-275. doi.org/10.2307/2991502

Shrier, L. A., Goodm an, E., \& Em ans, S. J. (1999). Partner condom usam ong adolescent girls with sexually transm ited diseases. Journal of Adolescent Health, 24(5), 357-361. doi.org/10.1016/S1054-139X(98)00133-5

Singh, S., \& Darroch, J. (2014).Adding it up. costs and benefits of contraceptive services. New York: Guttm acherInstitute and United Nations Population Fund: UNFPA). Retrieved Decem ber 01, 2016, from http://www.guttm acher.org/pubs/AIU-2012-estim ates.pdf

Singh, S., \& Darroch, J. E. (2012).Adding it up: Costs and benefits of contraceptive services. Guttm acher Institute and UNFPA.

Sniehotta, F. (2009). An experim ental test of the theory of planned behavior.Applied Psychology: Health and Well-Being, 1(2), 257-270, doi.org/10.1111/j.17580854.2009.01013.x

Tabachnick, B. G., \& Fidell, S. L. (2013). Using Multivariate Statistics (6th ed.). Pearson Education, Inc. United States of Am erica. 
Uganda Bureau of Statistics (UBOS) and ICF International Inc. (2012). Uganda Demographic and Health Survey 2011. Kampala, Uganda: UBOS and Calverton, Maryland: ICF International Inc.

Uganda Bureau of Statistics (UBOS) and ICF. (2018). Uganda Demographic and Health Survey 2016. Kam pala, Ugandaand Rockville, Maryland, USA: UBOS and ICF.

UNICEF. (2015). The national strategy to end child marriage and teenage pregnancy 2014/2015 - 2019/2020: A society free from child marriage and teenage pregnancy. Republic of Uganda.

UNICEF. (2016). Collecting and Reporting of Sex-and Age-Disaggregated Data on Adolescents at the Sub-National Level. Data Abstraction Guide - Novem ber 2016.

Varga, C. A. (2003). How gender roles influence sexual and reproductive health am ong South African adolescents. Studies in Family Planning, 34(3), 160-172. doi.org/10.1111/j.1728-4465.2003.00160.x

Verm a, V., \& Lê, T. (1996)An analysis of sam pling errors for the dem ographic and health surveys. International Statistical Review/Revue Internationale de Statistique, 265-294. doi.org/10.2307/1403786

Villarruel, A. M., Jem m ott III, J. B., Jem m ott, L. S., \& Ronis, D. L. (2004)redictors of sexual intercourse and condom use intentions am ong Spanishdom inant Latino youth: a test of the planned behavior theory. Nursing Research, 53(3), 172-181. doi.org/10.1097/00006199-200405000-00004

Whitaker, D. J., Miller, K. S., May, D. C., \& Levin, M. L. (1999). Teenage partners' com m unication about sexual risk and condom use: the im portance of parent teenager discussions. Family Planning Perspectives, 117-121. doi.org/10.2307/2991693

Widdice, L. E., Cornell, J. L., Liang, W., \& HalpernFelsher, B. L. (2006). Having sex and condom use: Potential risks and benefits reported by young, sexually inexperienced adolescents. Journal of Adolescent Health, 39(4), 588-595. doi.org/10.1016/j.jadohealth.2006.03.016

Williamson, N. (2014). State of the World Population 2013. Motherhood in Childhood: Facing the Challenge of Adolescent Pregnancy. New York: United Nations Population Fund.

Winship, C., \& Radbill, L. (1994). Sam plingweights and regression analysis. Sociological Methods \& Research, 23(2), 230-257. https://doi.org/10.1177/0049124194023002004 


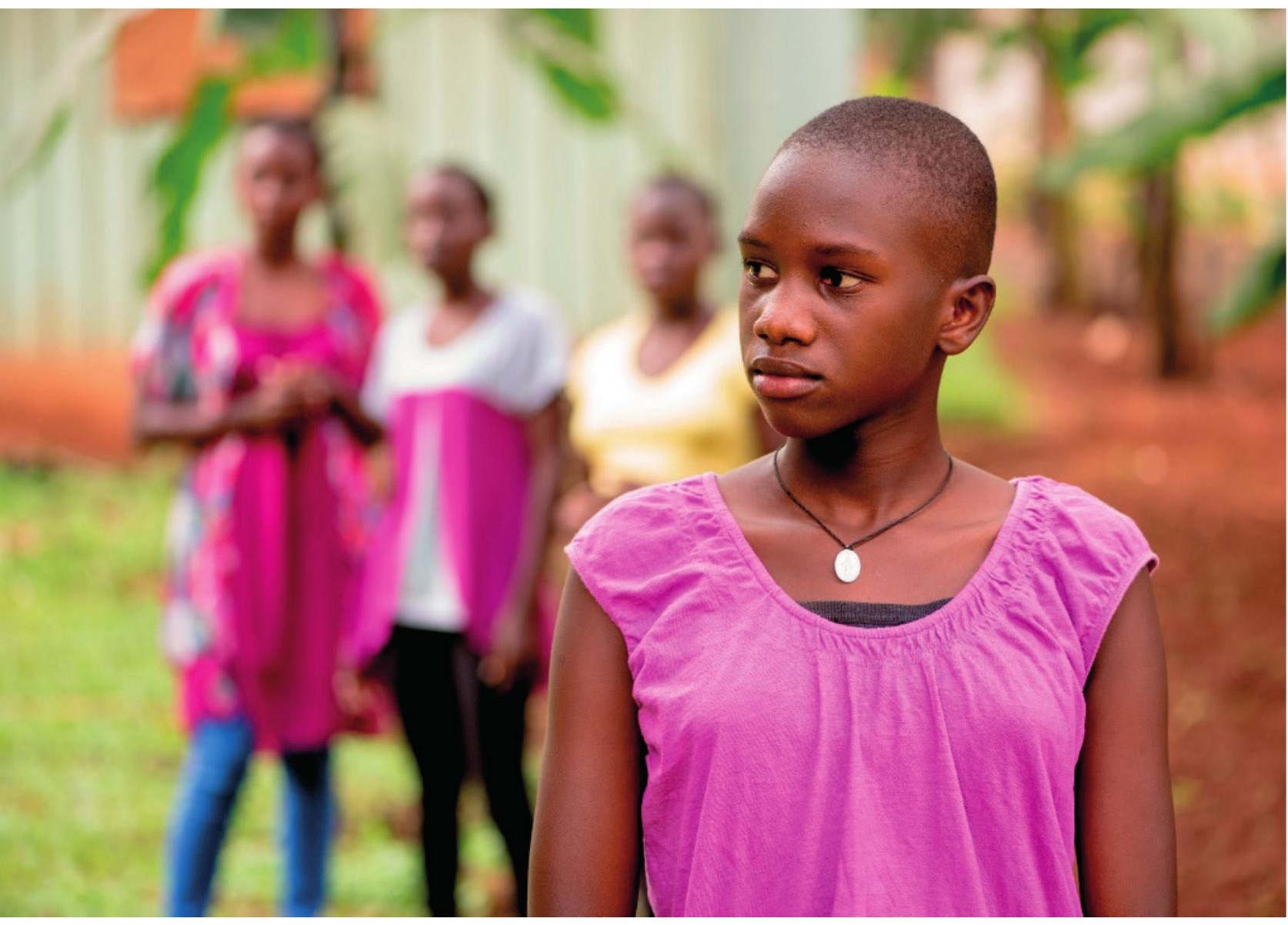




\section{Chapter 3}

\section{Gender norm s associted with adolescent sexual behaviors in Uganda}

\section{To be published as:}

Nalukwago, J., Crutzen, R., Van den Borne, B., Bukuluki, M. P., Bufum bo, L., Burke, M. H., Field, S., Zikusooka, A., Fiedler, A. A., \& Alaii, J. (subm itted) Gender norms associated with adolescent sexual behaviors in Uganda. 


\begin{abstract}
The relationship between gendered power relations and sexual behaviors of adolescents has been lim itedly explored in Uganda. A 2015 crosssectional survey covering 16 purposively selected districts of Uganda assessed perceptions and associations of gender norm s m easured using the Gender Equitable Men scale and sexual behaviors am ong adolescents $(\mathrm{N}=867)$. Findings indicate that behavioral intention to use contraception was m oderately correlated with a gender equitable norm towards reproductive health and pregnancy/ disease prevention am ong girls, $r$ $=.23(\mathrm{p}<.01 ; 95 \% \mathrm{CI} .14, .31)$ and boys, $\mathrm{r}=.22(\mathrm{p}<.01 ; 95 \% \mathrm{CI} .12, .31)$. This indicates adolescents' approval of the gender norm s underscoring that it is a woman's responsibility to avoid getting pregnant'. A m oderate correlation was found between self-efficacy to use condom s and the norm towards reproductive health and pregnancy/ disease prevention am ong girls, $\mathrm{r}=.29(\mathrm{p}<.01 ; 95 \% \mathrm{CI} .20, .37)$ and boys, $\mathrm{r}=.30(\mathrm{p}<.01 ; 95 \% \mathrm{CI} .21, .38)$. This im plies that adolescents approve gender inequitable norm s such as 'wom en who carry condom s on them are cheapHowever, there was no significant correlation am ongself-efficacy to use contraception and to use condom s, with sexual relationship/ habits am ong both girls and boys There was also no significant correlation between behavioral intention to only have one sexual partner and physical violence am ong either girls and boys. This indicates persistent inequitable gender norms that affect health service uptake among adolescents. Addressing inequitable gender norm s require working closely with girls and boys, prom oting inform ed peer and partner discussions, engaging in strategic partnerships with parents, religious, political, and community leaders, and enforcing health inform ation services to address $\mathrm{m}$ isconceptions.
\end{abstract}

K eywords Gender norm s, sexual behaviors, condom use, contraception, m ultiple sexual partners. 


\section{Introduction}

Gender norm attitudes and practices rem ain deeply entrenched in m any African societies (Wight et al., 2006; Gibson et al., 2014). Countries driven by gender inequalities that constrain individual behavior in sexual interactions often have the highest rates of HIV and teenage pregnancies (Hardee et al., 2014; Van den Berg et al., 2013; Richards et al., 2013). Wom en and girls face $m$ ore gendered risks than their $\mathrm{m}$ ale counterparts, which affects their social, econom ic and political opportunities (UNAIDS, 2016; UNICEF, 2015; Mbonye et al., 2012). Risks such as poverty, school dropout owing to pregnancy or early $m$ arriage, sexual harassm ent and continuing parental preference to invest in the education of boys, lim it girls from reaching their full potential (Bantebya et al., 2014; Am in et al., 2013; Ssewam ala et al, 2010; Burgess \& Cam pbell2016). Gender norm s and power dynam ics between $m$ en and wom en have been widely studied in the context of HIV and genderbased violence in adult populations (Nanda, 2011). However, less is known about the association between gender norm s and sexual behaviors am ong adolescents in Uganda, and whether adolescent approve or disapprove the gender inequitable norms Yet, $\mathrm{m}$ essages around gender norm $\mathrm{s}$ that influence behavior are transm itted early inife and internalized by adolescence into a young person's worldview (Vu et al., 2017). Therefore, adolescents' gender perspectives and inequitable gender norm s found to affect SRH service uptake need to be addressed in the design of adolescent health program s (Chandra-Mouli et al., 2017). This is because gender inequitable norm s often times lead to gender power imbalance and affects adolescents' ability to negotiate safe sex (UNESCO, 2017), thereby putting them at risk of HIV and unplanned pregnancies (UBOS, 2018). Thus, the present study focuses on understanding the gender norms associated with sexual and reproductive health (SRH) behaviors such as behavioral intention and self-efficacy to; use condom s, use contraception and reduction of m ultiple concurrent sexual partnerships as outcom e m easures. The Gender Equitable Men [GEM] scale was used to assess the gender norm $\sin$ this study.

\section{Methods}

\section{The Gender Equitable Men (GEM) scale}

This study used the GEM scale to explore the perceptions and associations of gender norm s and SRH behaviors am ong adolescent girls and boys aged 15-19. The GEM scale, which em erged out of a social constructionist perspective of gender identity, postulates that any given cultural setting provides $m$ ultiple versions of appropriate 
behavior for $m$ en and wom en (Pulerwitz \& Barker 2008). It contains thirty-four item $s$ that have been validated and used over tim e in different country settings am ong both $\mathrm{m}$ en and wom en (Vu et al., 2017; Pulerwitz \& Barkę2008; Singh et al., 2013; Shattuck et al., 2013; Harrison et al., 2006). The general discourse in studies that used the GEM Scale in sub-Saharan Africa (SSA) settings found that-both $m$ en and wom en were in high support for gender inequitable norm s, with wom en being less gender equitable (Flood \& Lang 2015; Vu et al., 2017; Harrison et al., 2006; Ezekiel et al., 2015). We adopted the GEM scale because it is a standardized m easure widely used to explore gender norms perspectives. The specific sub-groups/sub-scales adopted from the GEM scale to m easure gnder-related attitudes am ong adolescents include; dom estic chores/ household decisionm aking, sexual relationships/ habits, reproductive health and pregnancy/ disease prevention, and physical violence. These sub-groups were adopted based on previous research on gender norm s (Nanda 2011; Pulerwitz \& Barker 2008). The respondents who agreed or partly agreed to the GEM scale variables were identified as being gender inequitable.

\section{Study design and sampling}

We used data from a crosssectional survey, conducted in 2015, that covered 16 purposively selected districts of Uganda (Lira, Am uru, Ntungam o, Ibanda, Mbale, Kum i, Iganga, Buyende, Arua, Nebbi, Moroto, Kaabong, Mukono, Sem babule, Kasese, Kyenjojo). A stratified multistage probability sampling design was employed where sampling occurred in four stages: 80 parishes were random ly selected from the 16 districts using stratified, probability proportional to size (PPS) system atic sam pling, for which a list of villages in the parish was obtained and 3 villages random ly sam pled using PPS. Ten households from each random ly selected village and household sam ples were drawn with uniform probability using a sam pling fram e/list generated with the local leaders. A members list for each sampled household was generated and basic dem ographic inform ation about each household $\mathrm{m}$ em ber was collected and used for selection of eligible individual participants using a Kish grid. The latter is a m ethod for selecting $\mathrm{m}$ em bers within a household to be interviewed if there is $\mathrm{m}$ ore than one eligible $\mathrm{m}$ em ber in each stratum (CH,C2016; Kish, 1949). Although data from $m$ en and wom en aged 1-\$49 was collected, the current study only included data from 867 adolescent girls and boys aged 15-19.

\section{Measures}

Table 1 sum $m$ arizes the sociedem ographic andSRH behavioral $m$ easures, as well as the GEM scale m easures, including questions and response categories. The study assessed the following socio-dem ographics: age, education level, m arital status, 
religion, occupation, sexual debut, and begun childbearing. All three sexual behaviors (condom use, m ultiple sexual partnerships, and contraception use) were assessed with two item s (Behavioral intention and Selfefficacy) using a three to four-point Likert scale (e.g. Very likely, Likely, Unlikely, Very unlikely, and Extrem ely Confident, Moderately confident, Not at all confident). The survey tool was structured with autom atic skips to ensure respondents were only asked questions they could ethically respond to. This applied especially to questions of past and/or current sexual activity (e.g. sexual debut, contraceptive use) for which a conditional response $\mathrm{m}$ ay follow. Except in such occurrences, m ost questions on sexual and reproductive health were asked of every respondent, including general questions on health seeking, behavioral determ inants, and future intentions. The GEM scale measure used four item $\mathrm{s}$ (Dom estic chores and Household decisionm aking, Sexual relationships/ habits, Reproductive health and pregnancy/ disease prevention, and Physical Violence) whose variables were assessed using a three-point Likert scale (Agree, Partly agree, Do not agree).

Table 1: Socio-demographics, SRH behaviors, and GEM scale measures in this study

\begin{tabular}{|c|c|}
\hline Measures & Q uestions and response categories \\
\hline \multirow{10}{*}{$\begin{array}{l}\text { Socio- } \\
\text { demographic } \\
\text { characteristics }\end{array}$} & Age: Respondents were asked the age at their last birthday. \\
\hline & $\begin{array}{l}\text { Education level: Participants were asked their highest level of school. } \\
\text { Responses were: Primary (=1), "O" level (=2), "A" level }(=3) \text {, Tertiary (=4) }\end{array}$ \\
\hline & Marital status: Responses were Not married (=1), Married $(=2)$ \\
\hline & $\begin{array}{l}\text { Religion: Responses were Catholic (=1), Protestant (=2), Muslim (=3), } \\
\text { Pentecostal (=4), Seventh Day Adventist (=5), Other (=6) }\end{array}$ \\
\hline & Occupation: Responses were Subsistence farmer (=1), Commercial farmer (=2), \\
\hline & $\begin{array}{l}\text { Labourer/ domestic worker (=3), Petty trader/ Hawke }(=4) \text {, Owns business with } \\
3 \text { or more employees }(=5) \text {, Student }(=6) \text {, Other }(=7)\end{array}$ \\
\hline & $\begin{array}{l}\text { Sexual debut: For age at first sex, respondents were asked how old they were } \\
\text { when they had sexual intercourse for the very first tim e }\end{array}$ \\
\hline & Responses: Entered age at first sex (1), Did not enter age (2) \\
\hline & $\begin{array}{l}\text { Already had a child: Respondents were asked if they had a child at the tim e of the } \\
\text { survey. }\end{array}$ \\
\hline & Responses: Yes $(=1)$, No $(=0)$ \\
\hline \multirow{6}{*}{$\begin{array}{l}\text { Sexual and } \\
\text { Reproductive } \\
\text { Health } \\
\text { behaviors }\end{array}$} & Behavioral intention to use contraception: \\
\hline & a) How likely are you to use a contraceptive $m$ ethod in the next sixm onths? \\
\hline & Responses: Very likely (=3), Likely (=2), Unlikely (=1), Very unlikely (=0) \\
\hline & \\
\hline & Self-efficacy to use contraception: \\
\hline & $\begin{array}{l}\text { b) How confident are you that you can use a contraceptive } m \text { ethod if you want } \\
\text { to? }\end{array}$ \\
\hline
\end{tabular}




\begin{tabular}{|c|c|}
\hline Measures & Q uestions and response categories \\
\hline & $\begin{array}{l}\text { Responses: Extremely Confident }(=2), \text { Moderately confident }(=1), \text { Not at all } \\
\text { confident }(=0)\end{array}$ \\
\hline & $\begin{array}{l}\text { Behavioral intention to use condoms at every sexual encounter: } \\
\text { a) How likely are you to use a condom during sex in the next six m onths? } \\
\text { b) How likely are you to use a condom the next tim e you havesexual } \\
\text { intercourse? } \\
\text { Responses: Very likely }(=3) \text {, Likely }(=2) \text {, Unlikely }(=1) \text {, Very unlikely }(=0) \\
\text { Self-efficacy to use a condom at every sexual encounter: } \\
\text { c) It is easy to suggest to partner to use a condom } \\
\text { Responses recoded as: Strongly agree }(=3) \text {, Agree }(=2) \text {, Disagree }(=1) \text {, Strongly } \\
\text { disagree }(=0) \\
\text { d) How com fortable are you talking with a sexual partner about condom s? } \\
\text { Responses: Very comfortable (=2), Somewhat comfortable }(=1) \text {, Not very } \\
\text { comfortable }(=0)\end{array}$ \\
\hline & $\begin{array}{l}\text { Behavioral intention to have one sexual partner: } \\
\text { a) How likely are you to only have one sexual partner in the next six m onths? } \\
\text { Responses: Very likely (=3), Likely (=2), Unlikely }(=1) \text {, Very unlikely (0). }\end{array}$ \\
\hline & $\begin{array}{l}\text { Self-efficacy to avoid multiple concurrent sexual partnerships } \\
\text { b) How confident are you that you could have only one sexual partner in the } \\
\text { next six m onths? } \\
\text { Responses: Extremely Confident }(=2) \text {, Moderately confident }(=1) \text {, Not at all } \\
\text { confident }(=0) \text {. }\end{array}$ \\
\hline \multicolumn{2}{|r|}{ S } \\
\hline $\begin{array}{l}\text { Domestic chores } \\
\text { and Household } \\
\text { decision-making }\end{array}$ & $\begin{array}{l}\text { a) Changing diapers, giving a bath, and feeding children is the m other's } \\
\text { responsibility } \\
\text { b) A m an should have the final word about decisions in his hom e } \\
\text { c) A wom an's m ost im portant role is taking care of her hom e and cook for her } \\
\text { fam ily } \\
\text { All responses coded as: Agree (0), Partly agree (1), Do not agree (2) }\end{array}$ \\
\hline $\begin{array}{l}\text { Sexual } \\
\text { relationships/ } \\
\text { habits }\end{array}$ & $\begin{array}{l}\text { a) It is the } m \text { an who decides what type of sex to have } \\
\text { b) Men need sex m ore than wom en do } \\
\text { c) Men are always ready to have sex } \\
\text { d) You don't talk about sex, you just do it. } \\
\text { All responses coded as: Agree (0), Partly agree (1), Do not agree (2) }\end{array}$ \\
\hline $\begin{array}{l}\text { Reproductive } \\
\text { health and } \\
\text { pregnancy/ } \\
\text { disease } \\
\text { prevention }\end{array}$ & $\begin{array}{l}\text { a) It is a wom an's responsibility to avoid getting pregnant } \\
\text { b) Wom en who carry condom s on them arécheap' } \\
\text { c) I would be outraged if m y wife asked m e to use a condom } \\
\text { d) A m anm ust have sex with other wom en, even if things with his wife are fine } \\
\text { All responses coded as: Agree (0), Partly agree (1), Do not agree (2) }\end{array}$ \\
\hline $\begin{array}{l}\text { Physical } \\
\text { Violence }\end{array}$ & $\begin{array}{l}\text { a) A wom an should tolerate violence to keep the fam ily together } \\
\text { b) It is okay for a } m \text { an to hit his wife if she won't have sex with him } \\
\text { c) If a wom an cheats on a } m \text { an, it is okay for him to hit her } \\
\text { d) If som eone insults } m \text { e, I will defend } m \text { y reputation with force if I have to } \\
\text { e) There are tim es when a wom an deserves to be beaten } \\
\text { All responses coded as: Agree (0), Partly agree (1), Do not agree (2) }\end{array}$ \\
\hline
\end{tabular}

Source: Own adjustment based on CHC Evaluative survey data 


\section{Data analysis}

The GEM scale is com prised of item s categorized in two ways; gender inequitable norm s and equitable gender norms subscales (Antal \& Rothenbühler, 2015). The gender norm s survey instrum ent used in this study adopted 16 item s from the gender inequitable norm s subscale. The sub-groupings of the 16 item s (Table 4) adopted from the GEM scale was based on previous research on gender norm s which showed that GEM scale consists of several sub-scales/sub-groups (Nanda, 2011; Pulerwitz \& Barker, 2008). The use of the sub-scales within the GEM scale were deem ed appropriate based on the factor loadings in Table 6. The dropped item s were not assessed during data collection because they were not considered appropriate for the program context, and the unfavorable policy environm ent. Som e of the dropped item s include: I would never have a gay friend; If she wants, a wom an can have m ore than one sexual partner; A m an always deserves the respect of his wife and children.

\section{Sampling weights}

Before analysis, sam ple weights were calculated based on parish, village, household and household $\mathrm{m}$ em ber. The weights were determ ined based on probabilities thatthe parish is selected; the village is selected conditional to parish being selected; the household is selected conditional to the village being selected, and the household $\mathrm{m}$ em ber is selected conditional to household being selected. Those probabilities were $\mathrm{m}$ ultiplied, and then the inverse was taken as the individual sam pling weights (CHC, 2016). The weight dom ain variable was created, set as 1 if the person was included in the analysis, and 0 if not. In these analyses, the highest-level sam pling unit, the parish, was specified as the prim ary sam pling unit. Adding sam pling weights helped to ensure that individuals were sampled with equal probabilities. This aim ed at correcting the bias introduced by an im perfect sam pling fram e, com pensating for non-response and an under or over representation of certain groups (Antal \& Rothenbühler, 2015).

\section{Descriptive statistics analysis}

Descriptive statistics for socio-dem ographics includingage, education level, $\mathrm{m}$ arital status, religion, occupation, and sexual debut were analyzed to describe gender norm $\mathrm{s}$ characteristics in the data. Descriptive statistics disaggregated by gender were run to assess their perceptions of the gender norm s variables explored in this study. 


\section{Scale structure}

To assess the internal structure of the scales, factor analysis and om ega hierarchical were com puted for the GEM subscales (Crutzen \& Peters, 2017), whose eigenvalues and om ega hierarchical were deem ed appropriate for the $m$ easurem ent (Table 2). The $\mathrm{m}$ ean scores for the respective sub-scale item $\mathrm{s}$ were com puted tocombine them into one variable for analysis.

Table 2: Assessment of scale structure for GEM sub-scales

\begin{tabular}{|c|c|c|c|}
\hline GEM sub-scale & Eigenvalue & $\mathbf{\Omega}$ & $95 \% C I$ \\
\hline $\begin{array}{l}\text { Domestic chores and household decision-making sub- } \\
\text { scale }\end{array}$ & 1.61 & 0.76 & $0.74,0.79$ \\
\hline Sexual relationships/ habits sub-scale & 1.87 & 0.76 & $0.73,0.79$ \\
\hline $\begin{array}{l}\text { Reproductive health and pregnancy/ disease } \\
\text { prevention sub-scale }\end{array}$ & 1.43 & 0.56 & $0.51,0.62$ \\
\hline Physical violence sub-scale & 2.15 & 0.80 & $0.77,0.82$ \\
\hline
\end{tabular}

Note: Refer to Appendix for items in each sub-scale

Source: Own adjustment based on CHC Evaluative survey data

The sam e procedure was applied to the SRH behavior variables. The scale structure of the measurem ents for behavioral intention to use condom $\mathrm{s}$ at every sexual encounter (eigenvalue 1.58; $r=.79 ; 95 \% C I .76, .81$ ); and self-efficacy to use condom s at every sexual encounter (eigenvalue $1.55 ; r=.78 ; 95 \%$ CI.75, .80) were both deem ed appropriate The $\mathrm{m}$ ean of the variables was com puted to derive one variable for analysis.

Generating data associations: Using bivariate correlation analysis, associations between the GEM sub-scale variables and SRH behavior variables were analyzed. Using a frequentist approach, the m ost widely accepted m ethod would be to draw conclusions based on the confidence intervals (CI) for these associations (Crutzen, Peters \& Noijen, 2017).

\section{Ethical approval}

Ethical approval for the study was obtained from the United States of Am erica federally registered institutional review board of FHI 360 (Fam ily Health International), the Protection of Hum an Subjects Com mittee, under reference 616862-1, and in Uganda by the Governm ent accredited Makerere School of Public Health Research Ethics Com $m$ ittee, under reference 259. Consent to conduct the study was obtained from Uganda National Council for Science and Technology and 
Office of the President. The study team requested and obtained a waiver of written consent to increase confidentiality because signed inform ed consent form s would be the only link to the participants' identity in this study. Adolescent consenting procedures were undertaken in two ways: i) verbal inform ed consent was obtained for em ancipated adolescent 15-17 years (either m arried or not living under the care of a parent/guardian), and ii) verbal informed parental/guardian consent and adolescent assent were obtained for non-em ancipated adolescents 15-17 years ( $\mathrm{m}$ inors living under the care of a parent/guardian). For adolescents aged 1819, verbal inform ed consent was sought from each participant before anystudy specific activities were undertaken. Per ethical approval, verbal inform ed consent was obtained for each participant and docum ented via the signature of the study staff $\mathrm{m}$ em ber who obtained consent.

\section{Results}

A total of 867 adolescents participated in this study. Of these, 447 (52\%) were girls and $420(48 \%)$ boys. The $m$ ajority (55\%) were in the age group of $15-17$. Sixty-four percent $(64 \%)$ of both adolescent girls and boys had attained prim ary level education, and $33 \%$ attained secondary ordinary level education. The religious affiliation of the respondents shows that the $\mathrm{m}$ ajority were Catholics (43\%) followed by Protestants $(33 \%)$. Alm ost half $(49 \%)$ of the respondents reported that they were students. In term s of occupation, com m ercial farm ers were 19\%, subsistence farm ers $16 \%$, and laborers including dom estic workers were 4\%. Forty-nine (49\%) percent of the respondents were reportedly sexually active. Alm ost half, $48 \%$ of the respondents' age at first sexual debut was between 15 and 16 years. The m edian age at first sex in this study is 15 years. Am ong the sxually active, 11\% (96) were m arried and of these, $48 \%$ (46) were $\mathrm{m}$ arried at the age of 19 and $36 \%$ (35) at the age of 18 . Am ong the $\mathrm{m}$ arried, $85 \%$ (82) were living with their partner. A total of $13 \%$ reported already having a child at the tim e of the survey (Table 3 ). 
Table 3: Socio-demographic characteristics of respondents $(N=867)$

\begin{tabular}{|c|c|c|c|}
\hline \multirow[t]{3}{*}{ Measure } & \multicolumn{3}{|c|}{ Weighted frequency and percentage $(\%)$} \\
\hline & & Girls & Boys \\
\hline & $(N=867)$ & $(N=447)$ & $(N=420)$ \\
\hline \multicolumn{4}{|l|}{ Age } \\
\hline $15-17$ & $478(55 \%)$ & $237(53 \%)$ & $241(57 \%)$ \\
\hline $18-19$ & $389(45 \%)$ & $210(47 \%)$ & $179(43 \%)$ \\
\hline \multicolumn{4}{|l|}{ Education level } \\
\hline Prim ary level & $535(64 \%)$ & $276(64 \%)$ & $259(64 \%)$ \\
\hline Secondary ordinary level & $273(33 \%)$ & $140(33 \%)$ & $133(33 \%)$ \\
\hline Secondary advanced level & $16(2 \%)$ & $8(2 \%)$ & $8(2 \%)$ \\
\hline Tertiary level & $8(1 \%)$ & $4(1 \%)$ & $4(1 \%)$ \\
\hline \multicolumn{4}{|l|}{ Marital status } \\
\hline Married & $96(11 \%)$ & $44(10 \%)$ & $52(13 \%)$ \\
\hline Not $m$ arried & $768(89 \%)$ & $402(90 \%)$ & $366(87 \%)$ \\
\hline \multicolumn{4}{|l|}{ Religion } \\
\hline Catholic & $371(43 \%)$ & $188(42 \%)$ & $182(43 \%)$ \\
\hline Protestant & $288(33 \%)$ & $150(34 \%)$ & $138(33 \%)$ \\
\hline Muslim & $125(15 \%)$ & $62(14 \%)$ & $63(15 \%)$ \\
\hline Pentecostal & $61(7 \%)$ & $35(8 \%)$ & $26(6 \%)$ \\
\hline Seventh Day Adventists (SDA) & $10(1 \%)$ & $7(2 \%)$ & $3(1 \%)$ \\
\hline \multicolumn{4}{|l|}{ Occupation } \\
\hline Student & $420(49 \%)$ & $217(49 \%)$ & $203(49 \%)$ \\
\hline Subsistence farm er & $137(16 \%)$ & $64(14 \%)$ & $73(17 \%)$ \\
\hline Com m ercil farm er & $164(19 \%)$ & $80(18 \%)$ & $84(20 \%)$ \\
\hline Laborer (dom estic worker/m aid/house help) & $31(4 \%)$ & $17(4 \%)$ & $14(3 \%)$ \\
\hline Petty trader/hawker/vendor/boda-boda & $27(3 \%)$ & $16(4 \%)$ & $10(2 \%)$ \\
\hline Owns business with 3 or $\mathrm{m}$ ore em ployees & $28(3 \%)$ & $15(3 \%)$ & $13(3 \%)$ \\
\hline Other & $55(6 \%)$ & $35(8 \%)$ & $21(9 \%)$ \\
\hline \multicolumn{4}{|l|}{ Sexual debut (Age at first sex) } \\
\hline$<=12$ years & $30(7 \%)$ & $13(6 \%)$ & $17(9 \%)$ \\
\hline $13-14$ years & $84(20 \%)$ & $45(21 \%)$ & $39(20 \%)$ \\
\hline $15-16$ years & $200(48 \%)$ & $111(50 \%)$ & $89(45 \%)$ \\
\hline $17-18$ years & $102(24 \%)$ & $49(22 \%)$ & $53(27 \%)$ \\
\hline 19 years & $3(1 \%)$ & $3(1 \%)$ & 0 \\
\hline Already had a child & $111(13 \%)$ & $58(13 \%)$ & $53(13 \%)$ \\
\hline
\end{tabular}




\section{Perceptions of adolescents on gender norms explored in this study}

The findings in Table 4 indicate that the perceptions of adolescent girls and boys were quite sim ilaron $\mathrm{m}$ ost of the gender norm s explored in this study. For exam ple, there appears to be general agreem ent with dom estic chores and household decision $\mathrm{m}$ aking,and sexual relationships/ habits constructs. Both girls (84\%) and boys (84\%) agreed that changing diapers, giving a bath, and feeding children is the mother's responsibility. They also agreed that $\mathrm{m}$ en need sex $\mathrm{m}$ ore than wom en do (girls $=65 \%$ and boys $=65 \%$ ) and that $\mathrm{m}$ en are always ready to have sex (girls $=62 \%$ and boys $=$ $62 \%$ ). The sentim ents of both girls andboys were also $\mathrm{m}$ ore towards disagreem at with the norm s under physical violence, and partly reproductive health. Both girls (31\%) and boys (32\%) were in agreem ent with the statem ent 'I would be outraged if $\mathrm{m} y$ wife asked $\mathrm{m}$ e to use a condom 'Sim ilarly, both girls (28\%) and boys (29\%) agreed that 'A $\mathrm{m}$ an $\mathrm{m}$ ust have sex with other wom en, even if things with his wife are fine'. Slightly m ore boys $(25 \%)$ than girls $(19 \%)$ agreed with the statem ent that 'it is okay for a $\mathrm{m}$ an to hit his wife if she won't have sex wih him '. Additionally, $37 \%$ of girls and $40 \%$ of boys agreed that 'There are tim es a wom an deserves to be beaten' (Table 4). 
Table 4: Perceptions of adolescents on GEM scale norms $(N=867)$

\begin{tabular}{|c|c|c|c|}
\hline \multirow[t]{2}{*}{ G EM sales } & \multirow[t]{2}{*}{ G EM scale variables } & \multicolumn{2}{|c|}{ Agreed [N (\%)] } \\
\hline & & $\begin{array}{c}\text { G irls } \\
(\mathrm{N}=447)\end{array}$ & $\begin{array}{c}\text { Boys } \\
(\mathrm{N}=\mathbf{4 2 0})\end{array}$ \\
\hline \multirow{4}{*}{$\begin{array}{l}\text { Domestic } \\
\text { chores and } \\
\text { household } \\
\text { decision- } \\
\text { making }\end{array}$} & $\begin{array}{l}\text { 1) Changing diapers, giving a bath, and feeding } \\
\text { children is the } m \text { other's responsibility }\end{array}$ & $371(84 \%)$ & $346(84 \%)$ \\
\hline & $\begin{array}{l}\text { 2) A } m \text { an should have the final word about decisions } \\
\text { in his hom e }\end{array}$ & $338(78 \%)$ & $327(79 \%)$ \\
\hline & $\begin{array}{l}\text { 3) A wom an's m ost im portant role is taking care of } \\
\text { her hom e and cook for her fam ily }\end{array}$ & $375(85 \%)$ & $360(87 \%)$ \\
\hline & \multicolumn{3}{|c|}{ Mean $(M)=.23$ and Standard Deviation $(S D)=.39$} \\
\hline \multirow{5}{*}{$\begin{array}{l}\text { Sexual } \\
\text { relations/ } \\
\text { habits }\end{array}$} & $\begin{array}{l}\text { 4) It is the } m \text { an who decides what type of sex to } \\
\text { have }\end{array}$ & $199(54 \%)$ & $191(56 \%)$ \\
\hline & 5) Men need sex m ore than wom en do & $252(65 \%)$ & $230(65 \%)$ \\
\hline & 6) Men are always ready to have sex & $237(62 \%)$ & $221(62 \%)$ \\
\hline & 7) You don't talk about sex, you just do it. & $112(32 \%)$ & $100(31 \%)$ \\
\hline & \multicolumn{3}{|c|}{ Mean $(\mathrm{M})=.77$ and Standard Deviation $(\mathrm{SD})=.63$} \\
\hline \multirow{5}{*}{$\begin{array}{l}\text { Reproductive } \\
\text { health and } \\
\text { pregnancy/ } \\
\text { disease } \\
\text { prevention }\end{array}$} & $\begin{array}{l}\text { 8) It is a wom an's responsibility to avoid getting } \\
\text { pregnant }\end{array}$ & $260(64 \%)$ & $250(66 \%)$ \\
\hline & 9) Wom en who carry condom s on them are 'cheap' & $212(53 \%)$ & $215(56 \%)$ \\
\hline & $\begin{array}{l}\text { 10) I would be outraged if } \mathrm{m} y \text { wife asked } \mathrm{m} \text { e to use a } \\
\text { condom }\end{array}$ & $109(31 \%)$ & $105(32 \%)$ \\
\hline & $\begin{array}{l}\text { 11) A } m \text { an } m \text { ust have sex with other wom en, even if } \\
\text { things with his wife are fine }\end{array}$ & $113(28 \%)$ & $112(29 \%)$ \\
\hline & \multicolumn{3}{|c|}{ Mean $(\mathrm{M})=.96$ and Standard Deviation $(\mathrm{SD})=.57$} \\
\hline \multirow{5}{*}{$\begin{array}{l}\text { Physical } \\
\text { violence }\end{array}$} & $\begin{array}{l}\text { 12) A wom an should tolerate violence to keep the } \\
\text { fam ily together }\end{array}$ & $242(56 \%)$ & $232(58 \%)$ \\
\hline & $\begin{array}{l}\text { 13) It is okay for a m an to hit his wife if she won't } \\
\text { have sex with him }\end{array}$ & $78(19 \%)$ & $98(25 \%)$ \\
\hline & $\begin{array}{l}\text { 14) If a wom an cheats on a } m \text { an, it is okay for him to } \\
\text { hit her }\end{array}$ & $240(56 \%)$ & $235(59 \%)$ \\
\hline & $\begin{array}{l}\text { 15) If som eone insults } \mathrm{m} e \text {, I will defend } \mathrm{m} y \\
\text { reputation with force if I have to }\end{array}$ & $176(41 \%)$ & $178(45 \%)$ \\
\hline & $\begin{array}{l}\text { 16) There are tim es when a wom an deserves to be } \\
\text { beaten }\end{array}$ & $160(37 \%)$ & $162(40 \%)$ \\
\hline
\end{tabular}

Mean $(\mathrm{M})=.99$ and Standard Deviation $(\mathrm{SD})=.60$

Response categories on a 3-point Likert scale: Agree (0), Partly agree (1), Do not agree (2)

Single frequencies presented in the table are based on respondents who agreed or partly agreed to the GEM scale statem ents.

Source: Own adjustment based on CHC Evaluative survey data 


\section{Associations between gender norms and sexual behaviors among adolescents}

The findings in Table 5 indicate that there were no significant correlations between the gender equitable norm towards sexual relationships/ habits and behavioral intention and self-efficacy towards- contraceptive use; condom use; andnum berof sexual partners. A more general observation is that the highest correlations were found between behavioral intention and self-efficacy towards- contraceptive use, condom use, and the norm towards reproductive health and pregnancy prevention/ disease prevention. For exam ple, there was a m oderatepositive correlation between the norm towards reproductive health and pregnancy/ disease prevention and behavioral intention to use contraception, $r=.23(\mathrm{p}<.01 ; 95 \% \mathrm{CI} .16, .29)$, as well as self-efficacy to use condom $\mathrm{s}, r=.29(\mathrm{p}<.01 ; 95 \% \mathrm{CI} .23, .35)$. The norm towards reproductive health and pregnancy/ disease prevention has non-significant correlations with behavioral intention to have one sexual partner, and self-efficacy to avoid m ultiple concurrent sexual partnerships.

\section{Gender norms and contraception use among adolescents}

We found a moderate positive correlation between behavioral intention to use contraception and the norm towards reproductive health and pregnancy/ disease prevention am ong girls, $r=.23(\mathrm{p}<0.01 ; 95 \% \mathrm{CI} .14, .31)$ and boys, $r=.22(\mathrm{p}<.01$; $95 \%$ CI .12, .31). Behavioral intention to use contraception and dom estic chores and household decision making am ong girls and boys was not significant. Selfefficacy to use contraception and the norm towards reproductive health and pregnancy disease prevention had a m oderate positive correlation am ong girls $\zeta=.25(\mathrm{p}<.01$; $95 \%$ CI .16, .34) and boys, $r=.21$ ( $<<0.01 ; 95 \%$ CI .11, .30). There was no significant correlation between self-efficacy to use contraception and sexual relationship/ habits am ong both girls and boys (Table 5).

\section{Gender norms and condom use among adolescents}

The findings indicate a m oderate positive correlation between behavioral intention to use condom s at every sexual encounterand the norm towards reproductive health and pregnancy/ disease prevention for both girls, $r=.25(\mathrm{p}<.01 ; 95 \% \mathrm{CI} .16, .34)$ and boys, $r=.23$ ( $\mathrm{p}<.01 ; 95 \% \mathrm{CI} .13, .32)$. There is a m oderate positive correlation between self-efficacy to use condom $\mathrm{s}$ and he norm towards reproductive health and pregnancy/ disease prevention am ong girls, $r=.29$ (p < .01; 95\% CI .20, .37) and boys, $r=.30(\mathrm{p}<.01 ; 95 \% \mathrm{CI} .21, .38)$. There was no significant correlation between self-efficacy to use condom s and sexual relationship/ habits am ong girls and boys (Table 5). 


\section{Gender norms and number of sexual partners among adolescents}

The findings indicate a small positive correlation between selfefficacy to avoid multiple concurrent sexual partnerships and the norm towards use ofphysical violence am ong girls, $r=.13(\mathrm{p}<.05 ; 95 \%$ CI .04, .22), but no significant correlation am ong boys, $r=.07$ (95\% CI -.03, .16). There was no significant correlation between behavioral intention to only have one sexual partner and physical violence am ong girls and boys (Table 5).

Table 5: Correlates of GEM scale norms and SRH behaviors $(N=867)$

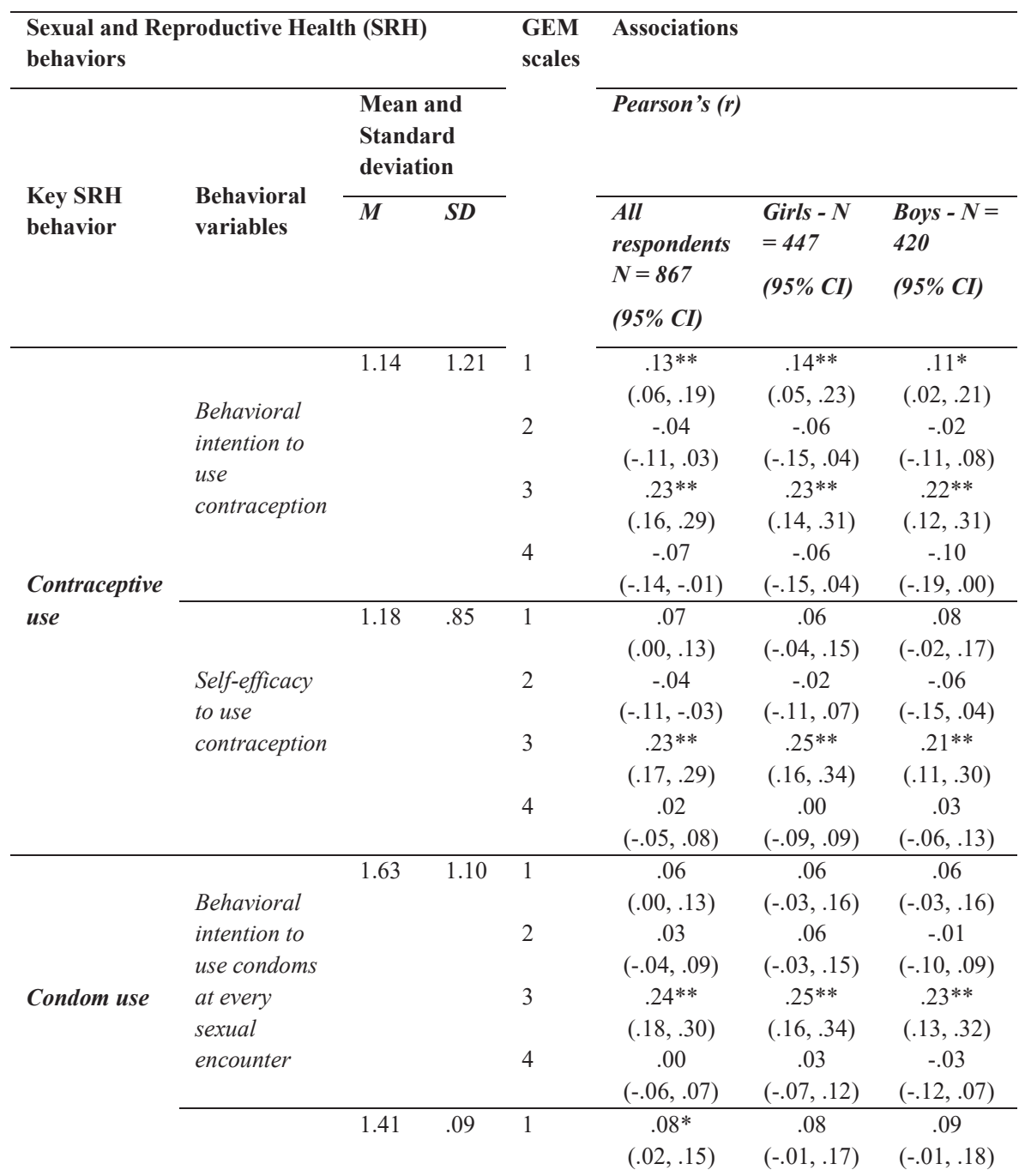




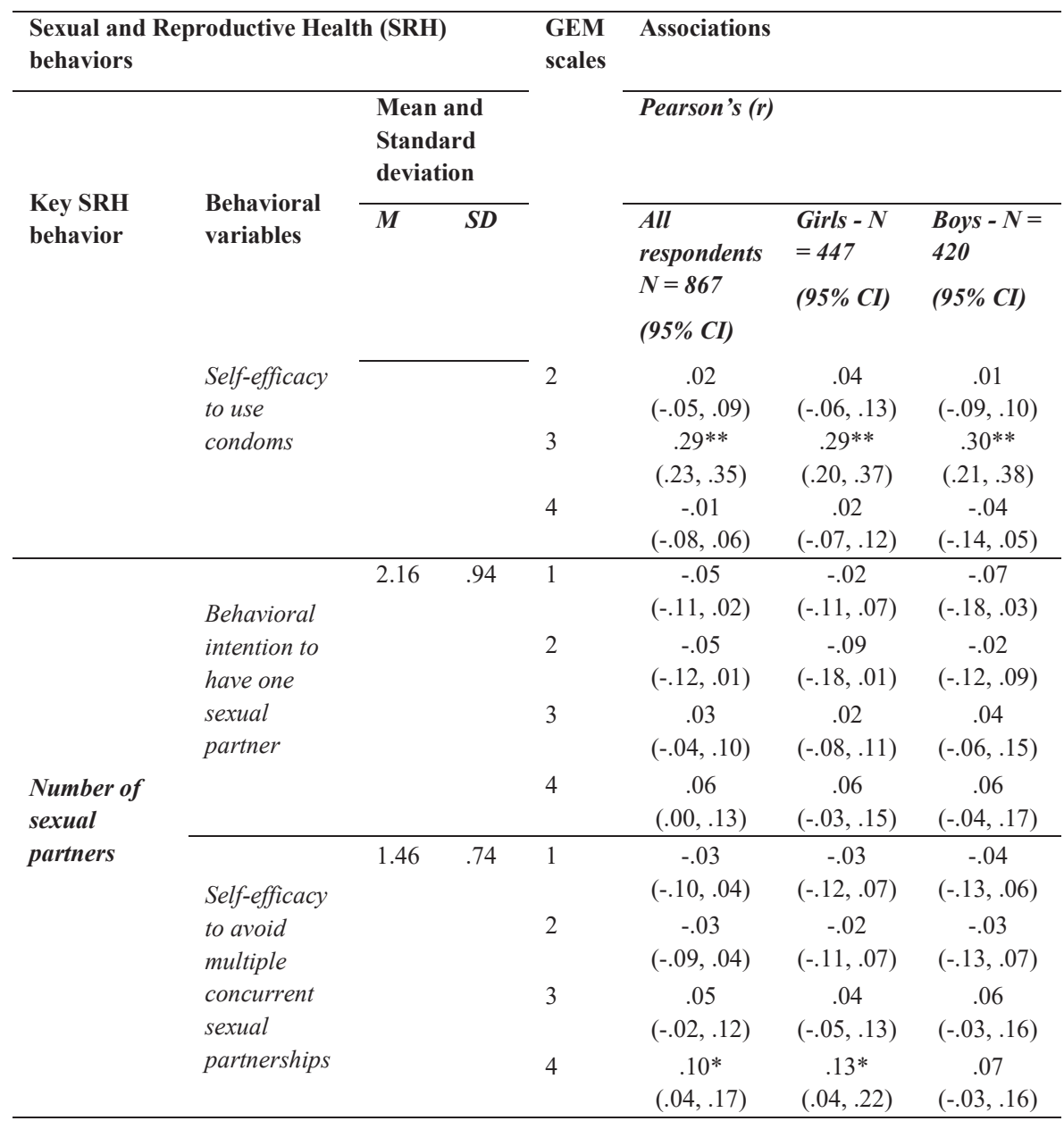

**. Correlation is significant at the 0.01 level (2-tailed).

*. Correlation is significant at the 0.05 level (2-tailed).

GEM scale: 1 = Domestic chores and household decision-making sub-scale; 2 = Sexual relationships/habits sub-scale; 3 = Reproductive health and pregnancy/disease prevention subscale; 4 = Physical violence sub-scale

Source: Own adjustment based on CHC Evaluative survey data 


\section{Discussion}

This study assessed the gender norm s associated with adolescent SRH behaviors such as behavioral intention to perform recom m ended behaviors including condom use and contraception use. The findings on contraceptive use, indicate positive correlations for behavioral intention to use contraception and self-efficacy to use contraception, with an equitable gender norm towards reproductive health and pregnancy/ disease prevention. The perceptions of adolescents were on average sim ilartowards the gender norm s underscoring that 'it is a wom an's responsibility to avoid getting pregnant', and 'wom en who carry condom s on them are cheap'with boys being more gender inequitable than girls Behavioral intention to use contraception was found to be correlated with an equitable gender norm towards dom estic chores/ household decision m aking.On average, adolescents had sim ilar views towards the gender inequitable norm $\mathrm{s}$ of $\mathrm{m}$ ale dom inance in decision $\mathrm{m}$ aking and the wom en's subordinate position oftaking care of a hom e. Regarding condom use, positive correlations were found for behavioral intention to use condom s at every sexual encounter, and self-efficacy to use condom s with an equitable gender norm towards reproductive health and pregnancy/ disease prevention. On average, both adolescent girls and boys agreed to the gender inequitable norm s such as 'wom en who carry condom s on them are cheap'. Regardingnum ber of sexual partners, our study found self-efficacy to avoid multiple concurrent partnerships to be correlated with an equitable gender norm regarding the use of physical violence in the partnership. However, this correlation was low. The perceptions of most of the adolescents were towards disapproval of the use of physical violence in $m$ aintaining a relationship with a sexual partner. Therefore, although the perceptions of girls and boys appeared to agree on norm s towards; dom estic chores/ household decision $\mathrm{m}$ aking, and sexual relationships/ habits, their sentim ents were more towards disagreem ent with the statem ents under physical violence.

These findings are com parable to other studies conducted in sub-Saharan Africa. In South Africa, it was found that a girl's respectability is gained by her being sexually available to her partner, allowing him sexual decision-m aking authority, being sexually faithful, and avoiding pregnancy-which is not necessarily synonym ous with practicing fem ale contraception (Varga 2003; Lary et al., 2004). Our study found that m ost girls and boys believed that it is a wom an's responsibility to avoid getting pregnant, and yet over a half agreed that wom en who carry condom $\mathrm{s}$ on them are 'cheap'. This finding also concurs with Pulerwitz et al, (2010) who found that gender norm $s$ that put $m$ en in a position of sexual dom inancdim it wom en's ability to control their own reproductive and sexual health, and the belief that girls who carry or suggest using condom s are prom iscuous (Varga2003; Pulerwitz et al., 2010). Other studies also found widespread resistance to the use of condom s in stable 
and long-term relationships because of their association with lack of trust and illicit sex (Maharaj \& Cleland 2005). A study in three sub-Saharan countries found that $\mathrm{m}$ ore prevalent traditional gender roles including "the $\mathrm{m}$ ale is supposed to take the initiative and responsibility for safe sex practices such as condom buying and negotiating", inhibit safe sex practices (Eggers et al., 2016). Our study found no significant correlation between behavioral intention to use condom s at every sexual encounter, self-efficacy to use condom s, and the norm towards sexual relationships/ habits am ong girls and boys. These findings seem to suggest that the design of adolescent health program s needs to consider addressing and changing negative gender norm $\mathrm{s}$ that hinder the use of condom s am ong adolescents. Inform ation and health com $m$ unication services such as $m$ ass $m$ edia and interpsonal com $m$ unication should be used to address gender norm s m isconceptions.

Gender inequitable norm s were found to be associated with multiple concurrent sexual partners, where having $\mathrm{m}$ ore $\mathrm{m}$ ale and casual partners are associated with physical violence (Shattuck et al., 2013; Dunkle et al., 2004). Shannon et al., (2012) found that $39 \%$ of boys in Botswana and Swaziland reported having multiple concurrent sexual partners com pared to $18 \%$ of girls (Shannon et al, 2012). Though our study found no significant correlation between self-efficacy to avoid m ultiple concurrent sexual partnerships and norm s towards physical violence, the correlation was higher am ong girls than boys.

The unm et need for contraception is high am ong adolescent girls. In Knya, $65 \%$ of parents or guardians reportedly objected to contraceptives use by unm arried adolescents, and $68 \%$ of the adolescents disapproved contraceptive use by unm arried adolescents (Kinaro, 2011). Childbearing beliefs indoctrinated am ong com m unity $\mathrm{m}$ em bes-such as 'a $\mathrm{m}$ anshould have the final word about decisions in his hom e', lim it girls from using contraception if perceived as being bound to the will of her husband (Paek et al., 2008). Yet, infertility is often blam ed on wom en, while infidelity is alm os never sanctioned for men (Mbonye et al, 2012). Our study found no significant correlation between behavioral intention to use contraception, selfefficacy to use contraception, and sexual relationships/ habits norm. This study dem onstrates the need to address adolescent SRH needs and dem ystify gender inequitable norm $\mathrm{s}$ that affect contraception use and steer $\mathrm{m}$ ultiple sexual partnerships am ong adolescents. It is im portant to work with adolescents through their social networks to devise strategies for addressing negative gender norm $\mathrm{s}$. This $\mathrm{m}$ ay involve assessing information needs on addressing gender norms, and holding gender integration com $\mathrm{m}$ unity dialogue $\mathrm{m}$ eetings with com $\mathrm{m}$ unity leaders, religious leaders, cultural leaders and elders who often steer the gender norm s. 


\section{Implications for adolescent health programming}

From the findings, the GEM scale seem ed to work for CHC program needs of depicting perceptions and attitudes am ong adolescents towards gender equitable norm s. Our findings also support previous sudies that dem onstrate a link between HIV risks, teenage pregnancy risks and gender equitable norm s $\mathrm{Vu}$ et al., 2017; Pulerwitz \& Barker, 2008; Shattuck et al., 2013;Kinaro, 2011; Murigi et al., 2010). Prom oting genderequitable attitudes, should start in childhood and continue during the form ative period of adolescence and into adulthood. Strategies that involve working closely with both girls and boys; prom oting inform ed peer and partner discussions; com m unitybased education; gender awareness trainings; engaging in progressive com m unity and religious discourses that question gender stereotypes; engaging in strategic partnerships with parents, religious, political, and com m unity leaders; and use of social and $\mathrm{m}$ ass $\mathrm{m}$ edia cam paigns, can im prove health bekraoral outcom es am ong adolescents (Hardee et al., 2014; Vu et al., 2017; El Feki, Heilm an \& Barker, 2017; Barnes et al., 2017). The findings from our study and sim ilar research in other countries underline the pertinent need to focus on the broader circumstances in which gender inequalities within society $m$ ay structure beliefs and norm $s$ that perpetrate differential exposure/risks of HIV infection, with m ore enhanced efforts targeting wom en and reenforcing involvem ent of m en Ezekiel et al., 2015).

\section{Study limitations}

This study had som e lim itations. Although the quantitative inequitable GEM scale $\mathrm{m}$ easure was useful in generating insights on gender norm s and sexual behaviors am ong adolescents, this study does not explain all the variations ingender related attitudes. To overcom e this, use of qualitative m ethods to triangulate findings related to the com plex notion of gender norm $\mathrm{s}$ is recom m endedhattuck et al., 2013). The internal structure of the Reproductive health and pregnancy/ disease prevention GEM sub-scale was not optim al given the om ega hierarchical of 0.56 , which $\mathrm{m}$ ight affect reliability of this specific sub-scale. The study did not $\mathrm{m}$ easure actual behavior, rather behavioral intention and self-efficacy were used as predictors of self-reported risky sexual behaviors am ong adolescents. Studies show that behavioral intention is the $\mathrm{m}$ ost im m ediate and im portant predictor of a behavior, which is in turn determ ined by attitudes towards the behavior, subjective norm s regarding it, and perceived control over it (Fishbein \& Ajzen, 2010; Webb \& Sheeran, 2006; Sheeran \& Orbell, 1998; Villarruel et al., 2004). Correlational studies show that intentions are reliably associated with behavior, such as condom use (Webb \& Sheeran, 2006; Sheeran \& Orbell, 1998). Therefore, future studies need to assess the associations between selfreported sexual behaviors and gender norm s, as well as the perceptions of adolescents on equitable gender norm s to draw com parisons with the present study. 


\section{Conclusion}

The study indicates that m ost girls and boys were in support ofand approved gender inequitable norm s which often tim es lead to gender power im balance and affects adolescents' ability to negotiate safe sex, thereby putting them at risk of HIV and unplanned pregnancies. Changing the negative perceptions requires a m ultipronged gender responsive approach for social change. Working with both girls and boys, and engaging influential stakeholders such as; peers, parents, healthcare workers, policy $\mathrm{m}$ akers, com munity and religus leaders, who create the environm ent where attitudes and world views are form edis pertinent. The findings in this study should be used to inform targeted solutions for designinggender responsive adolescent SRH program s. 


\section{APPENDIX}

Table 6: Factor Loadings (x 100) for Items included in the Gender-Equitable Men Scale for this study $(N=867)$

\begin{tabular}{|c|c|c|}
\hline G EM sales & G EM scale variables & Factor Loadings \\
\hline \multirow{3}{*}{$\begin{array}{l}\text { Domestic chores } \\
\text { and household } \\
\text { decision-making }\end{array}$} & $\begin{array}{l}\text { 1) Changing diapers, giving a bath, and feeding children } \\
\text { is the } m \text { other's responsibility }\end{array}$ & 0.74 \\
\hline & $\begin{array}{l}\text { 2) A m an should have the final word about decisions in } \\
\text { his hom } \mathrm{e}\end{array}$ & 0.69 \\
\hline & $\begin{array}{l}\text { 3) A wom an's m ost im portant role is taking care of her } \\
\text { hom e and cook for her fam ily }\end{array}$ & 0.77 \\
\hline \multirow{4}{*}{$\begin{array}{l}\text { Sexual relations/ } \\
\text { habits }\end{array}$} & 4) It is the $m$ an who decides what type of sex to have & 0.63 \\
\hline & 5) Men need sex $m$ ore than wom en do & 0.70 \\
\hline & 6) Men are always ready to have sex & 0.67 \\
\hline & 7) You don't talk about sex, you just do it. & 0.74 \\
\hline \multirow{4}{*}{$\begin{array}{l}\text { Reproductive } \\
\text { health and } \\
\text { pregnancy/ } \\
\text { disease } \\
\text { prevention }\end{array}$} & $\begin{array}{l}\text { 8) It is a wom an's responsibility } b \text { avoid getting } \\
\text { pregnant }\end{array}$ & 0.49 \\
\hline & 9) Wom en who carry condom s on them are 'cheap' & 0.62 \\
\hline & $\begin{array}{l}\text { 10) I would be outraged if } \mathrm{m} y \text { wife asked } \mathrm{m} \text { e to use a } \\
\text { condom }\end{array}$ & 0.65 \\
\hline & $\begin{array}{l}\text { 11) A } m \text { an } m \text { ust have sex with other wom en, even if } \\
\text { things with his wife are fine }\end{array}$ & 0.62 \\
\hline \multirow{5}{*}{ Physical violence } & $\begin{array}{l}\text { 12) A wom an should tolerate violence to keep the fam ily } \\
\text { together }\end{array}$ & 0.67 \\
\hline & $\begin{array}{l}\text { 13) It is okay for a } m \text { an to hit his wife if she won't have } \\
\text { sex with him }\end{array}$ & 0.63 \\
\hline & $\begin{array}{l}\text { 14) If a wom an cheats on a } m \text { an, it is okay for him to hit } \\
\text { her }\end{array}$ & 0.68 \\
\hline & $\begin{array}{l}\text { 15) If som eone insults } \mathrm{m} e \text {, I will defend } \mathrm{m} \text { y reputation } \\
\text { with force if I have to }\end{array}$ & 0.58 \\
\hline & 16) There are tim es when a wom an deserves to be beaten & 0.70 \\
\hline
\end{tabular}

Response categories on a 3-point Likert scale: Agree (0), Partly agree (1), Do not agree (2). Factor loadings are presented for analysis after im putation for $\mathrm{m}$ issing valus.

a. 1 com ponents extracted, using Principal Com ponent Analysis. 


\section{References}

Am in, S., Austrian, K., Chau, M., Glazer, K., Green, E., Stewart, D., \& Stoner, M. (2013). The Adolescent Girls Vulnerability Index: Guiding strategic investm entin Uganda.

Antal, E., \& Rothenbühler, M. (2015). Weighting in the Swiss Household Panel Technical report. Swiss Centre of Expertise in the Social Sciences and Clinical Trials Unit CTU - University of Bern, Switzerland. Accessed 18 October, 2017 from, http://forscenter.ch/wpcontent/uploads/2014/12/Weighting_technical_report.pdf

Bantebya, G. K., Muhanguzi, F. K., \& Watson, C. (2014). Adolescent girls in the balance: Changes and continuity in social norm $\mathrm{s}$ and practices around $\mathrm{m}$ arriage and education in Uganda. London: Overseas Development Institute.

Barnes J., Grandi S., Byrong., Keatm an T., Marta Balestrini M.(2017). Corporate evaluation on strategic partnerships for gender equality and the empowerment of women, Final Synthesis Report. UN Wom en Independent Evaluation Office.

Burgess, R., \& Cam pbell, C (2016). Creating social policy to support wom en's agency in coercive settings: a case study from Uganda.Global public health, 11(1-2), 48-64.

Chandra-Mouli, V., Param eshwar, P. S., Parry, M., Lane, C., Hainsworth, G., Wong, S., ... \& Say, L. (2017). A never-before opportunity to strengthen investm ent and action on adolescent contraception, and what we $\mathrm{m}$ ustdo to $\mathrm{m}$ ake full use of it. Reproductive health, 14(1), 85.

CHC-Com m unicationfor Healthy Com m unities (2016). Evaluative survey of an Integrated Health Communication Campaign in Uganda-Observation 1 Report. USAID and FHI 360. Kam pala, Uganda.

Crutzen, R. \& Peters G.-J.Y. (2017). Scale quality: alpha is an inadequate estim ate and factor-analytic evidence is needed first of all. Health Psychology Review, 11, 242-247.

Crutzen, R., Peters, G. J. Y., \& Noijen, J. (2017). Using Confidence Interval-Based Estim ation of Relevance to Select SocialCognitive Determ inants for Behavior Change Interventions. Frontiers in public health, 5.

Dunkle, K. L., Jewkes, R. K., Brown, H. C., Gray, G. E., Mcintryre, J. A., \& Harlow, S. D. (2004). Gender-based violence, relationship power, and risk of HIV infection in wom en attending antenatalclinics in South Africa. The lancet, 363(9419), 1415-1421.

Eggers, S. M., Aarø, L. E., Bos, A. E., Mathews, C., Kaaya, S. F., Onya, H., De Vries, H. (2016). Socio- cognitive predictors of condom use and intentionsamong adolescents in three sub-Saharan sites. Archives of sexual behavior, 45(2), 353-365.

El Feki, S., Heilm an, B. \& Barker, G., Eds. (2017).Understanding Masculinities: 
Results from the International Men and Gender Equality Survey (IMAGES) - Middle East and North Africa. Cairo and Washington, D.C.: UN Wom en and Prom undeUS.

Ezekiel, M., Chitam a, D., \& Mlang'a, E(2015). Gender equitable m en's attitudes and beliefs to reduce HIV risk and gender-based violence in Tanzania. Tanzania Journal of Health Research, 17(1).

Fishbein, M., \& Ajzen, I.(2010). Predicting and Changing Behavior. The Reasoned Action Approach. Psychology press. Taylor \& Francis Group. New York, USA.

Gibson, S., Kabuchu, H., \& Watkins, F. (2014). Gender Equality in Uganda: A Situational Analysis and Scoping Report for Gender Developm ent Partners Group. Commissioned by the UK Department for International Development (DfID) and Irish Aid.

Hardee, K., Gay, J., Croce-Galis, M., \& AfariDwam ena, N. A (2014). What HIV program s work for adolescent girls? JAIDS Journal of Acquired Immune Deficiency Syndromes, 66, S176-S185.

Harrison, A., O'sullivan, L. F., Hoffm an, S., Dolezal, C., \& Morrell, R.(2006). Gender role and relationship norm s am ong young adults in South Africa: $m$ easuring the context of $m$ asculinity and HIV risk.Journal of Urban Health, 83(4), 709-722.

Kinaro, J.W. (2011). Perceptions as a barrier to Contraceptive Use Among Adolescents: A case Study of Nairobi, Kenya. Population Studies and Research Institute (PSRI), University of Nairobi, Kenya.

Kish, L. (1949). A procedure for objective respondent selection within the household. Journal of the American Statistical Association, 44(247), 380-387.

Lary, H., Mam an, S., Katebalila, M., \& Mbwam bo, .J(2004). Exploring the association between HIV and violence: young people's experiences with infidelity, violence and forced sex in Dar es Salaam, Tanzania.International Family Planning Perspectives, 200-206.

Macphail, C., \& Cam pbell, C(2001). 'I think condom s are good but,aai, I hate those things': condom use am ong adolescents and young people in a Southern African township. Social science \& medicine, 52(11), 1613-1627.

Maharaj, P., \& Cleland, J (2005). Risk perception and condom use am ongm arried or cohabiting couples in KwaZulu-Natal, South Africa. International family planning perspectives, 24-29.

Mbonye, M., Nalukenge, W., Nakam anya, S., Nalusiba, B., King, R., Vandepitte, J., \& Seeley,J. (2012). Gender inequity in the lives of wom en involved insex work in Kam pala, Uganda.Journal of the international AIDS society, 15 (Suppl 1).

Murigi, M., Butto, D., Barasa, S., Maina, E., \& Munyalo, B (2016). Overcom ing Barriers to Contraceptive Uptake am ong Adolescents: The Case of Kiam bu County, Kenya. Journal of Biosciences and Medicines, 4(09), 1. 
Nanda, G. (2011). Com pendium of gender scales.Washington, DC: FHI, 360.

Paek, H.-J., Lee, B., Salm on, C. T., \&Witte, K. (2008). The contextual effects of gender norms, communication, and social capital on family planning behaviors in Uganda: a m ultilevel approach.Health Education \& Behavior, 35(4), 461-477.

Pulerwitz, J., \& Barker G. (2008). Measuring attitudes toward gender norm s am ong young $m$ en in Brazil: Developm ent and psychom etric evaluation of the GEM Scale. Men and Masculinities, 10(3), 322-338.

Pulerwitz, J., Michaelis, A., Verm a, R., \& Weiss, E.(2010). Addressing gender dynam ics and engaging men in HIV program s: lessons learned from Horizons research. Public health reports, 125(2), 282-292.

Richards, E., Zalwango, F., Seeley, J., Scholten, F., \& Theobald, S.(2013). Neglected older wom en andm en: Exploring age and gender as structural drivers of HIV am ong people aged over 60 in Uganda. African journal of AIDS research, 12(2), 71-78.

Shannon, K., Leiter, K., Phaladze, N., Hlanze, Z., Tsai, A. C., Heisler, M., . . W Weiser, S. D. (2012). Gender inequity norm $\mathrm{s}$ are associated with increased $\mathrm{m}$ ale perpetrated rape and sexual risks for HIV infection in Botswana and Swaziland. PloS one, 7(1), e28739.

Shattuck, D., Burke, H., Ram irez, C., Succop, S., Costenbader, B., Attafuah, J. D., . . . Guest, G. (2013). Using the Inequitable Gender Norm s scale and associated HIV risk behaviors am ong $\mathrm{m}$ en at high risk for HIV in Ghana and Tanzania. Men and Masculinities, 16(5), 540-559.

Sheeran, P., \& Orbell, S (1998). Do intentions predict condom use? Metaanalysis and exam ination of six moderator variables. British Journal of Social Psychology, 37(2), 231-250.

Singh K.A., Verm a R., \& Barker G (2013). Making Wom en Count: An Annual Publication on Gender and Evaluation by UN Wom en Multi Country Office for India, Bhutan, Sri Lanka and Maldives. UN Wom en.

Ssewam ala, F. M., Ism ayilova, L., Mckay, M., Sperber, E., Bannon, W., \& Alicea, S (2010). Gender and the effects of an econom ic em powerm ent program on attitudes toward sexual risk-taking am ong AIDS-orphaned adolescent youth in Uganda. Journal of Adolescent Health, 46(4), 372-378.

Uganda Bureau of Statistics (UBOS) and ICF. (2018). Uganda Dem ographic and Health Survey 2016. Kam pala, Uganda and Rockville, Maryland, USA: UBOS and ICF.

UNAIDS. (2016). Get on The Fast-Track: The life-cycle approach to HIV. Finding solutions for everyone at every stage of life.

UNESCO. (2017). Early and unintended pregnancy \& the education sector: Evidence review and recom $m$ endations. Paris, France: UNESCO.

UNICEF. (2015). The national strategy to end child $\mathrm{m}$ arriage and teenage pregnancy 2014/2015 - 2019/2020: A society free from child m arriage andteenage 
pregnancy. Republic of Uganda.

Van Den Berg, W., Hendricks, L., Hatcher, A., Peacock, D., Godana, P., \& Dworkin, S. (2013). 'One Man Can': shifts in fatherhood beliefs and parenting practices following a gender transform ative program $\mathrm{me}$ in Eastern Cape, South Africa. Gender \& Development, 21(1), 111-125.

Varga, C. A. (2003). How gender roles influence sexual and reproductive health am ong South African adolescents. Studies in family planning, 34(3), 160172.

Villarruel, A. M., Jem m ott III, J. B., Jem m ott, L. S., \& Ronis, D. (2004). Predictors of sexual intercourse and condom use intentions am ong Spanishdom inant Latino youth: a test of the planned behavior theory. Nursing research, 53(3), 172-181.

Vu, L., Pulerwitz, J., Burnett-Ziem an, B., Banura, C., Okal, J., \& Yam, E(2017). Inequitable gender norm s from early adolescence to young adulthood in Uganda: Tool validation and differences across age groups. Journal of Adolescent Health, 60(2), S15-S21.

Webb, T. L., \& Sheeran, P. (2006). Does changing behavioral intentions engender behavior change? A metaanalysis of the experimental evidence. Psychological bulletin, 132(2), 249.

Wight, D., Plum m er, M. L., Mshana, G., Wam oyi, J., Shigongo, Z. S., \& Ross, D..A (2006). Contradictory sexual norm s and expectations for young people in rural Northern Tanzania. Social science \& medicine, 62(4), 987-997. 



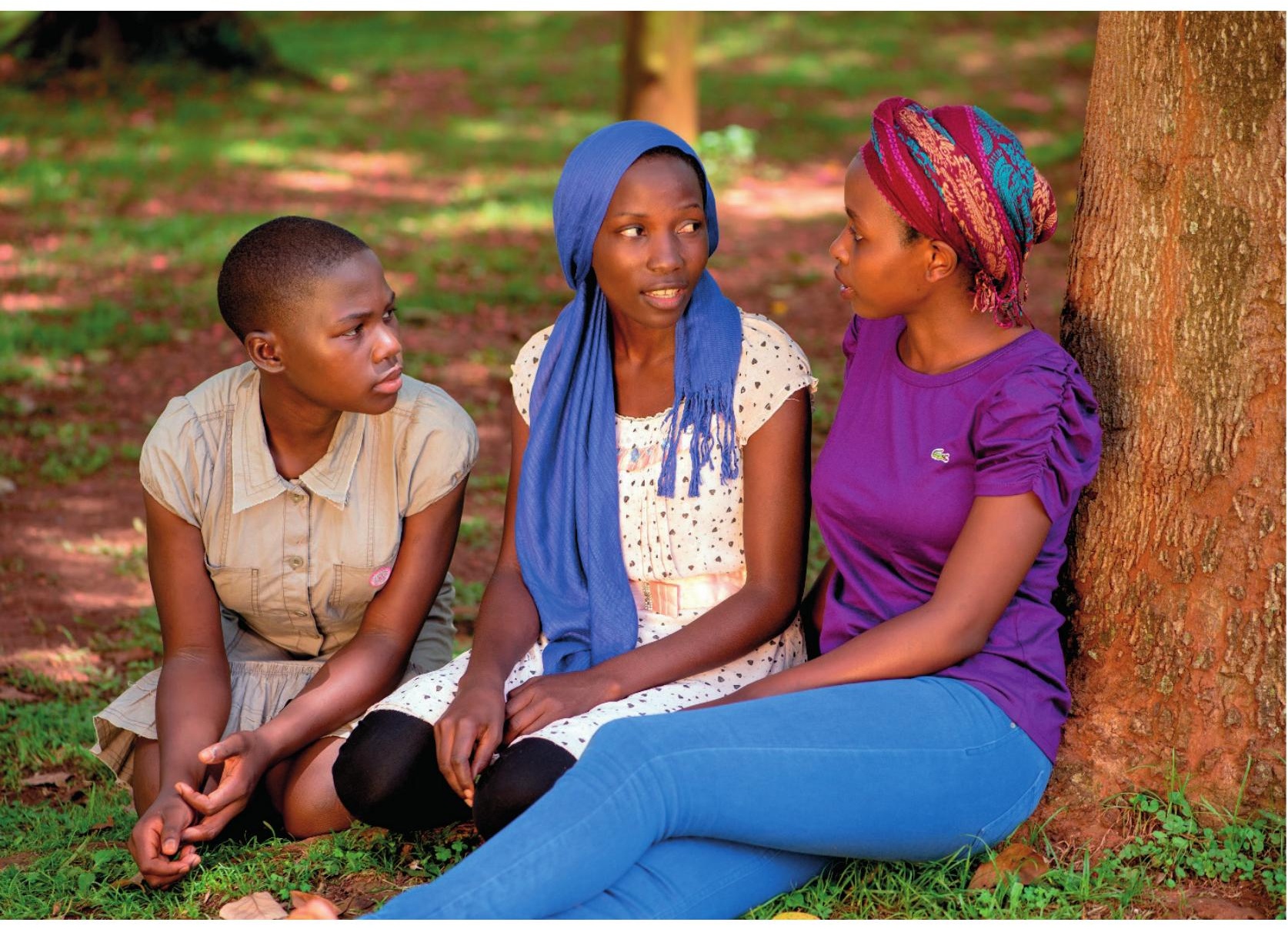




\section{Chapter 4}

\section{Adolescents discussing sexual behaviors with key influencing audiences}

\section{Published as:}

Nalukwago, J., Crutzen, R., Van den Borne, B., Bukuluki, P., Bufum bo, L., Batam wita, R., Zikusooka, A., Lenzi, R., Thom pson, G., \& Alaii, J. (2018). Adolescents discussing sexual behaviors with key influencing audiences. Global Journal of Health Science, 10, 91-106. 


\begin{abstract}
There is an increasing concern on early initiation of sexual activity am ong adolescents, increasing sexually transm itted infections, and teenage pregnancy in Uganda. Adolescents perceptions of these sexual behaviors $\mathrm{m}$ ight be the result of discussing sexual and reproductive health issues with key influencing audiences. This study qualitatively explored the effect of sexuality discussions with key influencing audiences by means of indepth interviews and focus group discussions with adolescents $(\mathrm{N}=83)$. Findings indicate that adolescence stage com es with changes of intense sexual desires, often presum ed difficult to control thus leading adolescents to engage in sexual activities. Adolescents indicated that they were aware of the sexual behaviors such as condom use, contraception use, and multiple concurrent partnerships, but intertwined with persistent $\mathrm{m}$ yths and $\mathrm{m}$ isconceptions. Although discussing sexuality issues with som eone was found to be instrum ental, adolescent highlighted challenges that hinder discussion with key influencers. Challenges include, parents lack of tim e to talk to their children; som e religious affiliations perceived to discourage use of contraception; lim ited skills of com m unity health workers to address adolescent information needs; meetings held in groups not followed up with age-focused or one-on-one discussions; negative health workers' attitudes and use of technical language; and peer pressure. These findings suggest the need to provide adequate and updated inform ation to clear any $\mathrm{m}$ isconceptions and strengthening of key influencers' communicaiton skills to gain confidence in addressing adolescent sexual and reproductive health needs.
\end{abstract}

Keywords: Adolescents, Condom use, Contraception, Multiple concurrent partnerships, Key influencers 


\section{Introduction}

There is increasing global concern on early initiation of sexual activity am ong adolescents, the increasing sexually transm itted infections, and teenage pregnancy (UBOS, 2018; UBOS, 2011; Kaestle et al., 2005; Brooks-Gunn \& Furstenberg Jr, 1989). Discussing sexual and reproductive health (SRH) issues with key influencing audiences to change adolescent sexual behaviors is pertinent. Sexuality education has featured prom inently in the global adolescent health discourse (Asam pong et al., 2013; Singh et al., 2005), where discussion of sexuality issues with key influencing audiences was found to be associated with adolescent sexual decision making (Meschke et al., 2002; Som ers et al., 2012). In Uganda, alarm ing adolescent health statistics have been recorded including, 19\% of adolescent girls aged 15-19 have had a live birth, $10 \%$ of girls and $17 \%$ of boys age $15-19$ reported to have had sexual intercourse by age 15 , and an HIV prevalence of $6 \%$ with $1.8 \%$ am ong adolescent girls and $0.4 \%$ am ong boys (UBOS, 2018). In Uganda, little is known about the effects of discussing sexual and reproductive health issues with key influencing audiences on adolescent sexual behaviors. This article explores adolescents' perceptions on adolescence stage, sexual behaviors and sexual behavioral changes associated with adolescent discussion and interactions with key influencing audiences such as parents, peers, health workers, village health team s (com m unity health workers) and religious leaders. Several studies found parent-adolescent com m nication to be effective in influencing adolescent sexual behaviors such as delayed sexual debut, condom use, reduction of m ultiple concurrent partnerships, and contraceptive use (Rodgers 1999; Biddlecom et al., 2009; Hadley et al., 2009; Eisenberg et al., 2006). However, there are persistent barriers in parent-adolescent com $\mathrm{m}$ unication concerning sex such as em barrassm ent, lack of knowledge, poorly defined values, fear of encouraging sexual activity, and inability to initiate and $\mathrm{m}$ aintain a conversation abaut the subject (Pick \& Palos, 1995; Werner-Wilson \& Fitzharris, 2001). When adolescents do not get sexuality inform ation from parents, they turn to and rely more on their peers for the inform ation (Whitaker \& Miller, 2000; Kioli, 2017). Peer-adolescent comm unication has been found to influence adolescent sexual behavior (Whitbeck et al., 1993). Health workers and com m unity health workers were found to be a major source of sexuality information for adolescents, often seen as role-models and experts in filling adolescent SRH inform ation needs (Jonas et al., 2017; Tilahun et al., 2012). There is increasing involvem ent of religious groups in local debates over sex education (Brewster et al., 1998), where religious leaders play a vital role of giving religious teachings about sex education. Religious teachings about sexuality that are against prem arital sex create the putative im pact of religion on sexual behavior (McCree et al., 2003; Landor et al., 2011; Kagim u et al., 2013). Individuals who attend religious services frequently 
receive religious $m$ essages against prem arital sex and are m ore likely to develop sexual attitudes and behaviors that are consistent with their religious doctrines (Odim egwu, 2005) Therefore, exploring the perspectives of adolescent interactions with key influencing audiences is imperative for guiding the design of context appropriate adolescent SRH program s. This study draws on qualitative data from Com $m$ unication for Healthy Com $m$ unities program on the behavioral perspectives of adolescent interactions with key influencing audiences.

\section{Communication for Healthy Communities Program}

Communication for Healthy Communities (CHC) is a fiveear program im plem ented through a June 2013 cooperative agreem ent between the United States Agency for International Development Uganda and FHI 360 (Fam ily Health International). It aim s to increase adoption of healthy behaviors through strengthened targeted social and behavior change com m unication (SBCC) of six integrated priority areas including; HIV/AIDS, fam ily planning, $m$ aternal and child health nutrition, $\mathrm{m}$ alaria and tuberculosis (CHC, 2016). Itsoverarching program $\mathrm{m}$ ing is based on the Socio-Ecological Model that looks beyond individuals to their social context including - interpersonal, institutional, com m unity and policy (Mckee et al., 2002; Golden \& Earp, 2012; Langille \& Rodgers, 2010. The social ecological paradigm is rooted in certain core principles concerning the interrelations am ong environm ental conditions, hum an behaviorand well-being. Environm ental settings are characterized as having multiple physical, social, and cultural dim ensionsthat can influence a variety of health outcom es (Stokols, 1996). Grounded in the underlying ideologies of the social ecological $\mathrm{m}$ odel, the program im plem ents an integrated SBCC cam paign (called OBULAMU?). OBULAMU? or "How is Life?" is an innovative approach to standardize and revitalize health com $m$ unication in Uganda by putting health in the context of day-to-day life. The cam paign prem ised on a Life Stage approach em ploys integrated strategies of inter-personal com m unication by cham pions such as hom e visits, com $\mathrm{m}$ unity health $\mathrm{m}$ obilization events, $\mathrm{m}$ ass $\mathrm{m}$ edia, social $\mathrm{m}$ edia, printd outdoor m edia. The integrated strategies trigger dialogue and selfreflection, provide knowledge, m otivationand skills on different health areas. The Life Stage approach identifies and addresses evolving health needs over different stages of an individual's life, rather than from adisease focused perspective. The four life stages addressed in the cam paign include: 1) Young adults (18 - 30 years) in relationships; 2) Pregnant women and their male partners; 3) Fam ily with children ( 0 - 14 years), targeting caregivers of children under five; and 4) Adolescent girls and boys (15 - 19 years) (CHC, 2016). The cam paign platform usesinter-personal com $m$ unication as the lead $\mathrm{m}$ edium, com $\mathrm{em}$ ented by $\mathrm{m}$ ass $\mathrm{m}$ edia, social $\mathrm{m}$ edia, printnd outdoor $\mathrm{m}$ edia to reach the targeted audiences. When the target audiences are exposed to all types of 
the cam paign interventions, then there is high exposure which is likely to lead to behavior change. The present qualitative study aims to exam ine the resultant behavioral changes of $\mathrm{CHC}$ Life Stage interventions among sexually active adolescents (girls and boys; 15-19 years) related to condom use, reduction ofm ultiple concurrent partnerships, and contraception use, with specific reference to adolescent interactions with key influencing audiences.

\section{Methods}

\section{Study methods}

The study used the following methods guided by the consolidated criteria for reporting qualitative research (Tong et al., 2007).

\section{Research team.}

A research team of both $m$ ale and fem ale data collectorsas recruited and trained on qualitative research processes, research ethics, consenting procedures, and on OBULAMU cam paign health $\mathrm{m}$ essaging platform . The data collectors were selected based on dem onstrated experience and perform ance during training and pretest of data collection tools. The recruited data collectors had knowledge of the local languages used in the selected study sites. This helped in conducting the interviews in the language com fortable for the participants.

\section{Study design}

Data for this study was obtained from a nonexperim ental qualitative study conducted between February to March 2017 in Uganda. Use of the non-experim ental qualitaive study approach helped to describe, gather an authentic understanding of, and find the reasons for adolescent health behavior and its social context (Marston \& King, 2006; Seale \& Silverm an, 1997; Baxter \& Jack, 2008; Creswell et al., 200)) The qualitative study used a case study of Com m unication for Healthy Com m unities program in Uganda. Qualitative case study m ethodology provides tods for researchers to study com plex phenom ena within their contexts Baxter \& Jack, 2008). The aim of a case study design is not to find out how often som ething occurs in a population, but rather what occurred, why it occurred, and what relationship exists am ong observed events. To generate health behavioral change insights from adolescents, the study em ployed a Most Significant Change m ethodology. The Most Significant Change m ethodology 
is a dialogical, story-based technique often used to generate knowledge on a phenom enon (Davies \& Dart, 2005; Dart \& Davies, 2003.

\section{Study setting}

Data was collected in four purposively selected districts of Lira, Mukono, Iganga, and Kyenjojo in Uganda. The sites selection was based on existence of program cam paign interventions specifically interpersonal com $\mathrm{m}$ unication and $\mathrm{m}$ ass $\mathrm{m}$ edia; urban and rural representation to achieve $\mathrm{m}$ axim um variatioin term $\mathrm{s}$ of geographical contexts; and existence of adolescent-focused sub-program activities such as the Determ ined, Resilient, Em powered, AIDSfree, Mentored Safe (DREAMS Core Package of Interventions Sum m ary), the Acelerating the Rise of Contraceptive Prevalence, and the Saving Mothers Giving Life program s (SMGL, 2014).

\section{Participant selection}

The study employed purposive sampling strategies particularly snowball and convenience sampling in the recruitment of participants. Using convenience sampling, adolescents were recruited for in-depth interviews (IDIs) through com m unity organizations by working with com m unity and peer cham pions, and program s that provide SRH services to young girls and boys such as School Health Program s, Straight Talk Foundation, and partners im plem enting Stepping Stones approach (ACORD, 2007) in selected districts. Convenience sam pling is a nonprobabilistic sam pling procedure that enabled researching subjects of the population that were easily accessible to the data collectors (Etikan et al., 2016; Farrokhi \& Mahm oudiHam idabad, 2012). Focus group discussion (FGD) participants were recruited using snowball sampling from IDI participants. Snowball sampling procedure enabled data collectors to access FGD inform ants through contact inform ation that was provided by IDI inform ants (Noy, 2008;Sadler et al., 2010). Adolescents who had been exposed to $\mathrm{CHC}$ interventions at various levels including $\mathrm{m}$ ass $\mathrm{m}$ edia, nothom ebased activations supported by cham pions, and cham pion hom e visits, were recruited for IDIs and FGDs. The study aim ed at recruiting potential sexually active adolescents 15-19 years for both IDIs and FGDs.

\section{Data collection methods}

In-depth interviews and focus group discussions were conducted in sequence. IDIs with adolescents aged 15-19 were conducted first and respondents contacts were taken to be contacted on another date to participate in FGDs. This helped in giving tim e for snowballing other FGD participants. FGDs were conducted after DIs with adolescents aged 15-19 and young lovers in relationships aged 18-30 because these 
target groups overlap and often have similar characteristics related to sexual behaviors. Interview guides for the IDIs and FGDs were developed using program SBCC strategy and objectives for the targeted population group, and they were refined during data collectors' training using trainee pre-test experience and using data from the pretest exercise. The questions in the interview guides focused onexistence and appropriateness of health services or information sources in the com $m$ unity, the environm ental (household, com m unity, structural, or health system ) factors perceived to affect ability to take up health services and healthy behaviors, health m essages that people have been exposed to, the perceived m ost significant contribution of integrated health com munication intervention in their lives and com $m$ unity, and noted health behavior changes. IDIs were conducted to gather detailed inform ation (Boyce \& Neale, 2006) on the effect of discussing selected health topics within the adolescent social networks on an individual's intentions and action/behaviors. A total of sixteen IDIs were conducted, eight for $\mathrm{m}$ ales and eight for fem ales.FGDs were conducted to understand how the norm ative environm ent and service delivery context in com munities potentially interacted with individual's health behaviors, and the role interpersonal com m unication played to com plem ent health com m unication.To enable full participation, FGDs were conducted separately with $\mathrm{m}$ ale and fem he respondents. In total, eight FGDs, four for $\mathrm{m}$ ales and four for fem ales were conducted. Each FGD had between $\& 12$ participants.

\section{Ethical approval}

Ethical approval was obtained from the federally-registered institutional review board of FHI 360 (Fam ily Health International), the Protection of Hum an Subjects Com $m$ ittee in the United States of Am erica, under reference 939934, and in Uganda by the Makerere School of Public Health Research Ethics Com mittee, under reference 446. Consent to conduct research was provided by Uganda National Council for Science and Technology and Office of the President. Oral inform ed consent was obtained from each participant before anystudy specific activities were undertaken. A waiver of written consent to increase confidentiality was sought because signed inform ed consent form s would be the only link to the participants' identity in the study population groups. A waiver of parental consent was also sought to protect adolescent participants' privacy, particularly around disclosure of sexual behavior, and because recruitm ent was conducted away from hom es in som e cases and based on convenience sam pling, which is not conducive to parental consent. Once eligibility was established for study participants, full verbal inform ed consent was obtained from each study participant aged 15-19 before any research activities were undertaken. Verbal inform ed consent was sought for $\mathrm{m}$ ature/ em ancipated $\mathrm{m}$ inors aged 15-17 years who were not under parental/ guardian care but catered for their 
own livelihood. Consent was docum ented for each participant viathe signature of the study staff $\mathrm{m}$ em ber who obtained consent.

\section{Data analysis}

Audio-recorded data from IDIs and FGDs collected in the local language was translated into English after verbatim transcription. The IDIs lasted an average of 45 $m$ inutes (excluding inform ed consent process), while FGDs lasted an average of 11/2 hours (excluding inform ed consent process). All interviews were audio recorded to ensure that all data were captured. NVivo 11 software was used to facilitate the data coding process. The software package provided a sim ple to work withstructure for creating codes and discovering them es (Zam awe, 2015; Abuya et al., 2013). Analysis codes, such as experience on adolescence stage, sexual behaviors (condom use, contraception use, m ultiple concurrent partnerships), and effect of key influencing audiences were developed to guide the generation of concepts that em erged from the data. Codes were also identified from reading the first set of transcripts. Them atic content analysis was used to organize the data into them es and subthem es used to develop em erging concepts and interpretthe m eaningof adolescent health behaviors drawn from the study. Them atic content analysis wasused to describe the naturalistic phenomenon of adolescent sexual behaviors. The analysis adopted analytic approaches ranging from impressionistic, intuitive, interpretive analyses to system atic and textual amlyses (Zam awe, 2015). Them atic content analysi was chosen to help in gaining direct inform ation from study participants without im posing preconceived categories or theoretical perspectives (Hsieh \& Shannon, 2005).

\section{Results}

\section{Demographic characteristics of respondents}

A total of 83 adolescents participated in the study. Of these, 16 respondents participated in in-depth interviews and 67 respondents participated in focus group discussions. Most of the respondents were fem ale. Regardingeducation level, $\mathrm{m}$ ost respondents had started secondary school, and $\mathrm{m}$ any were not $\mathrm{married}$. Most respondents were Protestants and Catholics (Table 1). 
Table 1: Demographic characteristics of Adolescents

\begin{tabular}{|c|c|c|c|c|}
\hline \multicolumn{2}{|c|}{ Demographic categories } & \multicolumn{3}{|c|}{ Frequency and percentage $(\%)$} \\
\hline & & $\begin{array}{l}\text { All adolescents (N } \\
=83)\end{array}$ & $\begin{array}{c}\text { Girls }(N= \\
\text { 53) }\end{array}$ & $\begin{array}{c}\text { Boys }(N= \\
30)\end{array}$ \\
\hline \multirow[t]{5}{*}{ Age } & 15 & $9(11 \%)$ & $5(9 \%)$ & $4(13 \%)$ \\
\hline & 16 & $5(6 \%)$ & $3(6 \%)$ & $2(7 \%)$ \\
\hline & 17 & $17(21 \%)$ & $13(25 \%)$ & $4(13 \%)$ \\
\hline & 18 & $18(22 \%)$ & $8(15 \%)$ & $10(33 \%)$ \\
\hline & 19 & $34(41 \%)$ & $24(45 \%)$ & $10(33 \%)$ \\
\hline \multirow{5}{*}{$\begin{array}{l}\text { Education } \\
\text { level }\end{array}$} & Started prim ary & $12(15 \%)$ & $8(15 \%)$ & $4(13 \%)$ \\
\hline & Com pleted prim ary & $15(18 \%)$ & $10(19 \%)$ & $5(17 \%)$ \\
\hline & Started secondary & $42(51 \%)$ & $29(55 \%)$ & $13(43 \%)$ \\
\hline & Com pleted secondary & $12(15 \%)$ & $5(9 \%)$ & $7(23 \%)$ \\
\hline & Higher than secondary & $2(2 \%)$ & $1(2 \%)$ & $1(3 \%)$ \\
\hline \multirow{4}{*}{$\begin{array}{l}\text { Relationship } \\
\text { status }\end{array}$} & Single & $54(65 \%)$ & $30(57 \%)$ & $24(80 \%)$ \\
\hline & Dating & $19(23 \%)$ & $15(28 \%)$ & $4(13 \%)$ \\
\hline & $\begin{array}{l}\text { Living with partner, but not } \\
\text { m aried }\end{array}$ & $1(1 \%)$ & 0 & $1(3 \%)$ \\
\hline & Married & $9(11 \%)$ & $8(15 \%)$ & $1(3 \%)$ \\
\hline \multirow[t]{3}{*}{ Religion } & Catholic & $28(39 \%)$ & $17(37 \%)$ & $11(42 \%)$ \\
\hline & Muslim & $10(14 \%)$ & $5(11 \%)$ & $5(19 \%)$ \\
\hline & Protestant & $34(47 \%)$ & $24(52 \%)$ & $10(39 \%)$ \\
\hline
\end{tabular}

\section{Experience of respondents on adolescence stage}

When asked about their experience on adolescence, the respondents $m$ entioned that adolescence stage com es with changes. They noted that the changes are often seen in increasing sexual desires and feelings that $\mathrm{m}$ ay $\mathrm{m}$ ake adolescents sexually active, and yet controlling the sexual desire is a challenge. The respondents further noted that adolescence is associated with a lot of peer influence that som etim es affects adolescents negatively because it leads them to engage in activities that they feel are not good. Others perceived adolescence as a tim e where youth have fun and face so $\mathrm{m}$ any tem ptations (Fi்ure 1). 


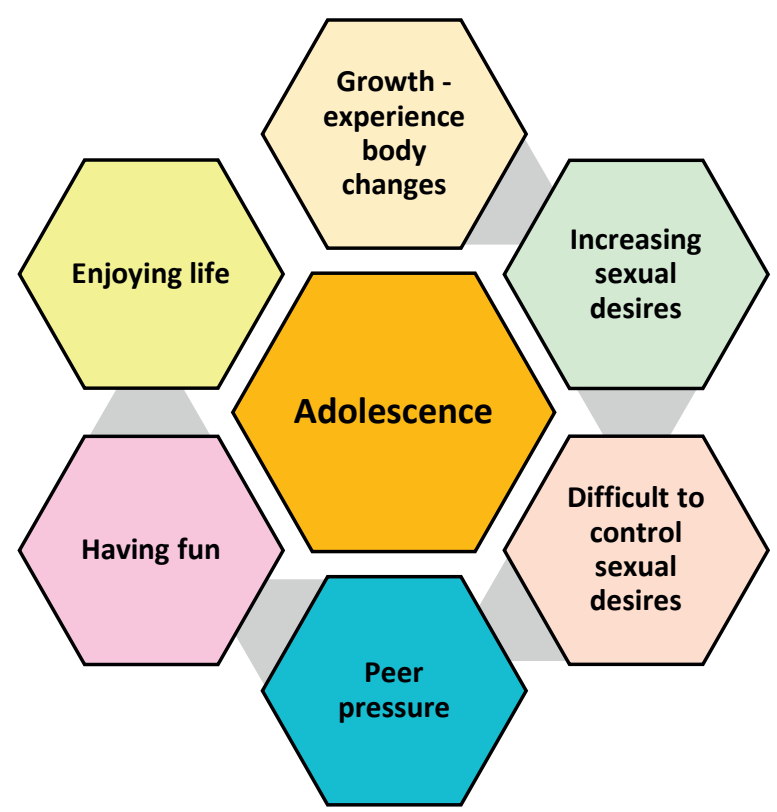

Figure 1: Respondents' experience on adolescence stage

The change is in growth, like at this moment I am an adolescent, yeah? I have started changing, let's say I am now experiencing my monthly periods. And another change is that I have started getting sexual feelings towards men. (IDI, Fem ale adolescent, Lira district).

Sometimes the sexual desires are intense and therefore, controlling the desires as you are not supposed to get involved in such (sexual) acts is a challenge. (IDI, Fem ale adolescent, Lira district).

I realized that I had many friends who bring peer pressure, and they make us do things that we should not have done as youths. The adolescent stage disturbs us a lot thus doing things that we shouldn't have done.... (IDI, Male adolescent, Lira district).

The youth of today like having fun and enjoying life and sexual pleasures and they say that the world is coming to an end hence living a reckless life. They don't care to use a condom during sex.... (IDI, Fem aleadolescent, Lira district). 


\section{Adolescent perceptions on sexual behaviors}

Sexual behaviors such as condom use, multiple concurrent partnerships, and contraception were explored in this study. The aim was to understand the perceptions of adolescents on sexual behaviors including, knowledge, attitudes, $m$ yths and $\mathrm{m}$ isconceptions.

\section{Perceptions on condom use}

Most of the respondents perceived that they had knowledge on condom s and were aware of the benefit of using them. Although som e adolescents noted that theydid not know how to use condom s, others highlighted that there are com plications and side effects associated with using condom $s$, an indication of existing $m y$ ths and $m$ isconceptions. The participants noted thatthe use of condom s prom otes prem arital sex, it causes diseases to wom en, and they affect sexual enjoym ent (Figure 2).

... a condom is a bit different in a way that it plays many roles or more than one function. It prevents us from contracting UTIS, STDs, HIV/AIDS, and even pregnancies... (FGD, Fem ale respondent, Mukono district).

Yes, it is true we are using condoms but they are promoting pre-marital sex. If they tell us to use condoms then also pre-marital sex will increase. (FGD, Male respondent, Iganga district).

These condoms are good but they talk badly about them.

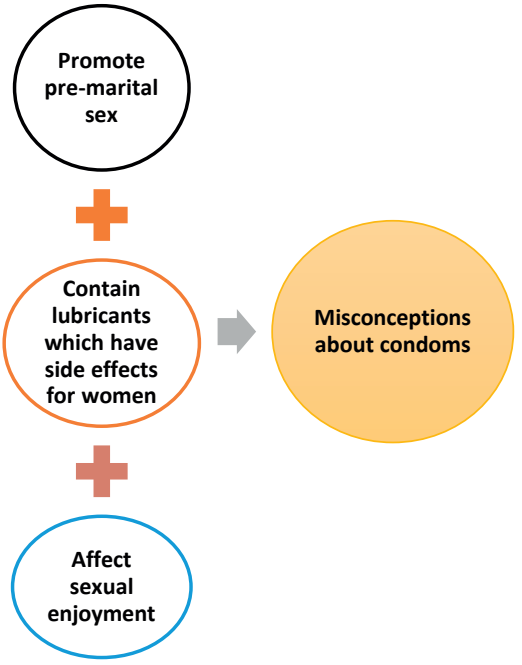

Figure 2: Adolescents' misconceptions about They say that when you use condoms, they contain lubricants which have side effects for women after use and that they may result into complications... (FGD, Fem ale respondent, Mukono district).

When using a condom, it's like licking a wrapped sweet, your saliva keeps it soft but you can never taste its sweetness, or it's like eating bananas used for making local brew. You can't feel the taste. (FGD, Male respondent, Kyenjojo district). 


\section{Perceptions on multiple concurrent partnerships}

Most of the respondents noted that they had a history of two or m ore sexual partners. The participants also stated that they knew the im portance of being faithful to one partner including, one knows the partner's health, it protects them from disases, and it brings trust in the relationship. However, others highlighted that faithfulness to one partner is not necessarily easy because youth are not always truthful, and there is usually no trust in the relationship. The respondents also highlight the existence of inter-generational sex, which often tim es causes gender power im balance and affects adolescents' ability to negotiate safe sex.

Being with one partner only is good because you will know your health; you are preventing disease and he also trusts you. (FGD, Fem ale adolescent, Lira district).

Faithfulness, that one is hard because you can decide to be faithful to your partner but it is still hard unless when you have got an older man. Getting your age-mate, he can cheat on you with another person and even make you cry. To me, that's impossible unless you have got an older man who has settled. (FGD, Fem ale respondent, Mukono district).

Having m ultiple sexual partners was seen as expensive for boys as they felt that they had to spend a lot of $\mathrm{m}$ oney im pressing grls. The respondents highlight the onset of feelings of responsibility with finances am ong boys. Transactional sex and $\mathrm{m}$ ultiple sexual relationships for $m$ oney and $m$ aterial gainwas $m$ entioned as a factor that $\mathrm{m}$ akes adolescents girls to have $\mathrm{m}$ ultiple concurent partnerships.

I would go and give out pocket money of Uganda shillings (UGX) 10,000/- [US\$ $1=U G X 3,696]$ and they would call me a rich man. ...I realized that every day I would spend like 50,000/-. ...I regretted the money I had spent yet I wanted to buy what to eat but I did not even have 100/- (FGD, Male respondent, Iganga district).

You might find a woman with three men like one is for paying for costs of making her hair, the second is to settle bills for her nail care, and the third is for paying rent. Such a woman may tell her husband to be faithful but the moment the husband leaves she cheats on him. (FGD, Fem ale respondent Mukono district).

\section{Perceptions on contraception use}

The respondents perceived that they had knowledge on contraception use. Many talked about the benefits of contraception (fam ily planning) as helping to have a 
num ber of children one could provide for. The respondents also highlighted the onset of feelings of responsibility to provide partner support in the use of contraception. Som e mentioned that they were aware of the possibility of using em ergency pills before sex to avoid getting pregnant. Most respondents also cited fears that contraception use has side effects which discourage adolescents from using it. They $\mathrm{m}$ entioned side effects such as infertility, swollen wounds and bleeding, making wom en dry, and loss of sexual appetite presum ed to result from using contraception (Figure 3).

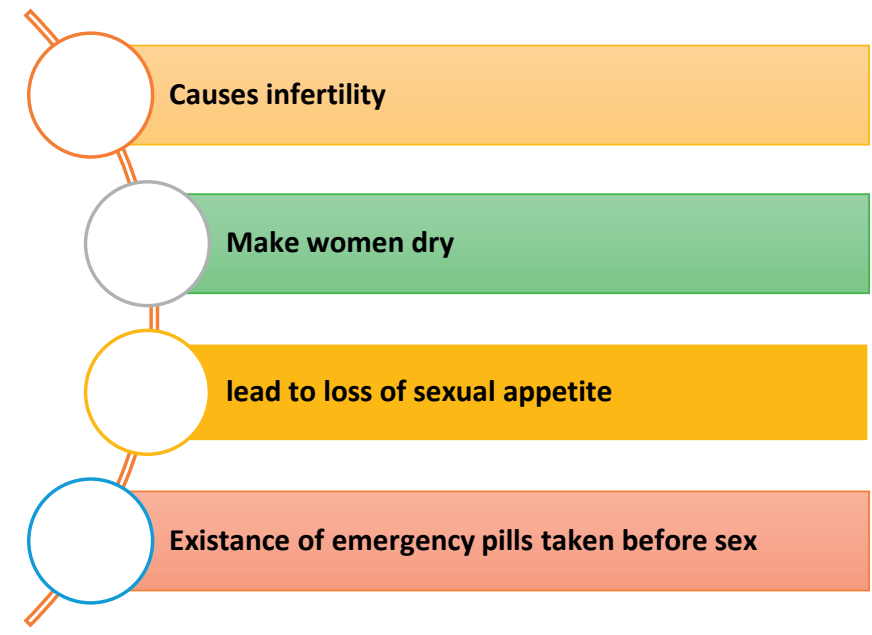

Figure 3: Adolescents' fears about contraception use

The change I have seen is that in the past people used to give birth to many children because there was no family planning, but now people are using family planning. In the near future when I get a wife, I will take her for family planning so that we have two children. This will allow us to take good care of them, feed them well. It will also be easy to take them to good schools. (FGD, Male respondent, Lira district)

But for my case, I have heard girls saying that there are certain emergency pills that you take before sex, and you can't get pregnant. (IDI, Fem ale adolescent, Kyenjojo dstrict).

When you talk about using family planning, they do use it, but end up becoming infertile! That's why they fear. (FGD, Fem ale respondent, Kyenjojo district). 
These injections have side effects. They make the woman dry, and you lose sexual appetite. (IDI, Fem ale adolescent, Kyenjojo district).

The effect of key influencing audiences on adolescent sexual behaviors

The respondents were asked if they discuss sexual behaviors such as condom use, $\mathrm{m}$ ultiple concurrent partnerships and contraception use with key influencers such as health workers, VHTs, parents, religious leaders, and peers. Most respondents m entioned that they had discussions with VHTs and peers, and a few with health workers, parents and religious leaders.

\section{Village health teams (VHTs)-adolescent interaction and its effect on adolescent sexual behavior}

Most adolescents mentioned that they had discussions with VHTs about sexual behaviors. They noted that their interaction with the VHTs had an effect on their behaviors towards behavior change. Som e highlighted that using the inform ation they got from VHTs they gained the confidence to start using condom s, contraception, reduce the num berof sexual partners, and going for HIV testing.

My discussion with the champion (VHT) focused on protection and he was interested in knowing how I go about protecting myself. He talked about family planning in case someone is not abstaining and the use of condoms and IUD. (IDI, Fem ale adolescent, Iganga district).

...he (VHT) just told me that I should leave women and I heeded what he was telling me... The change that I got that was good is that I used to think about girls but now I stopped thinking about them. (IDI, Male adolescent, Iganga district)

Yes, he (VHT) told me about HIV, and I took his advice and went for testing. I did it on 4th October, it was a Tuesday if my memory serves me right. I found that I was negative. (IDI, Male adolescent, Kyenjojo district).

However, the adolescents also highlighted challenges in interacting with VHTs. Som e respondents expressed concerns about the nature of m eeting they had with the VHTs. They noted that som e meetings were held in groups but not necessarily followed up with age-focused or one-on-one discussions to provide a conducive 
environm ent for sharing confidential inform ation. Others noted that the age of VHTs $\mathrm{m}$ ade it difficult for them to easily open up during discussions (Figure 4).

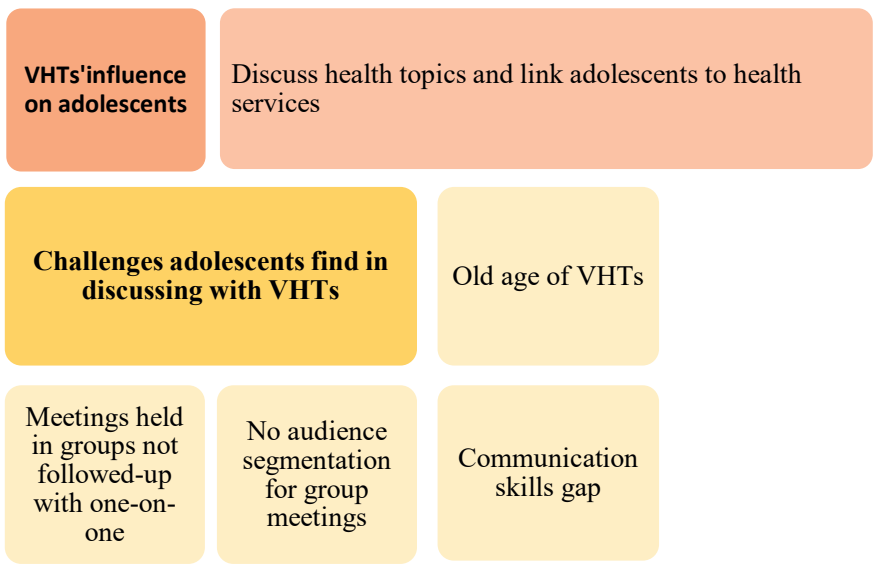

Figure 4: Effect of VH Ts discussing with adolescents

In my opinion, he (VHT) had no target because the meeting had individuals aged 65, 19, and 35. The young and old participated; thus, it was general. (IDI, Male adolescent, Mukono district).

We talked to him (VHT) while in a group. It would be very important to talk to him in one-on-one discussions since I would still need to get more information where I did not understand. (IDI, Male adolescent, Lira district).

What I feel like is an obstacle, is that at times the champions (VHTs) are of my father or mother's age. That is my problem. (IDI, Fem ale adolescent, Lira district).

\section{Health worker-adolescent interaction and its effect on adolescent behavior}

A few adolescents noted that health workers are key in providing inform ation and specific service delivery points that encourage adolescents to take up SRH services such as HIV testing. However, other adolescents had concerns about their interactions with health workers, highlighting that they use a lot of learned (technical) language, and $\mathrm{m}$ ay use harsh or abusive language with clients (Figure 5). 
Whenever you go to a health facility, the health workers give you a lot of information. For instance, taking an HIV test free of charge and sometimes they have a range of places where we can go to have the tests like at the health facilities. (FGD, Male respondent, Mukono district).

...sometimes the health worker gives me information but as usual, they have a learned language they use, ...so most people (friends) that we usually

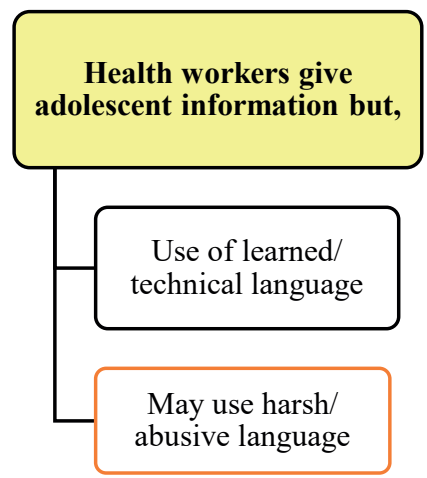

Figure 5: Adolescents' perception on discussing with health workers hang out with know us better than the health workers. (FGD, Male respondent, Mukono district).

For me what I would like to say is that midwives should change their ways. Sometimes you find her inside with the pregnant woman asking her if she is the one who impregnated the patient. She just shouts at you instead of encouraging you. (FGD, Fem ale respondent, Mukono district).

\section{Parent-adolescent interaction and its effect on adolescent behavior}

A few respondents $m$ entioned having discussions with parents. They noted that they try to get $\mathrm{m}$ ore SRHinform ation from the parents who they see as the first people to guide them, and adolescents pride in trust from parents. However, som adolescents expressed concern of non-availability of parents for SRH discussions because they are too busy and often do not have tim e for discussion or they try to avoid topics of sexuality (Figure 6).

Seen as the first

Adolescents pride

in trust from parents

\section{Challenge is}

parents are too busy

to talk to them

about SRH

people to guide

them

Figure 6: Adolescents' experience interacting with parents 
Parents are the first people to guide us; when they see us going astray, and tell us to protect ourselves, and take the right path in life. (IDI, Male adolescent, Kyenjojo district).

When you abstain, your parents trust you, but if you do not, they think their money used for taking you to school is being wasted. (FGD, Fem ale respondent, Kyenjojo district).

The challenge I face is that whenever I ask my mummy about some of these things (sexuality issues), she is too busy to discuss with me. (IDI, Fem ale adolescent, Mukono district).

\section{Religious leaders-adolescent interaction and its effect on adolescent behavior}

A few adolescents talked about interactions with religious leaders, noting that they help in advising the youth to behave well. However, others highlighted that som e religions $\mathrm{m}$ ight be discouraging the recommended $\mathrm{SRH}$ behaviors such as contraception use.

Religious leaders, they advise the youth; you should behave well, and we should listen to them. (IDI, Male adolescent, Kyenjojo district).

My engagement with church services motivated me. Some of the church members are orphans who have grown up within the church, so I got this opportunity to talk to them. I opened up to them and told them that they are now grown-ups... "So, you must protect yourselves". I guide them about controlling sexual desires even if they are in that age group (adolescents). (IDI, Fem ale respondent, Iganga district).

I am not a Muslim but I usually hear them say that the sharia law does not accept family planning (contraception) use. They say that it will kill their unborn children in the uterus thus limiting the number of children they should have. (FGD, Fem ale adolescent, Iganga district).

\section{Peer-adolescent interaction and its effect on adolescent behavior}

Most of the respondents $m$ entioned that peers are influential in getting them totake up SRH services. They listen to peer advise and are free to discuss sexuality issues with them. However, others noted that peer groups and pressure can som etim es lead them to engage in bad behavior. 
I want to say that close friends or people who we usually hang out with influence us. ...My friend can advise me to take an HIV test by giving an example of his real-life situation.... If your peer features in a health advert, you may decide to follow his advice. (FGD, Male respondent, Mukono district).

We have peer groups like I told you that make us lose focus. They make you leave something good and you do what is not right thus resulting in problems. (IDI, Male adolescent, Iganga district).

\section{Discussion}

This study explored adolescents' experiences on adolescence stage, perceptions on sexual behaviors, and the effect of interacting and discussing sexual behaviors with key influencers. The findings indicate that adolescence stage com es with changes such as intense sexual desires, which are perceived difficult to control. These findings support other studies which show that adolescence is a critical and vulnerable tim e of biological, physical, psychological change where youth face new challenges such as initiating sexual activity, entering the age of risk-taking, and entering into unions (Cortez et al., 2016; William son, 2014). With the realities of increasing sexual desires during adolescence, most adolescents indicated that they were aware of sexual behaviors such as condom use, contraception use, and multiple conurrent partnerships. However, Radecki and Jaccard (1995) found that adolescent perceptions of their knowledge about sex and birth control are only weakly correlated with their perform ance on knowledge tests about these topics, which suggests that perceptions of knowledge are not reflective of the actual knowledge an individual possesses. Thus, adolescent claim s of high knowledge levels on health risks should not be trusted (Jaccard et al., 2002). Our study concurs with these findings where adolescents presumed to have knowledge of health risks. However, what they called knowledge was actually laced with a lot of hearsay, $m$ yths, and $m$ isconceptions. This im plies that health prom otion practitioners still need to increase adolescents' knowledge on these SRH topics. Therefore, inform ation services remain im portant in clearing any $\mathrm{m}$ isconceptions and addressing any health concerns for increased service uptake.

Most adolescents in this study highlighted that discussing SRH issues with som eone was fundam ental in influencing their sexual behaviors. Several studies indicate that parent-adolescent interaction and com munication was found to be associated with reduced sexual risk taking on the part of adolescents (Asam pong et al.,2013; Dittus \& Jaccard, 2000; Jaccard et a., 2002). The function of parents is to m otivate and guide the behavior of their children (Jaccard et al., 2002). Whitaker and 
Miller (2000) found that peer norm s were associated m ore strongly with behavior for those adolescents who had not discussed sex or condom s with a parent than for those who had engaged in such discussions. The non-initiation of sex was found to be associated with adolescents believing parents care and hold high expectations for their children (Asam pong et al., 2013). Consistent with other studies, our findings indicate that adolescents see parents as the first people to give them guidance, and adolescents pride in being trusted by their parents. However, adolescents in our study indicated challenges that hinder parent-adolescent discussion such as parents being too busy and not having tim e to talk to their children. Sim ilar findings were reported in a study by Löfgren, Byam ugisha, Tillgren \& Rubenson (2009), in which parents' lack of time to talk to their children was noted to hinder parent-adolescent com m unication. Additionally, our findings concur with other studies which found that parents often have difficulty finding the right place and tim e for com m unication because they feel inadequately inform ed, em barrassed and uncom fortable idcussing sexuality topics (Feldm an \& Rosenthal, 2000; Jaccard et al., 2002; Taffa et al., 2017; Bastien et al., 2011). Other studies recom $m$ end that a com prehensive fam ily life education should be initiated at hom e, in the school, churches/m osques, and helth facilities, with a sense of responsibility assum ed by all partners; and there is need to educate parents for a better awareness on sexuality and change of attitude and practice towards adolescent sexuality (Taffa et al., 2017; Bastien et al., 2011; Löfgren et al., 2009). Our findings seem to suggest the need to sensitize parents about $\mathrm{m}$ aking tim $\mathrm{e}$ to talk to their children about sexuality before sexual debut. It is also im perative to strengthen parents' com m unication skills about SRH to boost their confience in talking about sexuality issues with adolescents.

Religious leaders were highlighted by adolescents in this study as being instrum ental in motivating and advising the youth to behave well. This finding is consistent with other studies which found that adolescents who reported not engaging in sexual intercourse cited religious or $m$ oral values as their $m$ otivation for abstinence from sexual activity (Odim egwu, 2005; Rostosky et al., 2004). However, our study also found that adolescents felt that som e religious affiliations were discouraging the use of contraception. This is consistent with other studies that reported significant correlations between $m$ ore conservative religious affiliations and a lack of contraceptive use am ong adolescent girls (Brewsteret al., 1998; Cooksey et al., 1996; Rostosky et al., 2004). Sim ilarly,Lefkowitz et al., (2004) found that individuals who followed their religions m ore closely were less likely to believe that condom s could prevent negative outcom es such as pregnancy orsexually transm itted diseases. And individuals who attended religious services m ore frequently had less fear about HIV (Lefkowitz et al., 2004). Our findings suggest the need for health prom otion program s to work closely with religious institutions in providing $\mathrm{SRH}$ inform ation that addresses $\mathrm{m}$ yths and $\mathrm{m}$ isconceptions, forem ost being learning from the experiences 
of existing adolescent health program s which have sensitized religious leaders on SRH issues. There is need for further research to understand how the religious leaders' SRH sensitization interventions lead to change in conservative religious doctrines that inhibit contraception and condom use.

Most adolescents in our study mentioned that they had discussions with village health teams (VHTs) about sexual behaviors such as condom use, contraception use, and m ultiple concurrent partnerships. They highlighted that VHTs gave them detailed inform ation which helped them in taking up health services. This supports other studies which found that com m unity helth workers can translate health and system inform ation into the com m unity's language, they can successfully teach concepts of prim ary or secondary prevention and im prove access to prenatal care, and they can facilitate com m unity participation in the heall system (Witm er et al., 1995; Denno et al., 2015; Liu et al., 2011). Our findings suggest that interpersonal com $\mathrm{m}$ unication is highly effective in com plem enting and clarifying generic $\mathrm{m}$ essages relayed through mass media (radio, TV, posters). Thus, an indiation that a com bination of channels in health com $\mathrm{m}$ unication program $\mathrm{m}$ ing is param ount in m essage saturation, rather thanthe use of one channel. However, adolescents in our study expressed concerns about VHTs being too old to address their inform ation needs, the com m unication skills of the VHTs, and m eetings held in groups not followed up with age-focused or one-on-one discussions. These findings suggest the utm ost im portance for health prom otion program s to address these concerns if adolescent health is to be improved. Such concerns can be addressed through recruiting and training age appropriate peer cham pions to work with adolescents, providing m ore resources for supportive supervision to facilitate VHTs' follow-up visits to adolescents $m$ et in groups andone-on-one discussions, if group $m$ eetings are to be held, age categorization and audience segm entation for the participants ought to be em phasized. This is consistent with other studies which recom m ended that, health authorities should lead efforts to define and endorse com munity health workers' roles, while providing strategies for training, supervision, rem uneration, recognition, career progression and quality assurance (Mwai et al., 2013), and evaluation program s should be cognizant of the fact that com mnity health worker program s grow and evolve in phases of continuous learning, im provem ent, and expansion of coverage (Liu et al., 2011). Therefore, drawing experiences from successfully piloted community health workers interventions is pertinent in im proving health prom otion program $\mathrm{m}$ ing.

Health workers were also identified as an important group that helps adolescents with health issues including giving them health inform ation. However, the adolescents highlighted that som etim es they do not go to health wokers because of their attitude, use of technical language and giving unclear inform ation. These findings support other studies that reported negative health workers' attitudes and 
inadequate skills to com m unicate to adolescents as barriers for service uptke by adolescents (Jonas et al., 2017; Chaibva et al., 2010; Chandra-Mouli et al., 2017; Jonas et al., 2018). Therefore, continuous m edical education as a m ethod of keeping abreast with current and updated knowledge for healthcare workers needs to be addressed, with specific reference on skills of handling adolescents. Adapting the use of successful piloted interventions in addressing $\mathrm{m}$ yths and $\mathrm{m}$ isconceptions such as the use of values clarification com ponent under the $\mathrm{CHC}$ program $(\mathrm{CHC}, 2016)$ is pertinent.

Adolescents in our study also highlighted that they find it convenient to discuss health issues with their peers, who often influence them both positively and som etim es negatively in health serve uptake. This finding is consistent with other studies which found that friends play an im portant role in both harm ful and positive activities of adolescents (Maxwell, 2002; Brendt, 1999). Adolescents' perceptions that their friends hold sexually liberal attitudes and are sexually active also influence their sexual choices (Whitbeck et al., 1993). Varga (2003) also found that adolescent relationships appear to be driven by pressure from peers and partners to engage in early and unprotected sex as $\mathrm{m}$ arkers of trust or com $\mathrm{m}$ itm ent. Our findings indicate that providing adequate SRH inform ation to adolescents should be a priori for guiding peer-adolescent discussions. Monitoring guided peer-adolescent discussions would be the first step in identifying knowledge gaps. This can be done through drawing lessons from existing adolescent health program s that work with adolescent groups and networks using $\mathrm{m}$ ethodologies such as stepping stones (ACORD, 2007) to assess how peer discussions are m oderated, and identify areasfor im provem ent.

This study confirm s the reality of sexual desires that drive adolescents to engage in sexual activities often with m ultiple concurrent partners. This contributes to the alarming adolescent SRH indicators of early sexual debut, increasing HIV prevalence, and teenage pregnancies in Uganda. The findings seem to suggest that for im proved adolescent health and behavioral outcom es, health prom otion program $\mathrm{s}$ need to invest in developing the com munication skills and bridging the SRH inform ation gaps of key influencing audiences such as com m unity health workes, health workers, parents, religious leaders, and peers. Additionally, continued provision of updated SRH inform ation to adolescents and the general public is im portant to bridge knowledge gaps. However, it is im portant to understand the unique inform ation needs of the different audiences for targeted program $\mathrm{m}$ ing. Therefore, continuous studies need to be done to understand the different and em erging inform ation needs of adolescents and their kg influencers. 


\section{Chapter 4}

\section{Study limitations}

This study had som e m ethodlogical lim itations that need to be considered. The study was conducted in only four districts of Uganda with a few sam pled participants, thus this could affect the generalizability of the findings. The study also used convenience sampling to recruit participants, but its limitation is that groups chosen by convenience sam pling are conducive to selfselection, adm inistrative decision, tim e of the class, num ber of the years of exposure and $m$ any ther polluting influences (Farrokhi \& Mahm oudiHam idabad, 2012).

\section{Conclusion}

Adolescent health has been placed on the global agenda where health prom otion developm ent practitioners are challenged with finding solutions towards addressing adolescent health problem s. Listening to the voice of adolescents them selves prøides the first opportunity to understand the contextual problem $\mathrm{s}$ and thereby work with them to findpracticable solutions. The need to integrate com $m$ unity and adolescent social network approaches to work synonym ously with health com munication interventions is im perativefor adolescent health program $\mathrm{m}$ ing. 


\section{References}

Abuya, B., Oketch, M., \& Musyoka, P. (2013). Why do pupils dropout when education is 'free'? Explaining school dropout am ong the urban poor in Nairobi. Compare: A Journal of Comparative and International Education, 43(6), 740762. doi.org/10.1080/03057925.2012.707458

ACORD. (2007). IMPLEMENTING STEPPING STONES: A Practical and Strategic Guide for Implem enters, Planners and Policy Makers. available at: https://www.k4health.org/sites/default/files/Im plem enting SteppingStones.pdf

Asam pong, E., Osafo, J., Bingenheim er, J. B., \& Ahiadeke, C. (2013)Adolescents and parents' perceptions of best tim e for sex and sexual com m unications from two com $m$ unities in the Eastern and Volta Regions of Ghana: im plication§or HIV and AIDS education. BMC International Health and Human Rights, 13(1), 40. doi.org/10.1186/1472-698X-13-40

Bastien, S., Kajula, L. J., \& Muhwezi, W. W. (2011).A review of studies of parentchild com m unication aboutsexuality and HIV/AIDS in sub-Saharan Africa. Reproductive Health, 8(1), 25. doi.org/10.1186/1742-4755-8-25

Baxter, P., \& Jack, S. (2008). Qualitative case study m ethodology: Study design and im plem enation for novice researchers. The qualitative report, 13(4), 544-559.

Biddlecom, A., Awusabo-Asare, K., \& Bankole, A. (2009). Role of parents in adolescent sexual activity and contraceptive use in four African countries. International Perspectives on Sexual and Reproductive Health, 72-81. doi.org/10.1363/3507209

Boyce, C., \& Neale, P. (2006). Conducting indepth interviews: A guide for designing and conducting in-depth interviews for evaluation input. Pathfinder International Tool Series, Monitoring and Evaluation - 2 .

Brewster, K. L., Cooksey, E. C., Guilkey, D. K., \& Rindfuss, R. R. (1998). The changing impact of religion on the sexual and contraceptive behavior of adolescent wom en in the United States. Journal of Marriage and the Family, 493- 504. doi.org/10.2307/353864

Brooks-Gunn, J., \& Furstenberg Jr, F. F. (1989). Adolescent sexual behavior. American Psychologist, 44(2), 249. doi.org/10.1037/0003-066X.44.2.249

Chaibva, C. N., Ehlers, V. J., \& Roos, J. H. (2010). Midwives perceptions about adolescents' utilisation of public prenatal services in Bulawayo, Zim babwe. Midwifery, 26(6), e16-e20. doi.org/10.1016/j.m idw.2009.01.001

Chandra-Mouli, V., Param eshwar, P. S., Parry, M., Lane, C., Hainsworth, G., Wong, S., ... \& Say, L. (2017). A neverbefore opportunity to strengthen investm ent and action on adolescent contraception, and what we $\mathrm{m}$ ust do to $\mathrm{m}$ ake full use ofit. Reproductive Health, 14(1), 85. doi.org/10.1186/s12978-017-0347-9

CHC - Com m unication for Healthy Com m unities. (2016). OBULAMU National Integrated Health Com m unication PlatformJune 2013 - June 2018.

Cooksey, E. C., Rindfuss, R. R., \& Guilkey, D. K. (1996). The initiation of adolescent 
sexual and contraceptive behavior during changing tim es.Journal of Health and Social Behavior, 59-74. doi.org/10.2307/2137231

Cortez, R., Saadat, S., Marinda, E., \& Odutolu, O. (2016). Adolescent Fertility and Sexual Health in Nigeria.

Creswell, J. W., Hanson, W. E., Clark Plano, V. L., \& Morales, A. (2007). Qualitative research designs: Selection and im plem entation The counselling psychologist, 35(2), 236-264. doi.org/10.1177/0011000006287390

Dart, J., \& Davies, R. (2003). A dialogical story-based evaluation tool: The m ost significant change technique. American Journal of Evaluation, 24(2), 137-155. doi.org/10.1177/109821400302400202

Davies, R., \& Dart, J. (2005). The 'm ost significant change'(MSC) technique. A guide to its use.

Denno, D. M., Hoopes, A. J., \& ChandraMouli, V. (2015). Effective strategies to provide adolescent sexual and reproductive health services and to increase dem and and com m unity suppør Journal of Adolescent Health, 56(1),S22-S41. doi.org/10.1016/j.jadohealth.2014.09.012

Dittus, P. J., \& Jaccard, J. (2000). Adolescents' perceptions of m aternal disapproval of sex: relationship to sexual outcom esl. Journal of Adolescent Health, 26(4), 268-278. doi.org/10.1016/S1054-139X (99)00096-8

DREAMS Core Package of Interventions Sum mary available at: https://www.pepfar.gov/docum ents/organization/269309.pdf

Eisenberg, M. E., Sieving, R. E., Bearinger, L. H., Swain, C., \& Resnick, M. D. (2006). Parents' com m unicationwith adolescents about sexual behavior: A $\mathrm{m}$ issed opportunity for prevention? Journal of Youth and Adolescence, 35(6), 893-902. doi.org/10.1007/s10964-006-9093-y

Etikan, I., Musa, S. A., \& Alkassim, R. S. (2016). Com parison of convenience sam pling and purposive sam plingAmerican Journal of Theoretical and Applied Statistics, 5(1), 1-4. doi.org/10.11648/j.ajtas.20160501.11

Farrokhi, F., \& Mahm oudiHam idabad, A. (2012). Rethinking convenience sam pling: Defining quality criteria. Theory and practice in language studies, 2(4), 784. doi.org/10.4304/tpls.2.4.784-792

Feldm an, S. S., \& A. Rosenthal, D. (2000). The effect of com munication characteristics on fam ily $\mathrm{m}$ em bers' perceptions of parentss sex educators. Journal of Research on Adolescence, 10(2), 119-150. doi.org/10.1207/SJRA1002_1

Golden, S. D., \& Earp, J. A. L. (2012). Social ecological approaches to individuals and their contexts: twenty years of health education \& behavior health prom otion interventions. Health Education \& Behavior, 39(3), 364-372. doi.org/10.1177/1090198111418634

Hadley, W., Brown, L. K., Lescano, C. M., Kell, H., Spalding, K., DiClem ente, R., ... \& Project STYLE Study Group. (2009). Parent-adolescent sexual com m unication: Associations of condom use with condom disssions. AIDS 
and Behavior, 13(5), 997-1004. doi.org/10.1007/s10461-008-9468-z

Hsieh, H. F., \& Shannon, S. E. (2005). Three approaches to qualitative content analysis. Qualitative Health Research, 15(9), 1277-1288. doi.org/10.1177/1049732305276687

Jaccard, J., Dodge, T., \& Dittus, P.(2002). Parent-adolescent com m unication about sex and birth control: A conceptual fram ework New Directions for Child and Adolescent Development, 2002(97), 9-42. doi.org/10.1002/cd.48

Jonas K, Crutzen R, van den Borne B, Reddy P. (2017). Healthcare workers' behaviors and personal determ inants associatedwith providing adequate sexual and reproductive healthcare services in sub-Saharan Africa: a system atic review BMC Pregnancy and Childbirth, 17(1), 86. doi.org/10.1186/s12884-017-1268$\mathrm{x}$

Jonas, K., Crutzen, R., Krum eich, A., Rom an, N., van den Borne, B., \& Reddy, P. (2018). Healthcare workers' beliefs, motivations and behaviours affecting adequate provision of sexual and reproductive healthcare services to adolescents in Cape Town, South Africa: a qualitative study. BMC Health Services Research, 18(1), 109. doi.org/10.1186/s12913-018-2917-0

Kaestle, C. E., Halpern, C. T., Miller, W. C., \& Ford, C. A. (2005). Young age at first sexual intercourse and sexually transm ittedinfections in adolescents and young adults. American Journal of Epidemiology, 161(8), 774-780. https://doi.org/10.1093/aje/kwi095

Kagim u, M., Guwatudde, D., Rwabukwali, C., Kaye, S., Walakira, Y., \& Ainom ugisha, D. (2013). Religiosityfor prom otionof behaviors likely to reduce new HIV infections in Uganda: A study am ong Muslim youth inWakiso district. Journal of Religion and Health, 52(4), 1211-1227. doi.org/10.1007/s10943-0119563-8

Kioli, F. N. (2017). An investigation into the socio-cultural and economic factors that influence pre-marital sexual behavior among adolescents: the case of Makadara division, Nairobi (Doctoral dissertation).

Landor, A., Sim ons, L. G., Sim ons, R. L., Brody, G. H., \& Gibbons, F. X. (2011). The role of religiosity in the relationship between parents, peers, and adolescent risky sexual behavior. Journal of Youth and Adolescence, 40(3), 296-309. doi.org/10.1007/s10964-010-9598-2

Langille, J. L. D., \& Rodgers, W. M. (2010). Exploring the influence of a social ecological model on schoolbased physical activity. Health Education \& Behavior, 37(6), 879-894. doi.org/10.1177/1090198110367877

Lefkowitz, E. S., Gillen, M. M., Shearer, C. L., \& Boone, T. L. (2004). Religiosity, sexual behaviors, and sexual attitudes during em erging adulthood.Journal of Sex Research, 41(2), 150-159. doi.org/10.1080/00224490409552223

Liu, A., Sullivan, S., Khan, M., Sachs, S., \& Singh, P. (2011). Com m unity dalth workers in global health: scale and scalability. Mount Sinai Journal of Medicine: A Journal of Translational and Personalized Medicine, 78(3), 419- 435. 
doi.org/10.1002/m sj.20260

Löfgren, J., Byam ugisha, J., Tillgren, P., \& Rubenson, B. (2009)The perspectives of in-school youths in Kam pala, Uganda, onthe role of parents in HIV prevention. African Journal of AIDS Research, 8(2), 193-200. doi.org/10.2989/AJAR.2009.8.2.7.859

Marston, C., \& King, E. (2006). Factors that shape young people's sexualbehaviour: a system atic review. The Lancet, 368(9547), 1581-1586. doi.org/10.1016/S0140-6736(06)69662-1

Maxwell, K. A. (2002). Friends: The role of peer influence across adolescent risk behaviors. Journal of Youth and Adolescence, 31(4), 267-277. doi.org/10.1023/A:1015493316865

McCree, D. H., Wingood, G. M., DiClem ente, R., Davies, S., \& Harrington, K. F. (2003). Religiosity and risky sexual behavior in African-Am erican adolescent fem ales. Journal of Adolescent Health, 33(1), 2-8. doi.org/10.1016/S1054139X (02)00460-3

Mckee, N., Manoncourt, E., Chin, S.Y. \& Carnegie, R. (2002). Chapter 12. Involving People, Evolving Behaviour: The UNICEF experience. In: SERVAES, J. (ed.), Approaches to Developm ent Com m unication, Paris: UNESCO.

Meschke, L. L., Bartholom ae, S., \& Zentall, S. R. (2002)Adolescent sexuality and parent-adolescent processes: Promoting healthy teen choices Journal of Adolescent Health, 31(6), 264-279. doi.org/10.1016/S1054-139X(02)00499-8

Mwai, G. W., Mburu, G., Torpey, K., Frost, P., Ford, N., \& Seeley, J. (2013). Role and outcom es of com $m$ unithealth workers in HIV care in sub-Saharan Africa: A system ati review. Journal of the International AIDS Society, 16(1). doi.org/10.7448/IAS.16.1.18586

Noy, C. (2008). Sam pling knowledge: The herm eneutics of snowball sam pling in qualitative research. International Journal of Social Research Methodology, 11(4), 327-344.

Odim egwu, C. (2005). Influence of religion on adolescent sexual attitudes and behaviour am ong Nigerian university students: affiliation or com $\mathrm{m}$ itm ent? African Journal of Reproductive Health, 125-140. doi.org/10.2307/3583469

Pick, S., \& Palos, P. A.(1995). Im pact of the fam ily on the sex lives of adolescents. Adolescence, 30(119), 667.

Radecki, C. M., \& Jaccard, J. (1995). Perceptions of knowledge, actual knowledge, and inform ation search behavior. Journal of Experimental Social Psychology, 31(2), 107-138. doi.org/10.1006/jesp.1995.1006

Rodgers, K. B. (1999). Parenting processes related to sexual risk-taking behaviors of adolescent males and fem ales.Journal of Marriage and the Family, 99-109. doi.org/10.2307/353886

Rostosky, S. S., Wilcox, B. L., Wright, M. L. C., \& Randall, B. A. (2004). The im pact of religiosity on adolescent sexual behavior: A review of the evidence. Journal of Adolescent Research, 19(6), 677-697. doi.org/10.1177/0743558403260019 
Sadler, G. R., Lee, H. C., Lim, R. S. H., \& Fullerøn, J. (2010). Recruitm ent of hard to-reach population subgroups via adaptations of the snowball sampling strategy. Nursing \& Health Sciences, 12(3), 369-374. doi.org/10.1111/j.14422018.2010.00541.x

Seale, C., \& Silverm an, D. (1997). Ensuring rigour in qualitative research.The European Journal of Public Health, 7(4), 379-384. doi.org/10.1093/eurpub/7.4.379

Singh, S., Bankole, A., \& Woog, V. (2005). Evaluating the need for sex education in developing countries: sexual behaviour, knowledge of preventing sexually transm itted infections/HIVand unplanned pregnancy. Sex education, 5(4), 307331. doi.org/10.1080/14681810500278089

SMGL. (2014). Saving Mothers Giving Life - Uganda, available at https://www.savingm othersgivinglife.org/docs/SMGL_Uganda_Backgrounder. pdf

Som ers, C. L., Tolia, S., \& Aagurthi, C. (2012). Parent-Adolescent relationships and adolescent sexual behavior: Patterns by adolescent gender. International Journal of Business and Social Science, 3(7).

Stokols, D. (1996). Translating social ecological theory into guidelines for comm unity health prom otion.American Journal of Health Promotion, 10(4), 282-298. doi.org/10.4278/0890-1171-10.4.282

Taffa, N., Haim anot, R., Desalegn, S., Tesfaye, A., \& Moham m ed, K. (2017). Do parents and young people com municate onsexual $\mathrm{m}$ atters. The Ethiopian Journal of Health Development (EJHD), 13(3).

Tilahun, M., Mengistie, B., Egata, G., \& Reda, A. A. (2012).Health workers' attitudes toward sexual and reproductive health services for unm arried adolescents in Ethiopia. Reproductive Health, 9(1), 19. doi.org/10.1186/1742-4755-9-19

Tong, A., Sainsbury, P., \& Craig, J. (2007). Consolidated criteria for reporting qualitative research (COREQ): a 32-item checklist for interviews and focus groups. International Journal for Quality in Health Care, 19(6), 349-357. doi.org/10.1093/intqhe/m zm 042

Uganda Bureau of Statistics (UBOS) and ICF International Inc. Uganda Dem ographic and Health Survey 2011. Kampala, Uganda UBOS and Calverton, Maryland: ICF International Inc. (2012).

Uganda Bureau of Statistics (UBOS) and ICF. (2018). Uganda Dem ographic and Health Survey 2016. Kam pala,Uganda and Rockville, Maryland, USA: UBOS and ICF.

Varga, C. A. (2003). How gender roles influence sexual and reproductive health am ong South African adolescents. Studies in Family Planning, 34(3), 160-172. doi.org/10.1111/j.1728-4465.2003.00160.x

Werner-Wilson, R. J., \& Fitzharris, J. L. (2001). How can $m$ others and fathers becom e involved in the sexuality education of adolescents? Journal of HIV/AIDS Prevention \& Education for Adolescents \& Children, 4(1), 49-59. 
doi.org/10.1300/J129v04n01_05

Whitaker, D. J., \& Miller, K. S. (2000). Parentadolescent discussions about sex and condom s: Impact on peer influences of sexual risk behavior. Journal of Adolescent research, 15(2), 251-273.

Whitbeck, L. B., Conger, R. D., \& Kao, M. Y. (1993). The influence of parentl support, depressed affect, and peers on the sexual behaviors of adolescent girls. Journal of Family Issues, 14(2), 261-278.

William son, N.- UNFPA (2014). State of the World Population 2013. Motherhood in Childhood: Facing the Challenge of Adolescent Pregnancy. New York: United Nations Population Fund.

Witm er, A., Seifer, S. D., Finocchio, L., Leslie, J., \& O'neil, E. H. (1995)Com m unity health workers: integral $\mathrm{mem}$ bersof the health care work force. American Journal of Public Health, 85(8_Pt_1), 1055-1058. doi.org/10.2105/AJPH.85.8_Pt_1.1055

Zam awe F. C. (2015). The im plication of using NVivo software in qualitative data analysis: Evidence-based reflections. Malawi Medical Journal, 27(1), 13-15. doi.org/10.4314/m m j.v27i1.4 



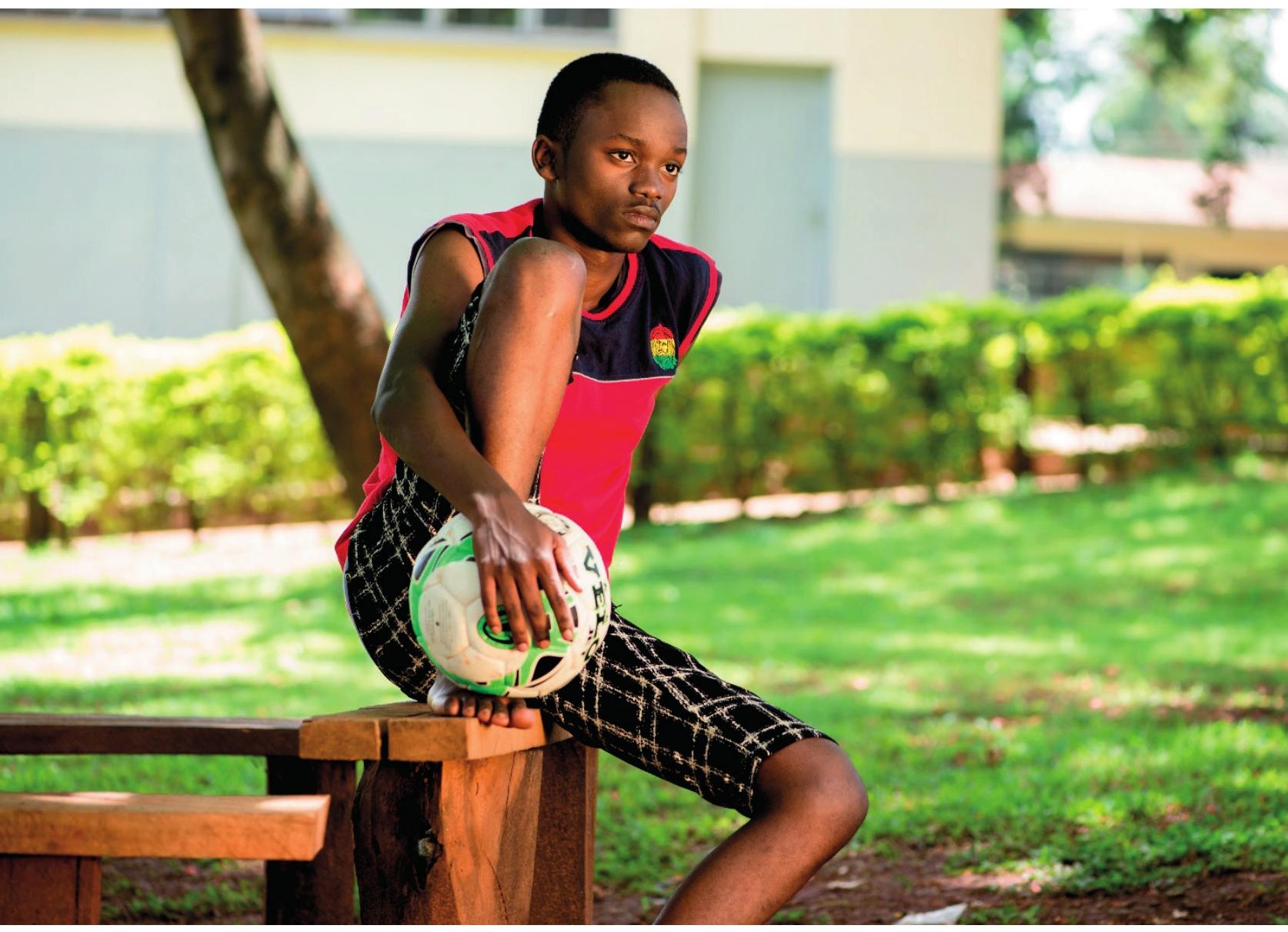




\section{Chapter 5}

\section{Application of core processes for understanding m ultiple concurrent sexual partnerships am ong adolescentsin \\ Uganda}

\section{Published as:}

Nalukwago, J., Alaii, J., Van Den Borne, B., Bukuluki, P. M., \& Crutzen, R. (2018). Application of core processes for understanding multiple concurrent sexual partnerships am ong adolescents in Uganda.Frontiers in Public Health, 6, 371. 


\begin{abstract}
Introduction: Adolescents in Uganda, as in other sub-Saharan countries, engage in sex with multiple concurrent partners, thus placing them at risk for HIV and unplanned pregnancies, but it is not clear why. This study explored why adolescents in Uganda engage in multiple concurrent sexual partnerships (MCSP).
\end{abstract}

Methods: This study used a Core Processes m ethodology. We used the processes of brainstorm ing, and identification of evidence and theoretical support, in various phases/steps of intervention planning, to provide possible explanations for adolescent MCSP.

Results: Adolescents were found to have lim ited knowledge of the risks associated with MCSP and perceived low risk for HIV. Peer influence to engage in MCSP exacerbated the problem am ong adolescents. Poor com munication with sexual partners and parents and societal indifference to multiple sexual partnerships increased perm issive attitudestowards infidelity. The unclear adolescent sexual and reproductive health policies ham pered access to services, and transactional sexual relationships with older (polygam ous) sexud partners increased the HIV risk. Adolescents were found to be $\mathrm{m}$ ore concerned about unplanned pregnancies than HIV risk.

Discussion: From the em pirical evidence, adolescent health program s in Uganda should incorporate com prehensive sexual health education on HIV and teenage pregnancy risk-reduction strategies. Programs should strengthen parental and com $\mathrm{m}$ unity support through enhanced collaborative training on om $\mathrm{m}$ unication with and for adolescents. Form ing strategic partnerships with various stakeholders for concerted efforts to address the MCSP problem am ong adolescents is critical.

K eywords Adolescents, Multiple Concurrent Sexual Partnerships, Determ inants, Core Processes, Intervention Mapping 


\section{Introduction}

Multiple sexual partnering is on the rise am ong adolescents aged 15-19 in Uganda. National surveys show that in 2016, 2.2\% of adolescent fem ales and $6.6 \%$ of $\mathrm{m}$ ales reported having two or $\mathrm{m}$ ore sexualpartners in the past $12 \mathrm{~m}$ onths com pared to 2011 (1.5\% for fem ales and 5.4\% for m ales) (UBOS, 2018; UBOS, 2018. Moreover, adolescents often have sexual partnerships that overlap for $\mathrm{m}$ onths or years (Santelli et al., 2013; Harrison et al., 2008; Lurie \& Rosenthal, 2010). These sexual partnerships are labeled as m ultiple concurrent sexual parnerships (MCSP). MCSP is associated with a heightened risk of sexually transm itted diseases (STDs), particularly HIV/AIDS (Rosenberg et al., 1999; Epstein \& Morris, 2011; Mah \& Halperin, 2010, Howard \& Wang, 2004). It is not yet clear why adolescents in Uganda engage in MCSP, which can also lead to health problem s of unplanned pregnancies and ultim ately a decreased quality of life. Most adolescent sexual behavior studiesin Uganda have focused on HIV prevention in light of condom use, and include lim ited explanations for MCSP. This study used Core Processes including brainstorm ing and the identification of em pirical evidence and theoretical support to explore persistent MCSP am ong adolescents in Uganda.

MCSP is defined in this study as an overlap of sexual partners in a given tim e period, with two or m ore sim ultaneous sexual partnerships. Adolescents who engage in MCSP increase the risk of acquiring and subsequently exposing partners in their sexual network to HIV (Rosenberg et al., 1999; Shelton et al., 2004; Pilgrim et al., 2015; Sawers \& Stillwaggon, 2010; Morris \& Kretzschm ar, 1997). Many individuals infected with HIV in sub-Saharan Africa have been found to be $m$ en and wom en in stable partnerships, although som e have becom e infected during MCSP within their stable relationship or their partner's engagem ent in MCSP (Cox et al., 2014). Thus, in order to design targeted adolescent health program s in Uganda, it is imperative to determ ine why there are persistent MCSP among adolescents. Identifying determinants for this behavior requires investigating individual, com $m$ unity and environm ental factorsßartholom ew et al., 2016).

This study used a Core Processes m ethodologyto explore why adolescents in Uganda engage in MCSP. Core Processes are a system atic way toanswer questions raised in various phases/steps of planning fram eworks for program developm ent (e.g., "Why do people in the priority population carry out the (risk) behavior?") (Bartholom ew et al., 2016). Identification and form ulations of these core processes originated from Veen (1984) and Lave and March (1993) and were further developed by Buunk and Veen (1995), Kok et al. (1996), Buunk and Van Vugt (2008), Buunk and Van Vugt (2013), Bartholom ew et al. (2001), Bartholom ew et al. (2006) Bartholom ew et al. (2011), and Bartholom ew et al. 2016). Although Core Processes are described in Intervention Mapping (Bartholom ew et al., 2016), they can be 
applied to any planning fram ework. So, Core Processes do not form a planning fram ework on their own, but rather operate as a system atic approach to address questions relevant to problem definition and solutions.

\section{Methods}

\section{The Core Processes methodology}

This study used the Core Processes m ethodology described in Intervention Mapping (Bartholom ew et al, 2016) to explore MCSP am ong adolescents in Uganda. The methodology provides a system atic way to answer questions raised in distinct phases/steps of planning fram eworks. The steps described in the m ethodology are crucial to answer questions in such a way that the chances of adequately addressing the problem with new research at hand are optim ized (Ruiter, Crutzen \& Kok, 2018). Using Core Processes $\mathrm{m}$ inimizes the likelihood of achieving a incomplete understanding and thus selecting ineffective solutions because the processes use available evidence before engaging in new research. The Core Processes involve six steps: 1) posing the problem question, 2) brainstorm ing for possible answers, 3 reviewing em pirical literature related to the problem, 4) identifying theoretical support based on the topic, concepts, and general theoretical approaches, 5) identifying and addressing new needs for research on the problem, and 6) proposing answers to the problem. The order of steps in the Core Processes is crucial; brainstorm ing (step 2) utilizes theoretical and em pirical knowledge arilable within the planning group that can later be com bined with em pirical findings (step 3) and theoretical support (step 4). As a result of com pleting the steps, the planners assem ble a set of potential answers to the problem from both the theoretical and the em pirical literature that fit with, suggest changes for, or add to provisional explanations. The six steps of the Core Processes used in the current study are detailed below.

\section{Posed the question of adolescents engaging in MCSP}

In the introduction, we noted why engaging in MCSP is a health risk. The point of departure of the study was the question "Why do adolescents in Uganda engage in MCSP?"

\section{Brainstorming on possible explanations for adolescent MCSP}

In 2017, brainstorm ing sessions to identify possible determ inants and factors explaining why adolescents engage in MCSP were held with various stakeholders and experts in Uganda. Studies argue that brainstorm ing is an intervention in which 
individuals and groups adhere to a set of rules while working in sessions designated to generate ideas (Litchfield, 2008). Brainstorm ing is conducted to 1) generate as $\mathrm{m}$ any ideas aspossible, 2) avoid criticism of proposed ideas, 3 ) attem pt to com bine and im prove previously articulated ideas, and 4) encourage generation of "wild" ideas, and 5) record all ideas for future consideration (Litchfield, 2008; Kram er, Kuo \& Dailey, 1997). A discussion guide is used to clarify the question flow and the em phasis placed on each question (Litchfield, 2008; Kram er, Kuo \& Dailey, 1997). Brainstorm ing allows people with m ultiple areas of expertise to com e together as a whole greater than the sum ofthe individual parts (Boddy, 2012).

The brainstorm ing sessions for this study were conducted during quarterly montoring activities undertaken by Com munication for Healthy Com m unities (CHC), a social and behavior change com $m$ unication program funded by thited States Agency for International Developm ent and im plem ented by Fam ily Health International 360 (FHI 360) (CHC, 2016). To focus the brainstorm ing sessions on topics related to adolescent sexual behaviors and sexual and reproductive health (SRH) needs, a discussion guide was developed based on the study objectives. The questions in the discussion guide focused on underscoring adolescent sexual behaviors (with specific reference to MCSP) and the risks associated with the behaviors, existence, and appropriateness of SRH services for adolescents and inform ation sources in the com m unity, the environm ental (household,om m unity, structural, or health system ) determ inants perceived to affect adolescents' ability to take up health services and healthy behaviors, and recom m ended strategies for addressing adolescent SRH needs and prom oting healthy behaviors. The same questions were asked in each session for consistency in generating a pool of explanations for why adolescents engage in MCSP.

First, separate brainstorming sessions were held with adolescents, com $m$ unity leaders (religious leaders, com m unity health workers, and local council leaders), and experts from the Ministry of Health in Uganda. Based on the outcom e of those sessions, brainstorm ing sessions were held with additional experts including behavioral scientists, health prom otion practitioners, sociologists, and m aitoringand-evaluation experts to draw on their practical experience in addressing adolescent health issues in various contexts in Uganda. The additional experts who participated in the brainstorm ing sessions were selected based on their knowledge of Uganda, expertise working with adolescents, and experience in designing and im plem enting adolescent health prom otion program s. In total, five bainstorm ing sessions were conducted: two with adolescents, two with community leaders, and one with additional experts. Each session had between 8-12 participants, and lasted an average of one hour. Studies indicate that attem pts to understand the process of behavior change or to develop an intervention should consider all levels of influence and related variables from individual to structural (Kaufm an et al., 2014; Kok et al., 2016). Therefore, based on the Social Ecological Model, the brainstorm ing sessions put particular em phasis on identifying and classifying behavioral determ inants and 
factors reflected at $\mathrm{m}$ ultiplelevels of influence (Kaufm an et al., 2014; McKee et al., 2002; Golden \& Earp, 2012) including individual, interpersonal, com m unity, institutional, and structural factors (Figure 1). The adolescents and com munity leaders were mobilized through com $m$ unity hdah workers who work with CHC. Sixteen adolescents (eight girls and eight boys), 15 com m unity leaders (eight fem ale and seven $\mathrm{m}$ ale), and eight experts (three fem ale and five $\mathrm{m}$ ale) participated in the brainstorm ing sessions. To ensure full participation, the sessions for $\mathrm{m}$ ale and fem ale participants were conducted separately. Prelim inary answers/explanations on the problem identified during the brainstorm ing session were written down to guide an extensive literature review on why adolescents engage in MCSP.

\subsection{Participants' informed consent}

Verbal informed consent was sought from each study participant prior to brainstorm ing sessions. Ethical approval and a waiver of written consent was obtained from the United States of Am erica's federally registered instiutional review board of FHI 360, the Protection of Hum an Subjects Com m ittee, under reference 939934, and in Uganda by the governm entaccredited Makerere School of Public Health Research Ethics Committee under reference 446. Verbal consent was preferred to $\mathrm{m}$ inim ize the risk of a loss of anonym ity because signed inform ed consents would have been a link to the participants' identity in this study. The consenting process was conducted in both English and a local language that participants understood. The purpose of the study was explained, and participants were given tim e to ask questions before voluntarily agreeing to participate in the study. Verbal inform ed consent was docum ented by recording the date and tim e when the consent was sought and the signature of the study staff $\mathrm{m}$ em ber who obtained consent.

\section{Reviewed empirical literature on adolescent MCSP}

Insights from the brainstorm ing sessionsinform ed an extensive literature search and review on adolescent MCSP. The literature review included a search of $\mathrm{m}$ ultiple electronic databases including Google Scholar, Cochrane central (via Cochrane library), Wolters Kluwer (via Ovid), PubMed, Em erald, and PsychINFO (via EBSCOhost) to retrieve em pirical studies on MCSP. The specific search term s used were multiple sexual partnerships, concurrent partnerships, multiple concurrent partnerships, factors, determ inants, correlates, gender, and predictors associated with MCSP. The search specifically focused on but was not limited to, studies of adolescents. Only studies that highlighted aspects of $\mathrm{m}$ ultiple sexual partnerships and MCSP am ong adolescents and those that compared adolescent MCSP with adult MCSP were considered. The extensive review of existing literature on MCSP am ong 
adolescents focused on learning what is known worldwide including sub-Saharan Africa, East Africa, and Uganda. The researchers identified issues of $\mathrm{m}$ issing links or what was not known or not clear in the literature about adolescent MCSP. The literature search ranged from 19902018, and approxim ately 120 studies were identified. However, we used 98 studies found to be related to the current study. Studies were selected based on the inclusion criteria of highlighting adolescent MCSP and factors associated with MCSP. We excluded those that explored sexual behaviors other than MCSP am ong adolescents. Findings from this review are presented in Figure 1 and Table 3.

\section{Identified theoretical support}

Theoretical support for the study was identified using three $\mathrm{m}$ ain approaches: topic, concept, and general theories (Bartholom ew et al., 2016). The topic approach involved a review of theoretical constructs used in the design of other em pirical studies on MCSP included in the literature review. Most of the included em pirical studies used theories to provide potential explanations for MCSP. The identified theories were used as the first step to select theoretical support for the present study.

The concepts approach involved scrutiny of ideas generated during the brainstorm ing sessions and grouping them by aspects of sim ilarity. For precision, related ideas from the brainstorm ing sessions and em pirical literatue were renam ed using theoretical labels.

The general theories approach involved exploring a vast array of theories that $\mathrm{m}$ ight offer detailed explanations and answers to the problem of adolescent MCSP. The study researchers further explored alternative theoretical fram eworks including behavioral, community and environm ental theories that had not been assessed through the topic and concept approaches.

\section{Identified and addressed new needs for research on adolescent MCSP}

From the selected em pirical literature, the $\mathrm{m}$ issing links or what is not yeltnown and rem ains unclear about adolescent MCSP were identified. Specific research questions for further exploration in Uganda were form ulated based on the literature review results.

\section{Proposed answers to reducing the problem of adolescent MCSP}

Using findings from the brainstorm ing sessions, literature review, and exploration of theoretical support, the researchers listed possible explanations as to why adolescents 
in Uganda engage in MCSP. These explanations will inform future adolescent health programming to decrease the MCSP behavior. The frequently listed possible explanations of the problem were ranked by order of im portance and changeability. Im portance refers to the determ inants that significantly contributeto the behavior, and changeability refers to determ inants that can be changed with available m ethods (Bartholom ew et al., 2016). The ranking procedure was adapted from Bartholom ew et al. (2016) as $0=$ less im portant, $+=$ im portant, and $++=$ very im portant and $0=$ hard to change, $+=\mathrm{m}$ ay be changed, $++=\mathrm{it}$ is changeable. The explanations/answers that appeared in all three theoretical support approaches (topic, concept, and general theories) and suggested practicable interventions to address the problem were ranked with high importance and changeability. Ranking of the possible explanations/answers helped to prioritize determ inants and factors for adolescent MCSP to guide targeted adolescent health program s.

It was im portant that the designplanning group for the program com pleted the previously described steps of the core processes instead of jum ping straight into research. Conducting new research requires resources including tim e, expertise and m oney. All available evidence and insight should be used before conducting new research to guide program design. The order of steps following the problem identification (step 1) is crucial: brainstorming (step 2) ensures utilizing the theoretical and em pirical knowledge that is available within the planning group, which can later be com bined with em piricalfindings (step 3) and identification of theoretical support (step 4). Taking these steps should improve new research strategies.

\section{Results}

\section{Findings from brainstorming sessions with stakeholders in Uganda (step 2 of core processes)}

Group brainstorm ing sessions with adolescents indicated that adolescents in Uganda engage in MCSP because of peer pressure, and a lack of basic needs drives them to engage in multiple transactional sexual relationships for money. Although som e adolescents suggested that engaging in MCSP was a way of exploring life, others noted that it was m orally not okay to have $m$ ultiple concurrent sexual partnersSom e adolescents alleged that occasionally parents encourage them to engage in transactional sex and early marriages to older sexual partners who $\mathrm{m}$ ay be polygam ous, which increases their risk for HIV. However, parent-adolescent com $m$ unication gapsm ake adolescents fearful of talking openly about sex(Table 1). 
Com $m$ unity leaders and policym akers from the Ministry of Health indicated parents' laxity and lack of discipline for their children, and fading com m unity support for disciplining children all contribute to the problem of adolescent MCSP. They further alluded to poor fam ily backgrounds that create an inappropriate environm ent for adolescent sexual behavior. For instance, som e parents were cited to be setting a bad exam ple by dressing in a m anner considered to be indecent, while dom estic violence reportedly drove adolescents away from hom es. Parentadolescent com $\mathrm{m}$ unication was $\mathrm{m}$ entiœn as lacking in hom es, and inadequate governm ent policies for prohibiting early $m$ arriages to lim it adolescent sexual activities. Away from hom e, som e churches were nted to expose adolescents to sexual risks during unchaperoned activities such as night prayers and concerts.

Brainstorm ing sessions were also held with additional experts, including behavioral scientists, health prom otion practitioners, sociologists, and m onitoring and evaluation specialists. Findings from these sessions indicated that individuals' attitudes and beliefs about $\mathrm{m}$ asculinity, such as "it is okay for a $\mathrm{m}$ an to have $\mathrm{m}$ any sexual partners", encourage $m$ ale adolescents to engage in MCSP. Male adolescents often believe that it is good to experim ent with m any sexual partners because they see it as a sign of braveness, and "being a $\mathrm{m}$ an". The experts further noted that adolescents lacked the confidence to com $m$ it to only one sexual partner. In this sense, self-confidence is often affected by other factors including an individual's environm ent(e.g., difficult fam ily situation) andthe need for m eans of survival (e.g., extrem e poverty). They noted that adolescents and their parents do not often perceive or they may not be aware of the risks of engaging in MCSP. Poverty was also indicated as a factor that $\mathrm{m}$ akes adolescents engage in transactional sex, including MCSP. Lim ited and inconsistent use of condom s am ong adolescents was highlighted as a challenge in $\mathrm{m}$ utiple sexual relationships. Table 1 sum $\mathrm{m}$ arizes the findings from the brainstorm ing sessions with stakeholders. 
Table 1: A summary of findings from brainstorming sessions on MCSP with stakeholders

\begin{tabular}{|c|c|}
\hline Stakeholder category & Main issues raised from the brainstorming sessions \\
\hline Adolescents & $\begin{array}{ll}\text { - } & \text { Peer pressure } \\
\text { - } & \text { Transactional sex } \\
\text { - } & \text { Exploring life } \\
\text { - } & \text { Morally not okay to have m ultiple concurrent sexual partners } \\
\text { - } & \text { Poor parent-adolescent com m unication } \\
\end{array}$ \\
\hline $\begin{array}{l}\text { Com } m \text { unity leaders and } \\
\text { policym akers }\end{array}$ & 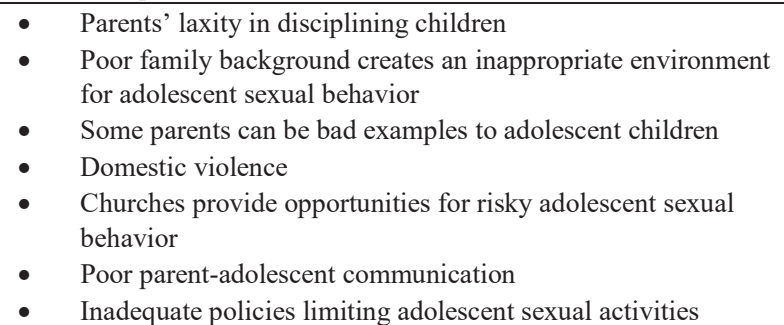 \\
\hline $\begin{array}{l}\text { Other experts in additional } \\
\text { fields (behavioral } \\
\text { scientists, health prom otion } \\
\text { practitioners, sociologists) }\end{array}$ & $\begin{array}{l}\text { - The belief that is okay to have } \mathrm{m} \text { any partners } \\
\text { - } \\
\text { - } \\
\text { MColescents believe it is good to experim ent with MCSP } \\
\text { - } \mathrm{m} \text { an } \\
\text { - } \quad \text { Pdolescents and parents do not see the risk of MCSP } \\
\text { - } \quad \text { Lim ited and inconsistent use of condoms in MCSP }\end{array}$ \\
\hline
\end{tabular}

Note. MCSP $=$ Multiple Concurrent Sexual Partnerships

\section{Findings from the review of empirical literature (step 3 of core processes)}

To synthesize em pircal literature findings on adolescent MCSP, the $m$ ain determ inants and levels of influence were categorized using the Social Ecological Model (Kaufm an et al.,2014; McKee et al., 2002; Golden \& Earp, 2012) as indicated in Figure 1. The findings indicate that adolescents often report having two or $\mathrm{m}$ ore sexual partners, and boys are $\mathrm{m}$ ore likely to have concurrent sexual partners than girls (UBOS, 2018; UBOS, 2012; Catania et al., 1989). Individual determ inants drawn from the literature indicate that adolescents perceive they have a low risk and susceptibility to HIV (Catania et al., 1989; Durbin et al., 1993). Others engage in MCSP with the belief that they already carry $\operatorname{HIV/AIDS}(30,31)$. Studies found that condom s are used less consistently in relationships with MCSP, which increases the risk of HIV spreading to the adolescent's sexual network (Harrison et al., 2008; Pulerwitz et al., 2010; MacPhail \& Cam pbell, 2001; Maharaj \& Cleland, 2004; Rom er et al., 1994). In addition, condom s were used less consistentlywith steady or regular sexual partners than with casual sexual partners (Harrison et al., 2008; Maharaj \& Cleland, 2004; Rom er et al., 1994). Adolescent girls who perceive to be 
in "serious" relationships are socially pressured to trust their partners, which constrains their ability to negotiate safe sex and results in the non-use of condom s (Harrison et al., 2008; Cox et al., 2014; MacPhail \& Cam pbell2001; Sm ith 2004; Sam uelsen 2006; Dolcini et al., 1995; Vasilenko SA, Lanza, 2014; Pulerwitz, Gortm ake \& DeJong, 2000). Although adolescents were found to be aware of the risks associated with MCSP, they continue to engage in these relationships (Durbin et al., 1993). Adolescent girls were found to be m ore concerned about unplanned pregnancy than HIV risk (Catania et al., 1989). Adolescents were also found to engage in transactional sexual relationships with older $m$ en and wom en for $m$ aterial gain or m oney, and the belief that relationships with these partners are stable Neem a, Musisi \& Kibom bo, 2004; KondeLule et al., 1997; Bantebya, Muhanguzi \& Watson, 2014; Nyanzi, Pool \& Kinsm an, 2001; Kelly et al., 203; Nobelius et al., 2010; LeClerc-Madlala, 2009). This is an indication that adolescents $\mathrm{m}$ ay have inadequate knowledge of the consequences of MCSP.

Poor com m unication with the prim ary sexual partner intersects between individual and interpersonal determinants. Studies indicated that poor sexual com $m$ unication with the prim ary sexual partner $m$ ight lead to seeking additional or other sexual partners (Catania et al., 1989; Durbin et al., 1993). Adolescents who engage in MCSP with older sexual partners often experience gender power im balances that lim it their power to negotiate for safe sex practices and $m$ ay feel uncom fortable talking to their sexual partner abait sex, and MCSP in general (LeClerc-Madlala, 2009; Nobelius et al., 2010; Jewkes \& Morrell, 2010; Teitelm an et al., 2016). Girls have been found to take a m ore passive role in initiating the use of condom ssince they believed that boys/m en need $\mathrm{m}$ ore sexhtan girls/wom en (Nyanzi, Pool \& Kinsm an, 2001. Furtherm ore, studies report that concurrent relationships with gender power im balances can be characterized by physical intim ate partner violence (Neem a, Musisi \& Kibom bo, 2004; Teitelm an et al., 2016; Fulu et al., 201.7 However, knowledge gaps on issues of sexuality and MCSP and poor com m unication skills of key influencers such as sexual partners, parents, and peers were found to lim it open discussion of sexuality, thereby precipitating MCSP am ong adolescent. Parents were found to have difficulty in finding the right place and time to com $m$ unicate with their children about sexuality. This is because parents often feel inadequately informed, embarrassed and uncom fortable discussing topics of sexuality (Bastien, Kajula \& Muhwezi, 2011; Feldm an \& Rosenthal, 2000; Jaccard, Dodge \& Dittus 2002; Taffa et al., 2017).

Adolescents were found to engage in MCSP because they believed that peers already had m ultiple sexual partners (Catania et al., 1989; Durbin et al, 1993). This is an indication that the social environm ent of adolescents ought to be critically scrutinized to underscore com m unitydriven factors that encourage MCSP. Studies indicate significant societal approval of MCSP, especially for boys $/ \mathrm{m}$ en. Societal 
norm s value sexual ignorance for girls while overlooking MCSP and sexual risk taking for boys, both of which contribute to the problem (Teitelm an et al., 2016; Jaccard, Dodge \& Dittus, 2002; Ehrhardt et al., 2009; Hardee et al., 2014). A m an's infidelity is com m only accepted and is often viewed as som ething inevitable that a wom an m ust sim ply expect and learn to tolerate L(eClerc-Madlala, 2009; Joshi, 2010). With this societal approval, adolescent boys were found to have more perm issive attitudes towards infidelity than girls (Dolcini et al., 1999; Konde-Lule et al., 1997; LeClerc-Madlala, 2009; Jewkes \& Morrell, 2010). Older m en and wom en were found to advance transactional sexual relationships with adolescent girls and boys with the belief that adolescents are still "safe" from infection (Neem a, Musisi \& Kibom bo, 2004). Similarly, early $m$ arriages to older $m$ en for $m$ aterial gain (precipitated by som e parents and adolescent girls), increase the girls' risk for HIV and teenage pregnancy because of their inadequate reproductive health education and subordinate position when negotiating safe sex with adult sexual partners (Neem a, Musisi \& Kibom bo, 2004Bantebya, Muhanguzi \& Watson, 2014). However, studies have also found that previously m arried adolescent girls ae more likely to have m ultiple sexual partnerships com pared to $\mathrm{m}$ arried or never $\mathrm{m}$ arried counterparts (Santelli et al., 2013). Com m unity beliefs about the nature of m en's strong sexual desires and needs create an oblique view of having concurrent sexual partners for boys, which is often seen as a sign of m asculinity (Pulerwitz et al., 2010; Bantebya, Muhanguzi \& Watson, 2014; LeClercMadlala, 2009; Varga, 1997; Varga, 2003). Cultural and religious beliefs that encourage having $m$ ore than one wife are perceived to prom ote MCSP (Jewkes \& Morrell, 2010; Mavhu et al., 201).

Beyond the social and cultural factors, there are institutional or health system factors that facilitate MCSP am ong adolescents and should not be overlooked. Studies indicate that health worker attitudes and inadequate com $\mathrm{m}$ unication skills for reaching adolescents discourage adolescents from seeking inform ation and services related to sexuality and MCSP (Neema, Musisi \& Kibom bo,2004; Bantebya, Muhanguzi \& Watson, 2014). Coupled with this is the inadequate availability of medical supplies in health facilities and inadequate quality of adolescent SRH services provided in Africa (Bantebya, Muhanguzi \& Watson, 2014). Structural barriers also aggravate the challenge of adolescent access to SRH services. Distances to health facilities, poor quality of health services, and the cost of SRH services discourage adolescents from seeking health care services and inform ation related to MCSP (Kaufm an et al., 2014; Bantebya, Muhanguzi \& Watson, 2014; Kajubi eal., 2011). The unfavorable policies on adolescent access to SRH services and lim ited gender equity laws constrain adolescents' access to services and increase gender power im balances (Kaufm an et al., 2014; Bantebya, Muhanguzi \& Watson, 2014. Figure 1 sum marizes the $\mathrm{m}$ ain findings identified in the em pirical literature on MCSP am ong adolescents. 


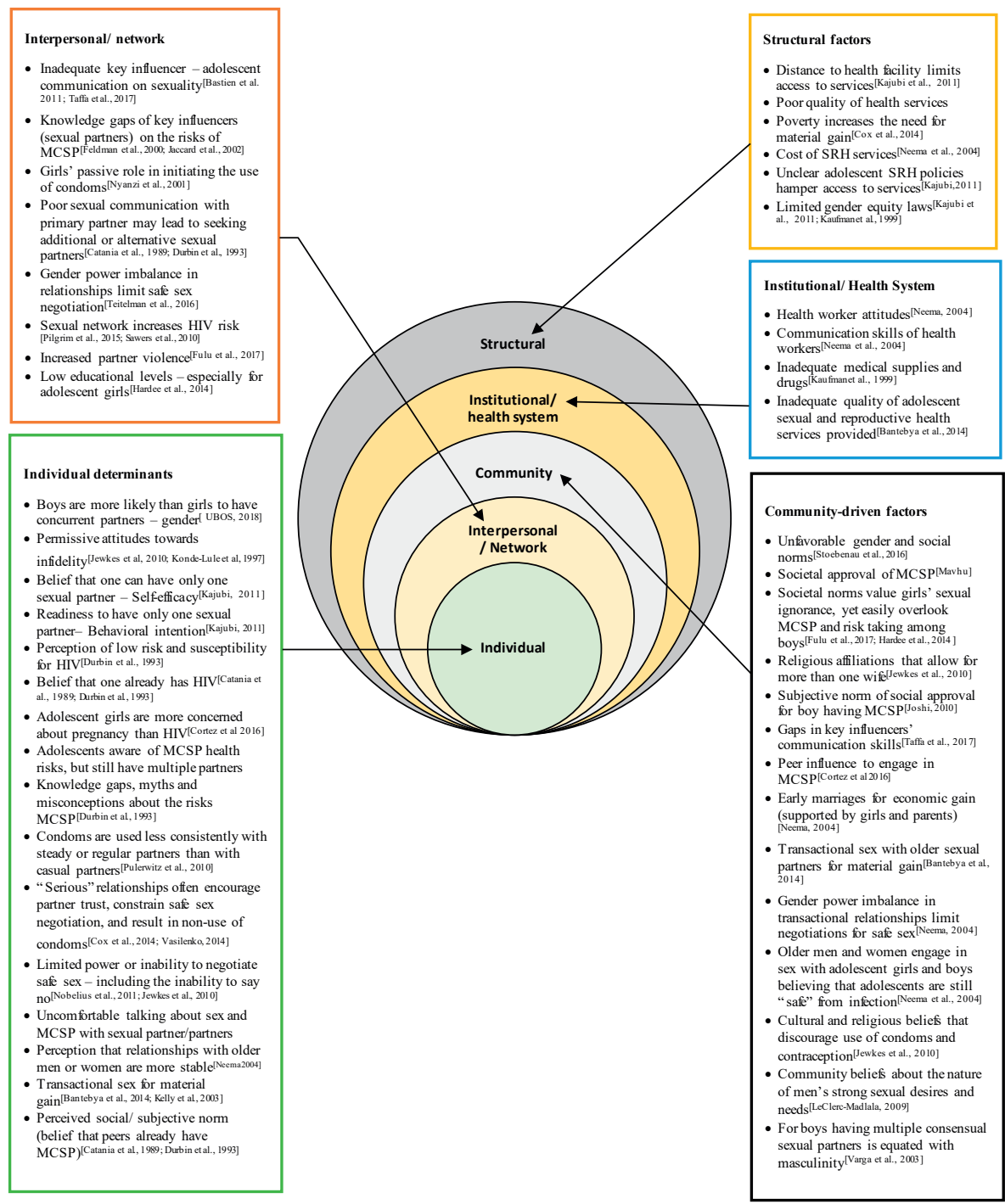

(MCSP = Multiple Concurrent Sexual Partnerships; SRH = sexual and reproductive health)

Figure 1: Determinants of multiple sexual partnerships among adolescents at all levels of the Social Ecological Model based on literature findings.

Source: Depiction of Social-Ecological Model adapted from Mckee et al.,(2002) and Kaufm an et al. (2014) 


\section{Theoretical support for the determinants of adolescent MCSP (step 4 of core processes)}

Supportive theoretical constructs were reviewed to generate possible answers to what is known about the problem of MCSP am ong adolescents. Using the topic approach, theoretical constructs from em piricalstudies were identified and reviewed in the current study. Six theories identified from other studies included: Theories of Reasoned Action and Planned Behavior (Albarracin et al., 2001; Fishbein \& Ajzen, 2011; Fishbein, 2007; DiClem ente, Crosby \& Kegler, 2009, Health Belief Model (Rosenstock, 1974; Janz \& Becker, 1984), Social Cognitive Theory (Bartholom ew et al., 2016; Bandura, 1989; Bandura, 2009), Social Exchange Theory (Cox et al., 2014), Social Ecological Model (Kaufm an et al., 2014; McKee et al., 2002; Golden \& Earp, 2012), and Social Norm s Theory (Berkowitz, 2003; Berkowitz, 2004; Lapinski \& Rim al, 2005; Oum et al., 2016). In the concept form ation approach, the ideas generated from the brainstorm ing session and em pirical literature were grouped and relabeled using these six theories. Labels such as attitude, perceived susceptibility beliefs, self-efficacy, and social/subjective norms were drawn from the aforem entioned theories.

Using the general theories approach, we reviewed theories that offered detailed explanations and provided potential answers to the problem of MCSP am ong adolescents to gain additional insights for explaining the problem. We explored alternative theoretical fram eworks that were not identified at the topic and concept approach steps but deem ed relevant for the MCSP problem. Two alternative theoretical frameworks explored included the SelfRegulation Theory and the Extended Parallel Process Model. To better understand and group sim ilar theoretical constructs in this study, all eight theories identified for review were classified into three categories: 1) individual, 2) com m unity, and 3) environm ental theories. Individual-level theories included Theories of Reasoned Action and Planned Behavior, Health Belief Model, Social Cognitive Theory, Extended Parallel Process Model, and the Self-Regulation Theory. Com m unitylevel theories included The Social Norm s Theory and the Social Exchange Theory. Environm entallevel theories only included The Social Ecological Model. To avoid replication, our review did not include theories that advanced constructs already known and identified in the brainstorm ing sessions and em pirical literature. Only theories that highlighted new and additional insight into the problem of MCSP (four in total) were reviewed and docum ented for application to this study (Table 2). 


\section{Individual-level theories}

Theoretical support on an individual level for the Extended Parallel Process Model indicates that peoples' perceptions of a threat often draw them to action. The m odel proposes the use of risk messaging to elicit fear and stimulate danger control responses (Popova, 2012; Witte, 1992; Witte 1994; McMahan, Witte, Meyer, 1998; Gore \& Bracken, 2005; Maloney, Lapinski \& Witte, 2011. However, to be effective, risk $\mathrm{m}$ essages $\mathrm{m}$ ust contain both a threat com ponent that creates a perception of personal susceptibility and severity and an efficacy component that provides inform ation about $m$ easures toem ploy in reducing the threat (Witte, 1992; Witte 1994; Peters, Ruiter \& Kok, 2013). Many interventions that attem pted to use a risk$\mathrm{m}$ essaging approach were found to be unsuccessful because they tended to focus on the fear com ponent and leave out efficacy(Peters, Ruiter \& Kok, 2013). Thus, they failed to $m$ eet the requirem ents as specified within the model. This modehelps explain and contextualize the perception of low-risk and susceptibility to HIV am ong adolescents in Uganda.

The Self-Regulation Theory postulates that self-regulation refers to selfgenerated thoughts, feelings, and actions that are planned and cyclically adapted to the attainm ent of personal goals (Boekaerts, 1999; Boekaerts, Pintrich \& Zeidner, 2000; Baum eister \& Vohs, 2004. The theory delineates aspects of self-m otivation to perform a behavior such as selfefficacy, goal setting, self-judgm ent, and selfevaluation. These self-m otivated actions $\mathrm{m}$ ay be critical in further understanding sexually active adolescents' low level of self-efficacy and m otivations for having MCSP. It is im portant to note that m otivation m ight not be driven only by the self, but also driven by other factors within one's environm ent that $\mathrm{m}$ ay influence a decision to engage in the behavior.

\section{Community-level theories}

The com m unitylevel Social Norms Theory describes the situation in which individuals incorrectly perceive the attitudes and/or behaviors of peers and com $m$ unity $m$ em bers to be different from or sim ilar to their owBerrkowitz, 2003; Berkowitz, 2004; Lapinski \& Rimal, 2005). The theory proposes that presenting com m unally accepted norm s- such as prom oting gender equity and discouraging early $m$ arriages - that exist in support of existing policies are pertinent. This im plies that to understand the problem of MCSP am ong adolescents, we need to know the policy environm ent in which com $\mathrm{m}$ unally accepted norm $\mathrm{s}$ for behavior changare found.

The Social Exchange Theory advances actions that are contingent on rewarding reactions from others (Em erson, 1976). The theory m ainly positions reciprocity or repaym ent in kind as the $\mathrm{m}$ ain exchange rule (Cropanzano \& Mitchell, 
2005). The notion that the recipient of a gift is som ehow obligated to provide a return gives more insight into understanding why adolescents engage in multiple transactional sexual relationships. Table 2 sum $\mathrm{m}$ arizes the theoretical support and application to the study.

Table 2: Theoretical support at the individual and community levels and its application to the problem of MCSP among adolescents in Uganda

\begin{tabular}{|c|c|c|}
\hline $\begin{array}{l}\text { Theoretical } \\
\text { support }\end{array}$ & $\begin{array}{l}\text { Main theoretical } \\
\text { constructs }\end{array}$ & Application to MCSP among adolescents \\
\hline \multicolumn{3}{|l|}{ Individual theories } \\
\hline $\begin{array}{l}\text { Extended Parallel } \\
\text { Process } \\
\text { Model [Popov, 2012; Witt, } \\
\text { 1992; Witt, 1994; McMahan et } \\
\text { al.,1998; Maloney et al., 2011; } \\
\text { Peters et al., 2013] }\end{array}$ & $\begin{array}{l}\text { The m odel advances } \\
\text { constructs of fear/threat, } \\
\text { efficacy, and responses to } \\
\text { danger in relation to } \\
\text { susceptibility and self- } \\
\text { efficacy. } \\
\text { Predicts that fear-arousing } \\
\text { persuasive m essages } \\
\text { should show an effect on } \\
\text { behavior only if both } \\
\text { efficacy and threat are } \\
\text { successfully m anipulated. }\end{array}$ & $\begin{array}{l}\text { Proposes the use of risk m essaging to elicit } \\
\text { fear or danger control responses for those } \\
\text { who perceive a low risk and susceptibility } \\
\text { to HIV. } \\
\text { It is im perative to note that som etim es the use } \\
\text { of risk m essaging to elicit fear m ay not } \\
\text { work if both com ponents of fear and } \\
\text { efficacy are not considered. Therefore, the } \\
\text { m odel helps explain the perceived low risk } \\
\text { and susceptibility to HIV am ong } \\
\text { adolescents. }\end{array}$ \\
\hline $\begin{array}{l}\text { Self-Regulation } \\
\text { Theory } \\
\text { Boekaekts et al., 2000; } \\
\text { Baumeister \& Vohs, 2004] }\end{array}$ & $\begin{array}{l}\text { Self-regulation refers to self- } \\
\text { generated thoughts, } \\
\text { feelings, and actions that } \\
\text { are planned and cyclically } \\
\text { adapted to the attainm ent } \\
\text { of personal goals. }\end{array}$ & $\begin{array}{l}\text { Delineates aspects of self-m otivation such as } \\
\text { self-efficacy, goal setting, self-judgm ent, } \\
\text { and self-evaluation. Adolescents engaging } \\
\text { in MCSP were found to have low self- } \\
\text { efficacy and there is lim ited inform ation on } \\
\text { their } m \text { otivation to engage in MCS. }\end{array}$ \\
\hline
\end{tabular}

\begin{tabular}{|c|c|c|}
\hline \multicolumn{3}{|c|}{ Community Theories } \\
\hline $\begin{array}{l}\text { Social Norms } \\
\text { Theory [Berkowitz, 2003; } \\
\text { Lapinski \& Rimal, 2005] }\end{array}$ & $\begin{array}{l}\text { States that our behavior is } \\
\text { influenced by incorrect } \\
\text { perceptions of how other } \\
\text { m em bers of our social } \\
\text { groups think and act } \\
\text { (m isconception). }\end{array}$ & $\begin{array}{l}\text { Outlines the pertinence of presenting } \\
\text { com } \mathrm{m} \text { unally accepted norm s that exist in } \\
\text { support of existing policies. This is an } \\
\text { indication that com m unally accepted } \\
\text { norm s, such as gender equity and } \\
\text { discouraging early m arriages- both of } \\
\text { which discourage MCSP - need to be } \\
\text { grounded in policy. }\end{array}$ \\
\hline $\begin{array}{l}\text { Social Exchange } \\
\text { Theory [Cox et al., 2014; } \\
\text { Emerson, 1976; Cropanzano } \\
\& \text { Mitchell, 2005] }\end{array}$ & $\begin{array}{l}\text { Delineates a two-sided } \\
\text { notion of m utually } \\
\text { contingent and rewarding } \\
\text { processes involving } \\
\text { "transactions" or sim ple } \\
\text { "exchange". }\end{array}$ & $\begin{array}{l}\text { Indicates that the recipient of a gift is } \\
\text { som dhow obligated to provide a return. } \\
\text { Therefore, adolescents' rational sense of } \\
\text { action to engage in MCSP m ay be based } \\
\text { upon a prior calculation of expected returns. }\end{array}$ \\
\hline
\end{tabular}

Note. MCSP = Multiple Concurrent Sexual Partnerships 
Identified and addressed the new needs for research on adolescent MCSP

\section{Missing links in the empirical literature on adolescent MCSP (step 5 of core processes)}

The study identified the $\mathrm{m}$ issing links in the em pirical literature about adolescent MCSP to address new research needs. Despite existing em pirical literature on adolescent MCSP, knowledge on why adolescents engage in MCSP is still lim ited. Such gaps continue to hinder the design of effective adolescent health-targeted program s addressing sexual behavior change. Missing links categorized by individual determ inants and environm ental agents were identified from the em pirical literature reviewed and theoretical support of the four alternative theories (Table 2).

\section{Individual determinants}

Even with the existing studies about sexual relationships of adolescents in Africa, there is still lim ited research on MCSP and interventions targeted towards reducing MCSP am ong adolescents (Stoebenau et al., 2016; Mushwana, 2015). Although studies found that $\mathrm{m}$ ales are $\mathrm{m}$ ore likely to have $\mathrm{m}$ ultiple concurrent sexal partners than fem ales, it is still unclear why adolescents with HIV are m ore likely to be fem ale than $m$ ale if MCSP increases the risk of contracting HIV (UBOS, 2018; Catania et al., 1989). It is also not yet clear why adolescents attending fam ily planning clinics are eager to address their reproductive concerns, but appear to be less concerned about STDs (Nalukwago et al., 2018-a; Cortez et al., 2016). This indicates an urgent need to discover why adolescents continue to risk contracting HIV through sexual activity.

We did not find literature that addressed new research at the com $m$ unitylevel, but new research needs were identified with environm ental agents.

\section{Environmental agents}

In Uganda, little is known about the motivations behind sexual behavior am ong adolescents and how these $\mathrm{m}$ ight differ by background factors such as gender and age. It is thus im portant to explore whether adolescents with an earlier sexual debut have unique attitudes or beliefs that $\mathrm{m}$ ake them $\mathrm{m}$ ore likely to have $\mathrm{m}$ any sexual partners than those who delay sexual debut (UBOS, 2018; Richter et al., 2015; Wubs et al., 2015). Gender differences in m ultiple concurrent sexual relationships need to be clearly assessed for targeted program $\mathrm{m}$ ing (Helleringer et al., 201). It is not clear in the literature whether relationships, wherein a wom an is younger than her sexual partner, are always characterized by sexual coercion or not, yet older $m$ en and wom en 
often engage with adolescent girls and boys with the belief that they are "safe" from infection (Neem a, Musisi \& Kibom bo, 2004; Richter et al., 2015Nalukwago et al., 2018-b). Many studies on MCSP report the lim itation of underreporting and under$\mathrm{m}$ easurem ent of $\mathrm{m}$ ultiple sexual partners am ong adolescentsS(antelli et al., 2013; Kajubi et al., 2011; Helleringer et al., 2011). This indicates the need to re-exam ine the role of MCSP and the resulting sexual networks in HIV transm ission (Mah \& Halperin, 2010). The ultim ate design of interventions should be able to im pact on adolescents' reference or peer group norm s, which have been found to influence sexual behaviors such as MCSP (Catania et al., 1989). Em otional aspects of relationships and ethnic cultural differences are often overlooked in research and practice on adolescent health in Africa. It is im portant to explore how other factors such as love, trust, and com $\mathrm{m}$ itm ent are associated with MCSP am ongdolescents (Cox et al., 2014; Catania et al., 1989). Table 3 sum $m$ arizes the $m$ issing links in the em pirical literature about MCSP am ong adolescentsby individual determ inants and environm ental agents.

Table 3: Missing links in the empirical literature and recommendations for further research on adolescent $M C S P$

\begin{tabular}{|c|c|}
\hline $\begin{array}{l}\text { Main issues for } \\
\text { MCSP }\end{array}$ & Missing links and recommendations for research on adolescent MCSP \\
\hline \multicolumn{2}{|c|}{ Individual determinants } \\
\hline Attitude & $\begin{array}{l}\text { - Need to explore whether adolescents with an earlier sexual debut have } \\
\text { unique attitudes or beliefs that m ake them m ore likely to have m any } \\
\text { sexual partners, or have had a longer tim e period to accrue partners } \\
\text { (Durbin et al., 1993). } \\
\text { - It is im portant to clarify the extent of HIV risk through m ultiple sex } \\
\text { partners am ong adolescents by quantifying the sequence and frequency } \\
\text { of sexual partners (Durbin et al., 1993; Kajubi et al., 2011). }\end{array}$ \\
\hline $\begin{array}{l}\text { Risk perception and } \\
\text { beliefs about } \\
\text { susceptibility to HIV }\end{array}$ & $\begin{array}{l}\text { - Need to exam ine why adolescents attending fam ily planning clinics are } \\
\text { eager to address their reproductive concerns but appear to be less } \\
\text { concerned about STDs (Nalukwago et al., 2018-a; Cortez et al., 2016). } \\
\text { It is unclear why adolescents with HIV are m ore likely to be fem ale } \\
\text { than m ale (UBOS, 2018; Catania et al., 1989). }\end{array}$ \\
\hline Self-efficacy & $\begin{array}{l}\text { - Little is known about the } m \text { otivations behind sexual behavior am ong } \\
\text { adolescents and how these m ight differ by gender and age (Durbin et } \\
\text { al., 1993; Nalukwago et al., 2018-a; Helleringer et al., 2011). }\end{array}$ \\
\hline \multicolumn{2}{|l|}{ Environmental agents } \\
\hline $\begin{array}{l}\text { Gender and social } \\
\text { norm s }\end{array}$ & $\begin{array}{l}\text { - Gender differences in concurrent relationships need to be clearly } \\
\text { assessed for targeted program m ing Nalukwago et al., 2018-a; } \\
\text { Helleringer et al., 2011). }\end{array}$ \\
\hline $\begin{array}{l}\text { Com m unication wilh } \\
\text { parents }\end{array}$ & $\begin{array}{l}\text { - Little is known about how parents can com m unicate with and influence } \\
\text { their adolescent children (Neem a et al., 2004; Nalukwago et al., } 2018 \\
\text { b). } \\
\text { - Little is known about how couples com m unicate, interact and resolve } \\
\text { problem s, especially with regard tosexual health (Cox et al., 2014). }\end{array}$ \\
\hline
\end{tabular}




\begin{tabular}{ll}
\hline $\begin{array}{l}\text { Other influencing } \\
\text { factors }\end{array}$ & $\begin{array}{l}\text { It is im portant to further explore the influence of other factors such as } \\
\text { trust, the social em barrassm ent when buying condom s, and sub } \\
\text { cultural differences with respect to sexual values (Catania et al., 1989). } \\
\text { - Understanding how the quality of relationships, such as love, trust, and } \\
\text { com m itm ent, influence engagem ent in MCSP is pertinenC(ox et al., } \\
\text { 2014). }\end{array}$ \\
\hline
\end{tabular}

Note. MCSP $=$ Multiple Concurrent Sexual Partnerships; STDs $=$ sexually transm itted diseases

\section{Specific research questions}

From the $\mathrm{m}$ issing links in existing literature, we identified specific research questions for further exploration. These include:

- How do the patterns of sex partners am ong adolescents com pare to tbse of the adult population?

- Why are adolescents $m$ oreconcerned about pregnancy than the risk of STDs and HIV?

- How do the attitudes and beliefs of adolescents with an early sexual debut influence their likelihood to have MCSP?

- What are the specific ethnic cultural, gender and social norms that precipitate MCSP am ong adolescents in Uganda?

- How do MCSP among adolescents increase HIV transm ission in the resultant sexual networks?

\section{Proposed answers for reducing the problem of adolescent MCSP (step 6 of core processes)}

The $\mathrm{m}$ ain findings from the brainstorming sessins, em pirical literature, and theoretical support indicate that it is im portant for health prom otion program $\mathrm{s}$ to address the recurrent factors that influence adolescents to engage in MCSP. These include attitude, perceived susceptibility, perceived social/subjective norm s, self efficacy, knowledge, com m unication with partners and other influencers, and social exchange/transactional sexual relations. The recurrent individual and environm ental determ inants identified in the brainstorming sessions, em pirical literature and supported by theory were ranked by im portance and changeability. Im portance refers to the determ inants that contribute significantly to the behavior, and changeability refers to the determinants that can be changed with the available methodsor interventions (Bartholom ew et al., 2016; 95.Ruiter, Crutzen \& Kok, 2018). The ranking helped in identifying highly im portant and changeable determ inants to guide future design of adolescent health interventions using the currently available evidence. Determ inants that were found to be im portant and changeable were ranked 
using $++=$ very im portant and $++=$ it is changeable. Table 4 sum $\mathrm{m}$ arizes the rankings of the identified list of determ inants that provide possible answersexplanations to the problem ofMCSP am ong adolescents. It is im portant to note that we did not find com m unitylevel answers to the problem .

Table 4: List of determinants providing possible answers for reducing adolescent MCSP

\begin{tabular}{|c|c|c|}
\hline Determinants & Importance & Changeability \\
\hline \multicolumn{3}{|l|}{ Individual determinants } \\
\hline Attitude - Individual & ++ & ++ \\
\hline Perceived susceptibility and risk to HIV & ++ & ++ \\
\hline Self-efficacy & ++ & ++ \\
\hline Perceived social/subjective norm & + & ++ \\
\hline Knowledge of the risks of MCSP - Individual & + & ++ \\
\hline Com $m$ unication with sexual partner andnfluencers & ++ & ++ \\
\hline Social exchange/transactional sexual relations & + & + \\
\hline \multicolumn{3}{|l|}{ Environmental agents } \\
\hline Attitude - Influencers & + & ++ \\
\hline Knowledge of the risks of MCSP - Influencers & + & ++ \\
\hline Social/group norm s & + & + \\
\hline Perceived social/subjective norm & + & ++ \\
\hline Com m unication withparents & ++ & ++ \\
\hline Com $\mathrm{m}$ unication with sexual partner & ++ & ++ \\
\hline Social exchange/transactional sexual relations & + & + \\
\hline Policy environm ent targeting adolescent access to SRH & ++ & + \\
\hline
\end{tabular}

\section{Discussion}

This study explored why adolescents in Uganda engage in MCSP. The findings will guide the design of targeted adolescent SRH program $\mathrm{s}$ in Uganda. The findings from the ranked determ inants delineate several factors associated with MCSP am ong adolescents at various levels of influence. The determ inants ranked by im portance and changeability generated a list of possible answers for designing targeted interventions that address the problem of adolescent MCSP. However, this list should be interpreted with caution, because it is not exhaustive. The list indicates what is known in the currently available literature. So, future interventions should rely on currently available evidence. 
The findings indicate that adolescents engage in MCSP because they perceive low risk and susceptibility to HIV (Catania et al., 1989; Durbin et al., 1993). With this perception, adolescents fail to see the risk associated with their sexual behavior (Dolcini et al., 1995). Poor com m unication with sexual partners and parents was found to be associated with adolescent MCSP both in the brainstorm ing sessions as well as in the literature (Bastien, Kajula \& Muhwezi, 2011; Feldm an \& Rosenthal, 2000; Jaccard, Dodge \& Dittus, 2002; Taffa et al., 2017; Nalukwago et al., 2018b). However, Dolcini et al. found that people who are com fortable talking about sex $\mathrm{m}$ ay simply be better at getting new sexual partners than those who are poor com $\mathrm{m}$ unicators Dolcini et al., 1995), and this $\mathrm{m}$ ight also be true for adolescents. This accentuates the need to further understand how adolescent couples com m unicate, interact and resolve problem s, especially with regard to sexual health and MCSP (Cox et al., 2014). Knowledge of the risks of MCSP am ong adolescents and their influencers was found to be inadequate and often intertwined with $m$ yths and $\mathrm{m}$ isconceptions (Hardee et al., 2014). Although several studies on adolescent sexual behaviors found that knowledge is weakly associated with the perform ance of the actual behaviors (Dolcini et al., 1995; Hardee et al., 2014; Nalukwago et al., 2018-a), inform ation services rem ain im portant in clearing $\mathrm{m}$ isconceptions and addressing health concerns. Brainstorm ing sessions and the literature showed that adolescents have low levels of self-efficacy towards having one sexual partner, often associated with the perception that peers have multiple sexual partners (Catania et al., 1989; Durbin et al., 1993). Com m unity influences, including societh approval of MCSP and beliefs about the sexual dom inance of m en KeClerc-Madlala, 2009; Joshi, 2010; Mavhu et al., 2011), were found to increase perm issive attitudes of adolescents and their influencers on infidelity (Dolcini et al., 1995; Konde-Lule et al., 1997; Jewkes $\&$ Morrell, 2010). Transactional sexual relationships whereby adolescents engage with older $\mathrm{m}$ en and wom en called 'sponsors' were found to be widespread Neem a, Musisi \& Kibom bo, 2004; Bantebya, Muhanguzi \& Watson, 2014; Nyanzi, Pool \& Kinsman, 2001; Kelly et al., 2003; Nobelius et al., 2011). Studies argue that the notion of transactional sexual relationships is deeply rooted in cultural contexts that m odel sexual relationships of exchange on traditional social institutions of courting and bride-wealth paym ents (LeClerc-Madlala, 2009; Nobelius et al., 2010). With these social influences, social norm s on MCSP including gender equity and discouraging early $\mathrm{m}$ arriages, com $\mathrm{m}$ unally deem ed as appropriate, need to be grounded in policy and effectively com $\mathrm{m}$ unicated to the general public (Teitelm an et a,12016; Hardee et al., 2014; Berkowitz, 2003; Lapinski \& Rimal, 2005). The unfavorable policy environm ent surrounding adolescent access to SRH contributes to the problem of adolescents engaging in MCSP (Kaufm an et al., 2014; Bantebya GK, Muhanguzi FK, Watson, 2014). It is im portant to work with and form strategic partnerships with 
multiple key players in the institutional and structural environm ent to create a conducive environm ent for adolescent health.

Even with the existing empirical literature, there are still unanswered questions and $\mathrm{m}$ issing links that need to be addressed to increase the understanding of why adolescents engage in MCSP. Not yet known are sexual relationship patterns am ong adolescents (Stoebenau et al., 2016; Mushwana et al., 2015), and why adolescents are more concerned about unplanned pregnancy than HIV risk (Nalukwago et al., 2018-a; Cortez et al., 2016). Several studies in Uganda have reported that adolescents are increasingly becom ing sexually active, depicted by early sexual debut since m anyadolescent's report starting sex as early as 14 and 15 years (UBOS, 2018; UBOS, 2012). However, it is not yet clear whether an early sexual debut eventually influences MCSP am ong adolescents(UBOS, 2018; Durbin et al., 1993; Richter et al., 2015; Wubs et al., 2015). The gap in understanding gender differences in multiple concurrent sexual relationships remains a challenge (Nalukwago et al., 2018-a; Helleringer et al., 2011). It is also not yet clear whether relationships in which an adolescent is younger than his or her sexual partner are characterized by violence and sexual coercion. It is im perative to understand the power balance dynam ics in all sexual relationships, including MCSP in the light of $\mathrm{m}$ arried and unm arried adolescents, and those who are inand-out of school (Kelly et al., 2003; Teitelm an et al., 2016; Nalukwago et al., 2018a; Helleringer et al., 2011). There is inadequate docum entation of the sequence and frequency of sexual paitners, coupled with underreporting of sexual partners among adolescents (Lurie \& Rosenthal, 2011; Kajubi et al., 2011). Other factors including ethnic cultural differences with respect to sexual values, and em otional aspects including love, trust, and com mitm ent have only been studied to a lim ited extent and data ne needed to understand how they influence adolescent MCSP (Cox et al., 2014; Catania et al., 1989). These gaps are a clear indication that additional research is needed to further understand the $\mathrm{m}$ issing links on why adolescents engage in MCSP. Studies recom $m$ end longitudinal research to understand the com plex notion of and ever changing sexual relationships of adolescents particularly in sub-Saharan Africa (Lurie \& Rosenthal, 2011; Howard \& Wang, D04; Catania et al., 1989).

Despite the gaps in the existing em pirical literature, reviewed studies provided relevant recom $m$ endations for designing targeted adolescent health program s. Several studies highlighted the need to intensify sexuality education and strengthen com m unication skills for adolescents and theirinfluencers (Catania et al., 1989; Durbin et al., 1993; Dolcini et al., 1995; Hardee et al., 2014). Health-prom otion program s need to com $m$ unicate the im portance of using condom $s$ and how to use dn enjoy sex with condom s to reduce the HIV risk am ong adolesents (Nobelius et al., 2010; Joshi, 2010). The use of $m$ ass $m$ edia coupled with faceto-face interaction and public dialogue is pertinent for reinforcing social-change interventions (Oum et al., 
2016). Gender integration should be central to health prom otion to address inequitable socio-cultural norm s that encourage adolescents to engage in MCSP (Pulerwitz et al., 2010; Pulerwitz, Gortm aker \& DeJong, 2000; Varga, 1997; Varga, 2003). It is vital to engage influential cultural institutions to prom ote longer carting for adolescents in relationships as a way of encouraging greater com $\mathrm{m}$ itm ent to one relationship and to deter casual and concurrent sexual partnerships (LeClerc-Madlala, 2009; Nobelius et al., 2010). Theoretical support drawn from the Social Norm s Theory indicates that to address social norm $\mathrm{s}$, it is important to develop norm $\mathrm{s}$ grounded in policy (Berkowitz, 2003; Lapinski \& Rim al, 2005. Therefore, health promotion programs need to partner will governments who have a role in legitim izing norm ative change efforts and work within a policy context Oum et al., 2016). Rather than solely depending on national surveys such as Dem ographic Health Surveys, program developm ent practitioners need to devise other routine m ethods of $\mathrm{m}$ onitoring the sequence and frequency of MCSP am ong adolescents in regard to HIV transm ission (Kajubi et al., 2011).

\section{Study Limitations}

This study generated insights from group brainstorm ing sessions and em pirical literature review of MCSP studies from countries other than Uganda. This m aylim it the generalizability of the findings to Uganda's population. However, additional studies of a similar nature can be conducted in Uganda to offer a contextual com parison of the findings. The few sub-cultural contexts described in this study $\mathrm{m}$ ight notprovide a deeper understanding of the $\mathrm{m}$ ulticultural divides in Uganda. Therefore, it is im perative to conduct further studies to understand the problem of adolescent MCSP within the confines of the multiple ethnic cultural settings in Uganda. Although the study used core processes including theoretical support to generate a list of possible answers for why adolescents engage in MCSP, this list is not exhaustive or conclusive in addressing the problem. This m eans that there $\mathrm{m}$ ight be other contributing factors that the currently available literature $m$ ay not have captured. 


\section{Conclusion}

MCSP am ong adolescents in Uganda is a problem attracting the attention of international and local developm ent partmers who are eager to understand why there is increasing HIV/AIDS am ong this population. Our findings indicate that program s targeted to reduce the num ber of sexual partners am ag adolescents in Uganda should strive to design integrated interventions that address the determ inants of MCSP at various levels of influence. The findings not only show the need to work with adolescents to understand the contextual and em erging health com $\mathrm{m}$ unication needs to appropriately position the risk of MCSP m essaging but they also indicate the need to involve and partner with other key players. Therefore, form ing strategic partnerships with adolescents' families, comm uniies, cultural and religious institutions, health facilities, and local governm ent for concerted efforts to address the problem of MCSP is critical 


\section{References}

Albarracin, D., Johnson, B. T., Fishbein, M., \& Muellerleile, P. A. (2001). Theories of reasoned action and planned behavior as models of condom use: a m eta analysis. Psychological bulletin. 1 27(1):142.doi:10.1037/0033-2909.127.1.142

Bandura A. (1989). Hum an agency in social cognitive theory. Am erican psychologist. 44(9):1175. doi: 10.1037/0003-066X.44.9.1175

Bandura A. (2009). Social cognitive theory of $m$ ass com $m$ unication. InMedia effects 2009 Jan 13 (pp. 110-140). Routledge, Stanford, CA.

Bantebya, G. K., Muhanguzi, F. K., \& Watson, C. (2014). Adolescent girls in the balance: Changes and continuity in social norm $\mathrm{s}$ and practices around $\mathrm{m}$ arriage and education in Uganda. London: Overseas Developm ent Institute.

Bartholom ew, L. K., Parcel, G. S., Kok, G., \& Gottlieb, N. H. (2001)Intervention Mapping; designing theory-and evidence-based health promotion programs. Mountain View, CA: Mayfield.

Bartholom ew, L. K., Parcel, G. S., Kok, G., \& Gottlieb, N. H.Planning health promotion programs; an Intervention Mapping approach, 2nd Ed. San Francisco, CA: Jossey-Bass. (2006).

Bartholom ew, L K., Parcel, G. S., Kok, G., Gottlieb, N. H., \& Fernández, M. E. (2011). Planning health promotion programs; an Intervention Mapping approach, 3rd Ed. San Francisco, CA: Jossey-Bass.

Bartholom ewEldredge, L. K., Markham, C. M., Ruiter, R. A. C., Fernández, M. E., Kok, G., \& Parcel, G. S. (2016). Planning health promotion programs: An Intervention Mapping approach, 4th edition. Hoboken, NJ: Wiley. ISBN-13: 978-1119035497.

Bastien, S., Kajula, L. J., \& Muhwezi, W. W. (2011).A review of studies of parentchild com m unicationabout sexuality and HIV/AIDS in sub-Saharan Africa. Reproductive health. 8(1):25. doi: 10.1186/1742-4755-8-25

Baum eister, R. F., \& Vohs, K. D. (Eds.)(2004). Handbook of Self-Regulation: Research, Theory, and Applications. Guilford Publications. New York.

Berkowitz, A. D. (2003). Applications of social norm s theory to other health and social justice issues. The social norm s approach to preventing school and college age substance abuse: A handbook for educators, counselors, and clinicians. 25979.

Berkowitz, A. D. (2004). The social norm sapproach: Theory, research, and annotated bibliography. Trum ansburg, N.Y.

Boddy, C. (2012). The nom inal group technique: An aid to brainstorm ing idas in research. Qualitative Market Research: An International Journal, 15(1), 6-18.

Boekaerts, M. (1999). Self-regulated learning: Where we are today. International journal of educational research. 31(6):445-57. doi: 10.1016/S08830355(99)00014-2 
Boekaerts, M., Pintrich, P. R., \& Zeidner, M. (Eds.) (2000). Handbook of SelfRegulation. Academic Press, California, USA.

Buunk, A. P., \& Van Vugt, M. (2013).Applying social psychology: From problems to solutions (2nd Ed.). London: Sage. ISBN 1446294161, 9781446294161.

Buunk, A. P., \& Veen, P. (1995). Sociale psychologie en praktijkproblemen: Van probleem naar oplossing. Bohn Stafleu Van Loghum. Weybridge, Engeland. doi: 10.1007/978-90-313-6418-3

Buunk, B. P., \& Van Vugt, M. (2008).Applying social psychology: From problems to solutions. London: Sage. doi: 10.4135/9781446280508

Catania, J. A., Coates, T. J., Greenblatt, R. M., Dolcini, M. M., Kegeles, S. M., Puckett, S., Corm an, M., \& Miller, J. (1989). Predictors of condom use and $\mathrm{m}$ ultiple partnered sex am ong sexually-active adolescent wom en: Im plications for aids-related health interventions.

CHC-Com m unication for Healthy Com munities. (2016)OBULAMU National Integrated Health Com m unication Platform . June 2013 June 2018. Kam pala.

Cortez, R., Saadat, S., Marinda, E., \& Odutolu, O. (2016). Adolescent fertility and sexual health in Nigeria. The World Bank, 1818 H Street NW, Washington.

Cox, C. M., Babalola, S., Kennedy, C. E., Mbwam bo, J., Likindikoki, S., \& Kerrigan, D. (2014). Determinants of concurrent sexual partnerships within stable relationships: a qualitative study in Tanzania. BMJ open. 4(2):e003680. doi: 10.1136/bm jopen2013-003680

Cropanzano, R., \& Mitchell, M. S. (2005). Social exchange theory: An interdisciplinary review. Journal of $\mathrm{m}$ anagem ent. 31(6):874900. doi: $10.1177 / 0149206305279602$

DiClem ente, R. J., Crosby, R. A., \& Kegler, M. C., editors. (2009). Em erging theories in health prom otion practice and research. John Wiley \& Sons. San Francisco, CA.

Dolcini, M. M., Coates, T. J., Catania, J. A., Kegeles, S. M., \& Hauck, W. W. (1995). Multiple sexual partners and their psychosocial correlates: the population-based AIDS in multiethnic neighborhoods (AMEN) study. Health Psychology. 14(1):22. doi: 10.1037/0278-6133.14.1.22

Durbin, M., DiClem ente, R. J., Siegel, D., Krasnovsky, F., Lazarus, N., \& Cam acho, T. (1993). Factors associated with multiple sex partners am ong junior high school students. Journal of Adolescent Health.14(3):202-7. doi: 10.1016/1054139X(93)90006-B

Ehrhardt, A. A., Sawires, S., McGovern, T., Peacock, D., \& Weston, M. (2009); Gender, em powerm ent, and health: what is it? Hor does it work?. Journal of acquired im m une deficiency syndrom e(1999). 51(Suppl 3):S96.

Em erson, R. M. (1976). Social exchange theory. Annual review of sociology. 2(1):335-62. doi: 10.1146/annurev.so.02.080176.002003 
Epstein, H., \& Morris, M. (2011).Concurrent partnerships and HIV: an inconvenient truth. Journal of the International AIDS Society. 14(1):13. doi:10.1186/17582652-14-13

Feldm an, S. S. A. \& Rosenthal D. (2000); The effect of commurication characteristics on fam ily mem bers' perceptions of parents as sex educators. Journal of Research on adolescence. 10(2):119-50. doi: 10.1207/SJRA1002_1

Fishbein, M. (2007). Prediction and change of health behavior: Applying the reasoned action approach. Psychology Press. New Jersey, London.

Fishbein, M., \& Ajzen, I. (2011). Predicting and changing behavior: The reasoned action approach. Taylor \& Francis.New York.

Fulu, E., Miedem a, S., Roselli, T., McCook, S., Chan, K. L., Haardörfer, R., Jewkes, R., Warner, X., Lang, J., Naved, R. T., \& Huque, H. (2017). Pathways between childhood traum a, intim ate partner violence, and harsh parentingfindings from the UN Multi-country Study on Men and Violence in Asia and the Pacific. The Lancet Global Health. 5(5):e512-22.

Golden, S. D., \& Earp, J. A. (2012); Social ecological approaches to individuals and their contexts: twenty years of health education $\&$ behavior health prom otion interventions. Health Education \& Behavior. 39(3):364-72. doi: $10.1177 / 1090198111418634$

Gore, T. D., \& Bracken, C. C. (2005). Testing the theoretical design of a health risk $\mathrm{m}$ essage: Reexam ining the $\mathrm{m}$ ajor tenets of the extended parallel process $\mathrm{m}$ odel. Health Education \& Behavior. 32(1):2741. doi: 10.1177/1090198104266901

Hardee, K., Gay, J., Croce-Galis, M., \& AfariDwam ena, N. A. (2014). What HIV program s work for adolescent girls?. JAIDS Journal of Acquired Im m une Deficiency Syndrom es.66:S176-85. doi: 10.1097/QAI.0000000000000182

Harrison, A., Cleland, J., \& Frohlich, J. (2008). Young people's sexual patnerships in KwaZulu-Natal, South Africa: patterns, contextual influences, and HIV risk. Studies in family planning. 39(4):295-308. doi: 10.1111/j.17284465.2008.00176.x

Helleringer, S., Kohler, H. P., Kalilani-Phiri, L., Mkandawire, J., \& Arm bruster, B. (2011). The reliability of sexual partnership histories: implications for the m easurem ent of partnership concurrencyduring surveys. AIDS (London, England). 25(4):503. doi:10.1097/QAD.0b013e3283434485

Howard, D. E., \& Wang, M. Q. (2004). Multiple sexualpartner behavior am ong sexually active US adolescent girls. Am erican Journal of Health Behavior. 28(1):3-12. doi: 10.5993/AJHB.28.1.1

Jaccard, J., Dodge, T., \& Dittus, P. (2002). Parent-adolescent com m unication about sex and birth control: A conceptual fram ework. New directions for child and adolescent developm ent. 2002(97):9-42. doi: 10.1002/cd.48

Janz, N. K., \& Becker, M. H. (1984). The health belief m odel: A decade laterHealth education quarterly. 11(1):1-47. doi: 10.1177/109019818401100101 
Jewkes, R., \& Morrell, R. (2010). Gender and sexuality: em erging perspectives from the heterosexual epidem ic in South Africa and im plications for HIV risk and prevention. Journal of the International AIDS society. 13(1):6. doi: $10.1186 / 1758-2652-13-6$

Joshi, A. (2010). Multiple sexual partners: perceptions of young m en in Uganda. Journal of health organization and managem ent. 24(5):520-7. doi: $10.1108 / 14777261011070547$

Kajubi, P., Green, E. C., Hudes, E. S., Kam ya M. R., Ru “ark, A. H., \& Hearst, N. (2011). Multiple sexual partnerships am ong poor urban dwellers in Kam pala, Uganda. JAIDS Journal of Acquired Imm une Deficiency Syndrom es. 57(2):153-6. doi: 10.1097/QAI.0b013e318211b466

Kaufm an, M. R., Cornish, F., Zim m erm an, R. S., \& Johnson, B. T. (2014). Health behavior change models for HIV prevention and AIDS care: practical recomm endations for a $\mathrm{m}$ ultievel approach. Journal of acquired im $\mathrm{m}$ une deficiency syndromes (1999). 66(Suppl3):S250. doi: 10.1097/00042560199912150-00003

Kelly, R. J., Gray, R. H., Sewankam bo, N. K., Serwadda, D., WabwireMangen, F., Lutalo, T., \& Wawer, M. J. (2003). Age differences in sexual partners and risk of HIV-1 infection in rural Uganda. JAIDS Journal of Acquired Im m une Deficiency Syndrom es. 32(4):44651. doi: 10.1097/00126334-20030401000016

Kok, G., Gottlieb, N. H., Peters, G. J., Mullen, P. D., Parcel, G. S., Ruiter, R. A., Fernández, M. E., Markham, C., \& Bartholom ew, L. K. (2016); A taxonom y of behaviour change methods: an Intervention Mapping approach. Health Psychology Review. 10(3):297-312. doi: 10.1080/17437199.2015.1077155

Kok, G., Schaalm a, H., De Vries, H., Parcel, G., \& Paulussen, Th. (996). Social psychology and health education. In: W. Stroebe \& M. Hewstone (Eds.). European review of social psychology. volume 7 (pp. 241-282). London: Wiley. doi: 10.1080/14792779643000038

Konde-Lule, J. K., Wawer, M. J., Sewankam bo, N. K., Serwadda, D., Kelly, R., Li, C., Gray, R. H., \& Kigongo, D. (1997). Adolescents, sexual behavior and HIV1 in rural Rakai district, Uganda. AIDS. 11(6):791-9. doi: 10.1097/00002030199706000-00012

Kram er, M. W., Kuo, C. L., \& Dailey, J. C. (1997). Theim pact of brainstorm ing techniques on subsequent group processes: Beyond generating ideas. Small Group Research, 28(2), 218-242.

Lapinski, M. K., \& Rimal, R. N. (2005). An explication of social norm s. Com $m$ unication theory. 15(2):12747.doi:10.1111/j.1468-2885.2005.tb00329.x

Lave, C. A., \& March, J. G. (1993).An introduction to models in the social sciences. University Press of Am erica.Boston Way, Lanham, Maryland 
LeClerc-Madlala, S. (2009). Cultural scripts for m ultiple and concurrent partnerships in southern Africa: why HIV prevention needs anthropology. Sexual health. 6(2):103-10. doi: 10.1071/SH08032

Litchfield, R. C. (2008). Brainstorm ing reconsidered: A goal-based view. Academy of Management Review, 33(3), 649-668.

Lurie, M. N., \& Rosenthal, S. (2010). Concurrent partnerships asa driver of the HIV epidem ic in subSaharan Africa? The evidence is lim ited. AIDS and Behavior. 14(1):17-24.

MacPhail, C., \& Cam pbell, C. (2001). 'I think condom s are good buahai, I hate those things': condom use am ong adolescents and young people in a Southern African township. Social science \& medicine. 52(11):1613-27. doi:10.1016/S0277-9536(00)00272-0

Mah, T. L., \& Halperin, D. T. (2010). The evidence for the role of concurrent partnerships in Africa's HIV epidem ics: a response to Lurie and Rosenthal. AIDS and Behavior. 14(1):25-8.

Maharaj, P., \& Cleland, J. (2004). Condom use within $\mathrm{m}$ arital and cohabiting partnerships in KwaZulu-Natal, South Africa. Studies in family planning. 35(2):116-24. doi: 10.1111/j.1728-4465.2004.00013.x

Maloney, E. K., Lapinski, M. K., (2011). Witte, K. Fear appeals and persuasion: A review and update of the extended parallel process model. Social and Personality Psychology Compass. 5(4):206-19. doi: 10.1111/j.17519004.2011.00341.x

Mavhu, W., Langhaug, L., Pascoe, S., Dirawo, J., Hart, G., \& Cowan, F. (2011). A novel tool to assess com $\mathrm{m}$ unity norm $\mathrm{s}$ and attitudes to $\mathrm{m}$ ultiple and concurrent sexual partnering in rural Zim babwe: participatory attitudinal ranking. AIDS care. 23(1):52-9. doi: 10.1080/09540121.2010.490257

McKee, N., Manoncourt, E., Yoon, C. S., 7 Carnegie, R. (2002). Involving People, Evolving Behaviour: The UNICEF Experience. Com m unication for developm ent and sodal change. Paris: UNESCO. 254.

McMahan, S., Witte, K., \& Meyer, J. A. (1998). The perception of risk m essages regarding electrom agnetic fields: extending the extended parallel process m odel to an unknown risk. Health Com munication 10(3):247-59. doi: $10.1207 / \mathrm{s} 15327027 \mathrm{hc} 1003$ _4

Morris, M., \& Kretzschm ar, M. (1997). Concurrent partnerships and the spread of HIV. AIDS. 11(5):641-8. doi: 10.1097/00002030-199705000-00012

Mushwana, L., Monareng, L., Richter, S., \& Muller, H. (2015). Factorsinfluencing the adolescent pregnancy rate in the greater Giyani Municipality, Lim popo Province-South Africa. International Journal of Africa Nursing Sciences. 2:108.

Nalukwago, J., Crutzen, R., Van den Borne, B., Bukuluki, M. P., Bufum bo, L., Batam wita, R., Zikusooka, A., Lenzi, R., Thom pson, G., \& Alaii, J. (2018b). 
Adolescents discussing sexual behaviors with key influencing audiences. Global Journal of Health Science, 10, 91-106

Nalukwago, J., Crutzen, R., van den Borne, B., Bukuluki, P. M., Bufum bo, L., Burke, H. M., Field, S., Zikusooka, A., Fiedler, A. A., \& Alaii, J. (2018a). SocioCognitive Factors Associated with Condom Use, Multiple Sexual Partnerships, and Contraception Use Am ong Sexually-Active Adolescent Girls in Uganda. Global Journal of Health Science. 10(8):41. doi:10.5539/gjhs.v10n8p41

Neem a, S., Musisi, N., \& Kibom bo, R. (2004). Adolescent sexual and reproductive health in Uganda: a synthesis of research evidence. New York: Alan Guttm acher Institute.

Nobelius, A. M., Kalina, B., Pool, R., Whitworth, J., Chesters, J., \& Power, R. (2011). Sexual partner types and related sexual health risk am ong outof-school adolescents in rural south-west Uganda. AIDS care. 23(2):252-9. doi:10.1080/09540121.2010.507736

Nobelius, A. M., Kalina, B., Pool, R., Whitworth, J., Chesters, J., \& Power, R. (2010). "You still need to give her a token of appreciation": the m eaning of the exchange of $\mathrm{m}$ oney in the sexual relationships of outof-school adolescents in rural southwest Uganda. Journal of sex research. 47(5):490-503. doi:10.1080/00224499.2010.494776

Nyanzi, S., Pool, R., \& Kinsm an, J. (2001). The negotiation of sexual relationships am ong school pupils in south-western Uganda. AIDS care. 13(1):83-98. doi: $10.1080 / 09540120020018206$

Oum, S., Igra, S., Kerner, B., \& Nguyen, G. (2016). Scaling up norm ative change interventions for adolescent and youth sexual and reproductive health: literature review findings and recom $\mathrm{m}$ endations.

Peters, G. J., Ruiter, R. A., \& Kok, G. (2013).Threatening com m unication: a critical re-analysis and a revised metaanalytic test of fear appeal theory. Health psychology review. 7(sup1):S8-31.doi: 10.1080/17437199.2012.703527

Pilgrim, N. A., Ahm ed, S., Gray, R. H., Sekasanvu, J., Lutalo, T., Nalugoda, F., Serwadda, D., \& Wawer, M. J. (2015). Multiple sexual partnerships am ong fem ale adolescents in rural Uganda: the effects of fam ily structure and school attendance. International journal of adolescent m edicine and health. 27(3):319 28. doi: 10.1515/ijam h-2014-0032

Popova, L. (2012). The extended parallel process model: Illum inating the gaps in research. Health Education \& Behavior. 39(4):455-73. doi: $10.1177 / 1090198111418108$

Pulerwitz, J., Gortm aker, S. L., \& DeJong, W. (2000). Measuring sexual relationship power in HIV/STD research. Sex roles. 42(7-8):637-60. doi: 10.1023/A:1007051506972

Pulerwitz, J., Michaelis, A., Verm a, R., \& Weiss, E. (2010). Addressing gender dynam ics and engaging $\mathrm{m}$ en in HIV program s: lessons learned from Horizons 
research. Public health reports. 125(2):282-92. doi: $10.1177 / 003335491012500219$

Richter, L., Mabaso, M., Ram jith, J., \& Norris, S. A. (2015). Early sexual debut: Voluntary or coerced? Evidence from longitudinal data in South Africa the Birth to Twenty Plus study. South African Medical Journal. 105(4):304-7.

Rom er, D., Black, M., Ricardo, I., Feigelm an, S., Kaljee, L., Galbraith, J., Nesbit, R., Hornik, R. C., \& Stanton, B. (1994). Social influences on the sexual behavior of youth at risk for HIV exposure. Am erican Journal of Public Health. 84(6):97785. doi: 10.2105/AJPH.84.6.977

Rosenberg, M. D., Gurvey, J. E., Adler, N., Dunlop, M. B., \& Ellen, J. M. (1999). Concurrent sex partners and risk for sexually transm itted diseases am ong adolescents. Sexually transm itted diseases. 26(4):208-12. doi: 10.1097/00007435-199904000-00004

Rosenstock, I. M. (1974). Historical origins of the health belief model. Health education m onographs. 2(4):32835. doi: 10.1177/109019817400200405

Ruiter, R. A., Crutzen, R., \& Kok, G. (2018, October 1). Core Processes for Developing Theory- and Evidence-Based Interventions. Retrieved from psyarxiv.com $/ \mathrm{j} 4 \mathrm{ftz}$

Sam uelsen, H. (2006). Love, lifestyles and the risk of AIDS: The $m$ oral worlds of young people in Bobo-Dioulasso, Burkina Faso. Culture, Health \& Sexuality. 8(3):211-24. doi: 10.1080/13691050600761185

Santelli, J. S., Edelstein, Z. R., Mathur, S., Wei, Y., Zhang, W., Orr M. G., Higgins, J. A., Nalugoda, F., Gray, R. H., Wawer, M. J., \& Serwadda, D. M. (2013). Behavioral, biological, and dem ogaphic risk and protective factors for new HIV infections am ong youth, Rakai, Uganda. Journal ofacquired im $m$ une deficiency syndrom es (1999). 63(3):393.doi: 10.1097/QAI.0b013e3182926795

Sawers, L., \& Stillwaggon, E. (2010). Concurrent sexual partnerships do not explain the HIV epidem ics in Africa: a system atic review of the evidence. Journal of the International AIDS society. 13(1):34. doi: 10.1186/1758-2652-13-34

Shelton, J. D., Halperin, D. T., Nantulya, V., Potts, M., Gayle, H. D., \& Holm es, K. K. (2004). Partner reduction is crucial for balanced "ABC" approach to HIV prevention. BMJ: British Medical Journal. 328(7444):891. doi: $10.1136 / \mathrm{bm} \mathrm{j} .328 .7444 .891$

Sm ith, D. J. (2004). Prem arital sex, procreation, and HIV risk in Nigeria. Studies in Fam ily Planning. 35(4):223-35. doi: 10.1111/j.0039-3665.2004.00027.x

Stoebenau, K., Heise, L., Wam oyi, I, \& Bobrova, N. (2010). Revisiting the understanding of "transactional sex" in sub-Saharan Africa: a review and synthesis of the literature. Social Science \& Medicine. 168:18697.

Taffa, N., Haim anot, R., Desalegn, S., Tesfaye, A., \& Moham m ed, K. (2017Do parents and young people com $\mathrm{m}$ unicate on sexualmatters. The Ethiopian Journal of Health Developm ent (EJHD). 13(3). 
Teitelm an, A. M., Jem m ott III, J. B., Bellam y, S. L., Icard, L. DQ'leary, A., Heeren, G. A., Ngwane, Z., \& Ratcliffe, S. J. (2016). Patner violence, power, and gender differences in South African adolescents' HIV/sexually transm itted infections risk behaviors. Health psychology. 35(7):751. doi: 10.1037/hea0000351

Uganda Bureau of Statistics (UBOS) and ICF International Inc. (2012). Uganda Dem ographic and Health Survey 2011. Kampala, Uganda: UBOS and Calverton, Maryland: ICF International Inc.

Uganda Bureau of Statistics (UBOS) and ICF. (2018). Uganda Dem ographic and Health Survey 2016. Kam pala, Uganda, and Rockville, Maryland, USA: UBOS and ICF.

Varga, C. A. (1997). Sexual decision-m aking and negotiation in the m idst of AIDS: youth in KwaZulu/Natal, South Africa. Health Transition Review. 45-67.

Varga, C. A. (2003). How gender roles influence sexual and reproductive health am ong South African adolescents. Studies in fam ily planning. 34(3):16072. doi: 10.1111/j.1728-4465.2003.00160.x

Vasilenko, S. A., \& Lanza, S. T. (2014). Predictors of m ultiple sexual partners from adolescence through young adulthood. Journal of Adolescent Health. 55(4):491-7. doi: 10.1016/j.jadohealth.2013.12.025

Veen, P. (1984). Sociale psychologie toegepast: Van probleem naar oplossing. Alphen aan den Rijn: Sam son.

Witte, K. (1992). Putting the fear back into fear appeals: The extended parallel process model. Com m unications Monographs. 59(4):329-49. doi:10.1080/03637759209376276

Witte, K. (1994). Fear control and danger control: A test of the extended parallel process model (EPPM). Com m unications Monographs. 61(2):11-34. doi:10.1080/03637759409376328

Wubs, A. G., Aarø, L. E., Kaaya, S., Onya, H., \& Mathews, C. (2015). Social cognition variables and victim ization as predictors of sexual debut am ong adolescents in South Africa and Tanzania: A m ultigroup SEM analysis. AIDS and Behavior. 19(12):2141-51. 



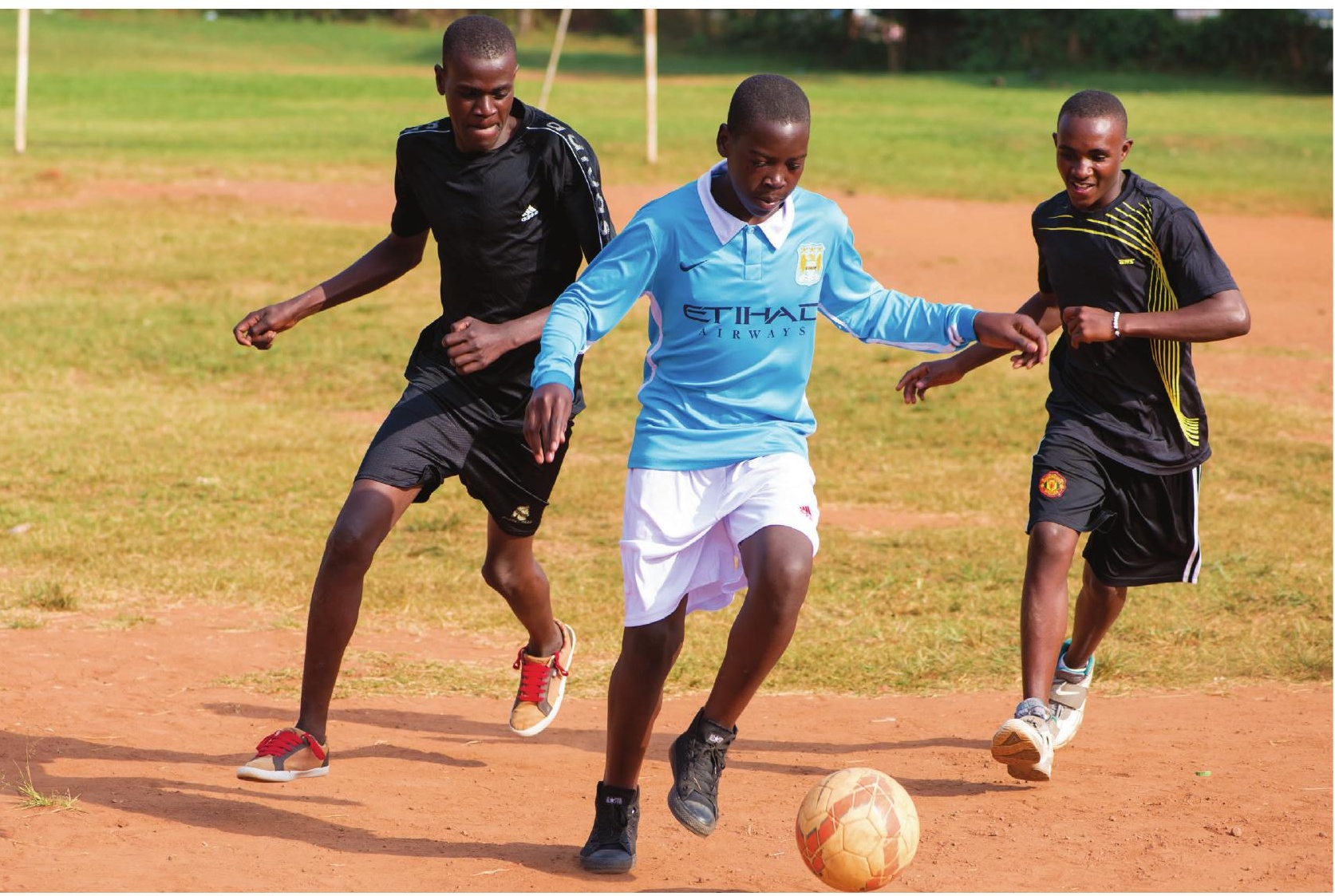




\section{Chapter}

\section{Process Evaluation of the Com m unication for Healthy Com m unitiesAdolescent Health Program in Uganda}

\section{To be published as:}

Nalukwago, J., Alaii, J., Van den Borne, B., Bukuluki, P. M., Kim bowa, M., Bockh, E., Coutinho, M. S., \& Crutzen, R (subm itted) Process evaluation of the Communication for Healthy Communities adolescent health program in Uganda. 


\section{Abstract}

Background: Evaluation of the contribution of adolescent health prom otion program s towards im proving adolescent sexual and reproductive health is lim ited in Uganda.

O bjective:This study evaluated an adolescent-focused intervention ("Accelerating the Rise in Contraceptive Prevalence"), of the USAID Com m unication for Healthy Com m unities program, in Uganda.

Research Design: A process evaluation design included quantitative and qualitative data collection m ethods.

Subjects: Study participants were adolescents and program im plem enters

Measures: The outcom es included program coverage and reach, and factors influencing im plem entation

Results: The program's activities were successfully implemented through collaborative partnerships with service partners and the com m nity. Interpersonal com $m$ unication com plem ented by $m$ ass $m$ edia $m$ essaging was effective in reaching and em powering adolescents with health inform ation to $\mathrm{m}$ ake inform ed choices for behavior change. The program used theoretical fram eworks to guide targted intervention implementation including audience segmentation and community em powerm ent.The use of $\mathrm{m}$ ass $\mathrm{m}$ edia $\mathrm{m}$ essaging without targeted placem ent was found to negatively affect program reach. Working through existing com m unity structures is im portantfor an effective reach of health prom otion program s. Lessons identified for scaling-up adolescent health program s include the need to harm onize training and deploym ent of com m unity cham pions by developm ent partners, recruit audience-specific influential champions, and link incom egenerating activities to health education interventions.

Conclusion: This study indicates the need to collaboratively develop and institutionalize effective m onitoring and evaluation strategies during the inception and design phases of adolescent health prom otion program s. This strategy will help program developers achieve appropriate accountability for efforts towards ownership and a continuation of gains.

K eywords Adolescents, Process Evaluation, Health Com m unication, Sexual and Reproductive Health, sub-Saharan Africa, Uganda 


\section{Introduction}

With the increasing population of adolescents in sub-Saharan Africa, the design of targeted adolescent sexual and reproductive health (SRH) programs has recently becom e a priority for governm ents an international developm ent partners. This follows the realization that adolescents contribute to the alarm ing health indicators of increasing HIV prevalence and teenage pregnancy globally (Hindin \& Fatusi, 2009, Paul-Ebhohim hen, Poobalan, \& Van Teijlingen 2008). While a significant proportion of Uganda's population are adolescents, adolescent SRH services are lim ited and do not address their needs (MOH, 2010; Birungi et al., 2008). This is partly due to the limited understanding of the SRH needs of adolescents as distinct from often generalized youth (Nalukwago et al., 2018-a). In Uganda, in 2016, adolescents had a $25 \%$ teenage pregnancy rate, and a $1.8 \%$ HIV prevalence for girls and $0.4 \%$ for boys (UBOS, 2018). Adolescents continue to face unm et SRH needs (e.g., 30\% contraception use in Uganda in 2016) (UBOS, 2018) and m aternal and child $\mathrm{m}$ ortality associated with unsafe deliveries (Bantebya, Muhanguzi, \& Watson, 2014; Loaiza \& Liang, 2013). These challenges are often aggravated by early $\mathrm{m}$ arriages and poverty that force adolescents to engage in multiple transactional relationships with older partners for $m$ aterial gain (Neem a, Musisi, \& Kibom bo 2004; Nobelius et al., 2010). Adolescents' beliefs regarding sex, contraceptive choices, and reproductive health are largely based on inform ation from peers and often characterized by inadequate knowledge, $\mathrm{m}$ yths, and $\mathrm{m}$ isconceptions (CHC, 2016-a; Nalukwago et al., 2018-b). However, m any adolescent health targeted program s are not evaluated for their contribution towards addressing adolescents' needs. This study evaluated the "Accelerating the Rise in Contraceptive Prevalence" (ARC) adolescent health interventions of the United States Agency for International Developm ent (USAID)-funded, Com m unication for Healthy Com m unitie(CHC) program in Uganda.

The CHC program was developed to support the Governm ent of Uganda and its im plem enting partners to address adolescent SRH needs. CHC isa five-year program im plem ented by a cqœerative agreem ent signed in June 2013, between USAID Uganda and FHI 360 (Fam ily Health International). The program aim ed to design and im plem ent quality healthcom m unication (HC) interventions to contribute to a reduction in HIV infections, total fertility, $\mathrm{m}$ aternal and child mortality, $\mathrm{m}$ alnutrition, $\mathrm{m}$ alariaand tuberculosis (CHC, 2016-b). A CHC-im plem ented process evaluation of adolescent SRH interventions guided program scaleup. A process evaluation provides inform ation on program im plem entation, whicis im portant for interpreting program outcom es and inform ing future efforts including generating critical lessons for im pact evaluations (Rashid et al., 2017; Androutsos et al., 2014; Joseph et al., 2015). This study presents the process-evaluation findings on how the 
CHC program 's prioritized health (and recom m ended) behaviorchange actions were received and adopted by adolescents.

The CHC program im plem entsn integrated cam paign called 'Obulam u? [How's Life?].' The cam paign platform uses a Life Cycleapproach to integrate health com $\mathrm{m}$ unication $\mathrm{m}$ essaging across age groups and public health topics. The program incorporates interventions that address the norm s of gender inequity, which act as barriers to health services uptake (CHC, 2016-b). The integrated Obulam u?cam paign delivers holistic m essages relevantto a person's stage of life rather than focusing on a fragm ented disease approach. The four life stages addressed in the cam paign include: 1) young adults (18-30 years) in relationships; 2) pregnant wom en and their $\mathrm{m}$ ale partners; 3 ) fam ilies with children(0-14 years) and targets caregivers of underfive children; and 4) adolescents (15-19 years) (CHC, 2016-b) as indicated in Figure 1 .

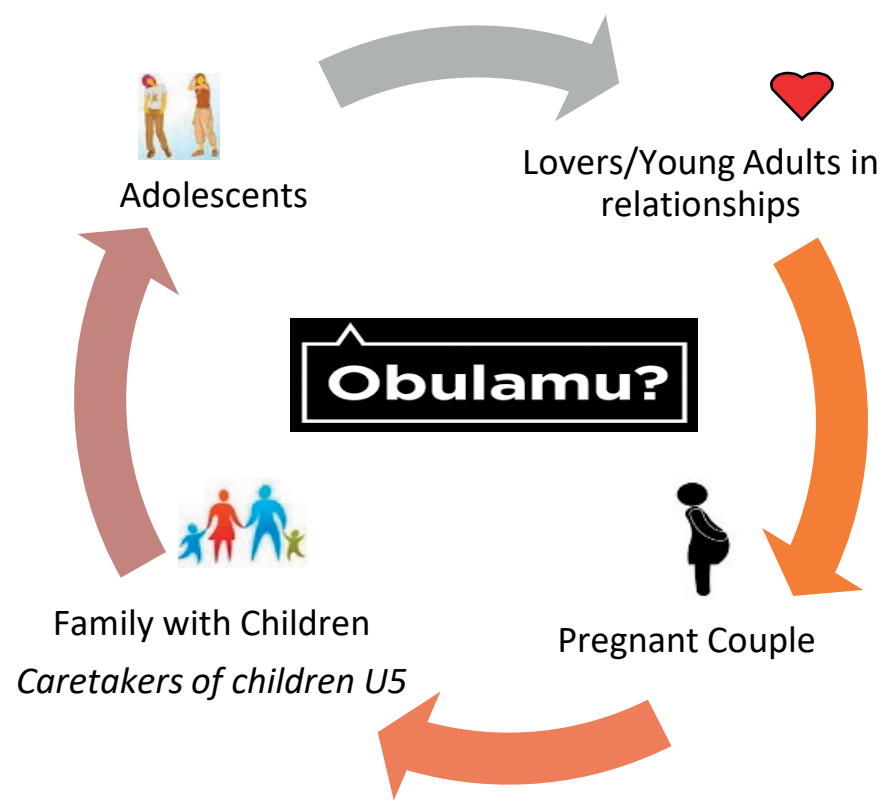

Children U5 - Children under five years

Figure 1: O bulamu? Life Cycle approach

Through its cam paign platform, CHC im plem ents the adolescerfocused com ponent of the Accelerating the Rise in Contraceptive Prevalence (ARC) program in Uganda, which addresses adolescent contraception needs (CHC, 2016-c). This process evaluation focused on ARC's adolescent SRH interventions to understand their 
current effect on future program $m$ ing. Use of proess evaluation to understand ARC's contribution was essential to avoid a "black-box evaluation" (m easuring and attributing outcom es to a program without exploring how the program was delivered) (Bartholom ew et al., 2016; Harachi et al., 1999).

\section{Methods}

\section{Program Description}

The ARC program, im plem ented in 2016, prim arily targets adolescent girls aged 15 19 (in and out of school), and young wom en aged 2024 and their partners in five districts (Kam uli, Iganga, Mayuge, Nam utum bæand Luuka) of East Central Uganda. These districts have the highest rates of teenage pregnancy (CHC, 2016-a). The secondary target audiences include adolescent boys aged 15-19 years and young $\mathrm{m}$ en aged 20-24 years, parents and guardians of adolescents, health workers, and religious leaders. Using the 360-degree com m unication approach indicated in Figure 2, the cam paign useda $\mathrm{m}$ ultichannel approach em ploying a variety of highdose and highintensity interpersonal com munication (IPC) activities including com m unity dialogues (CHC, 2016-b). IPC activities were com plem ented by radio, TV/video, outdoor m edia, and social $\mathrm{m}$ edia placem ents (CHC, 201-(b).

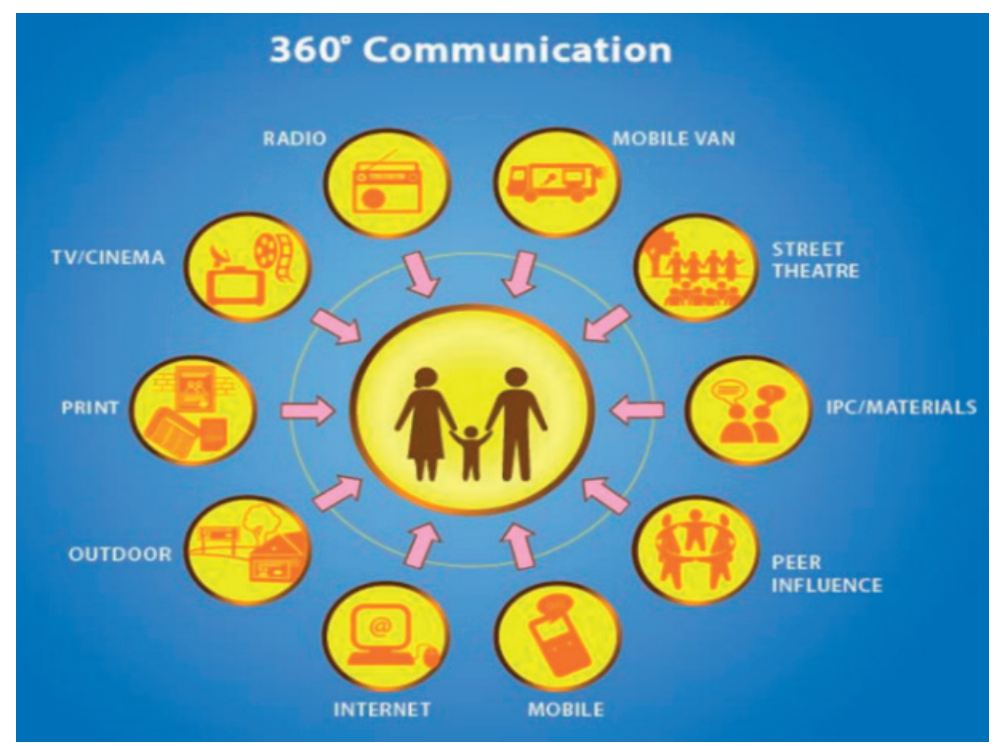

Figure 2: CH C's 360-degree communication approach for the ARC program 
The design and im plem entation of the ARC programwere grounded in the underlying ideologies of the Socio Ecological Model (SEM) illustrated in Figure 3. The m odel looks beyond individuals to their social context including interpersonal, institutional, com m unity and policy environm ents (CHC, 201-(b; Mckee, Manoncourt, Chin, \& Carnegie, 2002; Golden \& Earp, 2012). The sœial ecological paradigm is rooted in core principles concerning the interrelations am ong environm ental conditions, hum an behavior, and well-being. Environm ental settings are characterized as having m ultiple physical, social, and cultural dim ensions that an influence a variety of health outcom es (Stokols, 1996). The SEM was used to analyze the context in which the target audiences $m$ ade decisions, accessed services, and related socially to address barriers to change using theory- and evidence-based program $\mathrm{m}$ ing (CHC 2016b).

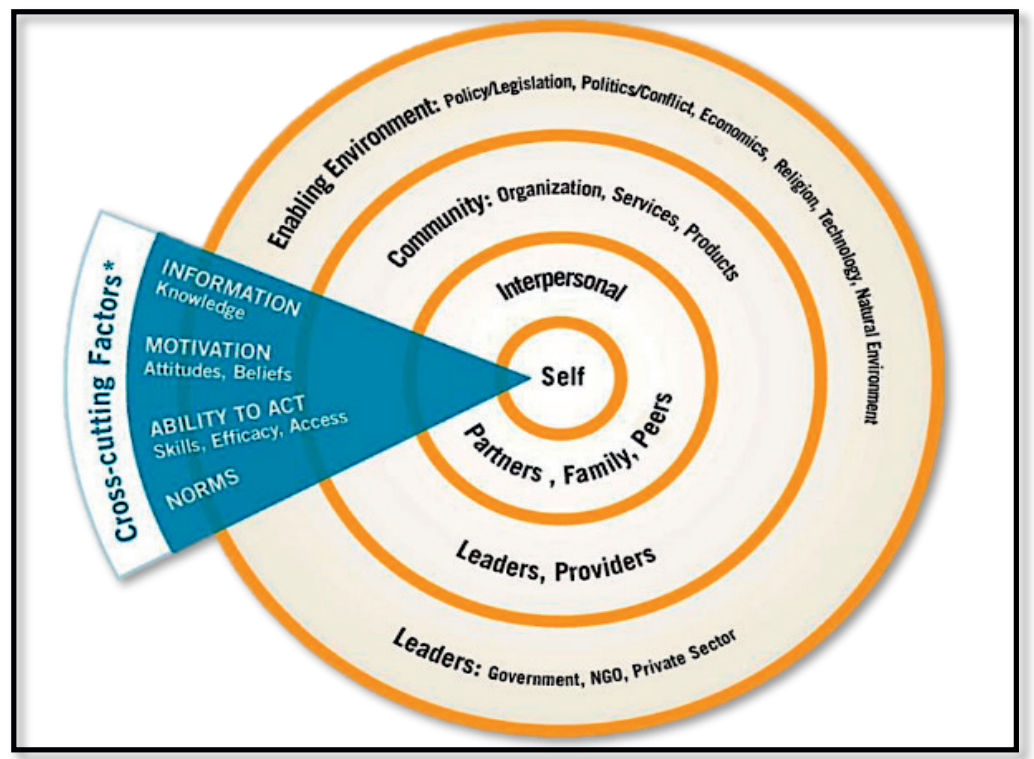

Figure 3: An illustration of the Social Ecological Model

Source: Mckee et al., 2002

\section{Study Design}

This study used a process evaluation design. We used a m ixedm ethods approach com bining quantitative and qualitative data collection $\mathrm{m}$ ethods as recom $\mathrm{m}$ ended for com plex interventions (Moore et al., 2015). 


\section{Data Collection methods}

Data collection included a review of CHC program records, direct observation during site-m onitoring activities, and consultations with program staff.

\section{Study team}

Planning a process evaluation requires sufficient expertise and experience to determ ire and achieve the aim s (Moore et al., 2015). This study drew expertise from a range of relevant disciplines including public health, behavioral science, health prom otion, prim ary care, sociology, m onitoring, evaluation, and research. The experts provided practical experience in the design and im plem entation of adolescent SRH programs from various settings, and objectivejudgm ents in the process evaluation.

\section{Review of program records}

The review of program records entailed an assessm ent of the program 's theoretical approaches, and docum ents related to activity im plem entation and research (see below).

\section{Assessment of program theoretical approaches}

All public health interventions reflect explicit and im plicit theories on how a course of action will solve a perceived problem (Mœre et al., 2013; Rossi, Lipsey, \& Freem an, 2004). Theories should clearly specify intervening processes or $m$ echanism s that link the program 's activities and outcom esH(arachi et al., 1999; Rawat et al., 2013). We assessed the theoretical constructs em bedded in the ARC program design and im plem entation.

\section{Assessment of documents for program activity implementation}

Process evaluation encom passes an assessment of the following: 1) program implem entation, 2) specific intervention activities, 3) context surrounding the activities, 4) responsible personnel, 5) target audiences, and 6) level of effort (Plum m er et al., 2006; Saunders, Evans, \& Joshi, 200)5 To understand context, we first reviewed the $\mathrm{CHC}$ and ARC program s' inception docum ents including the technical proposal and $\mathrm{HC}$ audit report. Next, we reviewed docum ents related to activity im plem entation, individual activity reports, $m$ onthly and quarterly reports, PowerPoint presentations, and $\mathrm{m}$ inutes from planning $\mathrm{m}$ eetings.

\section{Assessment of documents for program research}

We reviewed ARC research docum ents to understand the program 's diffusion in the com $\mathrm{m}$ unity and com $\mathrm{m}$ unity awareness. The reviewed docum ents included form ative assessments, evaluative surveys (quantitative/crosssectional), qualitative rapid assessm ents, and participatory action research reports. National surveys, including 
Uganda Dem ographic Health surveys, were reviewed to corroborate the ARC program research reports. The aim was to understand the program 's progrestowards addressing perform ance $\mathrm{m}$ esures/indicators.

\section{Direct observation during on-site monitoring}

ARC program staff shared their field observations. Approxim ately 12 process evaluation observations were conducted using a checklist during on-site m onitoring to assess the progress of activity im plem entation.

\section{Consultations with ARC program staff}

Consultations with ARC program staff provided a clear understanding of the program 's im plem entation approaches. The staff verbally agreed and voluntarily consented to participate in this study after a thorough explanation of the study purpose. In total, 10 program staff (five $m$ aleand five fem ale) were individually consulted.

\section{Evaluation Outcomes and Data Analysis}

The evaluation outcom es of interest were to understand ARC's program design and coverage, factors that influenced program implementation and the program's effectiveness in reaching the intended target populations. To ensure a structured data analysis based on the them es and code categories identified in program docum ents, we adopted Linnan and Steckler's (2002) process-evaluation com ponents. The com ponents include a description of the program context, reach, dose delivered, dose received, and fidelity (Bartholom ew et al., 2016). We analyzed data from January 2014 - Decem ber 2017, including theCHC program 's inception and design periods.

Qualitative content analysis of the available program docum ents was conducted (Jäger et al., 2016; Bess, King, \& LeMaster 2004). Content analysis refers to a system atic review of written docum ents produced byARC program staff and other stakeholders including village health team s (VHTs), per cham pions, com m unity leaders, and com $m$ unity $m$ em bers during program design and im plem entation (Bess et al., 2004). From the review of written docum ents, them es, code categioes, words, and phrases that captured salient program elem ents were developed in a com $\mathrm{m}$ on analysis fram ework reflected in the study evaluation questions (Table 1). Quantitative data from crosssectional surveys and rapid assessm ents that addressed the sudy objectives were analyzed using the program 's Monitoring, Evaluation and Learning (MEL) Plan including the program 's perform ance indicators on contraception use (FHI 360, 2015). The analysis focused on perform ance indicators such as exposure to fam ilyplanning m essages, knowledge, awareness and contraception prevalence rates am ong adolescents. The program planning/implementation team and 
com $m$ unity $m$ em bers (especially the target populationadolescents) were the $\mathrm{m}$ ain units of analysis. The use of both qualitative and quantitative data analysis techniques allowed for data saturation while inform ing the process evaluation. Data analysis software (NVivo for qualitative data and SPSS for quantitative data) was used for data structuring.

\section{Process evaluation questions for CHC's ARC program implementation}

In contextualizing the process evaluation components, this study explored the evaluation questions highlighted in Table 1.

Table 1: Process Evaluation Questions for CHC's ARC program

\begin{tabular}{|c|c|c|c|}
\hline Components & Q uestions & Indicators & Method \\
\hline Context & $\begin{array}{l}\text { What were the policy, social, and } \\
\text { econom ic environm ental } \\
\text { contexts before and during } \\
\text { program im plem entation? } \\
\text { What changes were m ade in the } \\
\text { policy environm ent for } \\
\text { adolescent health? Were } \\
\text { changes inform ed by evidence? } \\
\text { What ARC health-com m unication } \\
\text { program s or m essages were } \\
\text { adolescents exposed to before } \\
\text { and after the interventions? } \\
\text { How were various stakeholders } \\
\text { involved in the ARC program } \\
\text { design and im plem entation? }\end{array}$ & $\begin{array}{l}\text { Existing adolescent } \\
\text { health policies } \\
\text { addressing adolescent } \\
\text { SRH needs } \\
\text { Adolescent access to } \\
\text { SRH services } \\
\text { Adolescent exposure to } \\
\text { health m essages } \\
\text { Level of stakeholder } \\
\text { engagem ent and skill } \\
\text { developm ent for } \\
\text { em powerm ent }\end{array}$ & $\begin{array}{l}\text { Assessm ent of } \\
\text { theoretical } \\
\text { approaches } \\
\text { Assessm ent of } \\
\text { design and } \\
\text { practical } \\
\text { activity } \\
\text { im plem entation } \\
\text { docum ents } \\
\text { Consultations } \\
\text { with the } \\
\text { im plem entation } \\
\text { team }\end{array}$ \\
\hline Reach & $\begin{array}{l}\text { To what extent is the program } \\
\text { reaching the adolescents? } \\
\text { Were sub-groups within the } \\
\text { adolescent population being } \\
\text { m issed? Were som e subgroups } \\
\text { reached m ore than others? } \\
\text { Were unintended groups taking } \\
\text { part and benefiting from the } \\
\text { ARC program? } \\
\text { Were changes m ade during } \\
\text { program im plem entation? To } \\
\text { what extent were the changes } \\
\text { inform ed by evidence to ensure } \\
\text { effective reach? }\end{array}$ & $\begin{array}{l}\text { Percentage of intended } \\
\text { participants, } \\
\text { disaggregated by sub- } \\
\text { group } \\
\text { Percentage of } \\
\text { unintended users } \\
\text { Num berof changes } \\
\text { m ade during program } \\
\text { im plem entation to } \\
\text { ensure effective reach }\end{array}$ & $\begin{array}{l}\text { Assessm ent of } \\
\text { practical } \\
\text { activity } \\
\text { im plem entation } \\
\text { docum ents } \\
\text { Observation of } \\
\text { activities } \\
\text { during on-site } \\
\text { m onitoring } \\
\text { Consultations } \\
\text { with the } \\
\text { im plem entation } \\
\text { team }\end{array}$ \\
\hline $\begin{array}{l}\text { Dose } \\
\text { delivered }\end{array}$ & $\begin{array}{l}\text { How m uch ofthe program was } \\
\text { delivered? } \\
\text { What was delivered inconsistently } \\
\text { or om itted? Why? To what } \\
\text { extent were the planned } \\
\text { intended m essage dose and } \\
\text { intensity delivered? } \\
\text { Did any factors affect the delivered } \\
\text { dose? }\end{array}$ & $\begin{array}{l}\text { Percentage of the target } \\
\text { audience who } \\
\text { reported having seen } \\
\text { or heard m essages }\end{array}$ & $\begin{array}{l}\text { Assessm ent of } \\
\text { practical } \\
\text { activity } \\
\text { im plem entation } \\
\text { docum ents } \\
\text { Media m onitoring } \\
\text { reports }\end{array}$ \\
\hline
\end{tabular}




\begin{tabular}{|c|c|c|c|}
\hline Components & Q uestions & Indicators & Method \\
\hline $\begin{array}{l}\text { Dose } \\
\text { received }\end{array}$ & $\begin{array}{l}\text { What was the average dose } \\
\text { received by adolescents? } \\
\text { What parts of the intervention were } \\
\text { not received consistently? Why? } \\
\text { What was the difference in } \\
\text { results (based on the evaluation) } \\
\text { for intervention segm ents } \\
\text { delivered consistently and } \\
\text { inconsistently? }\end{array}$ & $\begin{array}{l}\text { Percentage of } \\
\text { adolescents who } \\
\text { dem onstrated } \\
\text { com prehensive } \\
\text { knowledge of } \\
\text { contraception, } \\
\text { approved of desired } \\
\text { behaviors and/or } \\
\text { health services on } \\
\text { contraception, and } \\
\text { intended to adopt the } \\
\text { sam e. } \\
\text { Percentage of sexually } \\
\text { active adolescent girls } \\
\text { aged } 15-19 \text { who used } \\
\text { m odern contraception } \\
\text { m ethods }\end{array}$ & $\begin{array}{l}\text { Assessm ent of } \\
\text { program } \\
\text { research } \\
\text { docum ents }\end{array}$ \\
\hline Fidelity & $\begin{array}{l}\text { How were the program } \\
\text { interventions and m essages } \\
\text { linked to theoretical m ethods in } \\
\text { practice? } \\
\text { Was the program im plem ented } \\
\text { with fidelity and quality? } \\
\text { Were the program interventions } \\
\text { im plem ented as planned? } \\
\text { Were there program interventions } \\
\text { that did not work? How did the } \\
\text { program use evidence and } \\
\text { feedback on what did not work } \\
\text { to learn and adapt the activity } \\
\text { im plem entation? }\end{array}$ & $\begin{array}{l}\text { The degree to which the } \\
\text { m essage was linked to } \\
\text { theoretical m ethods } \\
\text { and practical } \\
\text { applications, and } \\
\text { determ inants }\end{array}$ & $\begin{array}{l}\text { Narrative analysis } \\
\text { and assessm ent } \\
\text { of feedback } \\
\text { docum ents } \\
\text { Assessm ent of } \\
\text { research } \\
\text { docum ents }\end{array}$ \\
\hline
\end{tabular}

\section{Ethical considerations}

The FHI 360 institutional review board (the USA federally registered Protection of Hum an Subjects Com $\mathrm{m}$ ittee) waived written consent for this study (reference num ber 616862-1). The Ugandan Governm entaccredited Makerere School of Public Health Research Ethics Com m ittee also waived written consent (refeence 259). Participants were told the purpose of the study and given the opportunity to ask questions before agreeing to participate. Verbal inform ed consent was requested from ARC program staff before being interviewed. The date and tim e of verbal consent was noted for each participant accom panied by the responsible study staff $\mathrm{m}$ em ber's signature. 


\section{Results}

Our evaluation assessed the practical experience of the ARC program 's design and im plem entation. The analysis focused on three $m$ ain aspects: 1) context of program design, 2) areas of program success and 3) areas for strengthening the scale-up of adolescent health program s. Evaluation results should be interpreted with caution because they do not reflect the full im pact of the overarching OBULAMU? cam paign and the whole CHC program on adolescents. Rather, the central focus was on aspects that culm inated inthe ARC program 's design and im plem entation.

\section{The context of program design}

The program planning docum ents indicated that the ARC program was developed following the alarm ing health outcom es am ong adolescents in Uganda. Uganda's unm et need for fam ily planning was am ong the highest in subSaharan Africa- $31 \%$ am ong adolescent girls aged 15-19 (FHI 360, 2013; UBOS, 2012). Exacerbating the challenge of unm et need was gender inequality affecting health outcom es by lim iting wom en's decision-m aking power within fam ilies and their ability to access health services (FHI 360, 2013). The overall effectiveness of HC interventions in Uganda, even in late 2012, was identified as unclear and not well translated into health outcom es (CHC, 2014; FHI 360, 2013). The fragm entation of HC efforts was identified as a major problem. This was linked to the lack of collboration and coordination am ong diverse governm ent and developm ent partners responsible for designing and delivering $\mathrm{HC}$. Although $\mathrm{HC}$ cam paigns were found to be targeted to specific audiences, they had lim ited coverage and did not reach beyond urban centers. Messaging focused on top-down m essages delivered through lim ited channels relying heavily on printed $\mathrm{m}$ aterials, although only slightly m ore than a quarter of Uganda's population is literate (FHI 360, 2013; UBOS, 2012). Mass m edia cam paigns were not adequately intensive or linked with IPC and other com $\mathrm{m}$ unitybased approaches in m utually reinforcing ways (FHI 360, 2013). Thus, local com $m$ unities were not engaged as partners in their own behavior change, which $m$ ade it difficult to address gender and other social norm s that negatively affect health behaviors and service dem ands. Within facilities, health workers' lim ited IPC skills were found to contribute to a perception of unfriendly services in $\mathrm{m}$ any com $\mathrm{m}$ unities. Existing national $\mathrm{HC}$ strategies before the project intervention were still in draft form, and som e were outdated (CHC, 2014). Existing HC m aterials and activities conveying health-related social and behavior change com m unication (SBCC) m essages were occasionally contradictory. While strategies covered gender issues, actual $\mathrm{m}$ aterials negligibly included considerations for social system $\mathrm{s}$ and relationships that reinforced existing behaviors. Capacity gaps were identified as affecting the operationalization 
of working groups and task forces, e.g., the adolescent SRH working group. Services targeting adolescents were limited and/or poorly resourced with staff and commodities in general ( $\mathrm{CHC}, 2014 ; \mathrm{MOH}, 2010)$. These contextual factors (sum $\mathrm{m}$ arized in Figure 4) and the realization that there was aneed to target adolescent SRH needs - specifically addressing com $m$ unication on contraception use- led to the ARC program design.

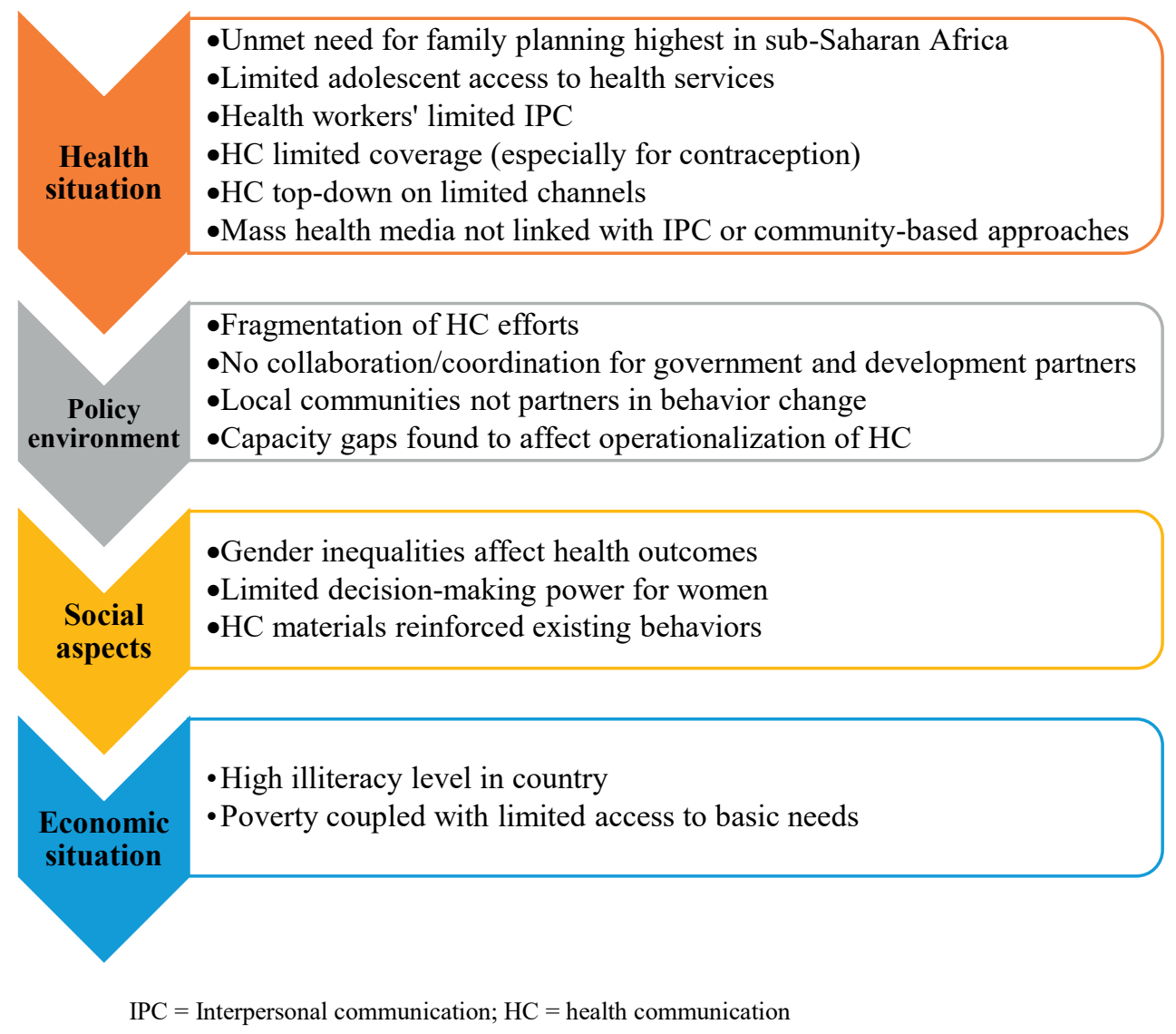

Figure 4: A summary of contextual issues identified before and during implementation of the ARC program for adolescent and young adult females 


\section{Areas of program success}

\section{Program coverage}

The findings showed that the ARC program was designed to increase knowledge and uptake of modern contraceptives am ong adolescents and young wom en of reproductive age in selected districts of Uganda. It aim ed to increase adolescent and young adult fem ales' com prehensive knowledgøf contraception and its benefits and equip them with inform ationto m ake inform ed choices (CHC, 2016a). Em bedded within the program was the explicit use of theoretical fram eworks, including the SEM, to define the prim ary target population and their key influencers. The program worked collaboratively with the Governm ent of Uganda through the Ministry of Health and other developm ent/im plem enting partners to conduct HC interventions including $\mathrm{m}$ ass $\mathrm{m}$ edia $\mathrm{m}$ essaging and IPC. For IPC, ARC planned to im plem ent 150 youth bashes or edutainm ent events and orient and deploy 150 comm unity cham pions. The $\mathrm{m}$ ass $\mathrm{m}$ edia plan was to develop and dissem inate print and outdoor HC m aterials such as posters, flyers, and billboards (CHC, 2015) and conduct m onthly broadcasts on radio including, 180 radio spots, $180 \mathrm{DJ}$ m entions and $90 \mathrm{DJ}$ led discussions called "Obulam u? Mom ents" on local radio stations with coverage in the five targeted districts.

\section{Program Reach}

ARC had intended quantitative outcom es focused on the number of the target populations reached by interventions and qualitative outcom es fæused on feedback from target audiences. Findings indicated that ARC staff conducted quarterly coordination meetings with service partners and developed joint im plem entation schedules linking dem and generation and service delivery interventions. Working in this partnership, the ARC program trained and deployed 1,303 cham pions (VHTs, peer cham pions, and com $\mathrm{m}$ unity leaders) who reached 202,060 adolescent girls and young wom en in hom evisits, one-on-one sessions and sm all groupdiscussions on contraception use. Som e adolescent girls and young adult wom en $\mathrm{m}$ ay have been reached $\mathrm{m}$ ore than once, and fem ales from nomparticipating districts $\mathrm{m}$ ay also have been reached. The ARC program conducted 53 com m unity edutainm ent events that were locally known as Kadankes, wherein 8,236 adolescent girls were reached with m essages on contraception use. The program had 6,240 radio placem ents on four local radio stations (Baba FM, NBS FM, and Kam uli Broadcasting Service, and Apex FM), and reached an estim ated 400,000 adolescents every quarter (CHC quarterly reports, 2015-2016). Prioritized health m essages included: using contraception to prevent teenage pregnancy, testing for HIV and receiving results, building healthy 
relationships with the opposite sex, delaying sexual debut, using condoms, and seeking accurate health inform ation.

ARC also reached secondary and unintended groups. For exam ple, the com m unity based interventions and the radio broadcasts reached $\mathrm{m}$ en and wom en beyond the targeted age group (CHC quarterly reports, 2015-2016). Im plicit in program implem entation was the use of other theoretical fram eworks to reach targeted audiences. Using the Diffusion of Innovations theory, the program adopted targeted im plem entation of com $m$ unity interventions including $\mathrm{m}$ aterials distrited in hotspots such as bars, bore-holes, m arkets, and trading centers to reach laggards. The program used the Em powerm ent theory to build com m unity capacity through collaborative partnerships and shared decision $\mathrm{m}$ aking IPC com plem ented by $\mathrm{m}$ ass m edia was found to be an effective $\mathrm{HC}$ approach by providing inform ation that em powered adolescents to $\mathrm{m}$ ake inform ed health choices (CHC, 2018). This is illustrated in the quotes below.

I used to think that other family planning methods are for women who have given birth and want to space their children. But the peers helped me understand that family planning can be used by any female above 15 years and their information was confirmed by the nurse who gave me the injection. (Fem aleadolescent, Nam utum ba district)

We get enough time with the champion so the level of discussion and understanding is far much better. Even the puzzling questions that someone would fear to ask in public, he/she will be free to ask since it is only two people. (Fem ale adolescent, Iganga distict)

\section{The dose delivered and received}

ARC program 's cross-sectional baseline and end-line surveys showed several selfreported and health service data changes am ong adolescents for fam ilyplanning services uptake. ARC evaluative surveys indicated that exposure to fam ily-planning m essages was $80 \%$ am ong adolescent girls. These fem ales showed a slight increase in knowledge on the use of m odern contraception m ethods (23\% at baseline to $37 \%$ at end-line) (Table 2). The proportion of adolescent girls who reported having one child decreased from $33 \%$ to $28 \%$ and those who reported having two or more children decreased from $10 \%$ to $6 \%$ (Bufum bo et al., 2016)

Although the CHC om nibus survey (2017) indicated that approval of the use of m odern contraceptives was $74 \%$, thecontraceptive prevalence rate was relatively low at 33\% (CHC \& IPSOS Lim ited, 2017) (Table 2). 
CHC evaluative surveys (2016) indicated that although there was a slight increase in prevalence at end-line, approval for contraception use rem ained high (basdine $85 \%$ and end-line $82 \%$ ). There was a slight increase in the use of contraceptives (baseline $17 \%$ ) and end-line 25\%) and knowledge about contraception (baseline $38 \%$ and endline 56\%) (Table 2).

Table 2: ARC program reach by performance indicators

\begin{tabular}{|c|c|c|c|c|c|c|}
\hline \multirow{2}{*}{\multicolumn{2}{|c|}{$\begin{array}{l}\text { Program Performance } \\
\text { Indicators }\end{array}$}} & \multicolumn{2}{|c|}{$\begin{array}{l}\text { ARC program } \\
\text { Evaluative Assessments }\end{array}$} & \multirow{2}{*}{$\begin{array}{l}\text { CH C } \\
\text { Listening/ } \\
\text { O mnibus } \\
\text { survey } \\
\text { June 2017 } \\
\text { East } \\
\text { Central } \\
\text { region } \\
\text { percentages } \\
(\%)\end{array}$} & \multicolumn{2}{|c|}{$\begin{array}{l}\text { CH C Evaluative } \\
\text { Surveys }\end{array}$} \\
\hline & & $\begin{array}{l}\text { Baseline } \\
\text { percentage } \\
(\%) \\
\text { October } \\
2015\end{array}$ & $\begin{array}{l}\text { End-line } \\
\text { percentage } \\
(\%) \\
\text { September } \\
2016\end{array}$ & & $\begin{array}{l}\text { Baseline } \\
\text { percentage } \\
(\%) 2015\end{array}$ & $\begin{array}{l}\text { End-line } \\
\text { percentage } \\
\text { (\%) } 2017\end{array}$ \\
\hline \multicolumn{2}{|c|}{$\begin{array}{l}\text { Exposure (heard or seen) to } \\
\text { fam ily planning m essages } \\
\text { (pregnancy delay or birth } \\
\text { spacing) }\end{array}$} & - & 80 & 74 & 59 & 60 \\
\hline \multicolumn{2}{|c|}{$\begin{array}{l}\text { Knowledge of the use of } \\
\text { m odern contraception } \\
\text { m ethods }\end{array}$} & 23 & 37 & - & 38 & 56 \\
\hline \multicolumn{2}{|c|}{$\begin{array}{l}\text { Approve the use of } \\
\text { contraceptives }\end{array}$} & 55 & 74 & 74 & 85 & 82 \\
\hline \multirow{2}{*}{$\begin{array}{l}\text { Intention to seek } \\
\text { contraceptive } \\
\text { services in the } \\
\text { next } 6 \mathrm{~m} \text { onths }\end{array}$} & $\begin{array}{l}\text { Not } \\
\text { Married }\end{array}$ & 40 & 58 & \multirow{2}{*}{86} & - & - \\
\hline & Married & 57 & 66 & & - & - \\
\hline \multirow{2}{*}{$\begin{array}{l}\text { Intention to use } \\
\text { contraceptives in } \\
\text { the next } 6 \\
\text { m onths }\end{array}$} & $\begin{array}{l}\text { Not } \\
\text { Married }\end{array}$ & 39 & 53 & \multirow{2}{*}{47} & 33 & 42 \\
\hline & Married & 54 & 67 & & 35 & 44 \\
\hline \multicolumn{2}{|c|}{$\begin{array}{l}\text { Contraceptive prevalence } \\
\text { rate (sexually active girls } \\
\text { currently using any m odern } \\
\text { m ethod of fam ily planning) }\end{array}$} & - & - & 33 & 17 & 25 \\
\hline
\end{tabular}

\section{Fidelity}

ARC records showed that im plem entation was done as planned and changes effected using the collaborative learning and adaptation approach to address em erging adolescent needs. The SEM theoretical framework was used in program implem entation to segm ent target audiences. ARC instituted measures to continuously assess progress in the implem entationof activities with quality and fidelity. The m easures included continuous quality-im provem ent $\mathrm{m}$ onitoring visits, 
progress review meetings, rapid assessm ents, and client exit interviews during com $m$ unity edutainm ent events. Thresults from the program assessm ents indicate that trained peer cham pions were able to execute their IPC activities to influence adolescents in adopting health-seeking behaviors and increasing access to contraceptive services (Batam wita, et al., 2016).However, som e cham pions revealed their difficulties in discussing som e fam ily planning topics related to an agegroup $\mathrm{m}$ ism atch/barrier between the cham pion and adolescent. Monitoring reports indicat that $90 \%$ of the cham pions required additional support, eg., refresher training, supervision, and identification $\mathrm{m}$ aterial access to effectively execute their work (MOH \& CHC, 2016). However, disaggregation of data in $\mathrm{m}$ ost program reports did not include targeted sub-group reach. This $\mathrm{m}$ ade it difficult to effecively evaluate and describe the ARC program 'sreach.

\section{Areas that did not work for the ARC program and where subsequent collaborative learning and adaptation occurred}

Records indicated that the ARC program did not work in som e areas and so staff used evidence and feedback to adapt and $\mathrm{m}$ ake changes in activity im plem entation. The program first targeted adolescent girls and young adult wom en without involving parents. However, m ost parents did not allow their adolescent girls to attend health edutainm ent events citing that they were avenues for girls to m eet with boys. This affected the num ber of adolescent girls attending health gatherings. The program used this evidence to design a parent com m unicatia cam paign. Com m unity interventions were halted in January and February 2016 following Parliam entary and Presidential elections. The elections disrupted com m unity healthedutainm ent events since they were $\mathrm{m}$ istaken as political rallies, and program cam paigm aterials were vandalized. This disruption cost tim e inthe effective im plem entation of planned ARC activities. At inception, the program targeted all com m unity cham pions, specifically VHTs attached to health facilities. This did not work because cham pionfollow-up was not $\mathrm{m}$ anageable and their work structure varied by implem enting partners, thereby $\mathrm{m}$ aking cham pion reporting difficult. To im prove followe, $\mathrm{CHC}$ changed the approach to focus on 10 cham pions per highvolum e site and opted to work with existing com $\mathrm{m}$ unity district structures to im prove reporting.

\section{Areas for strengthening in adolescent health programming}

The study findings highlighted lessons for strengthening and im proving adolescent health program $m$ ing in Uganda. 


\section{Targeted radio placements for adolescents}

Media channel mix was im portant for reaching dolescents. The key lesson from using $\mathrm{m}$ ass $\mathrm{m}$ edia (especially radio and TV) was that identifying the tim e when adolescents listen to radios was im portant. Adolescents reported specific tim es and radio program s of interest on selected days that $m$ otivate them to listen. Effective channels of com $\mathrm{m}$ unication for reaching this target group were radio com plem ented by IPC (CHC, 2018). Identifying high-volum e listener tim es of a target audience is evidence that inform ed programadaptation to place $\mathrm{HC}$ m essages inyouth-focused program s on radio and TV (CHC quarterly reports, 2015-2016).

Radios are more effective because those who do not read, can listen to radios and understand. (Fem ale adolescent, Kyenjojo district)

The method which is not effective is the TV because we don't own any, but the radio is very effective. (Male adolescent, Kyenjojo district)

Because on radio the information is not in-depth, even posters always highlight the briefs on major issues compared to the VHTs who give detailed information. (Male adolescent, Lira district)

\section{Harmonized training and deployment of champions by development partners}

Monitoring reports indicated that although there was an appreciation of ARC's IPC strategy to effectively engage com m uity cham pions, efforts to train and depby the cham pions were fragm ented am ong developm ent partners ( $\mathrm{MOH} \& \mathrm{CHC}, 2016$ ). Harm onization of IPC interventions am ong implem enting partners is critical for im proving adolescent health program $\mathrm{m}$ ing. Harm onization partner-led com $\mathrm{m}$ unity cham pion efforts should be spearheaded by the Governm ent.

You know the way the VHT [IPC] strategy has been implemented, it has not been straight forward because each partner who comes, they come with their own programs and they will all set targets for their programs, so we don't have specific targets for the VHTs. Their work depends on the partner who comes and wants to use them. However, under normal circumstances, the VHTs are supposed to work harmoniously within their villages to refer clients to facilities and carry out health education talks. (In-charge at a health facility in one participating district) Recruitment of traditional female sex educators/aunties as interpersonal champions

Traditional fem ale sex educators or aunties, popularly known as Ssengas, were identified as influential and credible sources of inform ation for adolescent girls. Therefore, recruitm ent of aunties as IPC cham pions was highlighted as vital. On the 
contrary, some program records showed that adolescents were alienated from interacting with aunties on sexuality issues because they were not updated with fastgrowing technological advancem ents. For example, the aunties' inability to use advanced com munication overinternet-based social media (popularly used for teenage com munication) distancesthem when discussing sexuality issues with adolescents. It was noted that some aunties do not keep secrets, which affects confidentiality in discussions of sexuality issues with adolescents. Therefore, equipping aunties with updated com m unicaton skills and effective supervision is pertinent.

Facebook has kept the aunties far from the adolescent. So, the adolescent learns most sexual issues from the internet because the aunt does not know what is trendy. Examples in her talk are archaic and unconnected to the present internet exposure. (Fem ale adolescent, Jinja district)

Aunties also do not keep confidentiality and speak loud about adolescent secrets at boreholes. (Fem aleadolescent, Mayuge district)

\section{Linking income-generating activities to health education}

Linking health education with livelihood and incom egenerating activities m otivates adolescents to seek health services. Livelihood interventions were identified as im portant in providing alternative choices for fem ale adolescents to receive incom e rather than depend on male partners (CHC quarterly reports, 2015-2016). This evidence guided program adaptation in integrating skills for incom egenerating activities including farm ing, kneading, weaving, and hairdressing to support fem ale adolescents' livelihoods.

Adolescents look towards employing themselves by waking up early to go cultivate or make bricks to keep them busy so that they do not run after sex. If properly done they can earn enough to pay for their school fees. (Fem ale adolescent, Kam uli district)

\section{Values Clarification Tool used to demystify gender and misconceptions about contraception use}

The use of Obulam u? Values Clarification Tool (VCT) (Figure 5) was im portant in highlighting gender issues and addressing $\mathrm{myths}$ and $\mathrm{m}$ isconceptions on contraception use during IPC discussions. Although the program trained cham pions on the use of the VCT, for m axim um benefit the use of the tool was only as effective as the user's ability to correctly apply the tool and avoid personal bias. The VCT assisted cham pions to re-evaluate their perceptions of adolescent SRH in regard to seeking information on sexuality and contraception services. However, the 
cham pions' ability to effedively use the VCT in their routine work was not detailed in ARC docum entation (CHC, 2016-d). Nonetheless, the VCT can be adapted in adolescent health program $\mathrm{m}$ ing and revised to reflect evolving/em erging issues and needs that apply to context.

\section{OBULAMU Values Clarification Tool}

\begin{tabular}{|l|l|l|l|}
\hline Statement & Yes & No & Don't know \\
\hline Family Planning (FP) & & & \\
\hline $\begin{array}{l}\text { Women need permission from their husbands before using Family } \\
\text { Planning. }\end{array}$ & & & \\
\hline Family Planning causes infertility. & & & \\
\hline $\begin{array}{l}\text { People below } 18 \text { years should get information about Family } \\
\text { Planning. }\end{array}$ & & & \\
\hline Having many children is a sign of wealth and prestige. & & & \\
\hline $\begin{array}{l}\text { Only the man can decide the number of children a family can } \\
\text { have. }\end{array}$ & & & \\
\hline
\end{tabular}

Figure 5: O bulamu? Valus Clarification Tool used by CH C for the ARC program

\section{Discussion}

CHC's planned ARC activities including training and deploying community cham pions to conduct health education talks, com $\mathrm{m}$ unity edutainm ent eventsind $\mathrm{m}$ assm edia m essage placem ents were successfully im plem ented in collaboration with service partners and the com m unity in Uganda. IPC com plem ented by $m$ ass $m$ edia was effective in reaching and em powering adolescents with health inform ation to $\mathrm{m}$ ake inform ed choices. Adolescent inteaction with the com $\mathrm{m}$ unity cham pions helped them understand contraception use inform ation to facilitate behavior change and service uptake. The ARC program used theoretical fram eworks to guide im plem entation (including the SEM for audience segm entation), rad Em powerm ent theory for com m unity em powerm ent through collaborative partnerships and shared 
decision $\mathrm{m}$ aking. Through its instituted $\mathrm{m}$ easures of assessing the progressof activity implem entation, we noted that the trained comm unity cham pions were able to execute their IPC activities. However, $m$ any cham pions were not confident about all health topics, which indicated that they needed additional refresher training. Our evaluation found that the use of $\mathrm{m}$ assm edia m essaging without targeted placem ent negatively affected program reach to the intended target audiences. National political elections disrupted health com $\mathrm{m}$ unication interventions because they were $\mathrm{m}$ istaken as partisan. Targeting a large num ber of com m unity cham pions was difficult for follow-up and reporting, therefore limiting the num ber to a manageable size and working with existing com m unity structures is im portant. Effective evaluation of program reach was challenged by the lim ited data disaggregation in most ARC reports, which did not indicate program reach to the various subgroups of the target population.

Our findings reflect those of other studies. Collaborative partnerships for com $m$ unity health and development provide opportunities for studying and contributing to em powerm ent (Fawcett et al.,1995). Previous studies found that shared decision $\mathrm{m}$ aking em powers individuals to exercise som e control over local services and recognize the im portance of $m$ atching program delivery to local needs, preferences, and cultural norm s (Durlak \& DuPre, 2008; Kegler \& Wyatt, 2003). Using m essage effect theories to design m essages for target audiences can enhance the probability of a cam paign's success (Randolph \& Viswanath, 2004. Mass-m edia m essaging by radio has been found to be a com $m$ on $m$ ethod for reaching adescents if $m$ atched with targeted $m$ essage placem ent. UBOS (2018) found that radio is the $\mathrm{m}$ ost com $\mathrm{m}$ on source for fam ily planning m essages inUganda since $57 \%$ of girls and $55 \%$ of boys reported hearing a fam ily-planning m essage on the radio. Wom en who view $m$ or fam ily planning $\mathrm{m}$ essages on television, radio, and print $\mathrm{m}$ edia were found to be $\mathrm{m}$ ore likely than those who see fewer m essages to use contraceptives (Medley et al., 2009). Multi-m edia cam paigns are $m$ ore likely to result in greater im pact since $m$ essagesear $\mathrm{m}$ utually reinforced (Bessinger et al., 2004). Com m unication channels including $\mathrm{m}$ edia and IPC should be selected and used in a way that reaches a high percentage of the target population multiple tim es over a given period, because the greater a cam paign's reach (exposure), the greater the behavior change (Snyder, 2007; Randolph \& Viswanath, 2004; Kwasnicka et al., 2016). Appropriately trained com $\mathrm{m}$ unity health workers caneffectively support the health system by im proving the com m unityfacility linkage (Malarcher et al., 2011; Mwai et al., 2013). Health authorities should lead efforts to define and endorse com $m$ unity health workers roles while providing strategies for training, supervision, rem uneration, recognition, career progression and quality assurance (Mwai et al., 2013; Nalukwago et al., 2018-b). 


\section{Lessons and implications for future programming}

Several lessons em erged from the findings of this evaluation that have implications on future adolescent health program $\mathrm{m}$ ing. First, it was noted thatrecruitm ent of cham pions with a greater influence on the target population was key. Adequately training and equipping selected cham pions with skills and updated inform ation was vital for reaching adolescents. Therefore, developm ent practitioners shouldadopt an integrated program-design approach to work collaboratively and harm oniously in providing continuous refresher training and cham pion deploym ent for effective im plem entation (Mwai et al., 2013; Liu et al., 2011; Nalukwago et al., 2018-b). Harm onization of partner-level championled efforts should be driven by the governm ent through the Ministry of Health. Second linking incomegenerating activities to health promotion programs is pertinent for reaching adolescents. Livelihood interventions provide alternative options for adolescents to generate incom e. Shehdi (2012) found that building wom en's individual incom es is essential for elim inating poverty since it helps to build a base for social change. Incom e generating activities change the livelihood of the poor including living conditions, housing, nutrition, savings, dress, m edical treatm ent, health, sanitation, liberalization, and education (Sheheli, 2012; Ahsan Ullah \& Routray, 2007). Third, program developers should adopt activity im plem entation tools that have been tested and used by other adolescent health program s. This will help new program s to scaleup best practices of existing projects for continuity towards sustainability. Overall, this evaluation indicates the pertinent need to periodically evaluate existing adolescent health program s to draw additional lessons for im plem entation and scaleup. Studies indicate that relatively few com munication interventions have been subjected to rigorous evaluation (Nahar et al., 1999; Bertrand et al., 2006). Most adolescent program s that exist do not system aticallydocum ent their activities, im plying that they cannot be evaluated objectively (Nahar et al., 1999). Few studies address the costs and cost-effectiveness of $\mathrm{m}$ ass com $\mathrm{m}$ unication program $\mathrm{m}$ ing, leaving funders and policym akers without the data necessary to determ ine which intervention strategies offer the greatest "bang for the buck" (Bertrand et al., 2006).

\section{Study limitations}

The study's findings have lim itations. Our evaluation was conducted retrospectively based on program records, and staff inform ation was sbject to recall bias. However, using multiple data sources helped in tracing the implementation footsteps to objectively evaluate the program. The study used adolescent selfreport data based on quantitative and qualitative program records, which are subject to bias. However, this self-report data provided practical insights into areas for strengthening scale-up of adolescent health program s. 


\section{Chapter 6}

\section{Conclusion}

Evaluation of CHC's ARC program showed that the cam paign'sm plem entationwas successful in the Ugandan context. Effective collaboration and partnerships with policy and development partners and community $\mathrm{members}$ in interteinn implem entationwas critical for ownership and continuing gains. However, full program m onitoring and evaluation requires detailed data disaggregation of program reach to various sub-groups of the target population and needs to be strengthened in scale-up programs. Strategies for m oitoring and evaluation of adolescent health program s should be collaboratively developed during program inception and design for proper accountability of HC program efforts. 


\section{References}

Ahsan Ullah, A. K. M., \& Routray, J. K.(2007). Rural poverty alleviation through NGO interventions in Bangladesh: how far is the achievem ent? International Journal of Social Economics, 34(4), 237-248.

Androutsos, O., Apostolidou, E., Iotova, V., Socha, P., Birnbaum , J., Moreno, L., ... \& ToyBox-study group. (2014). Process evaluation design and tools used in a kindergarten-based, fam ily-involved intervention to prevent obesity in early childhood. The Toy Box-study. Obesity Reviews, 15, 74-80.

Bantebya G. K., Muhanguzi F. K., \& Watson C. (2014). Adolescent girls in the balance: Changes and continuity in social norms and practices around marriage and education in Uganda. Retrieved February 25, 2017, from https://www.odi.org/sites/odi.org.uk/files/odi-assets/publications-opinionfiles/9180.pdf

Bartholom ew, L. K., Markham, C. M., Ruiter, R. A. C., Fernández, M. E., Kok, G., Parcel, G. S. (2016). Planning health promotion programs: An Intervention Mapping approach, 4th edition. Hoboken, NJ: Wiley. ISBN-13: 9781119035497.

Batam wita, R., Am ado, F., Kanakulya, R., Bufum bo, L., ... Fiedler, A. (2016). Increases in the contraceptive use and fam ily planning positive behaviors in East Central Uganda: The significant role of peer cham pions. Kam pala Uganda

Bertrand, J. T., O'reilly, K., Denison, J., Anhang, R., \& Sweat, M. (2006).System atic review of the effectiveness of $\mathrm{m}$ ass com $\mathrm{m}$ unication program $\mathrm{s}$ to change HIV/AIDS-related behaviors in developing countries. Health education research, 21(4), 567-597.

Bess, G., King, M., \& LeMaster, P. L. (2004). Process evaluation: how it works. American Indian and Alaska Native Mental Health Research the Journal of the National Center, 11(2), 109-120.

Bessinger, R., Katende, C., \& Gupta, N. (2004). Multi-m edia campaign exposure effects on knowledge and use of condom s for STI and HIV/AIDS prevention in Uganda. Evaluation and Program Planning, 27(4), 397-407.

Birungi, H., Mugisha, J. F., Nyom bi, J., Obare, F., Evelia, H., \& Nyinkavu, H. (2008). Sexual and reproductive health needs of adolescents perinatally infected with HIV in Uganda. FRONTIERS Final Report.

Bufum bo L., Batam wita R., Odke, P. et al., (2016). End line Assessment of Adolescent Girls and Young Women's contraceptive knowledge in East central Uganda (Busoga Region). Uganda, Com m unication for Healthy Com m unities (CHC) program

CHC - Com m unication for Healthy Com m unities. (2016). Gender Integration in Com munication for Healthy Com munities (CHC) Program ming: 
Contextualizing Gender in rolling-out OBULAMU campaign in Uganda. Kam pala.

CHC \& IPSOS Lim ited (2017). Third Listening/ Om nibus Survey report on audience feedback, June 2017. Kam pala. Uganda.

CHC Quarterly reports. (2015 - 2016). Communication for Healthy Communities Quarterly Reports (April 2015 - September 2016).

CHC-Com m unication for Healthy Com m unities. (2014). Health Com m unication in Uganda: Findings of an audit of strategies, activities/materials, and im plem enting partners in 2013/2014. Kam pala. Uganda.

CHC-Com m unication for Healthy Com m unitie(2015). Workplan - October 1, 2015 - Septem ber 30, 2016. Kam pala. Uganda.

CHC-Com m unication for Healthy Com m unities. (201ه). What's My Choice? Im plem entationguideContraception cam paign for adolescent girls and young wom en in EastCentral Uganda. Kam pah. Uganda

CHC-Com m unication for Healthy Com m unities. (2016). OBULAMU National Integrated Health Com m unication Platform. June 2013- June 2018.CHCCom $m$ unication for Healthy Com m unities. (2016). An evaluative survey of an Integrated Health.

CHC-Com m unicaion for Healthy Com m unities. (2018. Qualitative Assessment with Audiences to Inform Process and Outcome Evaluation of an Integrated SBCC Campaign in Uganda: Findings Related to Adolescents \& Young Adults. Kam pala. Uganda.

Durlak, J. A., \& DuPre, E. P. (2008). Im plem enation m atters: A review of research on the influence of im plem entationon program outcom es and the factors affecting im plem entationAmerican Journal of Community Psychology, 41(34), 327.

Fawcett, S. B., Paine-Andrews, A., Francisco, V. T., Schultz, J. A., Richter, K. P., Lewis, R. K., ... \& Lopez, C. M. (1995). Using em powerm ent theory in collaborative partnerships for com m unityhealth and developm ent American Journal of Community Psychology, 23(5), 677-697.

FHI 360. (2013). Technical Proposal. USAID/Uganda Com m unication for Healthy Com m unities (CHC). RFA617-13-000001. Kam pala, Uganda.

FHI 360. (2015). Monitoring, Evaluation and Learning Plan: Com m unication for Healthy Com m unities- Cooperative Agreem ent No: AID-617-A-13-00003. FHI 360

Golden, S. D., \& Earp, J. A. L. (2012). Social ecological approaches to individuals and their contexts: twenty years of health education \& behavior health prom otion interventions. Health Education \& Behavior, 39(3), 364-372. 
Harachi, T. W., Abbott, R. D., Catalano, R. F., Haggerty, K. P., \& Flem ing, C. B. (1999). Opening the black box: using process evaluation m easures to assess implem entation and theory buildingAmerican Journal of Community Psychology, 27(5), 711-731.

Hindin, M. J., \& Fatusi, A. O. (2009). Adolescent sexual and reproductive health in developing countries: an overview of trends and interventions. International Perspectives on Sexual and Reproductive Health, 35(2), 58-62.

Jäger, C., Steinhäuser, J., Freund, T., Baker, R., Agarwal, S., Godycki-Cwirko, M., ... \& Szecsenyi, J. (2015). Process evaluation of five tailored program s to im prove the im plem entationf evidence-based recom $m$ endations for chronic conditions in prim ary care.Implementation Science, 11(1), 123.

Joseph, S., Stevens, A. M., Ledoux, T., O'connor, T. M., O'connor, D. P., \& Thom pson, D. (2015). Rationale, design, and m ethods for process evaluation in the childhood obesity research dem onstrationproject. Journal of Nutrition Education and Behavior, 47(6), 560-565.

Kegler, M. C., \& Wyatt, V. H. (2003). A multiple case study of neighborhood partnerships for positive youth developm ent.American Journal of Health Behavior, 27(2), 156-169.

Kwasnicka, D., Dom browski, S. U., White, M., \& Sniehotta, F. (2016). Theoretical explanations for $\mathrm{m}$ aintenance of behaviour change: a system atic review of behaviour theories. Health Psychology Review, 10(3), 277-296.

Linnan, L., \& Steckler, A. (2002).Process evaluation for public health interventions and research (pp. 1-23). San Francisco: Jossey-Bass.

Liu, A., Sullivan, S., Khan, M., Sachs, S., \& Singh, P. (2011). Com m unity health workers in global health: scale and scalability. Mount Sinai Journal of Medicine: A Journal of Translational and Personalized Medicine, 78(3), 419435.

Loaiza, E., \& Liang, M. (2013). Adolescent pregnancy: a review of the evidence. UNFPA, New York, USA.

Malarcher, S., Meirik, O., Lebetkin, E., Shah, I., Spieler, J., \& Stanback, J. (2011). Provision of DMPA by com munityhealth workers: what the evidence shows. Contraception, 83(6), 495-503.

Mckee, N., Manoncourt, E., Chin, S.Y. \& Carnegie, R. (2002).Chapter 12. Involving People, Evolving Behaviour: The UNICEF experience. In: SERVAES, J. (ed.), Approaches to Developm ent Com m unication, Paris: UNESCO.

Medley, A., Kennedy, C., O'Reilly, K., \& Sweat, M. (2009).Effectiveness of peer education interventions for HIV prevention in developing countries: a system atic review and m etaanalysis. AIDS Education and Prevention, 21(3), 181-206. 
Ministry of Health (MOH) \& Com m unication forHealthy Com m unities (CHC). (2016). OBULAMU Site Improvement Monitoring System (OSIMS) visits to assess activity implementation progress in selected priority districts. Kam pala. Uganda.

Ministry of Health- MOH. (2010). Health Sector Strategic Plan III 2010/11-2014/15. Governm entof Uganda Kam pala, Uganda.

Moore, G. F., Audrey, S., Barker, M., Bond, L., Bonell, C., Hardem an, W., ... \& Baird, J. (2015). Process evaluation of com plex interventions: Medical Research Council guidance. BMJ, 350, h1258.

Moore, G., Audrey, S., Barker, M., Bond, L., Bonell, C., Cooper, C., ... \& Wight, D. (2013). Process evaluation in com plex public health intervention studies: the need for guidance.

Mwai, G. W., Mburu, G., Torpey, K., Frost, P., Ford, N., \& Seeley, J. (2013). Role and outcom es of com m unityhealth workers in HIV care in sub-Saharan Africa: a system atic review.Journal of the International AIDS Society, 16(1), 18586.

Nahar, Q., Am in, S., Sultan, R., Nazrul, H., Islam, M., T Kane, T., ... \& Tunon, C. (1999). Strategies to m eetthe health needs of adolescents: a review.

Nalukwago, J., Crutzen, R., van den Borne, B., Bukuluki, P. M., Bufum bo, L., Burke, H. M., ... \& Alaii, J. (2018) -a. Socio-Cognitive Factors Associated with Condom Use, Multiple Sexual Partnerships, and Contraception Use Am ong Sexually-Active Adolescent Girls in Uganda. Global Journal of Health Science, 10(8), 41.

Nalukwago, J., Crutzen, R., Van den Borne, B., Bukuluki, P., Bufum bo, L., Batam wita, R., Zikusooka, A., Lenzi, R., Thom pson, G., Alaii, J. (2018)b. Adolescents discussing sexual behaviors with key influencing audiences. Global Journal of Health Science, 10, 91-106.

Neem a, S., Musisi, N., \& Kibom bo, R. (2004). Adolescent sexual and reproductive health in Uganda: a synthesis of research evidence (Vol. 14): Alan Guttm acher Institute.

Nobelius, A. M., Kalina, B., Pool, R., Whitworth, J., Chesters, J., \& Power, R. (2010) You still need to give her a token of appreciation: the $m$ eaning of the exchange of money in the sexual relationships of out-of-school adolescents in rural southwest Uganda. Journal of Sex Research, 47(5), 490-503.

Paul-Ebhohim hen, V. A., Poobalan, A., \&Van Teijlingen, E. R. (2008). A system atic review ofschool-based sexual health interventions to prevent STI/HIV in subSaharan Africa. BMC Public Health, 8(1), 4.

Plum m er, M. L.,Wight, D., Obasi, A. I. N., Wam oyi, J., Mshana, G., Todd, J., ... \& Ross, D. A. (2006). A process evaluation of a school-based adolescent sexual 
health intervention in rural Tanzania: the MEMA kwa Vijana program me. Health Education Research, 22(4), 500-512.

Randolph, W., \& Viswanath, K. (2004). Lessons learned from public health mss $\mathrm{m}$ edia cam paigns $\mathrm{m}$ arketing health in a crowded $\mathrm{m}$ edia world Annu. Rev. Public Health, 25, 419-437.

Rashid, S., Moore, J. E., Tim m ings, C., Vogel, J. P., Ganatra, B., Khan, D. N., ... \& Straus, S. E. (2017). Evaluating implem entation of the World Health Organization's Strategic Approach to strengthening sexual and reproductive health policies and program s to address unintended pregnancy and unsafe abortion. Reproductive Health, 14(1), 153.

Rawat, R., Nguyen, P. H., Ali, D., Saha, K., Alayon, S., Kim, S. S., ... \& Menon, P. (2013). Learning how program s achieve their im pact: em bedding theory driven process evaluation and other program earning $\mathrm{m}$ echanism $\mathrm{s}$ in Alive \& Thrive. Food and Nutrition Bulletin, 34(3_supp12), S212-S225.

Rossi, P. H., Lipsey, M. W., \& Freem an H. E. (2004).Evaluation: A Systematic Approach, 6th edition. Sage Publications, Inc. USA.

Saunders, R. P., Evans, M. H., \& Jshi, P. (2005). Developing a process-evaluation plan for assessing health prom otionprogram im plem entation: a howto guide. Health Promotion Practice, 6(2), 134-147.

Sheheli, S. (2012). Im proving livelihood of rural wom en throughincom e generating activities in Bangladesh.

Snyder, L. B. (2007). Health com m unication cam paigns and their im pact donehavior. Journal of Nutrition Education and Behavior, 39(2), S32-S40.

Stokols, D. (1996). Translating social ecological theory into guidelines for com m unityhealth prom otion American Journal of Health Promotion, 10(4), 282-298. doi.org/10.4278/0890-1171-10.4.282

Uganda Bureau of Statistics (UBOS) and ICF International Inc. (2012). Uganda Demographic and Health Survey 2011. Kampala, Uganda: UBOS and Calverton, Maryland: ICF International Inc.

Uganda Bureau of Statistics (UBOS) and ICF. (2018). Uganda Demographic and Health Survey 2016. Kam pala, Uganda, and Rockville, Maryland, USA: UBOS and ICF. 



\section{Chapter 7}

General discussion 
This thesis prim arily aim ed at gaining insight into the determ inants of adolescent sexual and reproductive health behaviors, and drawing practical experiences from already existing adolescent health program s. These insights can inform an guide the design and scale-up of future adolescent sexual and reproductive health (SRH) program s that aim to address adolescent health needs. Thethesis com prises of five papers that represent two $\mathrm{m}$ ain parts. The first part of this thesis (Chapters 2-5) focuses on understanding the determ inants of adolescent sexual and reproductive health behaviors and needs. The second part of this thesis (Chapter 6) is a process evaluation of an existing adolescent health program in Uganda, using the case of an adolescent-focused com ponent of Com $m$ uication for Healthy Com m unities (CHC) program. This aim ed at underscoring practical experiences and lessons for future design and im plem entation of adolescent health program s. This concluding chapter presents the discussion of the main findings from the five papers in this thesis, $\mathrm{m}$ ethodological considerations, as well as im plications for policy and practice.

\section{Main findings}

\section{Socio-cognitive factors associated with adolescent sexual behaviors}

In Uganda, adolescent sexual and reproductive health needs are inadequately addressed because there is lim ited understanding of adolescent sexual behaviors to guide targeted program $\mathrm{m}$ ing. To provide insightsinto adolescent sexual behaviors, we explored the socio-cognitive factors of sexual behaviors am ong sexually active adolescent girls in Uganda. The first study question was, "What are the distinctive socio-cognitive factors associated with sexual behaviors among sexually active adolescent girls?". To address this question, a cross-sectional survey was conducted with sexually active adolescent girls $(\mathrm{N}=255)$ in 2015 covering 16 purposively selected districts in Uganda. From the results, it appears that knowledge on condom use and contraception was not significantly associated with their use among sexually active adolescent girls. We also found a strong negative correlation between being $\mathrm{m}$ arried and having $\mathrm{m}$ ultiple sexual partners. Yet, perceived behavioral control/ self efficacy, subjective norm, and behavioral intention were strongly associated with contraception use. These findings suggest that, in particular, increasing self-efficacy and subjective norm $\mathrm{s}$ towards contraception use $\mathrm{m}$ ay increase intention and actual use. Studies show that increasing self-efficacy and subjective norm towards contraception use $\mathrm{m}$ ay require adolescents discussing sexual behaviors with key influencing audiences including sex partners, parents, religious leaders, and health workers to im prove adolescent health outcom es (Nalukwago etal., 2018; Whitaker, Miller, May, \& Levin, 1999). It is indicated that efforts to understand contraception 
use am ong adolescents also benefit from exploration of other sociecognitive factors including gender norms or gender differences/inequalities, and social norm s (Chandra-Mouli et al., 2017; Pulerwitz, Michaelis, Verm a, \& Weiss, 2010; Varga, 2003; Baxter \& Abdool Karim, 2016). Thisthesis explored the gender norm $\mathrm{s}$ associated with adolescent sexual behaviors in the second study question.

\section{Gender norms associated with adolescent sexual behaviors}

Gender norm attitudes and practices rem ain deeply entrenched in m any African societies including Uganda, which often affects adolescent sexual behaviors and health outcom es. Our second study question was, 'What gender norms are associated with adolescent sexual behaviors?". Data from a crosssectional survey am ong adolescents $(\mathrm{N}=867)$ covering 16 purposively selected districts in Uganda was used to answer this question. The results show that the $m$ ajority of adolescent girls and boys were in support of gender inequitable norm s. Positive correlations were found between behavioral intention to use contraception and an equitable gender norm towards dom estic chores/ household decision m aking. Sim ilarly, positive correläbns were found am ong behavioral intention to use condom s at every sexual encounter, and self-efficacy to use condom $\mathrm{s}$ with an equitable gender norm towards reproductive health and pregnancy/disease prevention. These findings seem to suggest that changing the negative gender norm s/perceptions requires a m ultipronged genderresponsive approach for social change. Working with both girls and boys, and engaging influential stakeholders such as parents, health care workers, policym akers, com m unityand religious leaders, who create the environm entwhere gender-related attitudes and world views are form ed is pertinent. Em pirical studies show that countries driven by gender inequalities that constrain individual behavior in sexual interactions often have the highest rates of HIV and teenage pregnancies (Hardee et al., 2014; Van den Berg et al., 2013; Richards et al., 2013; Watts \& Seeley, 2014). Studies underline the pertinent need to focus on the broader circum stances in which gender inequalities within society $\mathrm{m}$ aystructure beliefs and norm s that pepetrate differential exposure/risks of HIV infection, with m ore enhanced efforts targeting wom en and reenforcing involvem ent of m en (Ezekiel et al., 2015). To further understand the social structural beliefs and the broader environm ent influencing adolescents' behaviors, we explored the effect of adolescents discussing sexual behaviors with key influencers.

\section{Adolescents discussing sexual behaviors with key influencers}

Our third study question was, "What is the effect of discussing sexual and reproductive health issues with key influencing audiences on adolescent sexual behaviors?". We used data from a qualitative study that conducted indepth 
interviews and focus group discussions with adolescents $(\mathrm{N}=83)$. This study revealed that parents were seen as the first people to give adolescents guidance and adolescents pride in being trusted by their parents. However, it was noted that parents were too busy and did not have tim e to talk to their children. Health workerswere also seen as an important source of sexuality inform ation for adolescents. However, health workers' attitude, use of technical language and giving unclear inform ation were highlighted as barriers to com $\mathrm{m}$ unication with adolescents. The results also indeate that adolescents found it convenient to discuss health and sexuality issues with their peers, who often influence them both positively and som etim es negatively in health service uptake. These findings suggest that health prom otion program s need to ivest in developing the com m unication skills andbridging the sexual and reproductive health inform ation gaps of key influencing audiences such as (com m unity) health workers, parents, religious leaders, and peers. To begin with, program s should provide adequate and updated SRH inform ation to adolescentsand the general public to bridge knowledge gaps and guide sexuality dialogues. Studies highlight that discussing sexuality issues with key influencing audiences is associated with adolescent sexual decision making with regards to delaying sexual debut, as well as the use of condoms and contraception (Som ers, Tolia, \& Anagurthi, 2012; Biddlecom, AwusaboAsare, \& Bankole, 2009; Hadley et al., 2009). However, adolescents highlight persistent barriers in com m unicting with key influencers such as inadequate knowledge, poorly defined values, fear of encouraging sexual activity, and inability to initiate and $\mathrm{m}$ aintain a conversation about sex (Pick \& Palos, 1995; Werner-Wilson \& Fitzharris, 2001). For targeted programm ing, it is im perative to understand the unique em erging needs of the different audiences and subgroups. In exploring the socio-cognitive factors and influencers of adolescent sexual behaviors, our study found lim ited literature on m ultiple concurrent sexal partnerships am ong adolescents in Uganda. This necessitated further exploration of the aspect of $\mathrm{m}$ ultiple concurrent sexual partnerships am ong adolescents.

\section{Multiple concurrent sexual partnerships among adolescents}

Adolescents in Uganda engage in sex with m ultiple concurrent partners, thus placing them at risk for HIV and unplanned pregnancies, but it is not clear why. The fourth study question was, "Why do adolescents engage in multiple concurrent sexual partnerships (MCSP)?". This study used a Core Processes m ethodology. We used the processes of brainstorm ing, and identification of evidence and theoretical support, in various phases/steps of intervention planning, to provide possible explanations for adolescent MCSP. The results show that multiple sexud partnering is on the rise am ong adolescents in Uganda, and these sexual partnerships often overlap for $m$ onths or years. The findings from the brainstorm ing sessions with various stakeholders 
(including adolescents, com munity leaders and policymakers, and expertsbehavioral scientists, health prom otion practitioners, and sociologists) highlighted several factors associated with MCSP am ong adolescents. They noted that peer influence and a lack of basic needs drive adolescents to engage in multiple transactional sexual relationships for m oney. Parents' laxity and lack of discipline for their children, and the fading com m unity support for disciplining children contribute to the problem of adolescent MCSP. It was noted that adolescents often lack the confidence to com $\mathrm{m}$ it to only one sexual partner. In thissense, self-confidence is often affected by other factors including an individual's environm ent (e.g., difficult fam ily situation) and theneed for m eans of survival (e.g., extrem e poverty). Em pirical studies indicate that MCSP is associated with higher sexually transm itted diseases (STDs) risks, particularly HIV/AIDS (Epstein \& Morris, 2011; Mah \& Halperin, 2010). Yet, adolescents engage in MCSP because they perceive low risk and susceptibility to HIV (Dolcini et al., 1995; Durbin et al., 1993). Poor com munication with sexual partners and parents was found to be associated with adolescent MCSP (Bastien et al., 2011; Taffa et al., 2017). Knowledge of the risks of MCSP am ong adolescents and their influencers was found to be inadequate and often intertwined with $\mathrm{m} y$ ths and $\mathrm{m}$ isconceptions (Hardee et al., 2014). Com m unity influences, including societal approval of MCSP and beliefs about the sexual dom inance of $\mathrm{m}$ en (Mavhu et al., 2011; LeClerc-Madlala et al., 2009), were found to increase perm issive attitudes of adolescents and their influencers on infidelity (Dolcini et al., 1995; Konde-Lule et al., 1997; Jewkes \& Morrell, 2010). The disconnect between policy and practice surrounding adolescent access to SRH contributes to the problem of adolescents engaging in MCSP (Bantebya et al., 2014). This indicates the need to work with and form strategic partnerships with multiple key players in th institutional and structural environment to create a conducive environm ent for adolescent health. Creating a conducive environment requires scanning the environment for existing adolescent health programs. Therefore, assessing the practical experience of existing program s towards addressing adolescent health needs is pertinent to guide the targeted design of future program s and saling-up of best practices. We conducted a process evaluation for an existing adolescent health program in Uganda to draw lessons for guiding future program $\mathrm{m}$ ing.

\section{Experience from an existing adolescent health intervention}

The fifth study question was, "What is the practical experience of the existing sexual and reproductive health programs towards addressing targeted adolescent health needs in Uganda?". To answer this question, an adolescent-focused contraceptive promotion intervention implemented by the Communication for Healthy Com munities program in Uganda i.e. Accelerating the Rise in Contraceptive 
Prevalence was selected for review. We used a process evaluation design including both quantitative and qualitative data collection m ethods. The results indicate that the planned program activities including, training and deploying com $m$ unity cham pions to conduct health education talks, com m unity edutainmret events, and $\mathrm{m}$ ass $\mathrm{m}$ edia placem ents were successfully im plem ented in collaboration with service partners ah the com $\mathrm{m}$ unity. Interpersonal com $\mathrm{m}$ unication com plem ented by $\mathrm{m}$ ass $\mathrm{m}$ edia was found to be effective in reaching and empowering adolescents with health inform ation to $\mathrm{m}$ ake inform ed choices. We found that the program used theoretical fram eworks to guide implementation including the Social Ecological Model for audience segm entation, and Em powerm ent theory for com m unity em powerm ent through collaborative partnerships and shared decision making. Through its institutionalized $\mathrm{m}$ easures of assessing activity im plem ention progress, we noted that the trained com m unity cham pions were able to execute their IPC activities. However, $\mathrm{m}$ any were not confident to addressall health topics, which is an indication that they needed $m$ ore refresher training. Our evaluation found that the use of $m$ ass media messaging without targeted placem ents (through identifying higholum e listener tim es of a target audience) negatively affected program reach to the intended target audiences. At inception, the program targeted all com munity champins, specifically Village Health Team s attached to health facilities. However, targeting a large num ber of com m unity cham pions was found to be diffilt in term s of followup and reporting. Therefore, this inform ed program adaptation that lim iting the num ber to a $\mathrm{m}$ anageable size (10 per health facility) and working through existing com munity structures is important. Effective evaluation of program reh was challenged by the lim ited disaggregation of data in $\mathrm{m}$ ost of the program reports which did not indicate reach of the different sub-groups of the target population. These findings seem to suggest the need to address training needs of com $m$ unity cham pino, work with the target audiences to design targeted $\mathrm{m}$ ass $\mathrm{m}$ edia schedules, and the institution of results-based $m$ onitoring and evaluation system $s$ that capture detailed program-related data. Other em pirical studies indicate that collaborative partnerships for com m unity health and developm ent provide an opportunity for studying and contributing to em powerm ent (Fancett et al., 1995). Studies also indicate that using $m$ essage effects theories to design m essages for target audiences can enhance the probability of a cam paign's success (Randolph \& Viswanath, 2004). Multim edia cam paigns are more likely to result in greater im pact as messages are mutually reinforced (Bessinger et al., 2004). Others show that appropriately trained com $m$ unity health workers can effectively support the health system by improving the com m unityfacility linkage (Malarcher et al., 2011; Mwai et al., 2013). Our evaluation identified lessons for future program $\mathrm{m}$ ing including, recruitm ent of cham pions that have a greater influence on the target population is key, linking incom egenerating activities to health prom otion program $\mathrm{s}$ is pertinent in reaching 
adolescents, and program development practitioners should adopt activity im plem entation tools that have been tested and used by other existing adlescent health program s.

\section{Methodological considerations}

This section discusses the m ethodological approaches used in the studies of this thesis. It highlights the study designs, the strengths, and lim itations of the adopted m ethodological approaches, and the theoretical considerations.

\section{Cross-sectional studies}

This thesis has two cross-sectional designed studies (Chapter 2 and 3). The first study presented in Chapter 2 exam ines the sociocognitive factors associated with condom use, multiple sexual partnerships, and contraception use am ong sexuallyactive adolescent girls in Uganda. The predictive $m$ easures of the variables studied in this chapter were approached theoretically using the Theory of Planned Behavior. The second study in Chapter 3 exam ines the gender norm s associated with adolescent sexual behaviors in Uganda. The variables in this study were measured using the Gender Equitable Men scale. However, due to the cross-sectional nature of these studies, the exam ined behavioral predictors were not studied over a long period of tim e to confirm the tem poral assum ptions. Em pirical literaturedicates that crosssectional studies are carried out at a one tim e point or over a short period (Levin, 2006). Cross-sectional studies save tim e and cost to conduct, and they help to answer $\mathrm{m}$ any types of research questions unrelated to longitudinal inferences (Kraem er et al, 2000). However, such studies are lim ited by the fact that they are carried out atone tim e point and give no indication of the sequence of events - whether exposure occurred before, after or during the onset of the studied outcom e. Thus, it is difficult to $\mathrm{m}$ ake causal inference, and the situation $\mathrm{m}$ ay provide differing results if another tim efram e is chosen (evin, 2006). Studies recom $m$ end that the $m$ ore the conclusions vary with which tim e point or which tim e scale is used, the $\mathrm{m}$ ore im perative it is to do longitudinal studies in order to truly understand the developm ental process and to confirm the tem poral assum ptions Kraem er et al., 2000; Sniehotta, 2009). It is im portant to note that the crosssectional studies in this thesis had som e lim itations. Their focus on sexually active adolescents provided relatively sm all sam ple sizes which $\mathrm{m}$ ade it hard to dem onstrate the association for som e variables, hence lim iting generalization to the entire population. The studies also covered fewer (16) districts of Uganda which has over 120 districts. This also lim ited the num ber of sam pled participants and affected the generalizability of the findings to the study population. 
For future research, increasing the num ber of study targeted districts and sam pled participants is recom $\mathrm{m}$ ended for greateigeneralizability.

\section{Qualitative studies}

Chapter 4 of this thesis is a non-experim ental qualitative design study that explored the effect of sexuality discussions with key influencing audiences by m eans of indepth interviews and focus group discussions with adolescents. Using this study design, convenience sam pling was used to recruit participants. Convenience sam pling involves drawing sam ples that are both easily accessible and willing to participate in a study (Teddlie \& Yu, 2007). However, its lim itation is that groups chosen by convenience sam pling are conducive to selfselection, adm inistrative decision, tim e of the class, num ber of the years of exposure and m any other polluting influences (Farrokhi \& Mahm oudiHam idabad, 2012). Therefore, the use of m ixed $m$ ethods, both quantitative and qualitative to triangulate findings related to understanding the com plex notion of adolescent sexual behaviors is recom m ended (Shattuck et al., 2013). The mixed methods complem ent each other ipproviding a broader understanding of the determ inants of adolescent sexual behaviors and existing adolescent health program $\mathrm{s}$. Studies show that the purpose of m ixing the quantitative and qualitative approaches is for triangulation, complem entarity, initiaion, developm ent, and expansion, to allow researchers generate databases that include inform ation that has both depth and breadth regarding the phenom enon under study (Onwuegbuzie \& Collins, 2007; Teddlie \& Yu, 2007. The success of a m ixed $\mathrm{m}$ ethods reseach project in answering a variety of questions is a function, to a large degree, of the com bination of sam pling strategies that are em ployedT(eddlie \& Yu, 2007). Mixed m ethods designs often use $m$ ultilevel sam pling with a com bination of random sam pling (e.e, probabilistic sam pling) and nonrandom sam pling (i.e., non probabilistic sam pling) schem es. Specifically, they often involve a com bination of probability and purposive sampling techniques. These multilevel sampling techniques are more general and inclusive in creating sample relationships to facilitate drawing of generalizable inferences (Onwuegbuzie \& Collins, 2007) For instance, probability sam pling used in quantitative studies that are triangulated with qualitative studies is a viable method in which to ascertain the measure of representation. This sam pling procedure provides $\mathrm{m}$ ore objective probable scenarios for equal chances of inclusion for targeted participants to reduce the sam pling bias (McCusker \& Gunaydin, 2015). The qualitative studies in this thesis also had som e lim itations. The studies relied on selfreported data which have lim itations of sexual activity recall bias and the potential for under-reporting of sexual behavior due to the sensitive nature of the subject (Mbalinda et al., 2015; Reid \& Aiken, 2011). Thus, exclusive reliance on adolescents' self-reports can lead to erroneous prevalence 
estim ates, and som etim es the discrepancies between the specificity and sensitivity of a self-report m easure can result from system atic error (Elgar, et al., 2005). Studies argue that the use of objective indicators for health including response to questions about specific health conditions or lim itations, and doctors' reports, are presum ably m ore objective than self-reported m easures (Bound, 1989).

\section{Review studies}

Chapter 5 of this thesis used a literature review approach to delineate core processes that draw theoretical and empirical support for generating a list of possible explanations/answers to why adolescents engage in multiple concurrent sexual partnerships. However, the list of possible explanations/answers generated from the review study $m$ ay not beexhaustive and conclusive in addressing the problem. This is because there is a possibility that not all studies related to the problem were reviewed or there could have been new research studies being conducted on the problem. Therefore, this im plies that there $\mathrm{m}$ ight be other contributing factors that $\mathrm{m}$ ay not have been captured in the currently available literature which $\mathrm{m}$ ay require further exploration. As such, additional studies of a similar nature should be conducted in Uganda to offer a contextual comparison of the findings, and to understand the problem within the confines of the $\mathrm{m}$ ultiple ethnic cultural settings in Uganda. Our study justifies that there are a lot of options between 'doing nothing' and 'conducting new research.' It shows that the order of steps in the core processes is crucial; brainstorm ing (step 2) ensures utilizing the theoretical and em pirical knowledge that is available within the planning group, which can later be com bined with em pirical findings (step 3) and theoretical support (step 4). In fact, going through these steps might actually improve new research: if new research should be conducted, then it should be clear what questions to ask and address in the research. As a result of com pleting the steps, the planners will have assem bled a set of potential answers from both the theoretical and the em pirical literature that fit with, suggest changes to, or add to the provisional explanations. In som e cases, this inform ation provides insight into the exact processes underlying the provisional answers. The inform ation $\mathrm{m}$ ay, at the sam e tim e, raise questions that the planning group had not thought of before. For exam ple, the planning group may want to know whether certain theoretical constructs that look prom ising are actually explanatory in relation to their population of interest. They m ay also want to know the particular way in which an explanation found in published research relates to their population. Studies show that literature reviews can tackle broader and more abstract questions, can engage in $\mathrm{m}$ ore post hoc theorizing without the danger of capitalizing on chance, can $\mathrm{m}$ ake a stronger case for a nulthypothesis conclusion, and can appreciate and use m ethodological diversity better (Baum eister \& Leary, 1997; Rosenthal \& DiMatteo, 
2001). To achieve this, the review should have adequate coverage of the cited literature with clarity about how $\mathrm{m}$ uch detail to give. As such, all reviews, regardless of their prim ary goal, should provide an overarching conceptualization, perspective, or point-of-view - called a take-hom e m essage - and not be content to m erely recount previous ideas and research (Baum eister \& Leary, 1997.)The review should explicitly say what the im plications for future research are. A literature review loses considerable value when it fails to tell the reader the nature of the evidence it presents and does not convey enough inform ation on the study topic (Baum eister \& Leny, 1997; Fagard, Staessen, \& Thijs, 1996; Benzies et al., 2006). Im perative to note is that review studies in this thesis had lim itations. The few subcultural contexts described in our study $\mathrm{m}$ ight not provide a deeper understanding of the $\mathrm{m}$ ulticultural divides in Uganda and how they influence adolescent sexual behaviors. Studies show that cultural setting provides $m$ ultiple versions of appropriate behavior for $m$ en and wom en (Pulerwitz \& Barker 2008). Yet, ethnic cultural differences are often overlooked in research and practice on adolescent health in Africa. For exam ple, studies show that cultural and religious beliefs that encourage having $\mathrm{m}$ ore than one wife are perceived to prom ote m ultiple concurrent sexual partnerships Jewkes \& Morrell, 2010; LeClerc-Madlala, 2009). And that the notion of transactional sexual relationships is deeply rooted in cultural contexts that m odel sexual relationships of exchange on traditional social institutions of courting and bride-wealth paym ents (LeClerc-Madlala, 2009; Nobelius et al., 2010). Such notions require the conduct of further studies to understand adolescent sexual behaviors within the confines of ethnic cultural differences and settings in Uganda. The studies should explore how power dynamics associated with gender norm s, roles, and relationships $\mathrm{m}$ ay contribute to adolescents' sexual behaviors. More so, future studies need to assess the associations between self-reported sexual behaviors and gender norm s, as well as the perceptions of adolescents on equitable gender norm s.

\section{Process evaluation studies}

Chapter 6 of this thesis used a process evaluation design to underscore the practical experience of an existing sexual and reproductive health program in Uganda targeted at addressing adolescent health needs. We used a mixed-methods approach, com bining quantitative and qualitative data collection m ethods. Studies show that process evaluation of complex interventions usually requires a combination of quantitative and qualitative m ethods (Moore et al., 2015). Process evaluation fulfills the need for information on program implem entation, which is importanfor interpreting program outcom es, and inform ing future efforts including generating critical lessons for im pact evaluations (Rashid et al., 2017; Androutsos et al., 2014; Joseph et al., 2015). The strength of a process evaluation is the ability to com bine 
$\mathrm{m}$ ultiple data sources. Studies indicate that by com bining data sources and $\mathrm{m}$ ethods, a $\mathrm{m}$ ore com plete picture of the process evaluation em erges, and this entails tracing the footsteps of program im plem entation (Bess et al., 2004; Rashid et al., 2017). However, process evaluation requires vigilance on the part of the evaluators to respect the trust that has been afforded them. This is because it is the evaluators who ultim atdy classify, aggregate, or disaggregate them es that em erge as a result of the planning process (Bess et al., 2004). To ensure that evaluators respected the trust afforded them, our study drew expertise from a range of relevant disciplinesincluding public health, behavioral science, health prom otion, prim ary care, sociology, m onitoring, evaluation, and research. The experts provided practical experience in the design and im plem entation of adolescent SRH program s from various settings, and objective judgm ens in the process evaluation. The lim itation of our process evaluation is that the study was conducted retrospectively based on program records, and staff inform ation was subject to recall bias. However, using m ultiple data sources helped in tracing the im plem entation footsteps to objectively evaluate the program . More so, the study used adolescent self-report data based on quantitative and qualitative program records, which are subject to bias. However, the selfreport data provided practical insights into areas for strengthening scale-up of adolescent health program s

\section{Theoretical considerations}

The study used various theoretical approaches and models to understand the determ inants of adolescent sexual behaviors. The Social Ecological Model (SEM) which looks beyond individuals to their social context including interpersonal, institutional, com m unity and policy environm ents (Mckee, et al., 2002; Golden \& Earp, 2012), was used to assess the interrelations am ong environm ental conditions, hum an behavior, and wellbeing that influence adolescent sexual behaviors. The SEM was instrum ental in defining and understanding the various levels of behavioral influence and the key players/influencers of behavior that needed to be targeted in adolescent health program $m$ ing. Fo exam ple, using the SEM, our study identified that parents, religious leaders, health workers, policym akers, peers, and cultural leaders are key influencers of adolescent sexual behaviors. Furtherm ore, theoretical constructs drawn from the Theory of Planned Behavior (TPB) were used to describe the data variables of the study in Chapter 2 of this thesis. The TPB constructs we used include intention, attitude, subjective norm, and perceived behavioral control/self efficacy (Fishbein \& Ajzen, 2010). The resuts in Chapter 2 showed that the sociocognitive factors of perceived behavioral control/self-efficacy, subjective norm, behavioral intention, and $\mathrm{m}$ arital status were strongly associated with using contraception. Although the predictive measures of the study were approached 
theoretically using TPB, the self-reported questionnaire was not structured as such. Therefore, given that the study was not designed to test TPB m eans that som e operationalizations were not in line with TPB guidelines (Fishbein \& Ajzen,2010). For exam ple, som e of the m easures we used such as discussing contraception and condom use with others- $m$ ight be indicative of subjective norm, but are not clearly in line with the conceptualization, nor the operationalization, as specified in the TPB (Fishbein \& Ajzen, 2010). Evidence from existing adolescent health program $\mathrm{s}$ (described in Chapter 6) shows that it is im portant to use theory and evidence-based program $\mathrm{m}$ ing to analyze the context in which the target audiences (adolescents) $\mathrm{m}$ ake decisions, access services, and relate socially in order to address barriers to change (CHC 2016). For exam ple, the CHCARC program described in Chapter 6 used theoretical fram eworks to guide im plem entation including the SEM for audience segm entation, and Em powerm ent theory for com m unity em powerm ent through collaborative partnerships and shared decision making. Overall, we found that the apparently strong influence of norm ative beliefs and subjective norm s, im pact of the social environm ent and health service structure, and adolescent's m eans for self realization (need for incom e generating activities) need to be targeted in addressing adolescent health needs.

\section{Implications for policy and practice in designing adolescent health programs}

\section{Policy Implications}

The intricacies of understanding adolescent health needs call for form ing strategic partnerships with various key players in the institutional and structural arena to create a conducive environm ent for adolescents. This m eans that concerted efforts from policym akers, parents, religious leaders, peer leaders and health workers in designing targeted adolescent health program s are required. Results of this thesis indicate that these stakeholders should act as advocates for actions geared towards increasing adolescents' access to sexual and reproductive health services to im prove health outcom es.

There is a clear indication that the unfavorable social norm s surrounding adolescent access to SRH contribute to the challenges associated with adolescent sexual behaviors. Therefore, social norm s that are com m unally deem ed as appropriate, such as gender equity and discouraging early $\mathrm{m}$ arriages, need to be grounded in policy and effectively com municated to the general public for action. Societal approval of m ultiple concurrent sexual partnerships and beliefs about the sexual dom inance of 
$\mathrm{m}$ en often lead to gender nequalities which $\mathrm{m}$ ay work against the desired policies on adolescent health.

Village Health Teams or Com munity Health Workers were identified as a key resource in reaching adolescents in this thesis. Therefore, Governm ent through Ministry of Health (health authorities) should lead efforts to define and endorse com $\mathrm{m}$ unity health workers' roles, while providing strategies for training, supervision, rem uneration, recognition career progression and quality assurance. Policy $m$ akers and practitioners ought to em brace the fact that com $\mathrm{m}$ unity health worker program $\mathrm{s}$ grow and evolve in phases of continuous learning, im provem ent, and expansion of coverage.

\section{Practical implications}

This thesis indicates that adolescents and their key influencers' knowledge of SRH issues is inadequate and often laced with a lot of hearsay, $\mathrm{m}$ yths, and $\mathrm{m}$ isconceptions. As such, inform ation services rem ain im portant in clearing any $\mathrm{m}$ isconceptions and addressing any health concerns for increased service uptake. Therefore, health prom otion praditioners need to develop participatory strategies such as prom oting inform ed parentadolescent communication, comm unitbased education, and provider-adolescent com m unication to enhance respect and confidentiality when serving adolescent clients. Program s should use social and $\mathrm{m}$ ass $\mathrm{m}$ edia cam paigns more extensively to provide adequate and updated SRH inform ation to guide sexuality dialogue of adolescents and their key influencers. Above all, developm ent practitioners in Uganda need to look m ore towards com mnity-driven change, rather than focus on the individual alone. More so, considering that $m$ any of the challenges are not entirely an inform ation gap, but $\mathrm{m}$ ore gender andsocial norm s related.

Interpersonal com $\mathrm{m}$ unication was found to be highly effective in com plem enting and clarifying generic $\mathrm{m}$ essages relayed through $\mathrm{m}$ ass $\mathrm{m}$ edia (radio, $\mathrm{TV}$, posters). This is an indication that a com bination of channels in health prom otion an com $m$ unication program $m$ ing is param ount in $m$ essage saturation, rather than these of one channel. Therefore, health prom otion practitioners need to develop strategies that enable com $\mathrm{m}$ unication channel $\mathrm{m}$ ix in adolescent health program $\mathrm{m}$ ing. However, it is always important to understand the unique information needs of the different audiences and subgroups for targeted program $m$ ing. Continuous studies need to be done to understand the different and em erging inform ation needs of adolescents and their key influencers.

Religious leaders were highlighted as being instrum ental in m otivating and advising adolescents to behave well. Studies show that individuals who attend religious services frequently receive religious m essages against prem arital sex and are m ore 
likely to develop sexual attitudes and behaviors that are consistent with their religious doctrines (Odim egwu, 2005; Kagim u et al., 2013;Maulana et al., 2012). Therefore, health prom otion practitioners need to engage in progressive religious discourses and work closely with religious institutions in providing SRH inform ation that addresses $\mathrm{m}$ yths and $\mathrm{m}$ isconceptions. Forem ost should be learning from the experiences of existing adolescent health program $\mathrm{s}$ which have sensitized religious leaders on SRH issues to cham pion the causeof adolescent health program $\mathrm{m}$ ing.

Gender integration should be central to health prom otion and adolescent health programming to address any inequitable sociecultural norms that influence adolescent sexual behaviors. Studies argue that gender norm $s$ that put $m$ en in a position of sexual dom inance were found to lim it wom en's ability to control their own reproductive and sexual health, as often seen in the belief that girls who carry or suggest using condom s are prom iscuous (Pulerwitz, Michaelis, Verm a, \& Weis 2010; Varga, 2003). Studies indicate that gender power relations and beliefs where young $m$ en often think that it is heroic to have many sexual partners, and girls engaging in transactional sex with older $m$ en who are seen as better ableto provide for them econom ically, influence adolescent sexual behavior (Bantebya et al., 2014; Centerwall \& Laack, 2008). As such, health prom otion program s should engage influential cultural institutions and policym akers in prom oting gender integration approaches towards addressing adolescent health needs. To start with, gender awareness training and gender inclusive program $m$ ingneed to be adopted. Both adolescent girls and boys should be given the opportunity to provide input into program designbased on their personal experience and needs.

\section{Conclusion}

The findings of this research provide insight and knowledge into the determ inants of adolescent sexual behaviors and underscore experiences from already existing adolescent health program s. This inform ationis im portant forfuture interventions to rely on the available evidence in the design of targeted adolescent health program $\mathrm{s}$ in Uganda. First, our research reveals that contraceptive uptake am ong adolescents is correlated with self-efficacy, subjective norm, and behavioral intention. These findings suggest that increasing self-efficacy and subjective norm s m ay increase intention to use contraception and actual contraception use. This implies that com m unitywide, rather than just individual change, should be a critical focus for adolescent health program $\mathrm{s}$. Second, it highlights that the $\mathrm{m}$ ajority of adolescent girls and boys were in support of gender inequitable norm s explored in the study. Thus, the use of a multipronged gender-responsive approach for social and behavior 
change to address the negative gender perceptions of adolescents is required. This $m$ eans that social and behavior change is enhanced if efforts target com m unitywide and social paradigm shifts because it is within such a context that betterindividual choices and outcom es are assured. Notably, the study circles around factors such as social and gender norm s which are not individualistic. They are also the sam e factors im plicated in the disconnect between policy and practice. Third, it indicates that adolescents desire inform ation, and more especially sexuality inform ation, from parents as their im mediate most respected/trusted source of knowledge. Thus, strengthening parent-adolescent com m unication is param ount. Fourth, it underscores that $\mathrm{m}$ utiple sexual partnering is on the rise am ong adolescents which puts them at higher risk of sexually transm itted diseases. Yet, knowledge gaps about health risks am ong adolescents and their key influencers are em inent Therefore, inform ation services that address knowledge gaps, $\mathrm{m}$ yths and $\mathrm{m}$ isconceptions are im portant. Above all, the design of future adolescent health targeted program s should be based on the experiences and lessons drawn from already existing program s for scaleup. 


\section{References}

Aarø, L. E., Mathews, C., Kaaya, S., Katahoire, A. R., Onya H., Abraham , C., \& De Vries, H. (2014). Prom oting sexual and reproductive health am ong adolescents in southern and eastern Africa (PREPARE): project design and conceptual fram ework.BMC Public Health, 14(1), 54.

Androutsos, O., Apostolidou, E., Iotova, V., Socha, P., Birnbaum, J., Moreno, L., .. \& ToyBox-study group. (2014). Process evaluation design and tools used in a kindergarten-based, fam ily-involved intervention to prevent obesity in early childhood. The Toy Box-study. Obesity Reviews, 15, 74-80.

Bantebya, G. K., Muhanguzi, F. K., \& Watson, C. (2014). Adolescent girls in the balance: Changes and continuity in social norm $\mathrm{s}$ and practices around $\mathrm{m}$ arriage and education in Uganda. London: Overseas Developm ent Institute.

Barnes J., Grandi S., Byrong., Keatm an T., \& Marta Balestrini M. (2017)Corporate evaluation on strategic partnerships for gender equality and the empowerment of women, Final Synthesis Report. UN Wom en Independent Evaluation Office.

Bastien, S., Kajula, L. J., \& Muhwezi, W. W. (2011). A review of studies ofparentchild com m unicationabout sexuality and HIV/AIDS in sub-Saharan Africa. Reproductive health. 8(1):25.

Baum eister, R. F., \& Leary, M. R. (1997). Writing narrative literature reviews. Review of general psychology, 1(3), 311.

Baxter C., \& Abdool Karim S. (2016). Com bination HIV prevention options for young wom en in Africa. African Journal of AIDS Research, 15(2), 109121.

Benzies, K. M., Prem ji, S., Hayden, K. A., \& Serrett, K. (2006). State-of-the-evidence reviews: advantages and challenges of including grey literature. Worldviews on Evidence-Based Nursing, 3(2), 55-61.

Bess, G., King, M., \& LeMaster, P. L. (2004). Process evaluation: how it works. American Indian and Alaska Native Mental Health Research the Journal of the National Center, 11(2), 109-120.

Bessinger, R., Katende, C., \& Gupta, N. (2004). Multi-m edia cam paignexposure effects on knowledge and use of condom s for STI and HIV/AIDSprevention in Uganda. Evaluation and Program Planning, 27(4), 397-407.

Biddlecom, A., Awusabo-Asare, K., \& Bankole, A. (2009). Role of parents in adolescent sexual activity and contraceptive use in four African countries. International Perspectives on Sexual and Reproductive Health, 72-81. https://doi.org/10.1363/3507209

Bound, J. (1989). Self-reported vs. objective measures of health in retirement models (No. w2997). National Bureau of Econom ic Research. 
Centerwall, E., \& Laack, S., (2008). Young Men as Equal Partners. RFSU, Riksförbundet för sexuell upplysning, The Swedish Association for Sexuality Education, Stockholm .

Chandra-Mouli, V., Param eshwar, P. S., Parry, M., Lane, C., Hainsworth, G., Wong, S., ... \& Say, L. (2017). A never-before opportunity to strengthen investm ent and action on adolescent contraception, and what we $m$ ust do to $\mathrm{m}$ ake full use of it.Reproductive health, 14(1), 85.

CHC-Com m unication for Healthy Com unities. (2016). OBULAMU National Integrated Health Com m unication Platform . June 2013 June 2018.CHCCom $m$ unication for Healthy Com m unities. (2016). An evaluative survey of an Integrated Health. Kam pala, Uganda.

Dolcini, M. M, Coates, T. J., Catania, J. A., Kegeles, S. M., \& Hauck, W. W. (1995). Multiple sexual partners and their psychosocial correlates: the populationbased AIDS in multiethnic neighborhoods (AMEN) study. Health Psychology.; 14(1):22.

Durbin, M., DiClem ente, R. J., Siegel, D., Krasnovsky, F., Lazarus, N., \& Cam acho, T. (1993). Factors associated with m ultiple sex partners am ong junior high school students. Journal of Adolescent Health. 14(3):202-7.

El Feki, S., Heilm an, B. \& Barker, G., Eds.(2017). Understanding Masculinities: Results from the International Men and Gender Equality Survey (IMAGES) - Middle East and North Africa. Cairo and Washington, D.C.: UN Wom en and Prom undoUS.

Elgar, F. J., Roberts, C., Tudor-Sm ith, C., \& Moore, L. (D05). Validity of selfreported height and weight and predictors of bias in adolescents. Journal of Adolescent Health, 37(5), 371-375.

Epstein, H., \& Morris, M. (2011). Concurrent partnerships and HIV: an inconvenient truth. Journal of the International AIDS Society. 14(1):13.

Ezekiel, M., Chitam a, D., \& Mlang'a, E. (2015). Gender equitable m en's attitudes and beliefs to reduce HIV risk and gender-based violence in Tanzania. Tanzania Journal of Health Research, 17(1).

Fagard, R. H., Staessen, J. A., \& Thijs, L. (1996). Advantages and disadvantages of the m etaanalysis approach. Journal of hypertension. Supplement: official journal of the International Society of Hypertension, 14(2), S9-12.

Farrokhi, F., \& Mahm oudiHam idabad, A. (2012). Rethinking convenience sam pling: Defining quality criteria. Theory and practice in language studies, 2(4), 784.

Fawcett, S. B., Paine-Andrews, A., Francisco, V. T., Schultz, J. A., Richter, K. P., Lewis, R. K., ... \& Lopez, C. M. (1995). Using em powerm ent theoryin collaborative partnerships for com muity health and developm ent American Journal of Community Psychology, 23(5), 677-697. 
Fishbein, M., \& Ajzen, I. (2010). Predicting and Changing Behavior. The Reasoned Action Approach. Psychology press. Taylor \& Francis Group. New York, USA.

Golden, S. D., \& Earp, J. A. (2012).Social ecological approaches to individuals and their contexts: twenty years of health education \& behavior health prom otioninterventions. Health Education \& Behavior.; 39(3):36472.

Hadley, W., Brown, L. K., Lescano, C. M., Kell, H., Spalding, K., DiClem ente, R., ... \& Project STYLE Study Group. (2009). Parent-adolescent sexual com m unication Associations of condom use with condom discussions. AIDS and Behavior, 13(5), 997-1004.

Hardee, K., Gay, J., Croce-Galis, M., \& AfariDwam ena, N. A. (2014). What HIV program swork for adolescent girls? Journal of Acquired Immune Deficiency Syndromes, 66, S176-S185.

Jewkes, R., \& Morrell, R. (2010). Gender and sexuality: em erging perspectiæs from the heterosexual epidem ic in South Africa and im plications for HIV risk and prevention. Journal of the International AIDS society. 13(1):6.

Jonas, K., Reddy, P., van den Borne, B., Sewpaul, R., Nyem bezi, A., Naidoo, P., \& Crutzen, R. (2016). Predictors of nurses' and midwives' intentions to provide $m$ aternal and child healthcare services to adolescents in South Africa. BMC Health Services Research, 16(1), 658.

Joseph, S., Stevens, A. M., Ledoux, T., O'connor, T. M., O'connor, D. P., \& Thom pson, D. (2015). Rationale, design, and methods for process evaluation in the childhood obesity research dem onstrationproject. Journal of Nutrition Education and Behavior, 47(6), 560-565.

Kagim u, M., Guwatudde, D., Rwabukwali, C., Kaye, S., Walakira, Y., \& Ainom ugisha, D. (2013). Religiosity for prom otion of behaviors likely to reduce new HIV infections in Uganda: A study am ong Muslim youth in Wakiso district. Journal of Religion and Health, 52(4), 1211-1227.

Konde-Lule, J. K., Wawer, M. J., Sewankam bo, N. K., Serwadda, D., Kelly, R., Li, C., Gray, R. H., \& Kigongo, D. (1997). Adolescents, sexual behavior and HIV-1 in rural Rakai district, Uganda. AIDS. 11(6):791-9.

Kraem er, H. C., Yesavage, J. A., Taylor, J. L., \& Kupfer, D. (2000). How can we learn about developm ental processes from crosssectional studies, or can we? American Journal of Psychiatry, 157(2), 163-171.

LeClerc-Madlala, S. (2009). Cultural scripts for m ultiple and concurrent partnerships in southern Africa: why HIV prevention needs anthropology. Sexual health. 6(2):103-10.

Levin, K. A. (2006). Study design III: Cross-sectional studies. Evidence-based dentistry, 7(1), 24.

Mah, T. L., \& Halperin, D. T. (2010). The evidence for the role of concurrent partnerships in Africa's HIV epidem ics: a response to Lurie and Rosenthal. AIDS and Behavior. 14(1):25-8. 
Malarcher, S., Meirik, O., Lebetkin, E., Shah, I., Spieler, J., \& Stanback, J. (2011). Provision of DMPA by com munityhealth workers: what the evidence shows. Contraception, 83(6), 495-503.

Maulana, A. O., Krum eich, A., \& van den Borne, B. (2012).In Their Eyes: HIV prevention from an Idam ic perspective in Lam u,Kenya. Health, Culture and Society, 2(1), 89-102.

Mavhu, W., Langhaug, L., Pascoe, S., Dirawo, J., Hart, G., \& Cowan, F. (2011). A novel tool to assess com m unity norm $\mathrm{s}$ and attitudes to multiplend concurrent sexual partnering in rural Zim babwe: participatory attitudinal ranking. AIDS care. 23(1):52-9.

Mbalinda, S. N., Kiwanuka, N., Eriksson, L. E., Wanyenze, R. K., \& Kaye, D. K. (2015). Correlates of ever had sex among perinatally HIV-infected adolescents in Uganda. Reproductive Health, 12(1), 96.

McCusker, K., \& Gunaydin, S. (2015). Research using qualitative, quantitative or $\mathrm{m}$ ixedm ethods and choice based on the research.Perfusion, 30(7), 537-542.

McKee, N., Manoncourt, E., Yoon, C. S., \& Carnegie, R (2008). Involving People, Evolving Behaviour: The UNICEF Experience. Com munication for developm ent and social change.: 254

Moore, G. F., Audrey, S., Barker, M., Bond, L., Bonell, C., Hardem an, W., ... \& Baird, J. (2015). Process evaluation of com plex interventions: Medical Research Council guidance. BMJ, 350, h1258.

Mwai, G. W., Mburu, G., Torpey, K., Frost, P., Ford, N., \& Seeley, J. (2013). Role and outcom es of com m unityhealth workers in HIV care in sub-Saharan Africa: a systematic review.Journal of the International AIDS Society, 16(1), 18586.

Nalukwago, J., Crutzen, R., Van den Borne, B., Bukuluki, P., Bufum bo, L., Batam wita, R., Zikusooka, A., Lenzi, R., Thom pson,G., Alaii, J. (2018)b. Adolescents discussing sexual behaviors with key influencing audiences. Global Journal of Health Science, 10, 91-106.

Nobelius, A. M., Kalina, B., Pool, R., Whitworth, J., Chesters, J., \& Power, R. (2010). "You still need to give her a token of appreciation": the m eaning of the exchange of $m$ oney in the sexual relationships of outof-school adolescents in rural southwest Uganda. Journal of sex research, 47(5):490-503.

Odim egwu, C. (2005). Influence of religion on adolescent sexul attitudes and behaviour am ong Nigerian university students: Affiliation or com $\mathrm{m}$ itm ent? African Journal of Reproductive Health, 125-140.

Onwuegbuzie, A. J., \& Collins, K. M. (2007). A typology of m ixed m ethods sam pling designs in social science research. The qualitative report, 12(2), 281-316.

Pick, S., \& Palos, P. A. (1995). Im pact of the fam ily on the sex lives of adolescest Adolescence, 30(119), 667.

Pilgrim, N. A., Ahm ed, S., Gray, R. H., Sekasanvu, J., Lutalo, T., Nalugoda, F., \& Wawer, M. J. (2014). Fam ily structure effects on early sexual debut 
am ong adolescent girls in Rakai, Uganda. Vulnerable Children and Youth Studies, 9(3), 193-205.

Pulerwitz, J., \& Barker, G. (2008). Measuring attitudes toward gender norm sam ong young $m$ en inBrazil: developm ent and psychom etric evaluation of the GEM scale. Men and Masculinities, 10(3), 322-338.

Pulerwitz, J., Michaelis, A., Verm a, R., \& Weiss, E. (2010). Addressinggender dynam ics and engaging $m$ en in HIV programs: lessons learned from Horizons research. Public Health Reports, 125(2), 282-292.

Randolph, W., \& Viswanath, K. (2004). Lessons learned from public health $\mathrm{m}$ ass m ediacam paigns $\mathrm{m}$ arketing health in a crowded m edia world Annu. Rev. Public Health, 25, 419-437.

Rashid, S., Moore, J. E., Tim m ings, C., Vogel, J. P., Ganatra, B., Khan, D. N., ... \& Straus, S. E. (2017). Evaluating implem entation of the World Health Organization's Strategic Approach to strengthening sexual and reproductive health policies and program s to address unintended pregnancy and unsafe abortion. Reproductive Health, 14(1), 153.

Reid, A. E., \& Aiken, L. S. (2011). Integration of five health behaviour m odels: com $\mathrm{m}$ on strengths and unique contributions to understanding condom use. Psychology \& Health, 26(11), 1499-1520.

Richards, E., Zalwango, F., Seeley, J., Scholten, F., \& Theobald, S. (2013). Neglected older wom en and men: Exploring age and gender as structural drivers of HIV am ong people aged over 60 in Uganda.African journal of AIDS research, 12(2), 71-78.

Rosenthal, R., \& DiMatteo, M. R. (2001). Metaanalysis: Recent developm ents in quantitative methods for literature reviews.Annual review of psychology, 52(1), 59-82.

Shattuck, D., Burke, H., Ram irez, C., Succop, S., Costenbader, B., Attafuah, J. D., . . . Guest, G. (2013). Using the Inequitable Gender Norm s scale and associated HIV risk behaviors am ong $\mathrm{m}$ en at high risk for HIV in Ghana and Tanzania. Men and Masculinities, 16(5), 540-559.

Sniehotta, F. (2009). An experim ental test of the theory of plamed behavior. Applied Psychology: Health and Well-Being, 1(2), 257-270.

Som ers, C. L., Tolia, S., \& Anagurthi, C. (2012). ParentAdolescent relationships and adolescent sexual behavior: Patterns by adolescent gender. International Journal of Business and Social Science, 3(7).

Taffa, N., Haim anot, R., Desalegn, S., Tesfaye, A., \& Moham m ed, K. (2017). Do parents and young people com $\mathrm{m}$ unicate on sexual $\mathrm{m}$ atters. Fe Ethiopian Journal of Health Developm ent (EJHD). 13(3).

Teddlie, C., \& Yu, F. (2007). Mixed m dtods sampling: A typology with exam ples.Journal of mixed methods research, 1(1), 77-100.

Van Den Berg, W., Hendricks, L., Hatcher, A., Peacock, D., Godana, P., \& Dworkin, S. (2013). 'One Man Can': shifts in fatherhood beliefs and parenting 
practices following a gender transform ative program $m$ e in Eastern Cape, South Africa. Gender \& Development, 21(1), 111-125.

Varga, C. A. (2003). How gender roles influence sexual and reproductive health am ong South African adolescents. Studies in Family Planning, 34(3), 160172.

Venkatesh, V., Brown, S. A., \& Bala, H. (2013). Bridging the qualitativequantitative divide: Guidelines for conducting $m$ ixed $m$ ethods research in inform ation system s.MIS quarterly, 37(1).

Vu, L., Pulerwitz, J., Burnett-Ziem an, B., Banur, C., Okal, J., \& Yam, E. (2017). Inequitable gender norm s from early adolescence to young adulthood in Uganda: Tool validation and differences across age groups. Journal of Adolescent Health, 60(2), S15-S21.

Watts, C., \& Seeley, J. (2014). Addressing gender inequality and intim ate partner violence as critical barriers to an effective HIV response in sub-Saharan Africa. Journal of the International AIDS Society, 17(1).

Werner-Wilson, R. J., \& Fitzharris, J. L (2001). How can mothers and fathers becom e involved in the sexuality education of adolescents? Journal of HIV/AIDS Prevention \& Education for Adolescents \& Children, 4(1), 4959.

Whitaker, D. J., Miller, K. S., May, D. C., \& Levin, M. L. (1999). Teenge partners' com $\mathrm{m}$ unication about sexual isk and condom use: the im portance oparentteenager discussions. Family Planning Perspectives, 117-121. 

Sum m ary 
Adolescents in Uganda, as in other sub-Saharan countries, are increasingly engaging in risky sexual behaviors such as early sexual debut and multiple and concurrent sexual partnerships, which expose them to health risks of HIV/AIDS and unplanned pregnancies. Adolescents are challenged with limited access to sexual and reproductive health $(\mathrm{SRH})$ services. A com plex $\mathrm{m}$ ix of factors including gaps in the adolescent SRH policy and cultural norm s regarding sexuality and fertility lim it not only the capacity of the existing health system to address their SRH needs, but also hinder adolescents from accessing available services. There is need to focus on understanding the determ inants of sexual behaviors am ong adolescents aged 15-19 as a distinct group from the oftengeneralized youth or young adults. Targeted adolescent health program $\mathrm{m}$ ing can impre when development practitioners distinctively assess the determ inants or factors associated with sexual behaviors (such as condom use, m ultiple sexual partnershipsand contraceptive use) am ong sexually active adolescents.

The studies reported in this thesis focused on two $\mathrm{m}$ ain goals. The first is to describe the determ inants of adolescent SRH behaviors and needs. The second is aim ed at underscoring the practical experiences and lessons from existing adolescent health program s for future design and scab-up. Results from studies in Chapter $2-6$ indicate that the adolescence stage com es with changes of intense sexual desires, often presum ed difficult to control thus leading adolescents to engage in sexual activities. The unm et need for contraception am ongadolescent girls was found to be high. Multiple concurrent sexual partnerships were found to be on the rise am ong adolescents, with persistent transactional sex and pre-m arital relationships that increase the risk of HIV and unplanned pregnancies. Adolescents them selves, however, were found to be m ore concerned about unplanned pregnancies than HIV risk. We found persistent inequitable gender norm $\mathrm{s}$ and social pressures that affect SRH service uptake am ong adolescents. Behavioralintention and self-efficacy to use contraception was found to be m oderately correlated with a gender equitable norm towards reproductive health and pregnancy/ disease prevention am ong both girls and boys. Although adolescents showed awareness of the risks of sexual behaviors such as condom use, contraception use, andrisks of $m$ ultiple concurrent partnerships, their knowledge of SRH issues was inadequate and often laced with a lot of hearsay, $m$ yths, and $\mathrm{m}$ isconceptions $\mathrm{We}$ found strong associations between feeling confident to discuss contraceptive $m$ ethods with a partner, being com fortable to use contraception, discussing contraception use with som eone, and contraception use. Interpersonal communication complemented by $m$ ass media messaging was found to be instrum ental in reaching and em povering adolescents with health inform ation to $\mathrm{m}$ ake inform ed choices regarding sexual behaviors.

Several conclusions in designing effective and targeted adolescent SRH program s can be drawn from the findings reported in this thsis. First, the findings suggest the need to continually provide adequate and updated inform ation to clear any $\mathrm{m}$ isconceptions. Strengthening parental and community support through enhanced collaborative training on communication with and for adolescents is pertinent to enable key influencers and adolescents gain confidence in addressing adolescent SRH needs. Second, changing the negative gender norm s/perceptions requires a $\mathrm{m}$ ultipronged gender-responsive approach for social change. Working 
with both girls and boys, and engaging influential stakeholders such as parents, health care workers, policymakers, com munity,and religious leaders, who create the environm ent where gender-related attitudes and world views are form ed is critical. Therefore, form ing strategic partnerships with various stakeholders for concerted efforts in addressing adolescent SRH needs is required. Third, the lessons identified for scaling-up adolescent health program s include the need to harm onize training and deploym ent of com $m$ unity chapions by developm ent partners whose efforts should be led by the governm ent through Ministry of Health, recruit audience-specific influential cham pions, and link incom egenerating activities to health education interventions.

Above all, experiences from existing adolescent health program s discussed in Chapter 6 of this thesis indicates the need to collaboratively develop and institutionalize effective $m$ onitoring and evaluation strategies during the inception and design phases of adolescent SRH prom otion programs. This will help program $\mathrm{m}$ ers achieve appropriate accountability for efforts towards ownership and a continuation of gains. 



\section{Valorisation}


Adolescents are a critical target population with regards to influencing global public health outcom es (WHO, 2011). In sub-Saharan Africa, including Uganda, m any adolescent girls and boys aged 15-19 years continue to face health challenges related to HIV/AIDS, teenage pregnancies, and lim ited access to sexual and reproductive health (SRH) services. Am ong adolescent girls aged 15-19 years in Uganda, 19\% have had a live birth, and an HIV prevalence of $1.8 \%$ was recorded am ong adolescent girls and $0.4 \%$ am ong boys (UBOS, 2018). Aggravating the health problem s in Uganda is that $\mathrm{m}$ ultiple concurrent partnerships are on the rise am ong adolescents. Yet, the use of condom s am ong adolescents is still relatively low, and the unm et need for contraception am ong girls is high. With such intricacies surrounding adolescents and their sexual behaviors, our study focused on understanding the determ inants of adolescent sexual and reproductive health needs to guide future program $\mathrm{m}$ ing. This study focused on understanding the socio-cognitive factors and gender norm s associated with adolescent sexual behaviors, assessing the effect of adolescents discussing sexual behaviors with key influencers, and understanding why adolescents engage in m ultiple concurrent sexual partnerships, as wdl as drawing lessons from an existing adolescent health program for scaleup.

The findings in this thesis show strong associations between perceived behavioral control/self-efficacy, subjective norm, and behavioral intention to use contraception. These findings suggest that increasing self-efficacy and subjective norm s towards conraception use $\mathrm{m}$ ay increase intention and actual use. As such, it is im portant to im prove contraception com $m$ unication am ong adolescents and their key influencers. More so, the findings evidently show that the $\mathrm{m}$ ajority of adolescent girls and boys were in support of gender inequitable norm s such as approval of $\mathrm{m}$ ale dom inance in health decision $\mathrm{m}$ aking, and agreem ent that wom en who carry condom $\mathrm{s}$ on them are cheap. These findings seemto suggest that the design of adolescent health program $\mathrm{s}$ needs to consider addessing and changing negative gender norm $\mathrm{s}$ that hinder the use of condom s, contraception and steer multiple sexual partnerships am ong adolescents. The findings further point out that parents, health workers, religious leaders, and peers were instrum ental in influencing adolescent sexual behaviors. However, challenges such as lim ited knowledge on the health risks, attitude, use of technical language and giving unclear inform ation were highlighted as barriers to com $m$ unication with adolescents. The rise of $m$ tilple sexual partnering am ong adolescents in Uganda should not go unnoticed as the findings show that these sexual partnerships often overlap for months or years. Factors such as lim ited knowledge, peer influence, poor com $m$ unication with sexual partner andparents, and societal indifference steered the problem. From the experience of an exising adolescent health program, the study findings indicate that the program activities were successfully implem ented through collaborative partnerships with service partners and the com m unityand that the program used theoretical fram eworks to guide targeted intervention im plem entation. Lessons drawn from the program include the pertinent need to link incom egenerating activities to health prom otion program $\mathrm{s}$, and adopting activity im plem entation tools that have been tested and used by other 
existing program s. These findings are of interest to governm ents including health authorities, policy $\mathrm{m}$ akers, and local leaders to inform nationally driven policy form ulation and straegies for adolescent sexual and reproductive health program s. The developm ent and implementing partners including donors, international and national non-governm ental organizations, civil society organizations, religious, cultural, and local leaders can use the findings to develop targeted and evidence based adolescent health interventions. The results are of interest to adolescents and their key influencers (parents, health workers, religious leaders) who can use them to be part of their change process as actors/advocates for the cause.

The results presented in this thesis suggest practicable solutions/activities for addressing adolescent sexual and reproductive health needs. The suggested solutions/activities provide a potential direction of focusing on both individual and com $m$ unityled efforts to address adolescent health behavior change. First, health prom otion program s should invest in developing the influencers' com m unication skills and provide adequate/up-to-date inform ation on sexual and reproductivehealth to guide dialogue am ong adolescents and their key influencers including health workers, parents, partners, and peers. Program s should adopt a m ultipronged genderresponsive approach to devise strategies for addressing negative/inequitable gender norms that affect adolescent sexual behaviors. The strategies include using participatory approaches that encourage working closely with both girls and boys to develop intervention efforts; promoting inform ed peer and partner discussions; com m unitybased education; gender awareness trainings; engaging in progressive com m unity and religious disourses that question gender stereotypes; and engaging in strategic partnerships with parents, religious, political, and com $\mathrm{m}$ unity leaders. The use of $\mathrm{m}$ ass $\mathrm{m}$ edia coupledwith face-to-face interaction and public dialogue is pertinent for reinforcing social-change interventions. Further still, it is im perative to recruit cham pions with a greater influence on the target population. Adequately training and equipping selected cham pions with skills and updated inform ation is critical. Secondly, linking incom egenerating activities to health prom otion program s is pertinent for reaching adolescents. Livelihood interventions provide alternative options for adolescents to generate incom e. It is im perative to intensify periodic evaluation of existing adolescent health program $\mathrm{s}$ to draw additional lessons for im plem entation and scaleup.

The findings in this thesis can be used to improve adolescent health program $\mathrm{m}$ ing in Uganda. Currenty, Uganda has initiated a nationwide drive of revising the com $m$ unity health workers strkegy that aim $s$ to harm onize partner interventions as a m eans to leverage key resources in the health sector. This study indicates that the efforts should focus on defining and endorsing com $\mathrm{m}$ unity health workers' roles while providing strategies for training, supervision, rem uneration, recognition, career progression and quality assurance. Through routine m onitoring and evaluation, phases of continuous learning, im provem at, and expansion of coverage should evolve as the com $m$ unity health worker program s grouwith new em erging issues widening their operational scope. Additionally, to create a conducive 
environm ent for adolescents and their key influencers such as parents and health workers, strategic partnerships should be form ed am ong developm ent practitionerin the institutional and structural arena. Routine dialogue $m$ eetings can be held am ong policym akers, parents, religious leaders, peer leaders and health workers to discuss contextual solutions and forge a way forward towards addressing the com plex and ever em erging adolescent health needs. Most im portantly, the com m unities and adolescents should be able to contribute to their own change efforts as key stakeholders. They should be involved in the planning and execution of change interventions. Cognizant that the adolescent health agenda in Uganda is grounded in policy, strategic partners should advocate for com $m$ unity dem and for gender equity and discouraging harm ful sodal values and practices including early $\mathrm{m}$ arriages. The policies affecting adolescent health should be effectively com $\mathrm{m}$ unicated (through com $\mathrm{m}$ unity dialogue $\mathrm{m}$ eetings, using $\mathrm{m}$ ass and social $\mathrm{m}$ edia, and interpersonal com $\mathrm{m}$ unication) to the general public for ation and further advocacy for change. Above all, the periodic (quarterly, annual, and ad-hoc) efforts to review and update the national adolescent health policies should consider addressing the em erging needs highlighted in this thesis. 
Acknowledgem ents 
Forem ost, I thank God for His grace, m ercies, and wisdom that enabled malk through $\mathrm{m} y \mathrm{PhD}$ trajectory to successful com pletion of this doctoral thesis. All glory and honor belong to Him .

I am grateful to FHI $360 \mathrm{~m}$ anagem ent for giving $\mathrm{m}$ e the opportutui to use the USAID-funded Com m unication for Healthy Com m unities (CHC) project data under RFA-617-13-000001 for $\mathrm{m}$ yPhD studies. Special thanks to a team com prising CHC key staff and Contracts and Grants staff including Anne Fiedler, Antje BeckerBenton, Dr. Angela Akol, Dr. Jane Alaii, Holly Dodge, Deborah Wood, Kokeb Kassa, and Christy Sm ith Foster for spearheading discussions leading to the approval to use CHC data. I appreciate the support of FHI 360 Uganda in providing a conducive environm ent that enabled $m$ eto conduct additional field work activities and for funding som e com ponents that contributed to $\mathrm{m}$ y study inclualig facilitation to participate in short courses, and international conferences to dissem inate study findings. I also appreciate the CHC staff/team who supported the data collection, cleaning and initial data analysis activities that contributed to this thesis.

My heartfelt appreciation and thanks go to $\mathrm{m}$ y supervisors, Prof.dr. Bart van den Borne, Prof. dr. Rik Crutzen, Dr. Jane Alaii, and Dr. Paul M. Bukuluki. You have supported $\mathrm{me}$ diligently and im m ensely through thiPhD journey in several ways - intellectually, financially, m orally and spiritually. Thank you for the tim e and knowledge you gave $\mathrm{m}$ e and for always being available when I needed you to clarify any issues. I could not have done this without you. I learnt a lot from your critical analysis and analytical thinking in discerning developm ent issues appertaining to adolescent health, and this has broadened $\mathrm{m} y$ research perspective. I take with $\mathrm{me}$ these skills into $\mathrm{m}$ y future engagem ents of developing and critiquing other scholarly and technical research works that contribute to scientific outputs. Your professional guidance has turned $\mathrm{me}$ into a strong intellectual researcher and scholar welt grounded in linking theory and practice of health prom otion and behavior change science. I am grateful to Maastricht University for funding components that contributed to $\mathrm{m}$ y study including ravel arrangem ents to the Netherlands, purchase of books relevant to $\mathrm{m} y$ study, tuition fees for courses related to the study, and article publications.

To Prof. dr. Bart van den Borne, thank you for the parental care and support you gave $m$ ein this journey. Your encouragem entand guidance helped $m$ edeal with and address academ ic and nonacadem ic issues that som etim es seem ed challenging.

I am especially indebted to Dr. Jane Alaiiwho introduced $m$ e to this path of pursuing a $\mathrm{PhD}$. Thank you, Jane, for identifying $\mathrm{m}$ y potential to attain this personal career goal in tandem with accom plishing aspects of CHC knowledge m anagem ent strategy to publish evaluative research findings, and for supporting $\mathrm{m}$ e through the entire process from beginning to the end.

Special thanks to Prof. dr. Rik Crutzen for the trem endous support in data analysis and write-up. Thank you for always being available to be consulted and to give critical and analytical input towards m aking the scientific write ups better. I am grateful that I had the opportunity to work on $\mathrm{m} y$ doctoral program under your guidance.

To colleagues at Maastricht University, Leon Kolenburg, Patricia Schenckendorff, and Kim van Hensberg and the entire GVO team, thank you for the 
support and making $\mathrm{m} y$ travels and stay at the Departm entf Health Prom otion seam less, enjoyable and $\mathrm{m}$ em orable. To $\mathrm{m} y$ friends, Chantal Ingabire, Kim Jonas Ncebakazi, Chitengela Minanago, Uchenna Onyekachi Okafor and Sam uel Yaw Lissah, thank you for accepting to be consulted anytim e and for $\mathrm{m}$ aking $\mathrm{m}$ y stay in the Netherlands sm ooth.

My heartfelt gratitude goes to $\mathrm{m}$ y fam ily for their unending love and support. To m y dear parents Lawrence M.Ssengero and Rose Nyakatura Ssengero, thank you for believing in $\mathrm{m}$ e and encouragng $\mathrm{m}$ e to go for $\mathrm{m} y$ dream . Thank you foraying the foundation and giving your all to ensure that I go through school and reach where I am now. You have supported $\mathrm{me} m$ orally, financially, and spiritually to see $\mathrm{me}$ through this PhD journey. I know that you are proud of $\mathrm{m}$ e and this achievem ent. To my sibings Cherry Kusem ererwa, Lillian Tusiim e, Daniel Kiggundu, Nicholas Tum uhairwe and John Paul Asaba, m any hugs for your encouragem ent, $m$ oral and spiritual support in this endeavor. You always encouraged $\mathrm{m}$ e to work hard and go beyond $\mathrm{m} y$ com fort zone. Thankyou all for being there for $\mathrm{m}$ e. Together we have $\mathrm{m}$ ade it! 
Author's Resum e 
Judith Nalukwago was born in Kam pala, Uganda, where she attended school. She pursued a Bachelors' degree majoring in Sociology at Kyam bogo University, Uganda, graduating in 2009, after which she worked as a Program Assistant at the National Union of Disabled Persons of Uganda, on an HIV prevention program . In 2011, she pursued a postgraduate Diplom a in Monitoring and Evaluation at the Uganda Managem ent Institute, graduating in 2012. She moved on to work with Malaria Consortium Uganda from 2011 to 2013, as aTechnical Officer-Monitoring and Evaluation. She further pursued a Masters in Managem ent Science (Monitoring and Evaluation) at Uganda Managem ent Institute, graduating in 2014. She has worked as a Monitoring and Evaluation Manager with FHI 360 (Fam ily Halth International) in Uganda, since December 2013, under the USAID-funded Com $m$ unation for Healthy Com $m$ unities Project, focused onaddressing six health areas including Maternal and Child Health, HIV/AIDS, TB, Malaria, Nutrition, and Fam ily Planning. During her tim e with FHI 360, she diligently pursued a sandwich doctoral/PhD program at Maastricht University in the Netherlands, while taking her responsibilities on the project. Since 2016, she worked with Maastricht University as a researcher until the completion of this doctoral thesis, mainly leading in the technical writing of scientific $m$ anuscripts, leadingdesign and conduct of qualitative and quantitative studies, and leading in data analysis for the studies. Specifically, she is skilled in conducting capacity building in Monitoring, Evaluation, Research, and Social and Behavior Change Com m unication for staff, im plem enting partners, and governm ent. She has technical expertise in Project Planning and Managementproposal development, program conceptualization, design and implem entation, partner coordination, $\mathrm{M} \& \mathrm{E}$ budget $\mathrm{m}$ anagem ent, financial and narrative reporting. Monitoring and Evaluation- developing and managing program M\& $\mathrm{E}$ system $\mathrm{s}$ including; M\& E plan developm ent, constructing programcontext specific theories of change, set-up of databases for tracking progress, and quality control m echanism s. Research- leading Evaluative surveys (Baseline, Midline, and Endline), form ative research, and directing operational research using both qualitative and quantitative $\mathrm{m}$ ethods, skills in designing studies, protocol and tools development, field supervision and data synthesis - cleaning and analysis, deploym ent of participatory assessm ent approaches including; Action Media methodology; Visualization in participatory program m ing (VIPP); and Rapid Participatory Assessm ents. With her expertise, Judith's particular interest is in the m eticulous application of theories of behavior change into the practice of developing, implem enting, and sustaining disease control and health behavior change interventions. This can contribute to change solutions in the developm ent discourse and practice. 
Publication list 
Nalukwago, J., Crutzen, R., Van den Borne, B., Bukuluki, P. M., Bufum bo, L., Burke, H. M., ... \& Alaii, J. (2018). Sociocognitive factors associated with condom use, multiple sexual partnerships, and contraception use am ongsexually-active adolescent girls in Uganda. Global Journal of Health Science, 10, 41-54.

Nalukwago, J., Crutzen, R., Van den Borne, B., Bukuluki, P., Bufum bo, L., Batam wita, R., Zikusooka, A., Lenzi, R, Thom pson, G., \& Alaii, J. (2018). Adolescents discussing sexual behaviors with key influencing audiences. Global Journal of Health Science, 10, 91-106.

Nalukwago, J., Crutzen, R., Van den Borne, B., Bukuluki, P.M., Bufum bo, L. Holly M. Burke, H.M., Field, S., Zikusooka, A., Fiedler, A.A., \& Alaii, J (subm itted) Gender norms associated with adolescent sexual behaviors in Uganda.

Nalukwago, J., Alaii, J., Van Den Borne, B., Bukuluki, P. M., \& Crutzen, R. (2018). Application of core processes for understanding multiple concurrent sexual partnerships am ong adolescents in Uganda.Frontiers in Public Health, 6, 371.

Nalukwago, J., Alaii, J., Van den Borne, B., Bukuluki, P. M., Kim bowa, M., Bockh, E., Coutinho, M. S., \& Crutzen, R. (submitted). Process evaluation of the Communication for Healthy Communities adolescent health program in Uganda. 

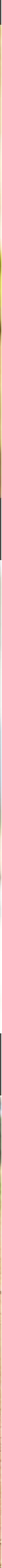